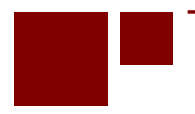

C E N T E R for RETIREMENT RE S E A R C H at BOSTON COLLEGE

\title{
WAGES AND THE VALUE OF NONEMPLOYMENT
}

\author{
Simon Jäger, Benjamin Schoefer, Samuel Young, and Josef Zweimüller \\ CRR WP 2020-4 \\ January 2020 \\ Center for Retirement Research at Boston College \\ Hovey House \\ 140 Commonwealth Avenue \\ Chestnut Hill, MA 02467 \\ Tel: 617-552-1762 Fax: 617-552-0191 \\ https://crr.bc.edu
}

Simon Jäger is an assistant professor of economics at the Massachusetts Institute of Technology (MIT). Benjamin Schoefer is an assistant professor of economics at the University of California, Berkeley. Samuel Young is a Ph.D. candidate in economics at MIT. Josef Zweimüller is a professor of economics at the University of Zurich. The research reported herein was performed pursuant to a grant from the U.S. Social Security Administration (SSA) funded as part of the Retirement Research Consortium. The opinions and conclusions expressed are solely those of the authors and do not represent the opinions or policy of SSA, any agency of the federal government, MIT, the University of California, Berkeley, the University of Zurich, or Boston College. Neither the United States Government nor any agency thereof, nor any of their employees, makes any warranty, express or implied, or assumes any legal liability or responsibility for the accuracy, completeness, or usefulness of the contents of this report. Reference herein to any specific commercial product, process or service by trade name, trademark, manufacturer, or otherwise does not necessarily constitute or imply endorsement, recommendation or favoring by the United States Government or any agency thereof. The authors would like to thank Karl Aspelund, Nikhil Basavappa, Carolin Baum, Niklas Flamang, Rene Livas, Peter McCrory, Damian Osterwalder, Johanna Posch, and Nina Roussille for excellent research assistance. The authors also thank four anonymous reviewers, and Pierre Cahuc, Steve Davis, Cynthia Doniger, Robert Hall, Jonathon Hazell, Patrick Kline, Alan Manning, Giuseppe Moscarini, Andreas Mueller and Ivan Werning, and audiences at Boston University, MIT, Penn State, SOLE 2019, Stanford, Stockholm IIES, UC Berkeley, UCLA, U Mannheim, Universidad Carlos III Madrid, University of British Columbia, University College London, All California Labor Economics Conference, Eastern Economic Association, IAB Perspectives on (Un-) Employment, IZA Evaluation of Labor Market Policies Conference, IZA/CREST/OECD Conference on Labor Market Policy, LMU Munich, University of Regensburg, NBER Economic Fluctuations and Growth, NBER Summer Institute Macro Perspectives, West Coast Matching Workshop, and Stanford SITE.

(C) 2020, Simon Jäger, Benjamin Schoefer, Samuel Young, and Josef Zweimüller. All rights reserved. Short sections of text, not to exceed two paragraphs, may be quoted without explicit permission provided that full credit, including $\odot$ notice, is given to the source. 


\begin{abstract}
About the Steven H. Sandell Grant Program
This paper received funding from the Steven H. Sandell Grant Program for Junior Scholars in Retirement Research. Established in 1999, the Sandell program's purpose is to promote research on retirement issues by scholars in a wide variety of disciplines, including actuarial science, demography, economics, finance, gerontology, political science, psychology, public administration, public policy, sociology, social work, and statistics. The program is funded through a grant from the Social Security Administration (SSA). For more information on the Sandell program, please visit our website at: http://crr.bc.edu/?p=9570, send e-mail to crr@bc.edu, or call (617) 552-1762.
\end{abstract}

\title{
About the Center for Retirement Research
}

The Center for Retirement Research at Boston College, part of a consortium that includes parallel centers at the National Bureau of Economic Research, the University of Michigan, and the University of Wisconsin-Madison, was established in 1998 through a grant from the U.S. Social Security Administration. The Center's mission is to produce first-class research and forge a strong link between the academic community and decision-makers in the public and private sectors around an issue of critical importance to the nation's future. To achieve this mission, the Center sponsors a wide variety of research projects, transmits new findings to a broad audience, trains new scholars, and broadens access to valuable data sources.

Center for Retirement Research at Boston College

Hovey House

140 Commonwealth Ave

Chestnut Hill, MA 02467

Tel: 617-552-1762 Fax: 617-552-0191

https://crr.bc.edu

\author{
Affiliated Institutions: \\ The Brookings Institution \\ Mathematica - Center for Studying Disability Policy \\ Syracuse University \\ Urban Institute
}




\begin{abstract}
Nonemployment is often posited as a worker's outside option in wage setting models such as bargaining and wage posting. The value of nonemployment is therefore a key determinant of wages. We measure the wage effect of changes in the value of nonemployment among initially employed workers. Our quasi-experimental variation in the value of nonemployment arises from four large reforms of unemployment insurance (UI) benefit levels in Austria. We document that wages are insensitive to UI benefit changes: point estimates imply a wage response of less than $\$ 0.01$ per $\$ 1.00$ UI benefit increase, and we can reject sensitivities larger than $\$ 0.03$. The insensitivity holds even among workers with low wages and high predicted unemployment duration, and among job switchers and recently unemployed workers. The insensitivity of wages to the nonemployment value presents a puzzle to the widely used Nash bargaining model, which predicts a sensitivity of $\$ 0.24-\$ 0.48$. Our evidence supports wage-setting models that insulate wages from the value of nonemployment.
\end{abstract}




\section{Introduction}

A prominent view in macroeconomics and labor economics is that workers' nonemployment outside options are a key determinant of wages. Most prominently, matching models of the aggregate labor market feature wage bargaining with nonemployment as the worker's outside option (Pissarides, 2000; Shimer, 2010; Ljungqvist and Sargent, 2017). This view helps explain aggregate wage dynamics such as the Phillips and wage curves: high unemployment weakens workers' threat point in bargaining, and thereby lowers wages (Beaudry and DiNardo, 1991; Blanchflower and Oswald, 1994; Ravenna and Walsh, 2008; Christiano et al., 2016). It also shapes policy debates, such as whether countercyclical unemployment insurance generosity may depress hiring during recessions by pushing up wage demands (Krusell et al., 2010; Hagedorn et al., 2013; Chodorow-Reich et al., 2018). The sensitivity of wages to the nonemployment value also determines the capacity of macroeconomic models to generate realistic labor demand fluctuations (Shimer, 2005; Hagedorn and Manovskii, 2008; Hall and Milgrom, 2008; Chodorow-Reich and Karabarbounis, 2016; Hall, 2017). In wage posting models, the nonemployment value also determines reservation wages of the unemployed, forming the cornerstone of firms' wage policies and the equilibrium wage distribution (Burdett and Mortensen, 1998; Manning, 2011). Similarly, firms pay wage premia above worker's nonemployment outside option in efficiency wage models (Shapiro and Stiglitz, 1984; Akerlof and Yellen, 1986; Katz, 1986). Yet, there exists no direct empirical estimate of the sensitivity of wages to the value of nonemployment.

We estimate the dollar-for-dollar sensitivity of wages to the nonemployment value arising from changes in unemployment insurance benefit (UIB) levels, which we analyze in a quasiexperimental research design studying four large UIB reforms in Austria in 1976, 1985, 1989, and 2001. ${ }^{1}$ The reforms raised UIBs differentially for workers based on their previous salaries by as much as $28 \%$ in 1985, for example. Our difference-in-differences design compares wage growth between workers eligible for increased UIBs (treatment group) and their unaffected peers (control group). We use administrative data on workers and firms going back to 1972. The Austrian UI context is particularly suitable: (i) most separators receive UI due to broad eligibility and high take-up, (ii) quitters are UI-eligible, ${ }^{2}$ (iii) there is no experience rating, (iv) and post-UI welfare benefits move nearly one-to-one with the reforms' UIB shifts.

We document that wages are insensitive to increases in UI benefit levels. We first visually analyze each reform nonparametrically. We sort workers into bins by their reference wages that determine UIBs, and then plot wages before and after each reform. These raw data do not reveal any wage responses among treated workers. Second, our difference-in-differences regression reveals point estimates for the dollar-for-dollar wage sensitivity below $\$ 0.01$ to a $\$ 1.00$ increase

${ }^{1}$ Only the 1989 reform has been studied, with a focus on unemployment spell duration (Lalive et al., 2006).

${ }^{2}$ Quitters have full benefit duration after a brief 28-day wait period. Wait periods are considerably longer in other OECD countries, such as three months in Germany, while U.S. quitters are, de jure, permanently ineligible. 
in UIBs after one and two years. Our confidence intervals rule out sensitivities above $\$ 0.03$ in our preferred specification with rich controls.

These estimates are an order of magnitude smaller than predicted by the widely used Nash bargaining model with nonemployment as the outside option. Here, wages are the weighted average of the job's inside value (e.g., productivity) - of which the worker receives a share equal to the worker bargaining power parameter -, and the worker's outside option - of which the worker receives one minus her bargaining power. UIBs boost workers' outside option by increasing the payoff during nonemployment but importantly also through an endogenous feedback effect on reemployment wages. We calibrate worker bargaining power to 0.1 , consistent with the micro evidence from firm-level rent sharing (i.e. inside value shifts from productivity changes). The basic Nash model then predicts that wages will increase by $\$ 0.48$ whenever UIBs increase by $\$ 1.00$. This prediction is robust to model refinements, such as equilibrium or micro responses. Additionally, incorporating institutional features, such as incomplete take-up or finite duration of benefits, results in predicted sensitivities of $\$ 0.24$. In fact, the Nash benchmark could only rationalize the insensitivity we document with full worker bargaining power, an assumption inconsistent with the small rent sharing elasticities in the data.

We also test a central cross-sectional prediction of the model: the pass-through of UI into outside options and wages is mediated by a worker's post-separation nonemployment duration. Yet, when we split up workers by their predicted post-separation time on UI (and other proxies for unemployment risk), both the bottom and top groups exhibit the zero wage effect. Relatedly, we find little evidence of larger sensitivity among workers with plausibly lower bargaining power (e.g., blue-collar or female workers) for whom wages should be more sensitive to outside options.

We rule out various confounders that could explain the wage insensitivity. First, standard wage stickiness is unlikely to explain the insensitivity, which extends to new hires (even those hired out of unemployment) whose wages are likely flexibly reset (and allocative for hiring in standard matching models, e.g., Pissarides, 2009). We also find no wage incidence after two years, or in firms exhibiting more flexible or volatile wage policies. Lastly, since the reforms should entail wage increases, standard downward wage rigidity should not bind.

Second, the insensitivity extends even to workers with frequent interaction with, and hence awareness of, the UI system (see Lemieux and MacLeod, 2000). Supplementary survey evidence indicates that Austrian employees know their own UIB levels. We additionally document wage insensitivity to age-specific - and thus simple and salient - reforms raising UIB duration.

Third, we investigate whether our findings could be explained by bargaining occurring with a firm's entire workforce rather than with individual workers (as in union bargaining models and as documented in Saez et al., 2019). We rerun the regressions with a firm-level average of the worker-level benefit changes. These wage sensitivities remain small and insignificant. While collective bargaining is prevalent in Austria, the institutional environment leaves substantial room 
for between-firm wage variation. Firms regularly deviate upward from the resulting industry-wide wage floors (mean wages exceed the floors by more than 30\%, Leoni and Pollan, 2011), and between-firm wage dispersion is large (Borovičková and Shimer, 2017)).

Fourth, robustness checks reveal that the reforms did not affect separations or sickness spells, suggesting that wage effects were not masked by composition or efficiency-wage effects.

To our knowledge, our paper is the first to quantitatively assess the wage effects of UI-induced outside option shifts against calibrated wage setting models. We complement studies of UI effects on search behavior and reemployment wages of unemployed workers (Feldstein and Poterba, 1984; Katz and Meyer, 1990; Krueger and Mueller, 2016; Schmieder et al., 2016; Le Barbanchon et al., 2017; Nekoei and Weber, 2017). Our focus on employed workers isolates the bargaining channel, whereas the unemployed are subject to multiple, perhaps offsetting, non-bargaining wage effects, such as skill depreciation (Dinerstein et al., 2019), job composition (McCall, 1970; Nekoei and Weber, 2017), or stigma (Kroft et al., 2013, 2016). Second, much of the literature focuses on benefit duration reforms, hence harder to price and map back into our model, and affecting only long spells.

Our evidence supports models that insulate wage setting from the nonemployment outside option. This set includes models with on-the-job search and job ladders, where competing job offers can serve as outside options in bargaining (e.g., Postel-Vinay and Robin, 2002; Cahuc et al., 2006; Altonji et al., 2013; Bagger et al., 2014). Interestingly, we do not find larger wage effects for recently unemployed workers, for whom nonemployment remains the outside option in these models. Another promising bargaining model is alternating offer (or credible) bargaining (Hall and Milgrom, 2008), in which the threat point is to extend bargaining rather than to terminate negotiations - thereby limiting the role of outside options in general. Wage posting models may be another promising route to explore, although they too can deliver large sensitivities.

Our findings also raise the question whether the short-run comovement between aggregate wages and labor market conditions, such as the Phillips curve and the wage curve (Beaudry and DiNardo, 1991; Blanchflower and Oswald, 1994; Winter-Ebmer, 1996; Blanchard and Katz, 1999), may arise from mechanisms other than fluctuations in workers' nonemployment outside option, such as compositional effects (Hagedorn and Manovskii, 2013; Gertler et al., 2016) or wage pressure from job-to-job transitions (Moscarini and Postel-Vinay, 2017).

The type of wage insensitivity we document is also a crucial theoretical ingredient for the capacity of matching models to produce realistic labor demand fluctuations (Shimer, 2005), where Nash bargained wages move procyclically with the nonemployment value and thereby provide stabilization (Shimer, 2004; Hall and Milgrom, 2008; Hall, 2017; Chodorow-Reich and Karabarbounis, 2016). Relatedly, our findings for limited short-run wage pressure from UI speak against large labor demand effects (Krusell et al., 2010; Hagedorn et al., 2013), and rationalize evidence for small employment effects from UI duration extensions in Chodorow-Reich et al. 
(2018) and positive employment spillovers on ineligible control workers in Lalive et al. (2015).

Section 2 derives wage-UIB sensitivity in our Nash benchmark, and discusses alternative models. Section 3 describes institutions, reforms, and data. Section 4 presents our empirical design and results. Section 5 studies subsamples and group bargaining. Section 6 concludes.

\section{Conceptual Framework}

We draw on wage bargaining to conceptualize and benchmark the wage effects of UI shifts through the outside option channel. Our point of departure, the canonical and widely used Nash bargain, predicts a wage-benefit sensitivity of 0.24-0.48: when UI benefits - or any components of the nonemployment payoff - go up by $\$ 1.00$, wages should increase by $\$ 0.24$ to $\$ 0.48$ - dramatically higher than our empirical estimate of a wage-benefit sensitivity below $\$ 0.03$ in Section 4 . We then discuss alternative wage setting models that insulate wages from the nonemployment value.

\subsection{Nash Bargaining}

We derive the sensitivity in our baseline model with risk-neutral agents, fixed job finding and separation rates, and UIBs as the only nonemployment payoff (with complete take-up and infinite potential duration). Going from an aggregate steady state, we study a surprise and permanent shift in UI benefits. In Section 2.2, we show how this baseline sensitivity extends to richer environments, such as other nonemployment payoffs (including without UI, as with incomplete take-up or finite duration), micro responses (e.g., search effort), and market-level adjustments.

\subsubsection{Basic Model: Wages, the Nonemployment Value, and UI Benefits}

The Nash-Bargained Wage Nash bargaining results in a wage that is the average of the inside value of a job, here productivity $p$, and the worker's outside option $\Omega$, weighted by worker bargaining power $\phi$ (equivalently, $w$ is outside option $\Omega$ plus share $\phi$ of surplus $p-\Omega$ ): ${ }^{3}$

$$
w=\phi \cdot p+(1-\phi) \cdot \Omega
$$

Hence, the sensitivity of the wage to the outside option is $1-\phi$ (and $\phi$ with respect to the inside option, e.g., productivity). This implies, for example, that if workers' bargaining power is zero,

\footnotetext{
${ }^{3}$ The firm and the worker choose wage $w=\arg \max _{\tilde{w}}(E(\tilde{w})-N)^{\phi}(J(\tilde{w})-V)^{1-\phi}$ (with employment value $E$, nonemployment value $N$, firm's job value $J$ and vacancy value $V)$. Firm's job value $J=p-w+\delta[V-J(w)]$ draws on productivity $p$. Jobs end exogenously with probability $\delta$, pushing the (infinitely lived) worker into nonemployment and destroying the firm's position (leaving no vacancy value $V)$. Going from $(1-\phi)(E(w)-N)=$ $\phi(J(w)-V) \Leftrightarrow(1-\phi)\left[\frac{w+\delta(N-E(w))}{\rho}-N\right]=\phi\left[\frac{p-w+\delta(V-J(w))}{\rho}-V\right]$ and eliminating continuation terms $(1-\phi) \delta(E(w)-N)=\phi \delta(J-V)$ due to bargaining next period, one obtains $w=\phi p+(1-\phi) \rho N-\phi \rho V$. We ignore $d V / d b$, either relying on canonical free entry $V=0$, or on a control group netting out $d V$ (Section 2.2). We assume $d p / d b=0$, but argue against room for quantitatively important $d p$ effects in Appendix Section $\mathrm{H}$.
} 
they are paid exactly their outside option, with which wages then move one-to-one.

The Nonemployment Outside Option The canonical specification of the worker's outside option is a job separation, potentially into temporary nonemployment (e.g., in matching models Pissarides, 2000; Shimer, 2005; Chodorow-Reich and Karabarbounis, 2016; Ljungqvist and Sargent, 2017). Nonemployment carries value $N$. Its flow value $\rho N$ (in continuous time, with discount rate $\rho$ ) consists of (instantaneous) payoff $b$ (UI benefits) and, at job finding rate $f$, the potential "capital gain" into reemployment $E\left(w^{\prime}\right)$ with its payoff wage $w^{\prime}$ :

$$
\Omega \equiv \rho N=b+f \cdot\left(E\left(w^{\prime}\right)-N\right)=\rho \frac{b+f \cdot E\left(w^{\prime}\right)}{\rho+f} .
$$

Reemployment flow value $\rho E\left(w^{\prime}\right)=w^{\prime}+\delta\left(N-E\left(w^{\prime}\right)\right)$, in turn, incorporates returning into $N$ at separation rate $\delta$. The nonemployment flow value $\rho N$ then consists of the amortized expected present value of the instantaneous payoffs from nonemployment, $b$, and reemployment, $w^{\prime}$ :

$$
\rho N=\underbrace{\frac{\rho+\delta}{\rho+f+\delta}}_{\begin{array}{c}
\equiv \tau \\
\text { Nonemployment Time } \\
\text { Post-Separation }
\end{array}} b+\underbrace{\frac{f}{\rho+f+\delta}}_{\begin{array}{c}
\text { Reemployment Time } \\
\text { Post-Separation }
\end{array}} w^{\prime} .
$$

Payoffs $b$ and $w^{\prime}$ are weighted by $\tau \equiv \frac{\rho+\delta}{\rho+f+\delta}$, capturing discounting and the expected time the worker will spend in nonemployment conditional on separating. A high discount rate $\rho \rightarrow \infty$ (e.g., due to myopia or liquidity constraints), a low job finding rate $f=0$, or a high subsequent separation rate $\delta \rightarrow \infty$ will put full weight on $b$ such that $\tau=1$ and $\rho N=b$ (the initial state after bargaining breaks down). A high job finding rate $f \rightarrow \infty$ implies $\rho N=w^{\prime}$.

The Wage-Benefit Sensitivity Our variation in the outside option is brought about by variation in workers' payoff while nonemployed, specifically shifts in UI benefit levels. With $\Omega=\rho N$ and plugging in the expression for $\rho N$ derived in (3), the Nash wage becomes:

$$
w=\phi \cdot p+(1-\phi) \cdot \overbrace{\left(\tau b+(1-\tau) w^{\prime}\right)}^{\Omega} .
$$

The wage sensitivity to $b$ works through outside option $\Omega$ and is therefore mediated by $1-\phi$ :

$$
\frac{d w}{d b}=(1-\phi) \cdot \overbrace{\left(\tau+(1-\tau) \frac{d w^{\prime}}{d b}\right)}^{d \Omega / d b} .
$$


The first term, $\tau$, is the mechanical effect of $b$ on $N$ through the instantaneous payoff while nonemployed. Second, the feedback effect, $(1-\tau) d w^{\prime} / d b$, captures that reemployment wages in future jobs (thus weighted by post-separation time in reemployment $1-\tau$ ) also respond to $b$.

Nash bargaining in the next job implies $\frac{d w^{\prime}}{d b}=\frac{d w}{d b}$. This allows us to solve for the wage-benefit sensitivity in terms of $\phi$ and $\tau$ as the fixed point in Equation (5):

$$
\frac{d w}{d b}=\frac{(1-\phi) \cdot \tau}{1-(1-\phi) \cdot(1-\tau)}
$$

Conversely, a given sensitivity $d w / d b$ and $\tau$ imply a bargaining power $\phi=\frac{1-d w / d b}{1+d w / d b \cdot\left(\tau^{-1}-1\right)}$. For intuition, Figure 1a plots a contour map of the predicted wage-benefit sensitivity as a function of worker bargaining power $\phi$ for various levels of $\tau$. The lower $\tau$, the lower the weight the outside option puts on UI benefit $b$, thereby insulating wages from $b$. By contrast, for $\tau=1$, such that $\rho N=b$, we have $\frac{d w}{d b}=1-\phi$. Figure 1 b plots the sensitivity as a function of $\tau$, for various levels $\phi$. The higher $\tau$, the more weight $b$ receives. For $\phi=1$, the wage is insulated from the outside option for any $\tau$; for $\phi=0$, the wage equals the outside option, and so $\frac{d w}{d b}=1$ for any $\tau>0$.

\subsubsection{Calibrating the Wage-Benefit Sensitivity}

We now calibrate the sensitivity in Equation (6) as a benchmark for the empirical estimates.

Calibrating $\phi$ We calibrate worker bargaining power to match the empirical dollar-for-dollar pass-through of firm-specific shifts in labor productivity $p$ (proxied for by profits and productivity shifts) into wages, $\phi=\frac{d w}{d p}$. Our source is the large body of rent sharing estimates (reviewed in, e.g., Manning, 2011; Card et al., 2018), as well as our own calculation based on Austrian data. Figure 2 plots the implied $\phi$ values in a meta study. Among these studies, we focus on worker-level specifications to net out composition effects. We calculate an average of 0.104 , hence setting $\phi=0.1{ }^{4}$ As a reference, we also list macro calibrations, which typically treat $\phi$ as a free parameter or set it to meet the Hosios condition of constrained efficiency in matching models.

The figure also foreshadows, assuming the Nash benchmark, the large, close to one, $\phi$ values implied by our estimated empirical wage insensitivity to the outside option. This striking inconsistency with the rent sharing estimates suggests a rejection of the baseline model.

Calibrating $\tau$ To calibrate $\tau$, we exploit the fact that the discount rate $\rho$ is small compared to empirical worker flow rates $f$ and $\delta$, such that $\tau \lesssim \frac{\delta}{\delta+f}$ (where $\rho \approx 0$ implies a lower bound

4 This benchmark is robust to excluding studies that use short-term fluctuations in productivity, which may have muted effects on wages due wage stickiness or insurance (see, e.g., Guiso et al., 2005). Several studies report estimates of the effects of more persistent shifts in productivity on wages (Guiso et al. (2005), Cardoso and Portela (2009), and Card et al. (2018)); averaging over these studies, we find an inverse-variance weighted mean of 0.103 . We also do not include studies that report profit-sharing elasticities, as those do not directly identify worker bargaining power, as we discuss in Appendix F. 
for $\left.\frac{d w}{d b}\right) . \tau$ then corresponds to an individual's expected fraction of post-separation time spent on UI, mirroring the familiar steady-state expression for aggregate unemployment.

We can directly measure this $\tau$ concept for actual separators. We start with our full regression sample and keep all individuals who, in the next year, separate into nonemployment for at least one day. Importantly, we do not impose that a separator ever take up UI. For each separator, we calculate her realized post-separation share of time spent on unemployment insurance (UI) or unemployment assistance (UA) (Notstandshilfe, which is indexed nearly one-to-one to an individual's UI benefit level and inherits our policy variation $d b$, as detailed in Footnote 21). We refer to "UI" in this paper typically as encompassing both programs.

We then assign each worker in our regression sample (whether she separates or not) her idiosyncratic predicted $\hat{\tau}_{i}$. We construct these predicted values because we may not see a separation for many of these workers, because the composition of these workers may differ from the separators, and because in Section 4.4 we will exploit heterogeneity in $\hat{\tau}_{i}$. Specifically, to construct $\hat{\tau}_{i}$, we plug a worker's pre-separation attributes (industry/occupation, tenure, experience, age, region, gender, separation year, and previous UI history) into the corresponding regression model estimated off the actual separators' realized $\tau_{i}{ }^{\prime}$ s (details in Appendix C). ${ }^{5}$

Table 1 reports the results for our regression sample, along with predicted values for non-UI states. The average of $\hat{\tau}_{i}$ across the entire regression sample yields an average expected time spent on UI, E[ $\left.\hat{\tau}_{i}\right]$, of $10.4 \%$ for our preferred specification in the first column (1). ${ }^{6}$ The columns show robustness to restrictions on the separator sample underlying the prediction. Each odd column considers employment restrictions of some (at least one day of) work within four post-separation years, thereby dropping emigrants or other permanent labor force exits. The column pairs also loop over "time restrictions": in our preferred specification, we stop including separators' labor market states at the earliest of 16 years, reaching age 70, or death (the longest horizons we can apply given the 2001 reform and the regression sample age restriction (54)), as well as either of retirement or disability, if "absorbing" (no subsequent employment or UI/UA spells in the next 16 years). The other columns additionally show robustness to stopping counting only at absorbing retirement in columns (3)-(4), or neither at disability nor retirement in columns $(5)-(6)$.

Benchmark Wage-Benefit Sensitivity In Table 1, we also report the implied wage-benefit sensitivities. For $\phi=0.1$, suggested by the micro studies on rent sharing, and an average

${ }^{5}$ The $R^{2}$ of the model is $9 \%$, and the unexplained variation captures a combination of unobservables, model misspecification, and likely also ex-post stochastic earnings realizations unrelated to the quality of the model.

${ }^{6}$ Appendix Table A.5 Panel A reports the realized $\tau$ values among the actual separators, whose somewhat higher average $\tau, 11.6 \%$, reflects composition differences from our full sample. Panel B reports for the full sample the naturally smaller unconditionally-realized (rather than predicted-in-case-of-separation) average $\tau$ of 3.9-4.1\%, reflecting that our full worker sample is stably employed unless taking up the separation outside option. 
$\tau=10 \%$ as described above, the predicted wage-benefit sensitivity is:

$$
\left.\frac{d w}{d b}\right|_{(\tau=0.104, \phi=0.1)}=(1-0.1) \cdot \frac{0.104}{1-(1-0.1)(1-0.104)} \approx 0.48
$$

That is, the calibrated Nash model predicts a $\$ 0.48$ wage response to a $\$ 1.00$ increase in UIBs. Even if calibrating $\phi=0.2$, the upper end of the rent sharing estimates, the model predicts a 0.29 sensitivity. Even for $\phi=0.5$, the middle of the macro targets inconsistent with microempirical evidence, we would find a sizable sensitivity of 0.09 . The table also reports the sensitivity respecting Jensen's inequality (as $d w / d b$ is nonlinear in $\tau$ ), which is similarly sized $\mathbb{E}\left[d w / d b\left(\hat{\tau}_{i}\right)\right]=0.46$, so our exposition reports $d w / d b\left(\mathbb{E}\left[\hat{\tau}_{i}\right]\right)$. Finally, in Section 4.4, we also study subsamples with $\tau$ ranging from 0.02 to 0.2 yielding predicted $\frac{d w}{d b}$ from 0.15 to above 0.60.

\subsection{Robustness}

The baseline model holds fixed all terms except for wages and UIBs, and hardwires UI and nonemployment. We now show that the baseline sensitivity extends exactly to richer nonemployment payoffs, general micro responses (e.g., search effort), and market-level adjustments. Second, a large sensitivity prevails with nonemployment without UI receipt (as with limited take-up).

\subsubsection{Richer Payoffs, Micro Reoptimization, and Market Adjustment}

Richer Payoff While Nonemployed The level-on-level sensitivity is invariant to the (hardto-measure) share of $b$ in a more general nonemployment payoff $z(b)$, as $z^{\prime}(b)=1$ since $b$ simply enters the budget constraint. For example, $z(b)$ may include leisure value or employment disutility $-v(\mathrm{MRS})$, search effort costs $c(e)$, unemployment stigma $\gamma$ (all normalized into money units by budget multiplier $\lambda$ ), and other nonwork-contingent income $y$ :

$$
z\left(b_{i}, \ldots\right)=b_{i}+\frac{-v_{i}-c_{i}\left(e_{i}\right)-\gamma_{i}}{\lambda_{i}}+y_{i}+\ldots
$$

Micro Choices and Market Adjustment We now also include vector c of choice variables (search effort,...), of which we permit micro-reoptimization in response to the reform, as well as vector $\mathbf{x}$ of exogenous variables (e.g. market-level labor demand) taken as given by the household, yet which we now permit to adjust. Now, values $N$ and $E$ are:

$$
\begin{aligned}
\rho N(b, \mathbf{c}, \mathbf{x}) & =\max _{\mathbf{c}}\left\{z(b, \mathbf{c}, \mathbf{x})+f(\mathbf{c}, \mathbf{x}) \cdot\left[E\left(w^{\prime}, b, \mathbf{c}, \mathbf{x}\right)-N(b, \mathbf{c}, \mathbf{x})\right]\right\} \\
\rho E(w, b, \mathbf{c}, \mathbf{x}) & =\max _{\mathbf{c}}\{w+\delta(\mathbf{c}, \mathbf{x}) \cdot[N(b, \mathbf{c}, \mathbf{x})-E(w, b, \mathbf{c}, \mathbf{x})]\} .
\end{aligned}
$$


We group the total derivative of $N$ in Equation (9) with respect to $b$, into four effects:

$$
\frac{d N}{d b}=\underbrace{\overbrace{\frac{\partial N}{\partial b}}^{=\tau}}_{\begin{array}{c}
\text { Mechanical } \\
\text { Effect }
\end{array}}+\underbrace{=\overbrace{\frac{\partial N}{\partial w^{\prime}}}^{1-\tau} \frac{d w^{\prime}}{d b}}_{\begin{array}{c}
\text { Feedback from } \\
\text { Wage Response }
\end{array}}+\overbrace{\underbrace{\nabla_{\mathbf{c}} N\left(b, \mathbf{c}^{*}, \mathbf{x}\right) \cdot \nabla_{b} \mathbf{c}^{*}}_{\text {Micro Re-Optimization }}}^{0 \text { By Envelope Theorem }}+\overbrace{\underbrace{\nabla_{\mathbf{x}} N \cdot \nabla_{b} \mathbf{x}}_{\text {Market Adjustment }}}^{\begin{array}{c}
\text { Net Out with } \\
\text { Control Group }
\end{array}},
$$

where $\nabla_{\mathbf{a}} f(\mathbf{a}, \mathbf{b})$ denotes the gradient of $f()$ over the subset of arguments given by vector $\mathbf{a}$. The first two terms are exactly the mechanical and feedback effects from the basic model.

Envelope Theorem: the Irrelevance of Micro Reoptimization The third term, capturing reoptimization of the agent's choices $\mathbf{c}$ in response to the shift in $b$, can be ignored by appeal to the envelope theorem, as in the neighborhood around the original optimum $\nabla_{\mathbf{c}} N\left(b, \mathbf{c}^{*}, \mathbf{x}\right)=\mathbf{0}$, where $\nabla_{\mathbf{c}} N\left(b, \mathbf{c}^{*}, \mathbf{x}\right) \nabla_{b} \mathbf{c}^{*}=\mathbf{0} .^{7}$ This result permits us to disregard rich responses in choice variables, and should carry over to unmodeled extensions with job search effort, reservation wages, liquidity effects, take-up and program substitution, or skill loss.

Netting out Market-Level Effects with a Control Group The fourth term accounts for shifts in factors $\mathbf{x}$ that the individual agent takes as given, e.g., shifts in job finding rate $f$ due to labor demand or labor force participation shifts, or crowd-out of substitute transfer programs entering $z$. We net out such effects with a control group. Consider treatment and control groups $T$ and $C$ in the same market $m(T)=m(C)$, for whom $d b^{T}>0$ and $d b^{C}=0$. For a given individual $i$ in market $m(i)$ and group $g(i)$, we split up $\mathbf{x}_{i}=\left(\boldsymbol{\mu}^{m(i)}, \boldsymbol{\iota}^{i}\right)$ into market-level variables $\boldsymbol{\mu}^{m}$, and worker/type-specific factors $\boldsymbol{\iota}^{i}$ perhaps differing between $T$ and $C$.

Control group $C$ is exposed to $d b^{T}$ only through market-level effects and own-wage spillovers. Our difference-in-differences strategy nets out market-level effects:

$$
\begin{gathered}
\frac{d N^{g}}{d b^{T}}=\frac{\partial N}{\partial b}+\frac{\partial N}{\partial w^{\prime}} \frac{d w^{\prime g}}{d b^{T}}+\nabla_{\iota} N \cdot \nabla_{b} \iota^{g}+\nabla_{\boldsymbol{\mu}} N \cdot \nabla_{b} \boldsymbol{\mu}^{m} \\
\Rightarrow \frac{d N^{T}}{d b^{T}}-\frac{d N^{C}}{d b^{T}}=\frac{\partial N}{\partial b}+\frac{\partial N}{\partial w^{\prime}} \cdot\left[\frac{d w^{\prime T}}{d b^{T}}-\frac{d w^{\prime C}}{d b^{T}}\right]+[\underbrace{\nabla_{\iota} N \cdot \nabla_{b} \iota^{T}-\nabla_{\iota} N \cdot \nabla_{b} \iota^{C}}_{\text {Assume }=0}] .
\end{gathered}
$$

We cannot evaluate the overall effect of potential $b$-sensitive $\boldsymbol{\iota}$, and thus must ignore them going forward. Examples are $b$-dependent transfers (e.g., $z(b)=b+x(b)$ ), statistical discrimination in hiring by mere treatment status, social stigma, or credit-worthiness changing with benefit level.

\footnotetext{
${ }^{7}$ Moreover, this benchmark underestimates the effect of non-small $b$ increases (the direction of our reforms) on $N$ (as permitting reoptimization weakly increases $N$ ), implying a conservative lower bound for $\frac{d w}{d b}$.
} 
Difference-in-Differences Sensitivity Rearranging Equation (13) yields a difference-indifferences version of the wage-benefit sensitivity - which we will empirically estimate - that exactly mirrors the simple model in Equation (6), which held fixed non-wage variables: ${ }^{8}$

$$
\frac{d w^{T}}{d b^{T}}-\frac{d w^{C}}{d b^{T}}=(1-\phi)\left(\tau+(1-\tau)\left[\frac{d w^{\prime T}}{d b^{T}}-\frac{d w^{\prime C}}{d b^{T}}\right]\right)=\frac{(1-\phi) \tau}{1-(1-\phi)(1-\tau)}
$$

Imperfect Labor Market Overlap We will assess consequences of potential imperfect labor market overlap between the groups in four ways. ${ }^{9}$ First, our empirical analysis in Section 4 starts by plotting raw data of wage growth for a continuum of worker groups sorted by income, permitting visual inspection of treatment and control observations around the cutoff. Second, in our regression framework, we add year- and group-specific fixed effects, and in one specification even firm-by-year fixed effects capturing difference-in-differences between treated and control colleagues in the same firm. Third, while our reforms are income-specific, in Appendix J we provide an additional difference-in-differences design that exploits sharp segmentation of treatment and control groups by date of birth, plausibly close substitutes in the same markets. Fourth, in Appendix Section E.1, we show that even if markets were perfectly segmented, the market-level wage-benefit sensitivity is similarly sized in calibrated equilibrium (DMP) models with Nash bargaining - with similar mathematical structure as the micro sensitivity. ${ }^{10}$

\subsubsection{Nonemployment Without UI}

Our benchmark Nash bargaining model assumes infinite UI benefit duration and universal, immediate take-up, such that $b$ adds into $z(b)$ for all individuals. In Austria, however, benefit duration is finite (see Section 3), while take-up is high but not universal (due to the waiting period for quitters and endogenous take-up decisions). In Appendix D, we derive the wagebenefit sensitivity in a three-state model that additionally features non-UI nonemployment (the nonemployed start out with or without UI receipt, then transition back and forth) - capturing concisely a variety of such otherwise hard-to-jointly-model-and-quantify detailed mechanisms.

\footnotetext{
${ }^{8}$ Here, we use $\partial(\rho N) / \partial b=\tau$ and $\partial(\rho N) / \partial w^{\prime}=1-\tau$ from Equation $(3), d w / d b=(1-\phi) \cdot d(\rho N) / d b$ from Equation (5), and $d w^{g} / d b^{T}=d w^{g} / d b^{T}$, implied by Nash bargaining in subsequent jobs.

${ }^{9}$ We also have evaluated the implicit assumption that the predicted wage effect remains within the firm's post-reform reservation wage, i.e. has sufficiently large initial firm surplus. Away from the most basic DMP setting, we have found that incorporating firing or hiring costs and specific human capital suffices to accommodate the predicted wage effects.

${ }^{10}$ The DMP equilibrium expression for the wage-benefit sensitivity we derive in Appendix Section E.1 is: $\frac{d w^{\mathrm{DMP}}}{d b} \approx \eta \frac{(1-\phi) u}{1-(1-\phi)(1-u)-(1-\eta) u} \approx 0.32$, where $u \approx 0.07$ now denotes the market-level unemployment rate (again here approximating $\rho=0$ ) and $\eta \approx 0.72$ (e.g., Shimer, 2005) is a DMP matching function parameter. Note that the $u$ here need not coincide with the $\tau$ (or the $\tau^{U}$ we provide in the extended model with nonemployment without UI receipt), as the rate here is cross-sectional rather than tracking a worker after a separation (and, respectively, as some of that non-UI nonemployment state is spent out of the labor force while the model at hand only considers those workers actively searching). For $u=0.05$ or $\eta=0.5$, the sensitivity would be 0.25 .
} 
The expected nonemployment value with this second nonemployment state mirrors the twostate baseline model, with $\rho N=\tau^{U} z^{U}(b)+\tau^{O} z^{O}+\left(1-\tau^{U}-\tau^{O}\right) w^{\prime}$, where $\tau^{U}$ is the share of time on UI, and $\frac{d z^{U}(b)}{d b}=1$. Now however, not all non-UI time $1-\tau^{U}$ is spent in reemployment (where the payoff (wage) is UI-sensitive: $1>\frac{d w}{d b}>0$ ), but fraction $\tau^{O}$ of post-separation time occurs in a state with a UI-insensitive nonemployment payoff $\frac{d z^{O}}{d b}=0$. Hence, this extension clarifies that, for a given $\tau^{U}$, such features attenuate the feedback effect $\frac{d w^{\prime}}{d b}$ in $\frac{d w}{d b}=\tau^{U} \cdot 1+\tau^{O} \cdot 0+\left(1-\tau^{U}-\tau^{O}\right) \cdot \frac{d w^{\prime}}{d b}$. This feature is thus a potentially powerful force, as the feedback accounts for $0.39 / 0.48=81.25 \%$ of the two-state sensitivity of $0.48 \approx(1-0.1) \cdot(0.1+0.9 \cdot 0.48) \approx 0.09+0.39$.

This formulation yields an intuitive variant of the familiar two-state sensitivity:

$$
\frac{d w}{d b}=\frac{(1-\phi) \tau^{U}}{1-(1-\phi)\left(1-\left(\tau^{U}+\tau^{O}\right)\right)} .
$$

To assess the attenuation of the feedback effect through non-UI nonemployment, Table 1 presents estimates for $\tau^{O}$ (i.e. we additionally measure nonemployment states without UI-sensitive payoffs, and predict this value from actual separators onto our regression sample, also detailed in Appendix Section C). Most time post-separation is spent reemployed, and only fraction $\tau^{O}=0.21$ is spent in non-UI nonemployment, such that the fraction of time reemployed $\tau^{E}=1-\tau^{U}-\tau^{O}$ is not much far from our baseline (two-state) assumption $\tau^{E}=1-\tau^{U}$. Of course, our measure of $\tau^{U}$ remains the same. The three-state model therefore preserves a high (though attenuated) wage-benefit sensitivity of 0.24 . Since in both benchmarks we still exclude other factors that would push up the sensitivity (e.g., discounting, the fact that Austrian UIBs are not taxed,...), going forward we refer to $0.24-0.48$ as the range of predicted wage-benefit sensitivities, and use the sensitivity from the simpler two-state model when including theoretical benchmarks for predicted wage growth in the empirical figures.

\subsubsection{Further Robustness and Extensions}

Appendix Section E.1 contains additional robustness checks, including specific models of finite benefit duration, limited take-up, wage stickiness, liquidity constraints/myopia, treatment and control groups in segmented markets with DMP equilibrium effects, and on the job search and endogenous separations, individual households with risk aversion, and multi-worker firms.

\subsection{Alternative Wage Setting Models}

We briefly discuss wage sensitivities to nonemployment values in alternative wage setting models.

Sequential Auctions In sequential auction models with on-the-job search and employer competition, wages are often still set by Nash bargaining (Cahuc et al., 2006). Unemployed workers initially use nonemployment as their outside option. Yet, while on the job, workers 
receive outside job offers that may dominate and replace the nonemployment outside option, such that $d \Omega_{i} / d N_{i}=0$, leaving wages insulated from shifts in $N$ and $b .{ }^{11}$ Yet, for workers without such offers, unemployment remains the outside option, and their wages should still exhibit the large sensitivity to benefit increases from standard Nash. ${ }^{12}$

Credible Bargaining Hall and Milgrom (2008) analyze wage setting by alternating offer bargaining in which threat points are to extend bargaining - rather than separating as in the Nash model, which we formally study in Appendix Section E.3. Outside options only become relevant in exogenous break-downs of bargaining - limiting their influence. ${ }^{13}$ Moreover, the wage can simultaneously exhibit outside-option insensitivity and empirically small productivity effects.

Wage Posting Survey evidence from US workers (Hall and Krueger, 2012) and German employers (Brenzel et al., 2014) suggests about equal relevance for bargaining and wage posting. Models of the latter (e.g., Albrecht and Axell, 1984; Burdett and Mortensen, 1998) can exhibit large wage-benefit sensitivities as well, albeit through very different mechanisms, and are more difficult to characterize and calibrate (in particular along a transition). Here, firms post jobs with predetermined wages. Workers accept jobs that dominate their outside option defined by reservation wages: staying put at the current wage if employed, and nonemployment if unemployed. Due to random search, firms set wages taking into account the entire distribution of outside options. The nonemployment reservation wage $R$ given by the nonemployment value $E(w=R)=N$, thus forms the cornerstone - the lower bound $\underline{w}$ - of firms' equilibrium wage policy distribution. ${ }^{14}$ Thus, $b$-induced shifts in $R$ trigger one-for-one responses at the low end of the wage distribution. But they also entail ripple effects through the entire equilibrium wage policy distribution. These effects and hence the implied wage sensitivities can be small in the knife-edge case of perfect homogeneity (Burdett and Mortensen, 1998). Yet, away from perfect homogeneity, as with heterogeneity in firm productivity, not only do the least productive

\footnotetext{
${ }^{11}$ Mortensen and Nagypal (2007), Fujita and Ramey (2012), Mercan and Schoefer (forthcoming) feature on-the-job search with the nonemployment outside option. Beaudry et al. (2012), Caldwell and Danieli (2018), Caldwell and Harmon (2018), and Conlon et al. (2018) find evidence consistent with job offers raising wages.

${ }^{12}$ These workers' wage is pinned down by: $E(w)=(1-\phi) \cdot N\left(b_{i}\right)+\phi \cdot\left(E(w)+J\left(x_{f}, w\right)\right)$, where $x_{f}$ is the matchor firm-specific productivity. An employed worker having received outside offer $x_{f}$, dominating $N$ yet dominated by the current job $\left(E(w)+J\left(x_{f}, w\right)-U(b)>W(w)+J\left(x_{f^{\prime}}, w\right)-U(b)>U(b)\right)$ renegotiates the current wage with that external job offer as the outside option: $E(w)=(1-\phi) \cdot\left[E(w)-E\left(w_{f^{\prime}}\right)\right]+\phi \cdot\left(E(w)+J\left(x_{f}, w\right)\right)$.

${ }^{13}$ Consider the firm's optimal strategy: to offer the worker her reservation wage $\underline{w}$, given by indifference between accepting and rejecting with her optimal counteroffer - equal to the firm's reservation wage $\bar{w}$ (with discount factor $\beta$, exogenous break-down probability $s$, and firm's cost of delay $\gamma): \frac{w+\beta \delta N}{1-\beta(1-\delta)}=z+(1-s) \beta \frac{\bar{w}+\beta \delta N}{1-\beta(1-\delta)}+s \beta N$. The firm's offer $\underline{w}=\frac{(1-\beta(1-\delta)) z+(1-s) \beta[(1-\beta(1-\delta)) \gamma+p(1-\beta(1-s))]}{1-\beta^{2}(1-s)^{2}}+\frac{\beta(s-\delta) \times(1-\beta) N}{1-\beta^{2}(1-s)^{2}}$ is insensitive to $N$ if $s=\delta$.

${ }^{14}$ The McCall (1970) reservation wage is $R=b+\left(\lambda_{U}-\lambda_{E}\right) \int_{R}^{\bar{w}}(w-R) f(w) d w$, and so $\frac{d R}{d b}=\left[1+\left(\lambda_{U}-\right.\right.$ $\left.\left.\lambda_{E}\right) \int_{R}^{\bar{w}} f(w) d w-\left(\lambda_{U}-\lambda_{E}\right) \int_{R}^{\bar{w}}(w-R) \frac{d f(w)}{d R} d w\right]^{-1}$, where $\lambda_{E}\left(\left(\lambda_{U}\right)\right.$ is the job offer arrival rate for the employed (unemployed) workers. A useful benchmark is $\lambda_{E}=\lambda_{U}$, for which $d R / d b=1$, mechanically shifting the nonemployment payoff. Away from $\lambda_{E}=\lambda_{U}, R$ responses also affect the opportunity cost of continuing search by accepting a job, as well as through equilibrium adjustments in $F(w)$, feeding back into the opportunity cost.
} 
firms (who pay $R$ ) adjust wages, but cascading effects can raise even the highest wages nearly one-to-one. ${ }^{15}$ Relatedly, we expect similar rippling effects (across submarkets) with directed search (Wright et al., 2017).

Some wage posting models also preclude firms from differentiating wages between treated and control workers (as in, e.g., Bontemps et al., 1999; Vuuren et al., 2000; Saez et al., 2019), motivating our additional design relating firm-level average wages to average treatment.

\section{Institutional Context, Reforms, and Data}

We review Austrian wage setting institutions, the UI system, our four reforms, and the data.

Wage Setting in Austria About 95\% of Austrian workers are covered by a central bargaining agreement (CBA) negotiated between unions and employer associations, typically at the industryby-occupation level. Besides working hours and conditions, CBAs also regulate wage floors (Bönisch, 2008)- such that in practice, additional negotiations at the establishment level as well as bilaterally regularly lead to substantially higher wages. ${ }^{16}$ Even in the early 1980 s, actually paid average wages exceeded CBA wage floors by 34\% (Leoni and Pollan, 2011), suggesting substantial scope for negotiations at the firm or worker level. At a macroeconomic level, the flexible wage setting institutions are mirrored in high levels of aggregate real and nominal wage flexibility (Hofer et al., 2001; Dickens et al., 2007), although our reforms entail benefit and hence potential wage increases. We also document direct evidence consistent with firm-specific rent-sharing and thus wage deviations in Austria even when controlling for industry-by-year and firm effects. ${ }^{17}$ Accordingly, Austria has large wage dispersion between firms, even within the same industry (Borovičková and Shimer, 2017). As robustness checks, we additionally study

${ }^{15}$ In the model of homogeneity, wage policies are an equilibrium of mixed (iso-expected-profit) strategies (with no mass points), characterized by $\underline{w}=R, \bar{w}=\left[1-\left(\frac{\delta}{\delta+\lambda_{E}}\right)^{2}\right] \tilde{p}+\left(\frac{\delta}{\delta+\lambda_{E}}\right)^{2} R$, and $F(w)=\left(\frac{\delta+\lambda_{E}}{\lambda_{E}}\right)\left(1-\sqrt{\frac{\tilde{p}-w}{\tilde{p}-R}}\right)$. While the bottom wage exhibits the one-to-one effect, the top wage sensitivity is $\frac{d \bar{w}}{d R}=\left(\frac{\delta}{\lambda_{E}+\delta}\right)^{2}$, i.e. the unemployment rate, squared, for $\lambda_{E}=\lambda_{U}$. In the model with heterogeneity, firms differ in productivity $p \in[\underline{p}, \bar{p}]$. Type $p$ 's wage policy $w(p)$ is (see Postel-Vinay and Robin, 2006): $w(p)=p-\int_{R}^{p} \frac{\lambda_{E}+\delta(1-\Gamma(p))}{\lambda_{E}+\delta(1-\Gamma(x))} d x \Rightarrow \frac{d w(p)}{d R}=1-\frac{\delta}{\lambda_{E}+\delta} \Gamma(p)$, where $\Gamma(p)=F(w(p))$ is the (offer-weighted) CDF, which depends on recruitment costs and is not generally characterized in closed form. The lower bound of the integral $(\Gamma(\underline{p})=F(w(\underline{p}))=0)$ makes clear that the least productive active firm pays $R$ and earns zero profit. To see the ripple effects, consider the top wage $(\Gamma(\bar{p})=1)$, which responds the least. Ballparking to $\lambda_{E}=\lambda_{U}$, implies that $\frac{\delta}{\lambda_{E}+\delta}=\frac{\delta}{\lambda_{U}+\delta}$ is the unemployment rate. Then, the lowest wage-UIB sensitivity (in the top) is one minus the unemployment rate. In the full model, $\Gamma(p)$ adjusts due to worker reallocation and $p$-specific recruitment responses. So unless $\lambda_{E}=\lambda_{U}$, feedback effects between $\Gamma(p)$ and $R$ emerge, amplifying or attenuating the effects.

${ }^{16}$ For example, comparative industrial relations work concludes that "in practice local works councils often negotiate supplementary wage increase" (OECD, 1994, p. 176).

${ }^{17}$ We use firm panel data from Bureau van Dijk from 2004 to 2016 and regress wages per employee on value-added per employee, controlling for firm and industry-by-year effects, estimating a level-on-level coefficient of 0.046 (SE 0.009). See Figure 2 for a comparison to coefficients from other settings. 
wage responses to firm- or industry-by-occupation level treatment definitions, and we zoom in on firms with particularly flexible wage policies or in industries with high growth rates.

Unemployment Insurance in Austria The Austrian UI system assigns benefit levels to granular reference wages. Appendix L plots these schedules by year, from 1976 to 2003, detailed in Section 4.1. The replacement rate was $41 \%$ at the beginning of our sample period, and benefits start at a minimum level and are capped. By 2001, the net replacement rate, $\frac{b_{i}}{\left(1-\tau_{i}\right) w_{i}}$, had increased to 55\%. Before 2001, the benefit schedule was based on gross income. UIBs are neither taxed nor means-tested, but UI recipients are required to search for jobs suitable to their qualifications. $^{18}$

Until 1989, benefit duration was only experience-dependent, with 12 (20, 30) weeks for workers with $12(52,156)$ weeks of UI contributions in the last two (two, five) years. From 1989 on, workers with sufficient experience aged 40-49 (above 50) were eligible for 39 (52) weeks. ${ }^{19}$

The Austrian UI system is particularly suitable for our study. First, workers that unilaterally quit are eligible for UI, ensuring that our UI variation shifts workers' outside options. ${ }^{20}$ Second, as a consequence of broad eligibility, relatively long PBD, and mandatory registration with the UI agency (for continuity of health insurance coverage), most workers who separate will take up UI. Appendix Table A.1 reports take-up rates after separations into nonemployment. $63.3 \%(66.2 \%)$ of nonemployment spells longer than 14 (28) days lead to take-up of UI. Third, workers ineligible or exhausting UI can apply for means-tested unemployment assistance (UA or Notstandshilfe), which track a given worker's reform-induced UIB shifts nearly one-to-one. ${ }^{21}$ So we will often denote by "UI" as encompassing both programs. Fourth, there is no experience rating. UI is financed by a payroll tax split between the worker and firm.

Four Large Reforms to the UI Benefit Schedule Figure 3 plots the four reforms we study as a function of nominal earnings (Panels (a)-(d)), and of contemporaneous earnings percentile (Panel (e)). These four particularly large increases in benefit levels differentially affected different segments of the earnings distribution. To cleanly test for pre-trends or anticipation effects, we exclude reforms in 1978 and 1982 and several small maximum-level inflation adjustments as the affected earnings regions had recently been exposed to other benefit reforms. In each panel of

${ }^{18}$ Income-independent UIB add-ons (e.g., in 2018 EUR 29.50 per dependent) are orthogonal to our variation.

${ }^{19} \mathrm{~A}$ program in place from 1988 to 1993 raised duration to 209 weeks for workers 50 or older, with 708 weeks employment in the last 25 years, residing in certain regions (Winter-Ebmer, 1998; Lalive and Zweimüller, 2004).

${ }^{20} \mathrm{By}$ contrast, US quitters are de-jure ineligible for UI. Compared to most European countries, Austrian UI features a very short wait period to claim UI benefits after a quit (four weeks). By contrast, the wait period is, e.g., 12 weeks in Germany, 45 days in Sweden, and 90 days in Hungary and Finland. Quitters in many other European countries such as the Netherlands, Portugal, and Spain are fully ineligible for UI benefits. See Venn (2012) for an overview.

${ }^{21}$ Precisely, $\mathrm{UAB}_{i}=\min \left\{0.92 \mathrm{UIB}_{i}, \max \left\{0,0.95 \mathrm{UIB}_{i}-\right.\right.$ Spousal Earnings $_{i}+$ Dependent Allowances $\left.\left._{i}\right\}\right\}$. Due to the spousal earnings means test, not all workers are eligible for UA. For 1990, Lalive et al. (2006) report median UA at $70 \%$ of median UIB. Card et al. (2007) gauge average 2004 UA at $38 \%$ of UI for a typical job loser. 
Figure 3, we plot the new schedule and the pre-reform schedule. Benefits and earnings are in nominal Austrian shillings (ATS). We convert EUR into ATS starting 1999 at rate 1 to 13.76. The timing and policy process is summarized in Appendix G.5. Three reforms were parts of legislation passed in parliament; the 1985 reform followed a decree from the Ministry of Social Affairs. The 2001 reform simplified the benefit schedule by switching from a gross to a net earnings base.

Data Our primary dataset is the Austrian Social Security Database (ASSD) (Zweimüller et al., 2009). The underlying spell data provide day-specific labor force status, and average earnings per days worked by employer and calendar year ("wages", detailed in Appendix Section G.1), but no hours information. It covers all private (and non-tenured public) sector employees from 1972 onward, and for most of our period excludes the self-employed and farmers. Earnings are censored at annual social security contribution caps (see Zweimüller et al., 2009). ${ }^{22}$ Across the sample years of a given reform, we harmonize the cap at the lowest censored percentile. The ASSD includes covariates such as gender, age, citizen status, and a white/blue collar indicator, and establishment ("firm") location and industry. We also draw on UI registry data (AMS) to validate our prediction of actual benefits based on lagged earnings (Appendix Section G.4).

\section{Estimating the Wage Effects of Four UIB Reforms}

We estimate $\sigma$, a dollar-for-dollar sensitivity of wages to the nonemployment value, by comparing reform-induced variation in UI benefits $d b_{i, t}$ with wage changes $d w_{i, t}=w_{i, t}-w_{i, t-1}$ :

$$
d w_{i, t}=\sigma \cdot d b_{i, t}
$$

We first plot raw data of wage against benefit changes by workers, and then implement a difference-in-differences regression analysis. We estimate a wage effect of $\$ 0.00$ to a $\$ 1.00$ benefit increase, with confidence intervals ruling out effects above $\$ 0.03$ even after two years. This insensitivity extends to new hires, and workers with high predicted time on UI.

\subsection{Variable Construction and Samples}

Wage Responses Our main outcome of interest is the change in average daily wages from one year to the next, $d w_{i, t}$ where $d w_{i, t}=w_{i, t}-w_{i, t-1}$, whose construction we detail in Appendix Section G.1. We will further normalize $d w_{i, t}$ by lagged wages $w_{i, t-1}$, so that we study percent wage growth (but will similarly normalize benefit changes $d b$, so that we will estimate the

\footnotetext{
${ }^{22}$ The statutory caps reported there are for 12 months of earnings. Our earnings data also capture two bonus payments entering the UIB calculation (see Appendix G.2 for a details). We have confirmed that our reforms did not affect the probability of censored $t+1$ earnings, so censoring is unlikely to mask positive wage effects.
} 
level-on-level sensitivity rather than an elasticity). For any job spell (lasting at most one calendar year), we divide total earnings by spell length (days). To account for job switching, we assign jobs by calendar month. Within a month, we prioritize the job with the longest spell in that year. Lastly, we calculate annual averages of these monthly values (excluding months without earnings) to obtain our year- $t$ wage measure.

Reform-Induced UI Benefit Level Changes Our variation in the nonemployment option arises from reform-induced shifts in UI benefit levels. Formally, a worker $i$ with UI-relevant attributes $\mathbf{x}_{i, t}$ receives benefits $b_{t}\left(\mathbf{x}_{i, t}\right)$ in year- $t$ benefit schedule $b_{t}($.$) . Our variation is the$ difference between this benefit level and the worker's counterfactual benefit absent the reform, i.e. under $t-1$ schedule $b_{t-1}\left(\mathbf{x}_{i, t}\right)$. In practice, UI benefit levels are a function of pre-separation reference wages, so that assignment variable $\mathbf{x}_{i, t}=\tilde{w}_{i, t}$ equals reference wage $\tilde{w}_{i, t}$ applicable in year $t$. We ignore additional factors such as the number of dependents, which largely entail lump sums orthogonal to our benefit variation. Our reform-induced variation in benefits is:

$$
d b_{i, t}\left(\tilde{w}_{i, t}\right)=b_{t}\left(\tilde{w}_{i, t}\right)-b_{t-1}\left(\tilde{w}_{i, t}\right)
$$

Hence, $d b_{i, t}$ captures benefit variation solely due to shifts in the benefit schedule. The variation is zero if the UI schedule remains unchanged between $t-1$ and $t$. Such years will form our placebo years. Reform years feature schedule changes for some workers $i \in T$, our treatment group. $d b_{i, t}$ is zero for workers forming our control group $C .{ }^{23}$ Importantly, UI reference wages are lagged wages - hence predetermined and unaffected by the reforms.

Reference Wages $\tilde{w}_{i, t} \quad$ We now describe our construction of reference wages and implied UIBs (with additional details in Appendix Section G.3). The earnings concept determining UIBs underwent slight changes over the decades spanned by our four reforms (administrative details in Appendix Section G.2). For the 2001 reform, the reference wage determining UIBs in year $t$ is the wage from the previous calendar year $t-1$, a rule in place since 1996: $\tilde{w}_{i, t}^{t \geq 1996}=w_{i, t-1}{ }^{24}$ Hence, we directly assign the benefit variation $d b_{i, t}=b_{t}\left(w_{t-1}\right)-b_{t-1}\left(w_{t-1}\right)$ by a worker's lagged wage $w_{i, t-1}$. Before 1996, UIBs were calculated based on the wage in the last full month before

${ }^{23}$ See Appendix Section I.1 for details on the sample construction. We construct the treatment group by selecting earnings percentiles that experienced a sizeable increase in their replacement rates due to the reform. We construct the control group by picking the same number of earnings percentiles adjacent to the treated earnings range. The nominal earnings ranges for the treatment $(\mathrm{T})$ and control $(\mathrm{C})$ regions for the four reforms in the baseline year are presented in Figure 3. For the 1976 and 1989 reforms, we exclude the lowest treated percentile because earnings growth is quite volatile for these individuals. For the 1985 reform, we exclude data three percentiles below the social security earnings cap (above which earnings are censored, so we could not accurately measure wage effects for these individuals). Our findings remained quantitatively unchanged with lower values for this upper limit. For the 1985 reform, we also include 11 earnings percentiles (the 50th through 60 th) between the treatment and control regions that had been slightly treated in prior years but also check robustness of our findings to excluding them.

${ }^{24}$ More precisely, UIBs for claims beginning before (after) June 30 of year $t$ depend on $t-2(t-1)$ income. 
unemployment (before 1988) or a moving average of wages during employment in the last six months (1988 to 1996). Because of wage growth, because we measure annual but not monthly wages, and because wages are potentially affected by the reform, we predict year- $t$ nominal wage levels based on year- $t-1$ wages, $\hat{w}_{i, t}=\bar{g}_{t, t-1} \cdot w_{i, t-1}$, by inflating lagged earnings with average nominal wage growth in our sample, $\bar{g}_{t, t-1}$, between $t-1$ and $t$ (whereby our strategy builds on simulated instruments as in Cutler and Gruber, 1996; Gruber and Saez, 2002; Kopczuk, 2005; Kleven and Schultz, 2014; Weber, 2014). In Appendix G.4, we validate that this procedure almost perfectly predicts wages and implied benefit levels across most of the earnings distribution. There, we also show graphically and in a regression (based on a job loser subsample using the information on actually paid benefits from the AMS data) that actual received UIBs tightly track our predicted levels, finding coefficients very close to one.

Sample Restrictions and Summary Statistics We restrict the sample to workers aged 25-54 employed in each of the 12 months of the base year (reform and placebo). ${ }^{25}$ For each reform, we include treatment earnings regions and adjacent, equally sized control earnings regions. Table 2 provides summary statistics for the treatment and control workers, by reform. This table is not a balance check. Instead, our design relies on a conditional parallel trends assumption discussed in Section 4.3. We also construct pre-reform placebo cross sections occupying the reform-year earnings percentiles.

\subsection{Non-Parametric Graphical Analysis}

We start with a non-parametric analysis of each reform to illustrate how our variation identifies wage-benefit sensitivities, which we normalize, going forward, by the worker's lagged wage $w_{i, t-1}$ :

$$
\frac{d w_{i, t}}{w_{i, t-1}}=\sigma \cdot \frac{d b_{i, t}}{w_{i, t-1}} .
$$

We plot raw data on wage growth of workers sorted by UI reference wages and hence UIB changes.

2001: Large Benefit Increase for Lower Earners Figure 4(a) shows the results for the 2001 reform, which we describe in particular detail. The x-axis indicates gross earnings in 2000, the pre-reform base year. These reference wages determine 2001 benefits. $^{26}$ Here, we collapse

\footnotetext{
${ }^{25}$ Individuals with fewer than 52 weeks of experience in the past two years would be eligible for at most 12 weeks of UI benefits. We found similar results with a laxer restriction of employment in December of the base year. The heterogeneity analysis by recent unemployment relaxes this restriction.

${ }^{26}$ The benefit schedule $b_{2001}($.$) is a function of net earnings while b_{2000}($.$) is a function of gross earnings, as with$ all schedules through 2000. We use an income tax calculator to translate gross earnings (which our administrative data provide) into net earnings to compute $b_{2001}($.$) . For visual consistency, we plot the 2001$ reform in terms of gross earnings. We thank David Card and Andrea Weber for sharing the tax calculator.
} 
the data into earnings percentiles.

The solid green line indicates the reform-induced benefit change for individuals at a given level of base year wages. The 2001 reform affected UI benefits for workers with base-year earnings below ATS 20,500 (32 ${ }^{\text {nd }}$ percentile of the earnings distribution).

The red lines with solid and hollow circles plot wage effects by base-year earnings at the oneand two-year horizon. For each percentile, we calculate the difference between wage growth from 2000 to 2001, when the reform was in place, and pre-reform wage growth from 1999 to 2000. (Analogously, two-year effects difference 2000-2 and 1998-2000 wage growth.) We normalize the wage effects to zero for the lowest percentile not receiving a benefit increase in 2001. There is no excess wage growth for workers treated with higher benefits, neither right below nor away from the threshold, neither at the one- nor the two-year horizon.

To provide a visual benchmark, we also plot the wage growth predicted by our calibrated bargaining framework in Section 2, as the dashed orange line. That is, we multiply benefit change with the calibrated wage-benefit sensitivity of 0.48 . Our analysis of the 2001 reform thus clearly rejects this benchmark.

Our analysis rests on the identification assumption that the average wage growth among groups treated by a benefit reform compared to the control group, whose benefits remained unchanged, would have followed parallel trends absent the reform. We shed light on this assumption in two ways. First, the flat wage effects across the control percentiles provide support for the identification assumption. A second test, reported in Appendix Figure A.1, lags both the reform period and the pre-period by two years, and checks whether the earnings percentiles affected by the 2001 reform experienced higher or lower excess wage growth in periods before 2000. Such different trends could then have masked a non-zero treatment effect during the 2001 reform. Appendix Figure A.1 shows no such effects for a placebo reform in 1999 (thus comparing 1999-2000 to 1998-9 wage growth) for the one-year earnings changes. At the two-year horizon, there is even some evidence of a positive pre-trend. While such a pre-trend would actually bias our results upward, it motivates our regression-based difference-in-differences analysis in Section 4.3, where we add time-varying industry/occupation and firm-by-year fixed effects as well as parametric earnings controls to net out such potential confounders. There, we also formally test for, and do not find, pre-trends across all of the reforms.

1989: Increase in Benefits for Low Earners Figure 4(b) presents the analysis of the 1989 reform, which increased benefits for workers with base-year earnings below ATS 12,600 by up to eight percentage points. The graph suggests moderate, positive average wage effects which even at the two-year horizon remain much smaller than the benchmark prediction. ${ }^{27}$

\footnotetext{
${ }^{27}$ For 1989 as for the other two reforms before 1995, we additionally confirm that the reform affected actual benefit levels by base-year earnings. In Appendix Figure A.2, the assignment variable-based on inflated lagged earnings - is again plotted with the green line and the actual benefit level with the red line, for the one-year and
} 
1985: Increase in Benefit Maximum Figure 4(c) plots the effects of the 1985 reform, which raised the maximum benefit level by $29 \%$ (ca. 7,600 ATS to 9,800 ATS) for higher earners. We find no evidence for wage increases among these workers.

1976: Increase for Low Earners The 1976 reform, analyzed in Figure 4(d), raised benefits for workers with earnings below 4,100 ATS. If anything, their wages differentially decrease.

The Average Sensitivity of Wages to UI Benefits Figure 5 is a scatter plot of excess wage growth against UIB change by earnings percentile across all four reforms (colors/symbols differentiate the reforms). Estimating the wage-benefit sensitivity in a linear regression reveals point estimates of $\hat{\sigma}=-0.005$ (SE 0.008) at the one-year horizon and of $\hat{\sigma}=0.028$ (SE 0.018) at the two-year horizon. At both horizons, the confidence interval of the slope includes zero and clearly excludes the predicted benchmarks slopes of 0.24 to 0.48 (depicted).

\subsection{Difference-in-Differences Design}

We next investigate the regression analogue of the non-parametric analysis, to formally test for pre-trends (e.g., due to anticipation effects) and to include a rich set of controls. The estimated wage-benefit sensitivities range from negative 3 to positive 0.7 cents on the dollar after one and two years. The confidence intervals for our preferred specifications reject sensitivities above 3 cents on the dollar.

\subsubsection{Econometric Framework}

Our difference-in-differences design regresses wage changes, $d w_{i, r, t}=w_{i, r, t}-w_{i, r, t-1}$, on reforminduced - actual and placebo - benefit changes, $d b_{i, r, t}$, both normalized by lagged wages:

$$
\begin{aligned}
\frac{d w_{i, r, t}}{w_{i, r, t-1}}= & \sigma_{0} \cdot\left(\mathbb{1}_{(t=r)} \times \frac{d b_{i, r, t}\left(\tilde{w}_{i, r, t}\right)}{w_{i, r, t-1}}\right)+\sum_{e=-L}^{-1} \sigma_{e} \cdot\left(\mathbb{1}_{(t=r+e)} \times \frac{d b_{i, r, t}\left(\tilde{w}_{i, r, t}\right)}{w_{i, r, t-1}}\right) \\
& +\tau_{r, P_{t-1}}+\theta_{r, t-1}+\gamma_{r, t} \ln w_{i, r, t-1}+X_{i, r, t-1}^{\prime} \phi_{r, t-1}+\epsilon_{i, r, t} .
\end{aligned}
$$

The coefficient of interest is $\sigma_{0}$, capturing the effect of the reform-induced benefit changes on wages. $r$ denotes specific reforms (as we let control variables vary between reforms). We control for earnings percentile fixed effects, $\tau_{r, P_{t-1}}$, and year effects, $\theta_{r, t-1}$, as well as additional control variables, in particular time-varying controls for lagged earnings, $\ln w_{i, r, t-1} \cdot{ }^{28}$ As we include

two-year horizons. Realized benefit changes closely track our reform-induced variation at the one-year horizon, validating our earnings inflation prediction and the benefit imputation. Another reform shifted the schedule in 1990, broadly for the control and treatment groups, explaining the shifted line for that year. Our two-year results are robust to excluding 1989. Moreover, in our regression specifications, we will only build on one-year benefit variation as a treatment variable even when we measure longer-term wage outcomes.

${ }^{28}$ We also include an eligibility control for the regional PDB extension described in Footnote 19. 
earnings percentile fixed effects, we set $\sigma_{-1}$ to zero. In addition to the one-year horizon, we also conduct the analysis using two-year wage outcomes (then normalizing $\sigma_{-2}$ to zero and omit $\sigma_{-1}$ ). The remaining variation in $d b_{i, r, t}$ that identifies the wage-benefit sensitivity $\sigma_{0}$ compares wage growth across earnings percentiles with and without reform-induced benefit changes in a year, and within a percentile over time, comparing actual to placebo reforms. We again normalize changes in wages and benefits by $i$ 's lagged wage.

Percentile fixed effects $\tau_{r, P_{t-1}}$ absorb permanent wage growth differentials across percentiles, e.g., due to mean reversion. They are reform-specific, i.e. common between reform and placebo years for a given reform, but separate between reforms. Calendar year effects, $\theta_{r, t-1}$, absorb aggregate wage growth shifts. Year-specific parametric earnings controls, $\ln \left(w_{i, r, t-1}\right)$, account for time-varying shocks to different parts of the earnings distribution. We then incrementally add covariates $X_{i, r, t-1}$ with year-specific coefficients to absorb other time-varying shocks. First, we add demographics (sex, cubic polynomials of experience, tenure, and age). The second set contains industry-by-occupation-by-year fixed effects $\gamma_{o(i, t-1), k(f(i, t-1)), t-1}$ (four-digit industry by white/blue collar occupation). Third, in our most fine-grained specification, firm-by-year effects $\psi_{f(i, t-1), t-1}$ isolate variation between workers in the same firm.

The core identification assumption of our difference-in-differences design requires conditional parallel trends: conditional on the controls, in particular percentile and year effects and timevarying parametric earnings controls, the average wage growth among groups treated by a benefit reform compared to those whose benefits remained unchanged would have followed parallel trends absent the reform. A potential violation of our identification assumption would occur if treated groups experienced an additional wage growth shock contemporaneous with the reform. ${ }^{29}$ We test the parallel trends assumption in the pre-period by assigning placebo reforms: in pre-reform years, $e<0$, we assign the average $d b / w$ of workers in a given earnings percentile in the actual reform year to workers in that percentile in $e<0$. A violation of the parallel trends assumption in the pre-period would occur if the placebo reforms were associated with excess wage growth as captured by $\sigma_{e} \neq 0$ for $e<0$ (as we include percentile fixed effects).

We estimate specification (19) using the procedure in Correia (2017) and stack data for all reforms $r \in\{1976,1985,1989,2001\}$. We restrict the earnings ranges for each reform to the "treatment" and "control" percentile groups of Section 4.2. For each reform, we add $L=3$ pre-period years (the maximal amount to still study the 1976 reform, since our data start in 1972). ${ }^{30}$ We report standard errors based on two-way clustering at the individual and the earnings percentile level (the level of our treatment variation). In Appendix Figure A.6, we confirm that other clustering levels (firm, percentile, individual, and reform-specific percentiles) lead to similar

\footnotetext{
${ }^{29}$ Since we include time-varying parametric controls for lagged earnings, $\ln w_{i, r, t-1}$, these types of shocks to different parts of the earnings distribution would have to be quite sharply delineated.

${ }^{30}$ We have also assessed robustness to longer pre-periods $(L=5)$ while dropping that earliest reform in unreported results.
} 
confidence intervals. We winsorize wage growth at the 1st/99th percentile; Appendix Figure A.7 confirms robustness to no winsorization as well as at the 5 th/95th percentiles.

\subsubsection{Visual Regression Results}

To provide a bridge between Figure 5 and our difference-in-differences specification (19), we plot wage growth against reform-induced benefit changes in binned scatter plots and incrementally add year effects, earnings percentile effects, and year-specific earnings controls in Figure 6 . The figure plots the slope, i.e. coefficient $\sigma_{0}$ in Equation (19), of a binned scatter plot of residualized earnings changes and benefit changes in the treatment year. ${ }^{31}$ The panels also plot, in orange, the predicted relationship from our calibrated Nash bargaining model. Panel A only includes year fixed effects as controls. Panel B adds earnings percentile fixed effects and Panel $\mathrm{C}$ adds a year-specific log-earnings control.

Across all three specifications, we find no evidence of positive effects of benefits on earnings. To assess our identifying assumptions, we present similar binned scatter plots in the $e=-3$ and $e=-2$ placebo years in Appendix Figure A.5. For $e=-2$, we find no evidence for placebo effects across specifications. For $e=-3$, we find some pre-trends or significant placebo estimates unless we include log earnings controls as is customary in the simulated instruments literature. The visual analysis also allows us to assess the validity of the conditional parallel trends assumption. At shorter horizons, the parallel trends assumption holds without additional controls. At longer horizons, it holds conditional on time-varying parametric controls for lagged earnings.

\subsubsection{Full Regression Results}

Mirroring the non-parametric analysis, the difference-in-differences analysis reveals that wages are insensitive to benefit changes. The point estimate for the wage-benefit sensitivity is $\hat{\sigma}=0.00$ (SE 0.013) after one year and $\hat{\sigma}=-0.027$ (SE 0.026) after two years in our preferred specifications with firm-by-year fixed effects. Confidence intervals thus let us rule out wage increases above $\$ 0.03$ for a $\$ 1.00$ increase in UIBs both at the one- and two-year horizon.

One-Year Effects Panel A in Table 3 presents one-year wage effects, i.e. estimates of $\sigma_{e}$. The regressor of interest is $\sigma_{0}$, capturing the wage growth associated with reform-induced benefit changes. Column (1) includes the same controls as in Figure 6(c), and the subsequent columns progressively add further controls. We have normalized $\sigma_{-1}$ to zero and assess pre-trends with $\sigma_{-3}$ and $\sigma_{-2}$. Across all six specifications, we cannot reject that both pre-period estimates are jointly equal to zero, which supports our identification assumption.

\footnotetext{
${ }^{31}$ We residualize the independent and dependent variables in the entire sample of reform and placebo years, so that the best fit lines match the coefficients in Table 3.
} 
Across columns, effects are quantitatively similar, centered at zero. Column (1), without control variables, estimates $\hat{\sigma}_{0}=-0.004$ (SE 0.016), ruling out effects above 0.03. Column (2) finds a similar estimate when adding Mincerian controls. Our estimates are even smaller at -0.014 and -0.019 in columns (3) and (4), with industry-occupation-year fixed effects and then all controls jointly, while standard errors remain unchanged.

Two-Year Effects Panel B in Table 3 reports the analogous longer-run effects of the reforms, at the two-year horizon. Column (4), with all controls, estimates $\hat{\sigma}=-0.022$ (SE 0.03). Similar estimates emerge with fewer controls in columns (1)-(3), ranging between -0.027 and 0.007 . The pre-period effects of placebo reforms remain statistically insignificant.

Intrafirm Variation Next we assess whether changes in the nonemployment outside option between workers within the same firm lead to wage changes, by including firm-by-year fixed effects in columns (5) and (6). At the one-year horizon (Panel A in Table 3), the within-firm variation also leads to zero effects, even more precisely estimated than those in columns (1)-(4). Similarly, at the two-year horizon (Panel B in Table 3), the effects remain small and insignificant.

Parametric Earnings Controls Consistent with the simulated instruments literature (Kopczuk, 2005; Kleven and Schultz, 2014), our main specifications include time-varying controls for (log) earnings. (As Figure 6 and Appendix Figure A.5 show, the parallel trends assumption holds in the pre-period without conditioning on parametric earnings controls. At longer horizons, it holds conditional on such controls.) We present variants of our main specification (column (4) in Table 3) with alternative earnings controls in Appendix Figure A.8, namely log, linear, and linear percentiles, which all yield very similar estimates around zero.

Validation Exercise To assess the extent to which reform-induced benefit changes, assigned based on lagged earnings, shift benefits implied by realized earnings, we estimate a variant of 19 with reform-induced benefit changes implied by realized earnings $\frac{b_{t}\left(w_{i, t}\right)-b_{t-1}\left(w_{i, t}\right)}{w_{i, r, t-1}}$ as the dependent variable. The contemporaneous coefficient on $\frac{d b_{i, r, t}\left(\tilde{w}_{i, r, t}\right)}{w_{i, r, t-1}}$ could be close to zero if, hypothetically, an individual's earnings were independently redrawn each year, because then wage earnings in $t=r-1$ would not predict earnings and thus benefits in $t=r$. We report results and write out the formal regression model in Appendix Table A.2. The analysis reveals a 0.807 (SE 0.013) coefficient at the one-year horizon and of 0.529 (SE 0.021) at the two-year horizon, confirming that the reforms affected benefits in the treatment percentiles. ${ }^{32}$ The effects

\footnotetext{
${ }^{32}$ Excluding the 2001 reform from this validation exercise (because the reform occurred at a time when benefits were determined based on lagged years' wages) yields quantitatively very similar results with a 0.762 (SE 0.013) coefficient at the one-year horizon and of 0.500 (SE 0.025) at the two-year horizon. We also report instrumental variable estimates in Appendix Table A.3, formally interpreting the validation exercise as a first stage relationship. The IV specification leaves our conclusions quantitatively unchanged as standard errors increase only slightly.
} 
are also stable when we add in more detailed controls, even firm-by-year effects. Moreover, pre-period coefficients now test whether the same earners have systematically seen benefits change due to schedule changes or wage growth. In line with our selection of reforms, these placebo effects are an order of magnitude smaller than the reform effects $(t=r) .{ }^{33}$

Transitory vs. Permanent Treatment Treatment status may be imperfectly persistent due to idiosyncratic wage changes. To evaluate this dynamic, we estimate "donut hole" treatment effects, whereby we drop individuals situated within varying bandwidths on both sides of the treatment/control earnings cutoff, hence particularly prone to switching status in future years. Coefficient estimates, reported in Appendix Figure A.9, indicate no evidence of increasing treatment effects, even when dropping $25 \%$ of our sample, suggesting that transitory treatment is unlikely to mask an underlying larger effect. This finding also suggests that potential limited capacity of firms to differentiate wages by treatment status around the cutoffs (as in wage posting models) may not drive the absence of wage effects. Finally, a subsample analysis in Section 5 will not find larger treatment effects for very stable earners, e.g., with a low predicted separation rate.

Accounting for Non-Taxation of UIBs Austrian UIBs are not taxed. Our gross-wagebased estimates should imply even smaller sensitivities, which we confirm in Appendix Table A.6 (graphical analysis in Appendix Figure A.18). There, we replicate our main results from Table 3 but rescale the untaxed UIB shifts into gross UIB shifts (imputing an individual's average net-of-tax rate following a tax calculator detailed in Appendix K). As the tax imputations are tentative, our main results use raw net (untaxed) UIBs, hence likely overestimating sensitivities.

Separation Effects To rule out selective attrition, we also report treatment effects on separations and sickness in Appendix H. Across specifications and outcomes, the benefit increases were associated with quantitatively negligible and largely statistically insignificant effects. ${ }^{34}$

\subsection{Wage Sensitivity by Post-Separation Time in Unemployment $\tau$}

As illustrated in Figure 1b, the baseline model's sensitivity of $N$ to $b$ - and thus that of $w$ to $b-$ increases in post-separation time on UI, $\tau$, the weight on instantaneous payoff $b$.

Reporting results in Figure 7, we now estimate wage effects across worker subsamples sorted into quantiles by their idiosyncratic predicted post-separation time on UI, $\hat{\tau}_{i}$, which is the weight the wage bargain puts on UIB $b$ in the wage equation (6). The quantiles, sorted within each

\footnotetext{
${ }^{33}$ Their very high precision renders the pre-reform one-year coefficients statistically significantly different from zero. For the two-year validation, we cannot reject that the pre-period coefficients are jointly equal to zero.

${ }^{34}$ By contrast, Jäger et al. (2018) document separation effects among workers from a reform that dramatically raised potential benefit duration for older workers in Austria, perhaps used as a bridge into early retirement.
} 
reform, start from deciles; to obtain additional dispersion, we further split the top and bottom decile into two ventiles each, and then further split up the resulting very top/bottom ventiles into two. We thereby study a total of 14 quantiles. On the x-axis, we plot the group-specific mean predicted $\hat{\tau}_{i}$. The y-axis reports two wage-benefit sensitivities. First, the yellow line (squares) plots the quantile-specific model-predicted wage-benefit sensitivity based on Equation (6) and $\phi=0.1$, inputting the quantile's mean $\hat{\tau}_{i}$. (A negative correlation between $\tau_{i}$ and $\phi_{i}$ would steepen the gradient.) Second, the blue line (circles) traces out the empirical sensitivities, as heterogeneous treatment effects from our main regression model (19) interacting reform-induced UIB shifts with indicators for a worker's $\hat{\tau}_{i}$ quantile.

Figure 7 reveals substantial variation in $\hat{\tau}_{i}$ - ranging from around 0.02 to nearly $0.20-$, and thus in the model-predicted wage-benefit sensitivity - from around 0.15 to above 0.60. By contrast, the empirical gradient of wage effects is flat at zero, just as much among workers likely to experience long periods of UI - for whom the UIB increases should mechanically raise nonemployment values by more - as among workers whose separations rarely entail UI receipt.

\subsection{New Hires' Wage Sensitivity}

Perhaps wage stickiness among incumbent workers slows down wage adjustments even after two years. We therefore estimate the treatment effects separately for job stayers and various mover types, whose wages are more likely to reset flexibly. By studying wages of new hires, this analysis also tests whether employer competition models (Cahuc et al., 2006) or contractual models with insurance (Beaudry and DiNardo, 1991; Bertrand, 2004) may play a role in the insensitivity of average (i.e. largely incumbent workers') wages.

Panel A of Table 4 displays the one- and two-year treatment effects for job stayers, and recalled workers and job switchers. We classify switchers by their first type of transition from the original job in the base year. We use our daily spell data to consider only post-separation wages rather than average annual earnings. ${ }^{35}$ We interact an indicator for each transition type with the $\sigma_{e}$ coefficients, the parametric year-specific earnings controls and the baseline earnings percentile fixed effects. Across the three transition types, the effects are small and insignificant. Despite the smaller subsamples, the confidence intervals exclude the 0.24-0.48 benchmark. Even recalled workers - who return to the same firm after unemployment - do not appear to bargain a higher wage when outside options improve.

We have also divided movers into "EE" movers, who directly move from one employer to another, and "EUE" movers, who first undergo an unemployment spell with UI receipt ("EUE"). ${ }^{36}$ Of particular theoretical interest are EUE movers. First, these workers receive UI benefits, and

\footnotetext{
${ }^{35}$ Recalled workers' one-year earnings are hence pre- and post-separation calendar year averages.

${ }^{36}$ To distinguish between EE, EUE, and ENE movers, we augment our monthly employment spell data with daily spell data and define EUE (ENE) movers as employer-to-employer transitions with at least one day of unemployment (nonemployment) between employment spells.
} 
then rebargain with their next employer with UI on hand. Second, the wage responses of these new hires from unemployment are allocative for aggregate employment in standard matching models. ${ }^{37}$ Third, these workers should exhibit the standard, large sensitivity of wages to UI shifts even in richer models with employer competition and external job offers as in Cahuc et al. (2006), because these workers' best outside option is still nonemployment.

Even the results for EUE movers, presented in Panel B of Table 4, do not reveal positive effects. In fact, the point estimates are negative, but turn insignificant with controls specific to transition type, and none of the upper confidence intervals includes the predicted value. ${ }^{38}$

Estimates for EE movers are in Table 4 Panel C. Confidence intervals again widen. Interestingly, this sample exhibits some positive effects at the one-year horizon, which however move to zero once we interact controls by transition type, and fully return to zero with firm-by-year effects. At the two-year horizon, estimates are very close to zero no matter the control specification, perhaps suggesting that initial (one-year) post-transition earnings may have been noisier.

There are a few caveats to consider. First, worker transitions may be affected by the reforms, and since we condition on an endogenous outcome, selection may show up as wage effects. Second, for EUE movers, there are non-bargaining channels affecting re-employment wages, such as reservation wages, skill depreciation, or employers' statistical discrimination by nonemployment duration. These potential confounds among EUE movers had in part motivated our strategy of primarily studying on-the-job wage changes of incumbent workers in the first place.

\section{The Missing Link Between Wages and Benefits}

We now dissect the wage-benefit insensitivity along the following three-element chain:

$$
\frac{d w_{i}}{d b_{i}}=\underbrace{\frac{d w_{i}}{d \Omega_{i}}}_{\begin{array}{c}
\text { Sensitivity of wages } \\
\text { to outside options }
\end{array}} \times \underbrace{\frac{d \Omega_{i}}{d N_{i}}}_{\begin{array}{c}
\text { Sensitivity of outside option } \\
\text { to nonemployment value }
\end{array}} \times \underbrace{\frac{d N_{i}}{d b_{i}}}_{\begin{array}{c}
\text { Sensitivity of nonemp. value } \\
\text { to UIB shifts }
\end{array}}
$$

To assess the relative importance of these three factors for the insensitivity result, we conduct a battery of heterogeneity analyses. In particular, for each dimension of heterogeneity, we run our main specification (mirroring column (4) in Table 3) and include interactions between

\footnotetext{
${ }^{37}$ Pissarides (2009) summarizes this paradigm. Richer models, as when firms face financial constraints, give allocative consequences to incumbents' wages too (e.g., under financial constraints as in Schoefer, 2015).

${ }^{38}$ In unreported results, we have investigated robustness to alternative earnings controls (based on the check of our main results in Appendix Figure A.8). Here, some point estimates for EUE movers were closer to zero. Moreover, EUE and EE estimates were stable around zero when we drop very low (perhaps noisy) earners. We have also tested for duration effects (consistently finding positive but insignificant effects), and conducted a calibration exercise to assess whether the duration channel can explain the negative wage effect using estimates of the elasticity of nonemployment duration to UIBs (Lalive et al., 2006; Card et al., 2015; Nekoei and Weber, 2017), and the semi-elasticity of wages to nonemployment duration (Schmieder et al., 2016). The calibration can rationalize the point estimates of the EUE wage effects when drawing from the very high end of these targets.
} 
heterogeneity group indicators with the treatment variable (and placebo treatments in pre-reform years). Table 5 presents a summary of these estimates. Appendix Section I.2 describes the variable construction. Except for the categorical variables, the top (bottom) estimates indicate lowest (highest) values of the heterogeneity variable. We find very little variation across groups. Additionally, we report below that wages remain insensitive to alternative treatment definitions (potential duration rather than benefit levels; firm- and industry-level average of the instrument).

\subsection{The Nonemployment Value and UI Benefits $d N / d b$}

A first reason why wages are insensitive to UI benefits may be that the nonemployment value does not move with the UI reform as predicted by our model.

Unemployment Risk We provide additional proxies for unemployment risk or for experience with the UI system, studying heterogeneity by unemployment (separation) risk, the local unemployment rate, and a direct prediction of time on UI unconditionally of a separation. These unemployment risk proxies are not consistently associated with larger one-year point estimates, and hover around zero.

Experience with, and Salience and Knowledge about UI Limited knowledge or salience of UIB levels could diminish wage responses (as, e.g., in the context of complex tax incentives in Abeler and Jäger, 2015). Several pieces of evidence speak against this explanation. First, wages remain insensitive even after two years and in response to large (and plausibly more salient) shifts. Second, even recent UI recipients (and EUE switchers in Section 4.5) - plausibly more aware of the UIB schedule (Lemieux and MacLeod, 2000) - do not exhibit higher sensitivity, which we test by splitting up the sample by a worker's actual UI history (months since last UI receipt or nonemployment spell). We find some suggestive evidence of larger effects for recently reemployed workers at the two-year horizon, which however remain insignificant. Third, compared to other sources of idiosyncratic variation in the nonemployment value, UIBs largely depend on recent earnings, information available to both parties. Fourth, we additionally analyze a 2006 Eurobarometer survey asking Austrian workers about beliefs about their hypothetical UI replacement rates. The histograms in Appendix Figure A.10, of beliefs and actual rates (from the AMS/ASSD, binned into the survey intervals), line up well. The average worker's rate is $64.03 \%$ (SE 0.72 ) in the survey, close to the $65.29 \%$ among actual recipients. ${ }^{39}$ Moreover, we found in unreported results that workers with more children correctly predict higher benefits. Fifth, we have found positive albeit noisily estimated effects of the reforms on UI take-up (Appendix Table

\footnotetext{
${ }^{39}$ The replacement rate can deviate from $55 \%$ due to lump sum benefits for dependents, and the earnings base for benefits post-1996 are lagged annual earnings rather than current as in the survey.
} 
A.4). Lastly, Jäger et al. (2018) document that employed workers separated in response to, and hence were aware of, UI PBD extensions in Austria.

Variation in UI Generosity From an Age-Specific PBD Reform Appendix J additionally reports the effects of reforms to the potential benefit duration (PBD) of UIBs (rather than their level) on incumbents' wages, exploiting a 1989 reform for workers aged 40 and above. We do not find wage effects of this dimension of UI generosity either, even two years after the reform. This design complements our previous designs as the treatment assignment was age- rather than past-income-based, the reform was permanent (rather than potentially eroded by inflation or subsequent benefit shifts), and perhaps more salient and simple (age-based). The age dimension divides workers who are almost certainly in the same market and close production substitutes.

\subsection{Outside Options and the Nonemployment Value $d \Omega / d N$}

A second reason why wages are insensitive to UI benefits may be that the nonemployment value (while shifting with $b$ ) may not shift the relevant outside option in wage bargaining.

External Job Offers and Job Mobility We sort workers by several measures of recent nonemployment, including months since UI receipt and months since last nonemployment spell. These measures proxy for the likelihood of not yet having received potential outside offers. Outside job offers may insulate wages from changes in the nonemployment value by ratcheting up wages as in models of employer competition and on the job search (Postel-Vinay and Robin, 2002; Cahuc et al., 2006). At the one-year horizon, we do not find that recently nonemployed workers exhibit larger wage-benefit sensitivities (Table 5). We find some, but statistically insignificant and quantitatively small, evidence for this prediction at the two-year horizon.

Group-Level Bargaining Rather than atomistic bargaining between one individual worker and one firm, real-world wage setting may occur with groups of workers (or employers). Here, the average worker's outside option may matter, as in union bargaining models, similarly for wage posting models in which firms are constrained to offer a single wage. First, we construct the average of the worker-level reform-induced benefit variation at the establishment level, as firms play an important role in Austrian wage setting (e.g., through plant-level works councils in Austria, see Section 3). Second, we do likewise at the industry-by-occupation level, at which collective bargaining agreements between employer associations and unions are typically concluded in Austria, typically distinguishing white and blue collar workers (e.g., white-collar workers in the insurance industry). Most CBAs cover all of Austria; some are state-specific (see Knell and Stiglbauer, 2012). Our industry proxy is 3-digit NACE. We plot histograms of benefit variation averaged at the group level in Appendix Figure A.11. We then adapt 
our worker-level regression specification (19) with the group-level treatment. We include the main controls from specification (19) and additionally include two sets of group-level control variables: reform-specific percentile fixed effects for (i) the average treatment at the group level in a given year and (ii) the reform-sample specific share of workers in the group cell with a positive treatment. ${ }^{40}$ We also report firm-level specifications with industry-by-occupation-by-year effects, and industry-by-year (3-digit, our CBA proxy) and occupation-by-year effects in the industry-by-occupation-level specifications.

Table 6 reports small firm-level point estimates ranging from 0.013 to 0.036 (0.024 to 0.035) at the one-year (two-year) horizon. The confidence intervals include the worker-level point estimates and zero. Table 6 also reveals pre-trend violations for the specification without industry-byoccupation-by-year effects. This suggests that firms with different shares of reform-affected workers were on different trends, perhaps because of industry-level shifts that were correlated with treatment intensity. When we include industry-by-occupation effects (specifications 3 and 4), comparing workers in the same industry and occupation but working at firms with different benefit shifts, we find that pre-trends are flat and point estimates for the pass-through remain between 0.033 and 0.036 with confidence intervals ruling out effects larger than 0.11 . Quantitatively, the evidence is hard to square with a firm-level variant of the Nash benchmark.

Table 7 reports results for the industry-by-occupation level. Point estimates are less stable across specifications and have substantially wider confidence intervals. In specifications with the most fine-grained controls, i.e. industry-by-year and occupation-by-year effects in columns (5) and (6), we find negative point estimates between -0.03 and $-0.05(-0.06$ and -0.14$)$ at the one-year (two-year) horizon, with confidence intervals including higher pass-through above 0.1. Specifications with fewer controls suggest larger effects, yet violate our identification assumption due to statistically significant placebo estimates in the pre-period, thus suggesting that the inclusion of control variables is important to account for, e.g., occupation-by-year-specific shocks. An additional caveat is that administrative industry proxies may only imperfectly overlap with actual CBA units and miss all regional differentiations. ${ }^{41}$

${ }^{40}$ Formally, letting $g(i, t-1)$ denote worker $i$ 's $t-1$ firm or industry-by-occupation group, average treatment in worker $i$ 's group $g$ is $\left(\frac{d b}{w}\right)_{g(i, r, t-1)}=\frac{1}{N_{g(i, t-1)}} \sum_{j \in g(i, t-1)} \frac{d b_{j, r, t}\left(\tilde{w}_{j, r, t}\right)}{w_{j, r, t-1}}$, where $N_{g(i, t-1)}$ denotes the worker count in group $g$ in period $t-1, d b_{j, r, t}$ again denotes worker $j$ 's reform-induced benefit change. Before averaging within group-by-year cells, we winsorize $d b / w$ at the 1 st and 99th percentiles. We then estimate: $\frac{d w_{i, r, t}}{w_{i, r, t-1}}=$ $\sigma_{0} \cdot\left(\mathbb{1}_{(t=r)} \times\left(\frac{d b}{w}\right)_{g(i, r, t-1)}\right)+\sum_{e=-L}^{-1} \sigma_{e} \cdot\left(\mathbb{1}_{(t=r+e)} \times\left(\frac{d b}{w}\right)_{g(i, r, t-1)}\right)+\tau_{r, P_{t-1}}+\theta_{r, t-1}+\gamma_{r, t-1} \ln w_{i, r, t-1}+$ $X_{i, r, t-1}^{\prime} \phi_{r, t-1}+\epsilon_{i, r, t}$. The main control variables are percentile fixed effects $\tau_{r, P_{t-1}}$, calendar year effects, $\theta_{r, t-1}$, year-specific parametric earnings controls, as well as a control for being eligible for extended benefits under the REBP. In the firm- (industry-) level specifications, these fixed effects are at the percentile (ventile, given the small group count) level.

41 The typical Austrian CBA mandates a wage floor ("Kollektivvertragslohn"), plus a percent raise for any job with above-floor prevailing wages ("Istlöhne"). In additional case studies of digitized CBAs (from the KVSystem Kollektivverträge Online data from the Trade Union Federation, with best coverage around the 2001 reform), wage floors did not appear to differentially shift for treated vs. untreated wage groups (instead continued to prescribe 
Lastly, in Table 5, we also include an heterogeneity analysis for worker-level wage effects by the firm's share of employees recently nonemployed, whose reservation wages may shift most with UI, and do not find larger wage responses in those firms.

\subsection{Wages and Outside Options $d w / d \Omega$}

A final reason why wages are insensitive to UI benefits may be that while UI benefits shift the nonemployment value, real-world wage setting is insensitive to outside options more generally.

Worker Bargaining Power Workers with lower bargaining power should exhibit larger sensitivity to outside options. We start by splitting workers by age, as well as occupation class (blue vs. white collar). The results show no clear effect heterogeneity. Since female workers' wages appear less sensitive to productivity shifts (Black and Strahan, 2001; Card et al., 2016), perhaps due to lower bargaining power, we then consider sex, finding somewhat larger effects among women at the one-year horizon (although the pattern reverses at the two-year horizon).

Firm Wage Premia We calculate firm fixed effects following the AKM methodology in (Abowd et al., 1999) and estimate the wage-benefit sensitivity in firms with high or low firm effects. In both groups, estimates are close to zero at the one-year horizon. At the two-year horizon, the sensitivity is around 0.1 in low-AKM firms, which is consistent with the idea that worker-sided renegotiation is more likely in firms with low wages (as in MacLeod and Malcomson, 1993). Yet, the estimated sensitivity remains below the calibrated benchmark.

Wage Adjustment Frictions and Infrequent Renegotiation Perhaps wage stickiness or downward wage rigidity in continuing jobs masks wage pass-through in the short run. Alternatively, rebargaining of a given wage may only occur if it otherwise were to leave the bargaining set, i.e. fall short of (exceed) the worker's (firm's) reservation wage (as in e.g., MacLeod and Malcomson, 1993). Several pieces of evidence speak against this explanation. First, we found no wage effects even after two years, when stickiness should bind for a smaller fraction of jobs. ${ }^{42}$ Second, most of our reforms should induce upward wage pressure, making downward wage rigidity less binding. Third, our visual inspection did not suggest wage effects even for larger treatment, where menu costs could be overcome. Fourth, we have not found positive wage effects in settings less constrained by wage rigidity, e.g., in new jobs or in growing industries. Fifth, we also have not found wage increases in job types perhaps reflecting lower worker surplus.

homogeneous wage increases). An attempt to systematically study CBA wage floors and wage growth (building on the Statistics Austria-based "CBA wage floor index" (Tariflohnindex) in Knell and Stiglbauer (2012)), was not feasible due to a small number of observations.

${ }^{42}$ More than half of wage contracts appear to reset each year (Barattieri et al., 2014; Sigurdsson and Sigurdardottir, 2016), and incumbents' wages are still half as sensitive to aggregate shocks as new hires' wages (Pissarides, 2009). Dickens et al. (2007) find lower downward wage rigidity in Austria than in Germany or the U.S. 
Moreover, we find a zero effect in subsamples of firms with flexible wage policies. We stratify firms by the standard deviation of within-firm wage growth, perhaps indicating wage differentiation facilitating wage pass-through. We also consider a proxy for a firm's distance from the CBA-level wage floor, approximated as the firm-level standard deviation of the residuals from a regression of log wages on industry-occupation-tenure-experience-year fixed effects.

The Prevalence of Wage Bargaining Perhaps wage bargaining may not determine realworld wage setting in any pocket of the Austrian labor market. However, a vast body of empirical work points to patterns consistent with wage bargaining, such as rent sharing. Moreover, survey evidence on the actual presence of bilateral bargaining suggests that both workers and employers report the presence of bargaining in a substantial part of the labor market (Hall and Krueger, 2012; Brenzel et al., 2014). Here, we do not find wage effects in subsamples that carry the correlates of prevalence of wage bargaining according to those surveys, such as tighter labor markets (lower unemployment), workers with higher education (our proxy: white rather than blue collar), in smaller firms, or among men. This suggests that even in pockets of the labor market where we expect bargaining to occur, nonemployment value shifts do not entail wage effects.

\section{Conclusion}

We have studied the effects of changes in the value of nonemployment on wages brought about by reforms to unemployment insurance (UI) benefit levels in Austria, a setting where UI enters the nonemployment scenario for most workers. Wages appeared fully insulated from these UI-induced shifts in the value of nonemployment, even after two years and in all pockets of the labor market. This limited wage pressure may carry over to other UI-like policies that boost workers' nonemployment value, at least in the short run and if group-specific.

This empirical wage insensitivity is inconsistent with the large theoretical sensitivity of the commonly used Nash bargaining model specified with nonemployment as workers' outside option. To reconcile our findings with that model, workers would need to hold nearly full bargaining power. Yet, this unitary bargaining power is in turn rejected by the large body of rent sharing estimates implying low worker bargaining power of around 0.1.

Our findings instead support wage setting protocols that insulate wages from nonemployment values. The kind of wage insensitivity we document also helps models of the aggregate labor market generate realistic labor demand fluctuations. Our findings also raise the possibility that the empirical comovement between wages and labor market conditions, such as the Phillips and wage curves, may be driven by mechanisms other than the procyclicality of workers' nonemployment value. 


\section{References}

Abeler, J. and S. Jäger (2015). Complex Tax Incentives. American Economic Journal: Economic Policy $7(3)$, $1-28$.

Abowd, J. A. and T. Lemieux (1993). The Effects of Product Market Competition on Collective Bargaining Agreements: The Case of Foreign Competition in Canada. The Quarterly Journal of Economics 108(4), 983-1014.

Abowd, J. M., F. Kramarz, and D. N. Margolis (1999). High Wage Workers and High Wage Firms. Econometrica 67(2), 251-333.

Acemoglu, D. and W. B. Hawkins (2014). Search with Multi-worker Firms. Theoretical Economics 9(3), 583-628.

Akerlof, G. A. and J. L. Yellen (1986). Efficiency Wage Models of the Labor Market. Cambridge University Press.

Albrecht, J. W. and B. Axell (1984). An Equilibrium Model of Search Unemployment. Journal of Political Economy 92(5), 824-840.

Altonji, J. G., A. A. Smith, and I. Vidangos (2013). Modeling Earnings Dynamics. Econometrica $81(4)$, $1395-1454$.

Andolfatto, D. (1996). Business Cycles and Labor Market Search. The American Economic Review, $112-132$.

Arai, M. (2003). Wages, Profits, and Capital Intensity: Evidence from Matched Worker-firm Data. Journal of Labor Economics 21(3), 593-618.

Arai, M. and F. Heyman (2009). Microdata Evidence on Rent-sharing. Applied Economics 41(23), $2965-2976$.

Bagger, J., B. J. Christensen, and D. T. Mortensen (2014). Wage and Labor Productivity Dispersion: The Roles of Total Factor Productivity, Labor Quality, Capital Intensity, and Rent Sharing. Working Paper, Royal Holloway.

Bagger, J., F. Fontaine, F. Postel-Vinay, and J.-M. Robin (2014). Tenure, Experience, Human Capital, and Wages: A Tractable Equilibrium Search Model of Wage Dynamics. American Economic Review 104 (6), $1551-96$.

Barattieri, A., S. Basu, and P. Gottschalk (2014). Some Evidence on the Importance of Sticky Wages. American Economic Journal: Macroeconomics 6(1), 70-101.

Barth, E., A. Bryson, J. C. Davis, and R. Freeman (2016). It's Where You Work: Increases in the Dispersion of Earnings across Establishments and Individuals in the United States. Journal of Labor Economics 34(S2), S67-S97.

Beaudry, P. and J. DiNardo (1991). The Effect of Implicit Contracts on the Movement of Wages over the Business Cycle: Evidence from Micro Data. Journal of Political Economy (4), 665-688.

Beaudry, P., D. A. Green, and B. Sand (2012). Does Industrial Composition Matter for Wages? A Test of Search and Bargaining Theory. Econometrica 80(3), 1063-1104. 
Bertrand, M. (2004). From the Invisible Handshake to the Invisible Hand? How Import Competition Changes the Employment Relationship. Journal of Labor Economics 22(4), 723-765.

Black, S. E. and P. E. Strahan (2001). The Division of Spoils: Rent-sharing and Discrimination in a Regulated Industry. American Economic Review 91(4), 814-831.

Blanchard, O. and L. F. Katz (1999). Wage Dynamics: Reconciling Theory and Evidence. American Economic Review 89(2), 69-74.

Blanchflower, D. G. and A. J. Oswald (1994). The Wage Curve. MIT press.

Blanchflower, D. G., A. J. Oswald, and P. Sanfey (1996). Wages, Profits, and Rent-sharing. The Quarterly Journal of Economics 111(1), 227-251.

Bönisch, M. (2008). Kollektivvertragliche Abdeckung in Österreich. Statistische Nachrichten 3(2008), $207-211$.

Bontemps, C., J.-M. Robin, and G. J. Van den Berg (1999). An Empirical Equilibrium Job Search Model with Search on the Job and Heterogeneous Workers and Firms. International Economic Review 40(4), 1039-1074.

Borovičková, K. and R. Shimer (2017). High Wage Workers Work for High Wage Firms. NBER Working Paper No. 24074.

Brenzel, H., H. Gartner, and C. Schnabel (2014). Wage Bargaining or Wage Posting? Evidence from the Employers' Side. Labour Economics 29, 41-48.

Burdett, K. and D. T. Mortensen (1998). Wage Differentials, Employer Size, and Unemployment. International Economic Review 39(2), 257-273.

Cahuc, P., F. Marque, and E. Wasmer (2008). A Theory of Wages and Labor Demand with Intra-firm Bargaining and Matching Frictions. International Economic Review 49(3), 943-972.

Cahuc, P., F. Postel-Vinay, and J.-M. Robin (2006). Wage Bargaining with On-the-job Search: Theory and Evidence. Econometrica $74(2), 323-364$.

Caldwell, S. and O. Danieli (2018). Outside Options in the Labor Market. Working Paper.

Caldwell, S. and N. Harmon (2018). Outside Options, Wages, and Bargaining: Evidence from Coworker Networks. Working Paper.

Card, D., A. R. Cardoso, J. Heining, and P. Kline (2018). Firms and Labor Market Inequality: Evidence and Some Theory. Journal of Labor Economics 36(S1), S13-S70.

Card, D., A. R. Cardoso, and P. Kline (2016). Bargaining, Sorting, and the Gender Wage Gap: Quantifying the Impact of Firms on the Relative Pay of Women. The Quarterly Journal of Economics 131(2), 633-686.

Card, D., R. Chetty, and A. Weber (2007). Cash-on-hand and Competing Models of Intertemporal Behavior: New Evidence from the Labor Market. The Quarterly Journal of Economics 122(4), 1511-1560.

Card, D., F. Devicienti, and A. Maida (2013). Rent-sharing, Holdup, and Wages: Evidence from Matched Panel Data. Review of Economic Studies 81(1), 84-111.

Card, D., D. S. Lee, Z. Pei, and A. Weber (2015). Inference on Causal Effects in a Generalized Regression Kink Design. Econometrica 83(6), 2453-2483. 
Cardoso, A. R. and M. Portela (2009). Micro Foundations for Wage Flexibility: Wage Insurance at the Firm Level. The Scandinavian Journal of Economics 111(1), 29-50.

Carlsson, M., J. Messina, and O. N. Skans (2016). Wage Adjustment and Productivity Shocks. The Economic Journal 126(595), 1739-1773.

Chodorow-Reich, G., J. Coglianese, and L. Karabarbounis (2018). The Limited Macroeconomic Effects of Unemployment Benefit Extensions. Working Paper.

Chodorow-Reich, G. and L. Karabarbounis (2016). The Cyclicality of the Opportunity Cost of Employment. Journal of Political Economy 124(6), 1563-1618.

Christiano, L. J., M. S. Eichenbaum, and M. Trabandt (2016). Unemployment and Business Cycles. Econometrica 84(4), 1523-1569.

Christiano, L. J., M. S. Eichenbaum, and M. Trabandt (2017). On DSGE models. Unpublished paper, Northwestern University.

Christofides, L. N. and A. J. Oswald (1992). Real Wage Determination and Rent-sharing in Collective Bargaining Agreements. The Quarterly Journal of Economics 107(3), 985-1002.

Conlon, J. J., L. Pilossoph, M. Wiswall, and B. Zafar (2018). Labor Market Search With Imperfect Information and Learning. NBER Working Paper No. 24988.

Correia, S. (2017). Linear Models with High-Dimensional Fixed Effects: An Efficient and Feasible Estimator. Working Paper.

Cutler, D. M. and J. Gruber (1996). Does Public Insurance Crowd Out Private Insurance? The Quarterly Journal of Economics $111(2), 391-430$.

Dickens, W. T., L. Goette, E. L. Groshen, S. Holden, J. Messina, M. E. Schweitzer, J. Turunen, and M. E. Ward (2007). How Wages Change: Micro Evidence from the International Wage Flexibility Project. Journal of Economic Perspectives (2), 195-214.

Dinerstein, M., R. Megalokonomou, and C. Yannelis (2019, July). Human Capital Depreciation. Working Paper.

Du Caju, P., F. Rycx, and I. Tojerow (2011). Inter-Industry Wage Differentials: How Much Does Rent Sharing Matter? The Manchester School 79(4), 691-717.

Estevão, M. and S. Tevlin (2003). Do Firms Share Their Success with Workers? The Response of Wages to Product Market Conditions. Economica 70(280), 597-617.

Fakhfakh, F. and F. FitzRoy (2004). Basic Wages and Firm Characteristics: Rent Sharing in French Manufacturing. Labour 18(4), 615-631.

Feldstein, M. and J. Poterba (1984). Unemployment Insurance and Reservation Wages. Journal of Public Economics 23(1-2), 141-167.

Fujita, S. and G. Ramey (2012). Exogenous Versus Endogenous Separation. American Economic Journal: Macroeconomics 4(4), 68-93.

Garin, A. and F. Silvério (2018). How Does Firm Performance Affect Wages? Evidence from Idiosyncratic Export Shocks. Working Paper. 
Gertler, M., C. Huckfeldt, and A. Trigari (2016). Unemployment Fluctuations, Match Quality, and the Wage Cyclicality of New Hires. NBER Working Paper No. 22341.

Gertler, M. and A. Trigari (2009). Unemployment Fluctuations with Staggered Nash Wage Bargaining. Journal of Political Economy 117(1), 38-86.

Gruber, J. and E. Saez (2002). The Elasticity of Taxable Income: Evidence and Implications. Journal of Public Economics 84(1), 1-32.

Guiso, L., L. Pistaferri, and F. Schivardi (2005). Insurance within the Firm. Journal of Political Economy 113(5), 1054-1087.

Gürtzgen, N. (2009). Rent-sharing and Collective Bargaining Coverage: Evidence from Linked EmployerEmployee Data. The Scandinavian Journal of Economics 111(2), 323-349.

Hagedorn, M., F. Karahan, I. Manovskii, and K. Mitman (2013). Unemployment Benefits and Unemployment in the Great Recession: The Role of Macro Effects. NBER Working Paper No. 19499.

Hagedorn, M. and I. Manovskii (2008). The Cyclical Behavior of Equilibrium Unemployment and Vacancies Revisited. American Economic Review 98(4), 1692-1706.

Hagedorn, M. and I. Manovskii (2013). Job Selection and Wages Over the Business Cycle. American Economic Review 103(2), 771-803.

Hall, R. E. (2017). High Discounts and High Unemployment. American Economic Review 107(2), 305-30.

Hall, R. E. and A. B. Krueger (2012). Evidence on the Incidence of Wage Posting, Wage Bargaining, and On-the-Job Search. American Economic Journal: Macroeconomics 4 (4), 56-67.

Hall, R. E. and P. R. Milgrom (2008, August). The Limited Influence of Unemployment on the Wage Bargain. American Economic Review 98(4), 1653-1674.

Hansen, G. D. (1985). Indivisible Labor and the Business Cycle. Journal of Monetary Economics 16(3), 309-327.

Hildreth, A. K. (1998). Rent-sharing and Wages: Product Demand or Technology driven Premia? Economics of Innovation and New Technology 5(2-4), 199-226.

Hildreth, A. K. and A. J. Oswald (1997). Rent-sharing and Wages: Evidence from Company and Establishment Panels. Journal of Labor Economics 15(2), 318-337.

Hofer, H., K. Pichelmann, and A.-U. Schuh (2001). Price and Quantity Adjustments in the Austrian Labour Market. Applied Economics 33(5), 581-592.

Jäger, S. and J. Heining (2019). How Substitutable are Workers? Evidence from Worker Deaths. Working Paper.

Jäger, S., B. Schoefer, and J. Zweimüller (2018). Marginal Jobs and Job Surplus: Evidence from Separations and Unemployment Insurance. Working Paper.

Katz, L. F. (1986). Efficiency Wage Theories: A Partial Evaluation. NBER Macroeconomics Annual 1, 235-276.

Katz, L. F. and B. D. Meyer (1990). The Impact of the Potential Duration of Unemployment Benefits on the Duration of Unemployment. Journal of Public Economics 41(1), 45-72. 
Kleven, H. J. and E. A. Schultz (2014). Estimating Taxable Income Responses Using Danish Tax Reforms. American Economic Journal: Economic Policy 6(4), 271-301.

Kline, P., N. Petkova, H. Williams, and O. Zidar (2019). Who Profits from Patents? Rent-Sharing at Innovative Firms. The Quarterly Journal of Economics 134(3), 1343-1404.

Knell, M. and A. Stiglbauer (2012). Reference Norms, Staggered Wages, and Wage Leadership: Theoretical Implications and Empirical Evidence. International Economic Review 53(2), 569-592.

Kopczuk, W. (2005). Tax Bases, Tax Rates and the Elasticity of Reported Income. Journal of Public Economics 89(11-12), 2093-2119.

Kroft, K., F. Lange, and M. Notowidigdo (2013). Duration Dependence and Labor Market Conditions: Evidence from a Field Experiment. Quarterly Journal of Economics 128(3), 1123-1167.

Kroft, K., F. Lange, M. J. Notowidigdo, and L. F. Katz (2016). Long-term Unemployment and the Great Recession: The Role of Composition, Duration Dependence, and Nonparticipation. Journal of Labor Economics 34(S1), S7-S54.

Krueger, A. B. and A. I. Mueller (2016). A Contribution to the Empirics of Reservation Wages. American Economic Journal: Economic Policy 8(1), 142-79.

Krusell, P., T. Mukoyama, and A. Sahin (2010). Labour-market Matching with Precautionary Savings and Aggregate Fluctuations. The Review of Economic Studies 77(4), 1477-1507.

Lalive, R., C. Landais, and J. Zweimuller (2015, December). Market Externalities of Large Unemployment Insurance Extension Programs. American Economic Review 105(12), 3564-3596.

Lalive, R., J. Van Ours, and J. Zweimuller (2006). How Changes in Financial Incentives Affect the Duration of Unemployment. The Review of Economic Studies 73(4), 1009-1038.

Lalive, R. and J. Zweimüller (2004). Benefit Entitlement and Unemployment Duration: The Role of Policy Endogeneity. Journal of Public Economics 88(12), 2587-2616.

Le Barbanchon, T., R. Rathelot, and A. Roulet (2017). Unemployment Insurance and Reservation Wages: Evidence from Administrative Data. Journal of Public Economics.

Lemieux, T. and W. B. MacLeod (2000). Supply Side Hysteresis: The Case of the Canadian Unemployment Insurance System. Journal of Public Economics 78(1-2), 139-170.

Leoni, T. and W. Pollan (2011). Lohnentwicklung und Lohnunterschiede in der Industrie seit 2000. WIFO Monatsberichte, WIFO October.

Ljungqvist, L. and T. J. Sargent (2017). The Fundamental Surplus. American Economic Review 107(9), 2630-65.

MacLeod, W. B. and J. M. Malcomson (1993). Investments, Holdup, and the Form of Market Contracts. The American Economic Review, 811-837.

Manning, A. (2011). Imperfect Competition in the Labor Market. In Handbook of Labor Economics, Volume 4, pp. 973-1041. Elsevier.

Margolis, D. N. and K. G. Salvanes (2001). Do Firms Really Share Rents with Their Workers? IZA Discussion Paper Series no. 330.

Martins, P. S. (2009). Rent Sharing before and after the Wage Bill. Applied Economics 41(17), 2133-2151. 
McCall, J. J. (1970). Economics of Information and Job Search. The Quarterly Journal of Economics, $113-126$.

Mercan, Y. and B. Schoefer (forthcoming). New Jobs and Old Jobs: Quits, Replacement Hiring, and Vacancy Chains. American Economic Review: Insights.

Merz, M. (1995). Search in the Labor Market and the Real Business Cycle. Journal of Monetary Economics (2), 269-300.

Mortensen, D. T. and E. Nagypal (2007). More on Unemployment and Vacancy Fluctuations. Review of Economic Dynamics 10(3), 327-347.

Moscarini, G. and F. Postel-Vinay (2017). The Job Ladder: Inflation vs. Reallocation. Working Paper.

Nekoei, A. and A. Weber (2017, February). Does Extending Unemployment Benefits Improve Job Quality? American Economic Review 107(2), 527-561.

OECD (1994). Collective Bargaining: Levels and Coverage. In OECD Employment Outlook, Chapter 5. OECD.

Pissarides, C. A. (2000). Equilibrium Unemployment Theory. MIT press.

Pissarides, C. A. (2009). The Unemployment Volatility Puzzle: Is Wage Stickiness the Answer? Econometrica $77(5), 1339-1369$.

Postel-Vinay, F. and J.-M. Robin (2002). Equilibrium Wage Dispersion with Worker and Employer Heterogeneity. Econometrica 70(6), 2295-2350.

Postel-Vinay, F. and J.-M. Robin (2006). Microeconometric Search-Matching Models and Matched EmployerEmployee Data. In Advances in Economics and Econometrics: Theory and Applications, Ninth World Congress, Volume 2.

Ravenna, F. and C. E. Walsh (2008). Vacancies, Unemployment, and the Phillips Curve. European Economic Review 52(8), 1494-1521.

Rogerson, R. (1988). Indivisible Labor, Lotteries and Equilibrium. Journal of Monetary Economics 21(1), $3-16$.

Saez, E., B. Schoefer, and D. Seim (2019). Payroll Taxes, Firm Behavior, and Rent Sharing: Evidence from a Young Workers' Tax Cut in Sweden. American Economic Review 109(5), 1717-63.

Schmieder, J. F., T. von Wachter, and S. Bender (2016). The Effect of Unemployment Benefits and Nonemployment Durations on Wages. American Economic Review 106(3), 739-77.

Schoefer, B. (2015). The Financial Channel of Wage Rigidity. Working Paper.

Shapiro, C. and J. E. Stiglitz (1984). Equilibrium Unemployment as a Worker Discipline Device. The American Economic Review 74(3), 433-444.

Shimer, R. (2004). The Consequences of Rigid Wages in Search Models. Journal of the European Economic Association 2(2-3), 469-479.

Shimer, R. (2005). The Cyclical Behavior of Equilibrium Unemployment and Vacancies. American Economic Review 95(1), 25-49.

Shimer, R. (2010). Labor Markets and Business Cycles. Princeton University Press Princeton, NJ. 
Sigurdsson, J. and R. Sigurdardottir (2016). Time-Dependent or State-Dependent Wage-Setting? Evidence from Periods of Macroeconomic Instability. Journal of Monetary Economics 78, 50-66.

Stole, L. A. and J. Zwiebel (1996). Intra-firm Bargaining Under Non-Binding Contracts. The Review of Economic Studies 63(3), 375-410.

Van Reenen, J. (1996). The Creation and Capture of Rents: Wages and Innovation in a Panel of UK Companies. The Quarterly Journal of Economics 111(1), 195-226.

Venn, D. (2012). Eligibility Criteria for Unemployment Benefits. OECD Social, Employment and Migration Working Papers, No. 131..

Vuuren, A. v., G. J. Van Den Berg, and G. Ridder (2000). Measuring the Equilibrium Effects of Unemployment Benefits Dispersion. Journal of Applied Econometrics 15(6), 547-574.

Weber, C. E. (2014). Toward Obtaining a Consistent Estimate of the Elasticity of Taxable Income Using Difference-in-differences. Journal of Public Economics 117, 90-103.

Winter-Ebmer, R. (1996). Wage Curve, Unemployment Duration and Compensating Differentials. Labour Economics 3(4), 425-434.

Winter-Ebmer, R. (1998). Potential Unemployment Benefit Duration and Spell Length: Lessons from a Quasi-Experiment in Austria. Oxford Bulletin of Economics and Statistics 60(1), 33-45.

Wright, R., P. Kircher, B. Julien, and V. Guerrieri (2017). Directed Search: A Guided Tour. NBER Working Paper No. 23884.

Zweimüller, J., R. Winter-Ebmer, R. Lalive, A. Kuhn, J.-P. Wuellrich, O. Ruf, and S. Buchi (2009). Austrian Social Security Database. Austrian Center for Labor Economics and the Analysis of the Welfare State Working Paper No. 0903. 
Tables 
Table 1: Predicted Fraction of Post-Separation Time on UI $(\tau)$ and Wage-Benefit Sensitivity $(d w / d b)$

\begin{tabular}{|c|c|c|c|c|c|c|}
\hline \multirow{2}{*}{$\begin{array}{l}\text { Time Restriction: } \\
\text { Reemployment Restriction: }\end{array}$} & \multicolumn{2}{|c|}{ Ret'nt or Disability } & \multicolumn{2}{|c|}{ Retirement } & \multicolumn{2}{|c|}{ No Restriction } \\
\hline & 4-Year & None & 4-Year & None & 4-Year & None \\
\hline & $(1)$ & $(2)$ & $(3)$ & $(4)$ & $(5)$ & $(6)$ \\
\hline
\end{tabular}

Panel A: Fraction of Post-Separation Time $(\tau)$ (Predicted Values)

$\begin{array}{ccccccc}\text { UI-Affected Nonemployment }-\hat{\tau}^{U} & \mathbf{0 . 1 0 4} & 0.105 & 0.096 & 0.095 & 0.094 & 0.092 \\ \text { Unemployment Insurance - } \hat{\tau}^{U: U I} & \mathbf{0 . 0 8 3} & 0.083 & 0.076 & 0.074 & 0.073 & 0.070 \\ \text { Unemployment Assistance - } \hat{\tau}^{U: U A} & \mathbf{0 . 0 2 1} & 0.022 & 0.020 & 0.022 & 0.020 & 0.022 \\ \text { Employment }-\hat{\tau}^{E} & \mathbf{0 . 6 8 4} & 0.588 & 0.648 & 0.564 & 0.633 & 0.555 \\ \text { Other Nonemployment }-\hat{\tau}^{O} & \mathbf{0 . 2 1 2} & 0.307 & 0.255 & 0.341 & 0.274 & 0.353\end{array}$

Panel B: Predicted Wage Benefit Sensitivity $(d w / d b)$

Baseline: Two-State $d w / d b$ Prediction

$\begin{array}{lllllll}\mathrm{E}\left[d w / d b\left(\hat{\tau}_{i}\right)\right] & \mathbf{0 . 4 6 2} & 0.462 & 0.442 & 0.437 & 0.434 & 0.426 \\ d w / d b\left(\mathrm{E}\left[\hat{\tau}_{i}\right]\right) & \mathbf{0 . 4 8 4} & 0.486 & 0.464 & 0.461 & 0.458 & 0.453\end{array}$

Robustness: Three-State dw/db Prediction

\begin{tabular}{lcccccc}
$\mathrm{E}\left[d w / d b\left(\hat{\tau}_{i}\right)\right]$ & $\mathbf{0 . 2 5 1}$ & 0.217 & 0.224 & 0.195 & 0.217 & 0.190 \\
$d w / d b\left(\mathrm{E}\left[\hat{\tau}_{i}\right]\right)$ & $\mathbf{0 . 2 4 4}$ & 0.201 & 0.208 & 0.174 & 0.196 & 0.165 \\
\hline
\end{tabular}

Note: The first five rows present estimates of the predicted amount of time a worker would spend on unemployment insurance $\hat{\tau}^{U: U I}$, on unemployment assistance $\hat{\tau}^{U: U A}$, which we also pool into a single UI-affected state $\hat{\tau}^{U}$ (the sum of $\hat{\tau}^{U: U I}$ and $\hat{\tau}^{U: U A}$, where unemployment assistance is included because it is indexed nearly one-for-one with UI, and we refer to "UI" in the text as encompassing both), employed $\hat{\tau}^{E}$, and in other nonemployment $\hat{\tau}^{O}$. The $\tau$ values for our preferred specification, column (1), are calculated as follows. Starting with our baseline regression sample, we keep individuals who separate from employment into nonemployment for at least one day in the next year and return to employment at least once within the next four years. For these actual separators, we calculate post-separation share of time spent in each of the above labor market states. We stop including labor market states in this share at the earliest of 16 years, reaching age 70, death, or absorbing retirement or disability (defined as entering retirement or disability and without any subsequent employment or UI/UA spells). Using the separators sample, we estimate a regression model predicting the time spent in each state based on individuals' pre-separation characteristics comprising of industry by white/blue collar fixed effects, tenure, experience, age, region, year and previous UI history. We then use this model to predict the specific $\tau \mathrm{s}$ for the entire regression sample (including non-separators). The reported $\tau$ estimates are the average predictions across the entire regression sample. The $d w / d b$ predictions plug in the predicted $\tau$ values into the two- and three-state model wage-benefit sensitivity expressions (see Section 2.1 and Appendix Section D respectively). The $\mathrm{E}\left[d w / d b\left(\hat{\tau}_{i}\right)\right]$ estimates report the average sensitivity first plugging in the individual-level $\hat{\tau}_{i}$ sensitivities into the wage-benefit expressions and then taking the average across individuals (thus respecting Jensen's Inequality). The $d w / d b\left(\mathrm{E}\left[\hat{\tau}_{i}\right]\right)$ estimates plug in the average $\hat{\tau}_{i}$ values from rows (1) to (6) into the wage-benefit sensitivity expressions. Columns (3) and (4) also stop counting at absorbing retirement but not disability, and columns (5) and (6) stop counting labor market states only at the earliest of 16 years or age 70. The reemployment-restriction columns (1), (3) and (5) requires that individuals in the separator sample return to re-employment (at any job) sometime in the next four years (for at least one day). Appendix Table A.5 reports the realized $\tau$ values for the separator samples and the analysis sample unconditionally on a separation. 
Table 2: Summary Statistics

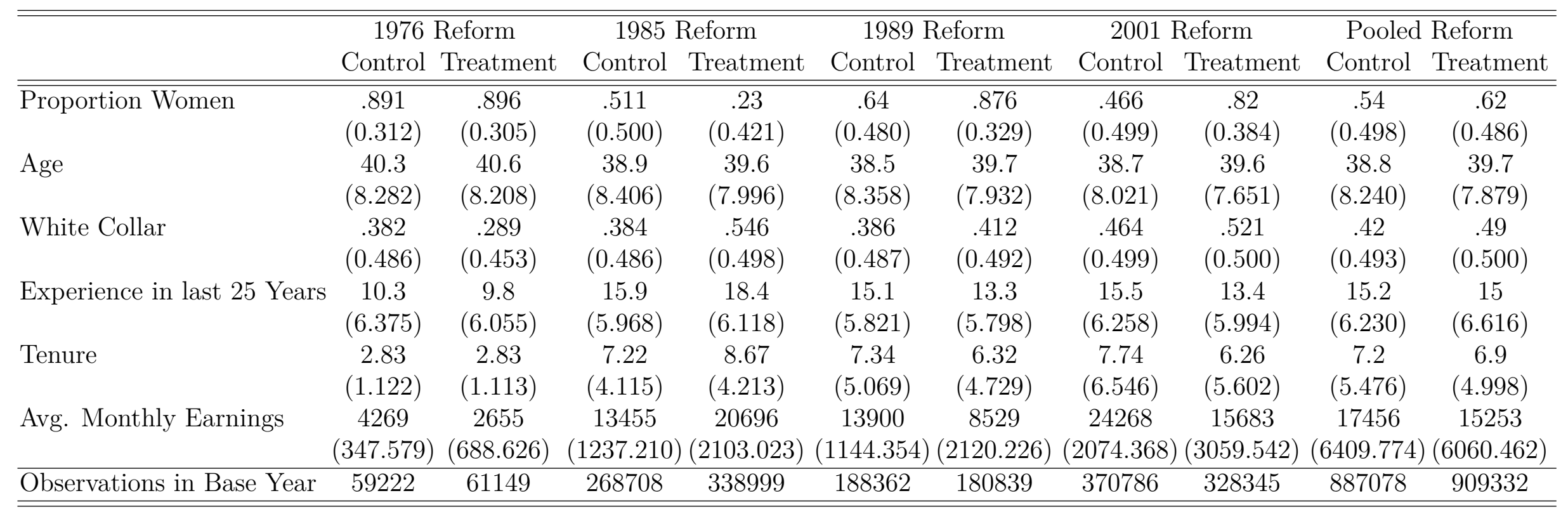

Note: This table includes summary statistics for the control and treatment regions for the four reforms that make up the pooled sample on which we run our analysis: 1976, 1985, 1989, and 2001. Standard deviations are reported in parentheses beneath the means. All values are calculated from individuals employed all 12 months in the base year for the reform, which is defined as the year prior to the reform, e.g., 1975 for the 1976 reform. The pooled sample appends the four reform samples together. The actual number of observations in the base year will be slightly larger than the sum of the treatment and control groups for the 1985 reform sample and thus the pooled sample because the control region is shifted slightly down the income table to account for repeated treatment in a small section of the income distribution during the placebo period for that reform. Importantly, this table is not a balance check between "treatment" and "control" regions, which naturally must differ in a given cross section. Instead, our difference-in-differences design (with varying treatment intensity within the treatment group) relies on a conditional parallel trends assumption which we discuss in Section 4.3. 
Table 3: Estimated Wage Effects: Difference-in-Differences Regression Design

\begin{tabular}{|c|c|c|c|c|c|c|}
\hline \multicolumn{7}{|c|}{ Panel A: 1-Year Earnings Effects } \\
\hline & $(1)$ & $(2)$ & $(3)$ & (4) & $(\overline{7(5)}$ & (6) \\
\hline Placebo: 3 Yr Lag & $\begin{array}{l}0.016 \\
(.017)\end{array}$ & $\begin{array}{r}-0.002 \\
(.016)\end{array}$ & $\begin{array}{l}0.016 \\
(.018)\end{array}$ & $\begin{array}{l}0.014 \\
(.016)\end{array}$ & $\begin{array}{l}0.022 \\
(.013)\end{array}$ & $\begin{array}{l}0.028 \\
(.014)\end{array}$ \\
\hline Placebo: 2 Yr Lag & $\begin{array}{r}-0.001 \\
(.014)\end{array}$ & $\begin{array}{l}-0.014 \\
(.015)\end{array}$ & $\begin{array}{l}-0.007 \\
(.015)\end{array}$ & $\begin{array}{l}-0.009 \\
(.015)\end{array}$ & $\begin{array}{l}0.018 \\
(.014)\end{array}$ & $\begin{array}{l}0.014 \\
(.014)\end{array}$ \\
\hline Treatment Year & $\begin{array}{l}-0.004 \\
(.016)\end{array}$ & $\begin{array}{l}-0.001 \\
(.017)\end{array}$ & $\begin{array}{l}-0.019 \\
(.015)\end{array}$ & $\begin{array}{c}-0.014 \\
(.016)\end{array}$ & $\begin{array}{l}0.002 \\
(.013)\end{array}$ & $\begin{array}{c}-0.0004 \\
(.013)\end{array}$ \\
\hline Pre-p F-test p-val & 0.532 & 0.581 & 0.413 & 0.381 & 0.245 & 0.119 \\
\hline $\begin{array}{l}R^{2} \\
N(1000 \mathrm{~s})\end{array}$ & $\begin{array}{r}.048 \\
7139\end{array}$ & $\begin{array}{r}.067 \\
7139\end{array}$ & $\begin{array}{r}.076 \\
7138\end{array}$ & $\begin{array}{r}.094 \\
7138\end{array}$ & $\begin{array}{l}.257 \\
6299\end{array}$ & $\begin{array}{l}.281 \\
6298\end{array}$ \\
\hline $\begin{array}{l}\text { Mincerian Ctrls } \\
\text { 4-Digit Ind.-Occ. FEs } \\
\text { Firm-Year FEs }\end{array}$ & & $\mathrm{X}$ & $\mathrm{X}$ & $\begin{array}{l}\mathrm{X} \\
\mathrm{X}\end{array}$ & $\mathrm{X}$ & $\begin{array}{l}\mathrm{X} \\
\mathrm{X} \\
\mathrm{X}\end{array}$ \\
\hline \multicolumn{7}{|c|}{ Panel B: 2-Year Earnings Effects } \\
\hline & $(1)$ & $(2)$ & $(3)$ & (4) & $(5)$ & (6) \\
\hline Placebo: 3 Yr Lag & $\begin{array}{l}-0.007 \\
(.021)\end{array}$ & $\begin{array}{l}-0.025 \\
(.021)\end{array}$ & $\begin{array}{l}-0.001 \\
(.025)\end{array}$ & $\begin{array}{r}-0.001 \\
(.024)\end{array}$ & $\begin{array}{l}-0.003 \\
(.022)\end{array}$ & $\begin{array}{l}0.007 \\
(.022)\end{array}$ \\
\hline Treatment Year & $\begin{array}{l}-0.007 \\
(.031)\end{array}$ & $\begin{array}{l}0.007 \\
(.031)\end{array}$ & $\begin{array}{l}-0.027 \\
(.032)\end{array}$ & $\begin{array}{c}-0.022 \\
(.03)\end{array}$ & $\begin{array}{r}-0.022 \\
(.026)\end{array}$ & $\begin{array}{l}-0.027 \\
(.026)\end{array}$ \\
\hline Pre-p F-test p-val & 0.752 & 0.241 & 0.966 & 0.962 & 0.878 & 0.742 \\
\hline$R^{2}$ & .103 & .125 & .14 & .16 & .305 & .332 \\
\hline$N(1000 \mathrm{~s})$ & 5039 & 5039 & 5038 & 5038 & 4434 & 4433 \\
\hline Mincerian Ctrls & & $\mathrm{X}$ & & $\mathrm{X}$ & & $\mathrm{X}$ \\
\hline 4-Digit Ind.-Occ. FEs & & & $\mathrm{X}$ & $\mathrm{X}$ & & $\mathrm{X}$ \\
\hline Firm-Year FEs & & & & & $\mathrm{X}$ & $\mathrm{X}$ \\
\hline
\end{tabular}

Note: These results pool four reforms to the replacement rate schedule in Austria, and are based on specification (19). Standard errors based on two-way clustering at the individual and earnings percentile level are in parentheses. The null hypothesis of the F-test is that the coefficients of interest are jointly all equal to 0 in the pre-period. The Mincerian controls include time-varying polynomials of experience, tenure, and age; time-varying gender indicators, and a control for being REBP eligible. The industry-occupation controls are time-varying fixed effects for each four-digit industry interacted with an indicator for a blue vs. white-collar occupation. All specifications also include reform-specific earnings percentile fixed effects, year fixed effects, and year-specific log earnings controls. 
Table 4: Wage Effects by Individual Labor Market Status Transition Types

Panel A: Effects by Transition Type

\begin{tabular}{|c|c|c|c|c|c|c|c|c|}
\hline \multirow[b]{2}{*}{ Time Horizon } & \multicolumn{2}{|c|}{ Full Sample } & \multicolumn{2}{|c|}{ Job Stayers } & \multicolumn{2}{|c|}{ Recalled Workers } & \multicolumn{2}{|c|}{ Job Movers } \\
\hline & 1-Year & 2-Year & 1-Year & 2-Year & 1-Year & 2-Year & 1-Year & 2-Year \\
\hline Est. Wage Effect & $\begin{array}{l}-0.014 \\
(0.016)\end{array}$ & $\begin{array}{l}-0.022 \\
(0.030)\end{array}$ & $\begin{array}{l}-0.026 \\
(0.013)\end{array}$ & $\begin{array}{l}-0.027 \\
(0.021)\end{array}$ & $\begin{array}{c}0.061 \\
(0.139)\end{array}$ & $\begin{array}{c}0.007 \\
(0.137)\end{array}$ & $\begin{array}{c}0.054 \\
(0.096)\end{array}$ & $\begin{array}{l}-0.035 \\
(0.090)\end{array}$ \\
\hline Base-Year Transition Rate & & & 0.828 & 0.705 & 0.040 & 0.057 & 0.069 & 0.110 \\
\hline \multirow[t]{4}{*}{$\begin{array}{l}\text { Mincer + Ind.-Occ. FEs } \\
\end{array}$} & $\mathrm{X}$ & $\mathrm{X}$ & $\mathrm{X}$ & $\mathrm{X}$ & $\mathrm{X}$ & $\mathrm{X}$ & $\mathrm{X}$ & $\mathrm{X}$ \\
\hline & \multicolumn{8}{|c|}{ Panel B: Employment-Unemployment-Employment Mover: } \\
\hline & \multicolumn{4}{|c|}{ 1-Year Earnings Effects } & \multicolumn{4}{|c|}{ 2-Year Earnings Effects } \\
\hline & $(1)$ & $(2)$ & $(3)$ & $(4)$ & $(5)$ & $(6)$ & $(7)$ & $(8)$ \\
\hline Est. Wage Effect & $\begin{array}{l}-0.372 \\
(0.146)\end{array}$ & $\begin{array}{l}-0.215 \\
(0.140)\end{array}$ & $\begin{array}{l}-0.337 \\
(0.161)\end{array}$ & $\begin{array}{l}-0.249 \\
(0.228)\end{array}$ & $\begin{array}{c}-0.126 \\
(0.147)\end{array}$ & $\begin{array}{l}-0.104 \\
(0.154)\end{array}$ & $\begin{array}{c}-0.064 \\
(0.194)\end{array}$ & $\begin{array}{l}-0.115 \\
(0.237)\end{array}$ \\
\hline Base-Year Transition Rate & 0.022 & 0.022 & 0.022 & 0.022 & 0.035 & 0.035 & 0.035 & 0.035 \\
\hline Transition-Specific Controls & & $\mathrm{X}$ & & $\mathrm{X}$ & & $\mathrm{X}$ & & $\mathrm{X}$ \\
\hline Mincer + Ind.-Occ. FEs & $\mathrm{X}$ & $\mathrm{X}$ & $\mathrm{X}$ & $\mathrm{X}$ & $\mathrm{X}$ & $\mathrm{X}$ & $\mathrm{X}$ & $\mathrm{X}$ \\
\hline Firm FEs & & & $\mathrm{X}$ & $\mathrm{X}$ & & & $\mathrm{X}$ & $\mathrm{X}$ \\
\hline
\end{tabular}

Panel C: Direct Job-to-Job Movers

\begin{tabular}{|c|c|c|c|c|c|c|c|c|}
\hline & \multicolumn{4}{|c|}{ 1-Year Earnings Effects } & \multicolumn{4}{|c|}{ 2-Year Earnings Effects } \\
\hline & $(1)$ & $(2)$ & $(3)$ & $(4)$ & $(5)$ & $(6)$ & $(7)$ & $(8)$ \\
\hline Est. Wage Effect & $\begin{array}{c}0.267 \\
(0.102)\end{array}$ & $\begin{array}{c}0.187 \\
(0.097)\end{array}$ & $\begin{array}{c}0.271 \\
(0.099)\end{array}$ & $\begin{array}{c}0.002 \\
(0.103)\end{array}$ & $\begin{array}{c}0.108 \\
(0.106)\end{array}$ & $\begin{array}{c}0.009 \\
(0.113)\end{array}$ & $\begin{array}{c}0.021 \\
(0.107)\end{array}$ & $\begin{array}{l}-0.134 \\
(0.147)\end{array}$ \\
\hline Base-Year Transition Rate & 0.047 & 0.047 & 0.047 & 0.047 & 0.075 & 0.075 & 0.075 & 0.075 \\
\hline Transition-Specific Controls & & $\mathrm{X}$ & & $\mathrm{X}$ & & $\mathrm{X}$ & & $\mathrm{X}$ \\
\hline Mincer + Ind.-Occ. FEs & $\mathrm{X}$ & $\mathrm{X}$ & $\mathrm{X}$ & $\mathrm{X}$ & $\mathrm{X}$ & $\mathrm{X}$ & $\mathrm{X}$ & $\mathrm{X}$ \\
\hline Firm FEs & & & $\mathrm{X}$ & $\mathrm{X}$ & & & $\mathrm{X}$ & $\mathrm{X}$ \\
\hline
\end{tabular}

Note: The results show $\sigma_{0}$ coefficients from estimating Equation (19) but interacting an indicator for each transition type with the $\sigma_{0}$ and $\sigma_{e}$ coefficients. We also vary the parametric earnings controls by transition type. The specifications indicating Transition-Specific Controls interact all controls with the transition types. The estimates are from specification (4) in Table 3. Stayers refers to incumbent workers who remain employed at the same firm the entire next year or for two years in the specifications with a two-year outcome. Recalled refers to individuals who leave their current employer for another employer or nonemployment and then return to their original employer within the next year or two (depending on the specification horizon). Job Movers refers to individuals who move to another employer in the following year or two years, with or without and intermediate unemployment spell. EUE Movers refers to the subset of job movers who receive unemployment insurance before moving to their next employer. JtoJ Movers refers to the subset of job movers who have no intervening months of nonemployment before starting work at another employer. 
Table 5: Heterogeneity of Nonemployment Effects on Wages: One- and Two-Year Effects

\begin{tabular}{|c|c|c|c|c|c|c|c|c|}
\hline & \multicolumn{4}{|c|}{ 1-Year Effects } & \multicolumn{4}{|c|}{ 2-Year Effects } \\
\hline & \multicolumn{2}{|c|}{$1^{\text {st }}$ Quintile } & \multicolumn{2}{|c|}{$5^{\text {th }}$ Quintile } & \multicolumn{2}{|c|}{$1^{\text {st }}$ Quintile } & \multicolumn{2}{|c|}{$5^{\text {th }}$ Quintile } \\
\hline \multicolumn{9}{|l|}{ Unemployment Risk } \\
\hline Predicted Months UE & -0.061 & $(0.026)$ & -0.001 & $(0.031)$ & -0.062 & $(0.053)$ & 0.050 & $(0.046)$ \\
\hline Predicted Separation Rate & -0.024 & $(0.026)$ & -0.009 & $(0.032)$ & -0.045 & $(0.047)$ & 0.070 & $(0.043)$ \\
\hline Local Unemployment Rate & 0.014 & $(0.025)$ & 0.000 & $(0.028)$ & 0.006 & $(0.037)$ & -0.023 & $(0.043)$ \\
\hline Months since UI Receipt & -0.036 & $(0.040)$ & -0.034 & $(0.053)$ & 0.088 & $(0.053)$ & -0.195 & $(0.095)$ \\
\hline Months since Non-Emp. & -0.064 & $(0.051)$ & -0.026 & $(0.047)$ & 0.041 & $(0.053)$ & -0.054 & $(0.073)$ \\
\hline \multicolumn{9}{|l|}{ Firm Characteristics } \\
\hline Industry Growth Rate & -0.018 & $(0.038)$ & -0.026 & $(0.028)$ & -0.025 & $(0.035)$ & -0.053 & $(0.039)$ \\
\hline Wage Premium (AKM FE) & -0.014 & $(0.032)$ & -0.029 & $(0.035)$ & 0.091 & $(0.043)$ & 0.013 & $(0.037)$ \\
\hline SD of Earnings Growth & -0.004 & $(0.020)$ & -0.027 & $(0.042)$ & 0.059 & $(0.026)$ & -0.009 & $(0.048)$ \\
\hline Wage Distance from CBA Floor & -0.007 & $(0.026)$ & -0.032 & $(0.034)$ & -0.012 & $(0.033)$ & -0.023 & $(0.053)$ \\
\hline Share Non-Emp Last 2 Yrs & -0.015 & $(0.030)$ & 0.012 & $(0.033)$ & 0.055 & $(0.029)$ & -0.035 & $(0.038)$ \\
\hline \multicolumn{9}{|l|}{ Worker Characteristics } \\
\hline Tenure & 0.013 & $(0.036)$ & -0.033 & $(0.023)$ & 0.078 & $(0.054)$ & 0.007 & $(0.031)$ \\
\hline Age & 0.006 & $(0.030)$ & -0.045 & $(0.022)$ & -0.068 & $(0.055)$ & -0.065 & $(0.037)$ \\
\hline Male/Female & -0.031 & $(0.026)$ & 0.007 & $(0.018)$ & 0.037 & $(0.034)$ & -0.055 & $(0.044)$ \\
\hline Blue/White Collar & -0.020 & $(0.020)$ & -0.008 & $(0.025)$ & -0.014 & $(0.030)$ & -0.030 & $(0.054)$ \\
\hline
\end{tabular}

Note: The table shows $\sigma_{0}$ coefficients from estimating Equation (19) but interacting an indicator for each different heterogeneity group category with the $\sigma_{0}$ and $\sigma_{e}$ coefficients in Equation (19). Standard errors are reported in parentheses. We also vary the parametric earnings controls by heterogeneity type, allowing for differential earnings growth patterns by heterogeneity type. The estimates are from specification (4) in Table 3 that include Mincerian and industry/occupation controls but not the firm-by-year fixed effects. See Section 5 and Appendix I.2 for more details about the construction of each heterogeneity group. For the cuts by months since most recent UI receipt/nonemployment, to pick up workers recently hired, we relax the sample restriction requiring 12 months of employment in the base year. 
Table 6: Wage Effects: Difference-in-Differences Regression with Firm-Level Variation

\begin{tabular}{|c|c|c|c|c|c|c|c|c|}
\hline & \multicolumn{4}{|c|}{ 1-Year Earnings Effects } & \multicolumn{4}{|c|}{ 2-Year Earnings Effects } \\
\hline & $(1)$ & $(2)$ & $(3)$ & $(4)$ & $(5)$ & $(6)$ & $(7)$ & $(8)$ \\
\hline Placebo: 3 Yr Lag & $\begin{array}{r}-0.090 \\
(.026)\end{array}$ & $\begin{array}{l}-0.081 \\
(.025)\end{array}$ & $\begin{array}{l}-0.021 \\
(.027)\end{array}$ & $\begin{array}{l}-0.004 \\
(.027)\end{array}$ & $\begin{array}{l}-0.094 \\
(.033)\end{array}$ & $\begin{array}{r}-0.079 \\
(.033)\end{array}$ & $\begin{array}{l}-0.005 \\
(.037)\end{array}$ & $\begin{array}{l}0.022 \\
(.036)\end{array}$ \\
\hline Placebo: 2 Yr Lag & $\begin{array}{l}-0.056 \\
(.023)\end{array}$ & $\begin{array}{l}-0.059 \\
(.023)\end{array}$ & $\begin{array}{l}-0.010 \\
(.026)\end{array}$ & $\begin{array}{l}-0.008 \\
(.026)\end{array}$ & & & & \\
\hline Treatment Year & $\begin{array}{l}0.016 \\
(.027)\end{array}$ & $\begin{array}{l}0.013 \\
(.027)\end{array}$ & $\begin{array}{l}0.034 \\
(.027)\end{array}$ & $\begin{array}{l}0.036 \\
(.027)\end{array}$ & $\begin{array}{l}0.030 \\
(.043)\end{array}$ & $\begin{array}{l}0.024 \\
(.043)\end{array}$ & $\begin{array}{l}0.035 \\
(.042)\end{array}$ & $\begin{array}{l}0.033 \\
(.042)\end{array}$ \\
\hline Pre-p F-test p-val & 0.002 & 0.004 & 0.734 & 0.953 & 0.005 & 0.016 & 0.888 & 0.548 \\
\hline$R^{2}$ & .055 & .074 & .079 & .097 & .111 & .133 & .142 & .163 \\
\hline$N(1000 \mathrm{~s})$ & 7139 & 7139 & 7138 & 7138 & 5038 & 5038 & 5038 & 5038 \\
\hline $\begin{array}{l}\text { Mincerian Ctrls } \\
\text { 4-Digit Ind.-Occ. FEs }\end{array}$ & & $\mathrm{X}$ & $\mathrm{X}$ & $\begin{array}{l}\mathrm{X} \\
\mathrm{X}\end{array}$ & & $\mathrm{X}$ & $\mathrm{X}$ & $\begin{array}{l}\mathrm{X} \\
\mathrm{X}\end{array}$ \\
\hline
\end{tabular}

Note: These results pool four reforms to the replacement rate schedule in Austria, and are based on specification (19) with the variation in benefits aggregated at the firm-level, detailed in Footnote 40. See Section 5.2 for more details about the construction of the firm-level instrument, and Footnote 40 for the regression specification. Standard errors are in parentheses and two-way clustered at the firm and individual level. The null hypothesis of the F-test is that the coefficients of interest are all jointly equal to 0 in the pre-period. The Mincerian controls include time-varying polynomials of experience, tenure, and age; time-varying gender indicators, and a control for being REBP eligible. The industry-occupation controls are time-varying fixed effects for each four-digit industry interacted with an indicator for a blue vs. white-collar occupation. All specifications also include the baseline controls in Table 3, reform-specific firm-treatment intensity percentile fixed effects and firm share treated percentile fixed effects. 
Table 7: Wage Effects: Difference-in-Differences Regression with Industry-Occupation Level Variation

\begin{tabular}{|c|c|c|c|c|c|c|}
\hline & \multicolumn{6}{|c|}{ Earnings Effects } \\
\hline & (1) & $(2)$ & $(3)$ & (4) & $(5)$ & $(6)$ \\
\hline & \multicolumn{6}{|c|}{ Panel A: 1-Year Horizon } \\
\hline \multirow[t]{2}{*}{ Placebo: 3 Yr Lag } & 0.139 & 0.100 & 0.530 & -0.005 & 0.053 & 0.015 \\
\hline & $(0.094)$ & $(0.094)$ & $(0.064)$ & $(0.105)$ & $(0.098)$ & $(0.099)$ \\
\hline \multirow[t]{2}{*}{ Placebo: 2 Yr Lag } & 0.059 & 0.037 & 0.307 & -0.043 & 0.009 & -0.015 \\
\hline & $(0.068)$ & $(0.068)$ & $(0.045)$ & $(0.073)$ & $(0.072)$ & $(0.072)$ \\
\hline \multirow[t]{2}{*}{ Treatment Year } & 0.304 & 0.326 & 0.219 & 0.273 & -0.052 & -0.029 \\
\hline & $(0.073)$ & $(0.075)$ & $(0.083)$ & $(0.085)$ & $(0.086)$ & $(0.084)$ \\
\hline Pre-p F-test p-val & 0.313 & 0.528 & 0.000 & 0.724 & 0.846 & 0.920 \\
\hline \multirow{3}{*}{$\begin{array}{l}R^{2} \\
N(1000 \mathrm{~s}) \\
\end{array}$} & 0.070 & 0.087 & 0.081 & 0.072 & 0.082 & 0.098 \\
\hline & 7138 & 7138 & 7138 & 7138 & 7138 & 7138 \\
\hline & \multicolumn{6}{|c|}{ Panel B: 2-Year Horizon } \\
\hline \multirow{2}{*}{ Placebo: 3 Yr Lag } & 0.054 & 0.006 & 0.452 & -0.100 & -0.025 & -0.048 \\
\hline & $(0.074)$ & $(0.073)$ & $(0.073)$ & $(0.074)$ & $(0.110)$ & $(0.104)$ \\
\hline \multicolumn{7}{|l|}{ Placebo: 2 Yr Lag } \\
\hline \multirow[t]{2}{*}{ Treatment Year } & 0.160 & 0.225 & 0.007 & 0.187 & -0.140 & -0.059 \\
\hline & $(0.096)$ & $(0.090)$ & $(0.097)$ & $(0.092)$ & $(0.128)$ & $(0.121)$ \\
\hline Pre-p F-test p-val & 0.463 & 0.931 & 0.000 & 0.178 & 0.819 & 0.640 \\
\hline$R^{2}$ & 0.133 & 0.156 & 0.145 & 0.137 & 0.146 & 0.168 \\
\hline$N(1000 \mathrm{~s})$ & 5041 & 5041 & 5041 & 5041 & 5041 & 5041 \\
\hline Mincerian Ctrls & & $\mathrm{X}$ & & & & $\mathrm{X}$ \\
\hline 3-Digit Ind. FEs & & & $\mathrm{X}$ & & $\mathrm{X}$ & $\mathrm{X}$ \\
\hline Occ. FEs & & & & $\mathrm{X}$ & $\mathrm{X}$ & $\mathrm{X}$ \\
\hline
\end{tabular}

Note: These results pool four reforms to the replacement rate schedule in Austria, and are based on specification (19) with the variation in benefits aggregated at the industry-occupation level. See Section 5.2 for more details about the construction of the industry-occupation-level instrument, and Footnote 40 for the regression specification. Standard errors are in parentheses and two-way clustered at the industry-occupation and individual level. The null hypothesis of the F-test is that the coefficients of interest are all jointly equal to 0 in the pre-period. The Mincerian controls include time-varying polynomials of experience, tenure, and age; time-varying gender indicators, and a control for being REBP eligible. The industry controls are time-varying fixed effects for each three-digit industry, and the occupation controls are time-varying indicators for a blue vs. white-collar occupation. All specifications also include the baseline controls in Table 3, reform-specific industry-treatment intensity ventile fixed effects and industry share treated ventile fixed effects. 
Figures 
Figure 1: Nash Bargaining: Relationship between Wage-Benefit Sensitivity $\frac{d w}{d b}$ and Bargaining Power $\phi$ and Time in Nonemployment $\tau$

(a) $\frac{d w}{d b}$ and $\phi$, by $\tau$

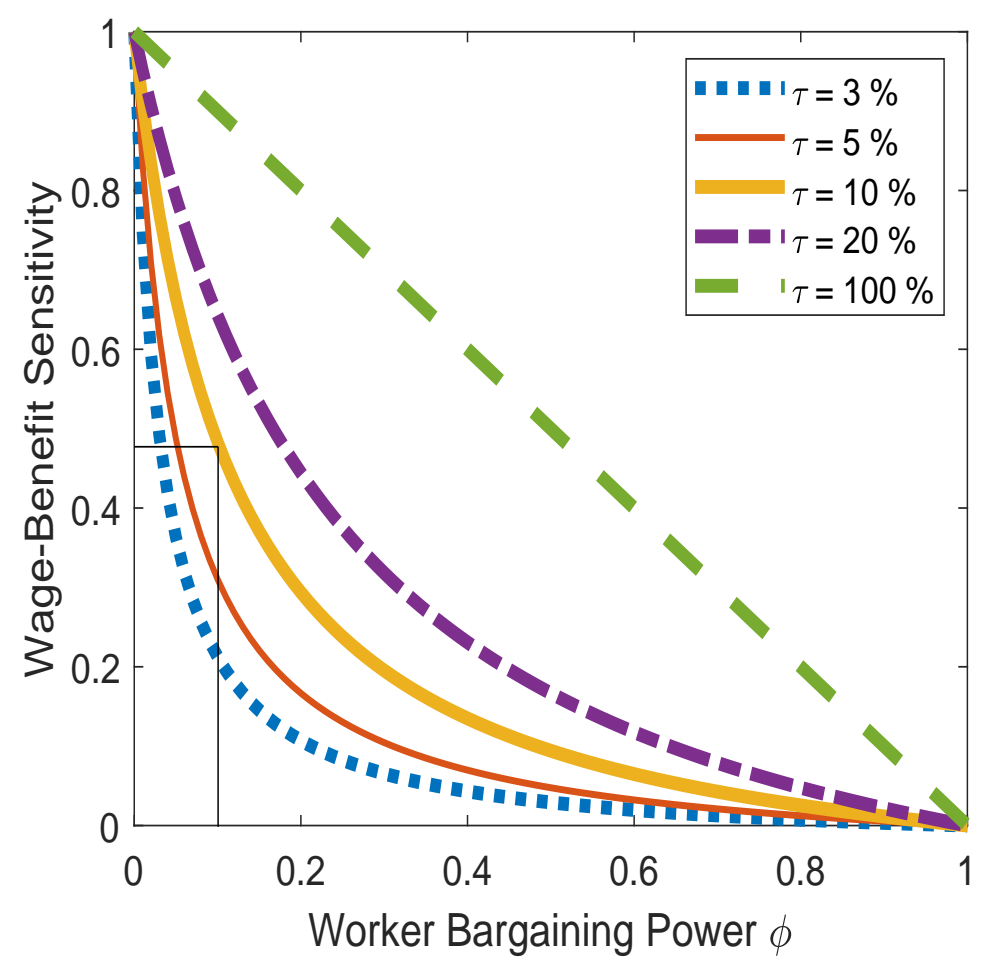

(b) $\frac{d w}{d b}$ and $\tau$, by $\phi$

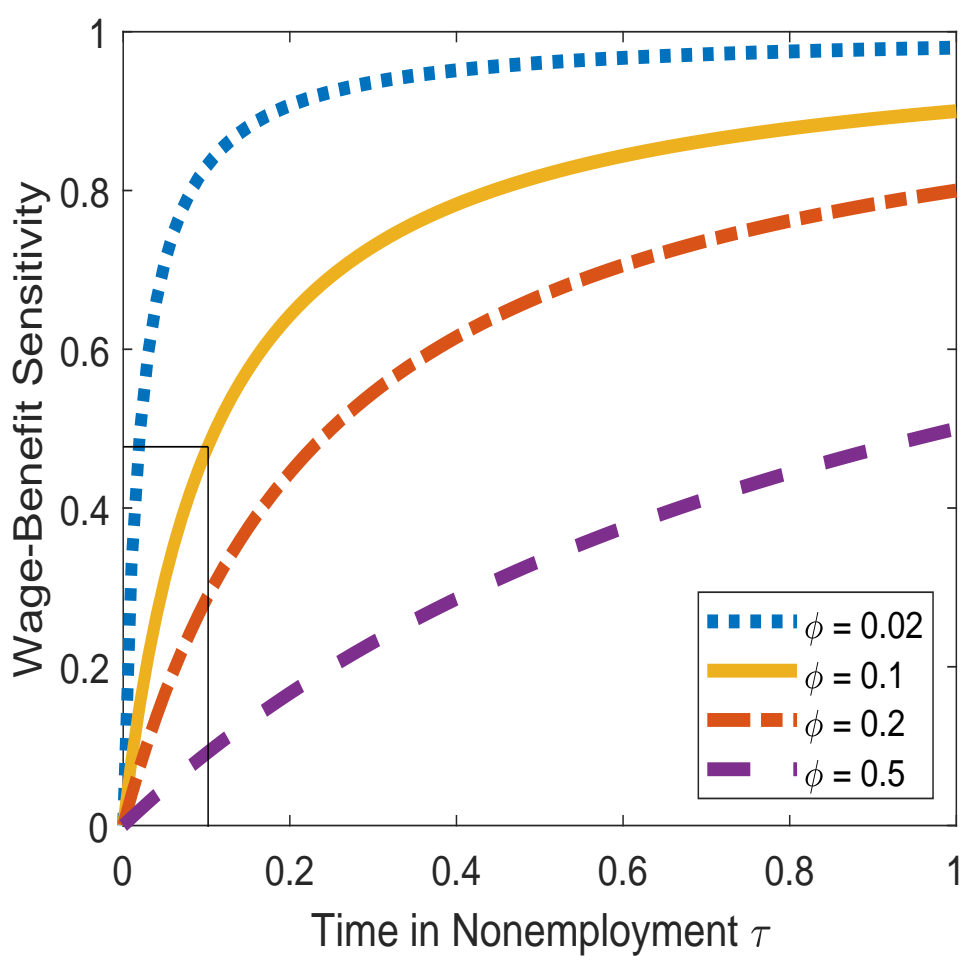

Note: The figure plots the relationship between wage-benefit sensitivity $\frac{d w}{d b}$, and worker bargaining power $\phi$, and time in nonemployment $\tau$, as predicted by Equation (6). We vary $\tau$, the post-separation time spent in nonemployment, $(\tau \in\{3 \%, 5 \%, 10 \%, 20 \%, 100 \%\})$, and worker bargaining power $\phi$ $(\phi \in\{0.02,0.1,0.2,0.5\})$. Our calibration $(\tau=0.1$ and $\phi=0.1)$ predicts a sensitivity of 0.48 , depicted in the thin line departing from $\phi=0.1$, crossing the solid line $(\tau=10 \%)$ and ending at the 0.48 sensitivity (left panel), and depicted in the thin line departing from $\tau=0.1$, crossing the solid line $(\phi=0.1)$ in the right panel. 
Figure 2: Overview of Estimates and Calibrations of Worker Bargaining Power

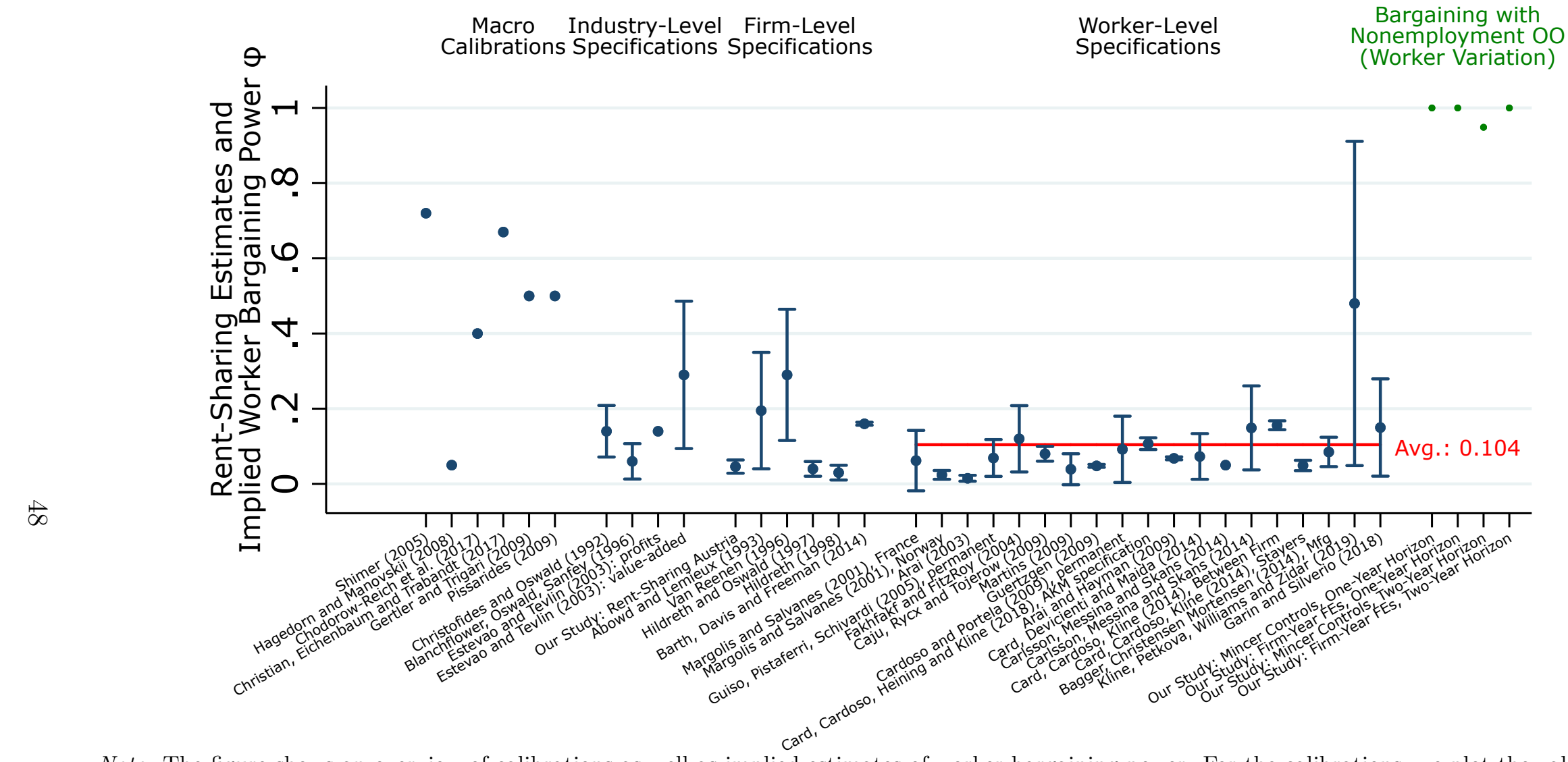

Note: The figure shows an overview of calibrations as well as implied estimates of worker bargaining power. For the calibrations, we plot the values used in the respective papers. For the estimates, we build on the meta-study in Card et al. (2018) and use level-on-level specifications from the papers included in the overview if those are reported. In addition, we report recent estimates from Kline et al. (2019) (Table 8, Panel A, column 12, avg. non-inventor stayer earnings), Garin and Silvério (2018), an estimate from Card et al. (2018) relating value-added and AKM firm effects (Table 4, Panel A, row 3), and our own estimate for Austria. For the study of rent-sharing in Austria, we use firm panel data from Bureau van Dijk from 2004 to 2016 and regress wage costs per employee on value-added per employee, controlling for firm and industry-by-year effects in a level-on-level specification. Some of the estimates surveyed in Card et al. (2018) are cast as elasticities and are thus upper bounds for the implied worker bargaining power when rent-sharing elasticities are calculated (see Appendix Section F). Among the worker-level specifications, we calculate an inverse variance weighted mean of the estimates among those studies that either report level-on-level specifications or rent-sharing elasticities (we omit studies with profit-sharing elasticities since these do not provide bounds for bargaining power). For our study, we plot the implied worker bargaining power under the assumption that nonemployment is the outside option based on the results in Table 3. Specifically, we plot the implied $\phi$ based on the estimates in columns (2) and (6) of both panels in Table 3 and report $\phi=1$ if the point estimate would imply even higher values. 
Figure 3: Unemployment Benefit Schedules and Reforms

(a) 1976 Reform

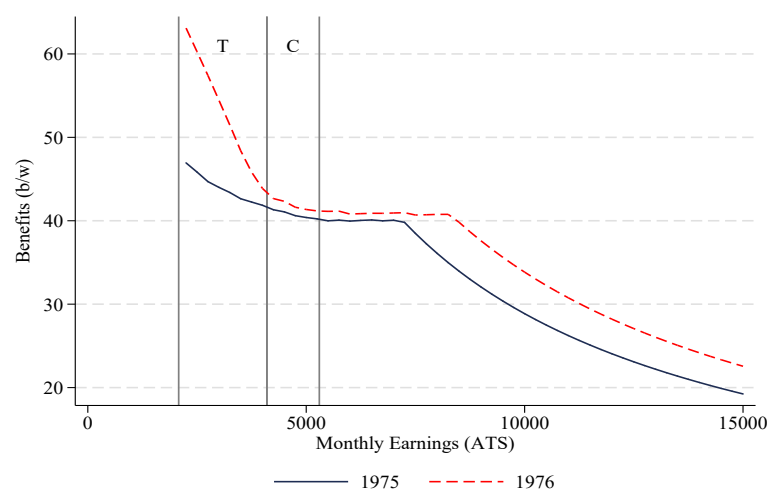

(c) 1989 Reform

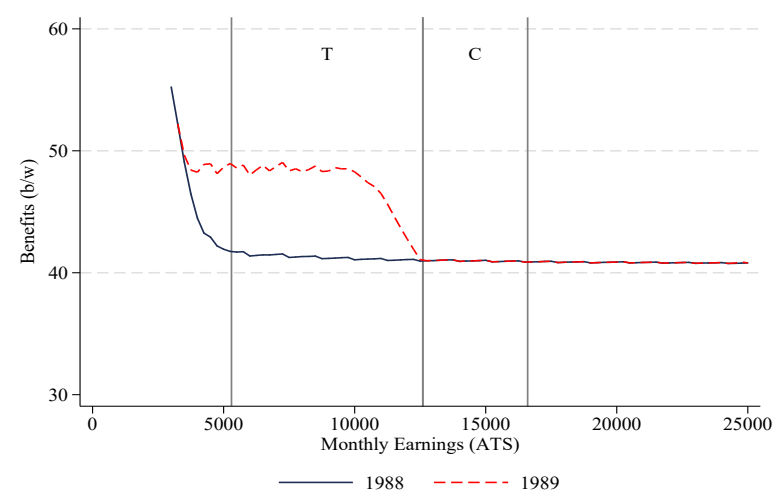

(b) 1985 Reform

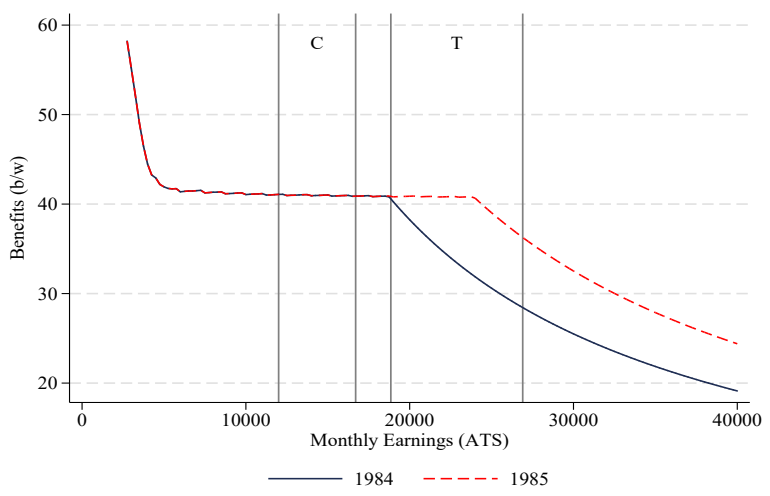

(d) 2001 Reform

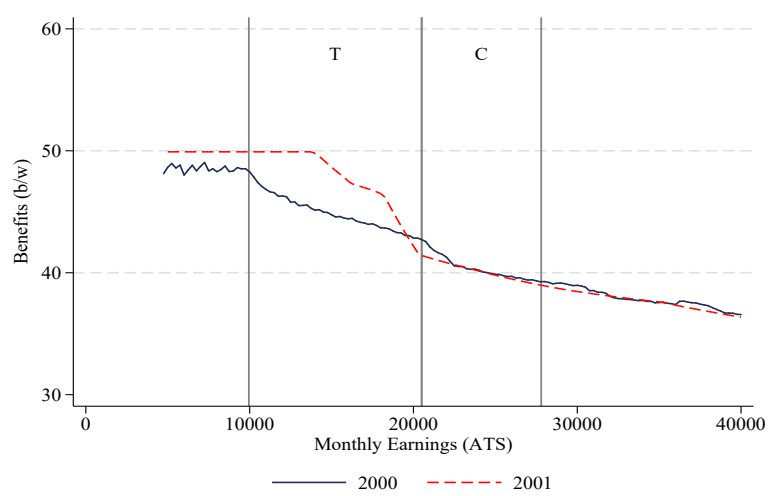

(e) Reform Benefit Changes by Earnings Percentiles

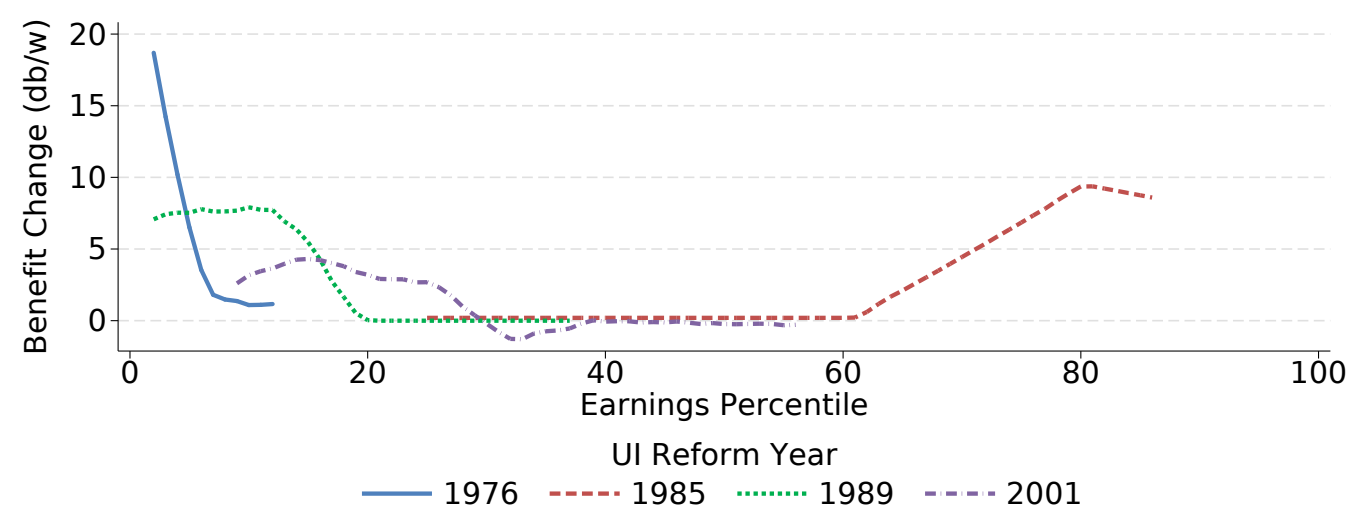

Note: Figures (a)-(d) plot the unemployment benefit schedule before and after each of the four reforms we analyze. The $\mathrm{x}$-axis shows the income relevant for calculating benefits while the $\mathrm{y}$-axis plots the benefits, calculated as the unemployment benefits divided by income. The $\mathrm{T}$ and $\mathrm{C}$ labels delineate the treatment and control earnings ranges included in the analysis. See footnote 23 and Appendix Section 4.1 for more details about how the treatment and control regions for each reform were selected. The nominal earnings ranges for the treatment $(\mathrm{T})$ and control $(\mathrm{C})$ regions for the four reforms are 1976: T: 2080 to 4100 ATS, C: 4100 to 5300 ATS; 1985: T: 18850 to 26900 ATS, C: 12000 to 16700 ATS; 1989: T: 5300 to 12600 ATS, C: 12600 to 16600 ATS; and 2001: T: 9950 to 20500 ATS, C: 20500 to 27800 ATS. Figure (e) plots the reform induced benefit change for each reform in earnings percentile space. 
Figure 4: Nonparametric Benefit Changes and Wage Effects

(a) 2001 Reform

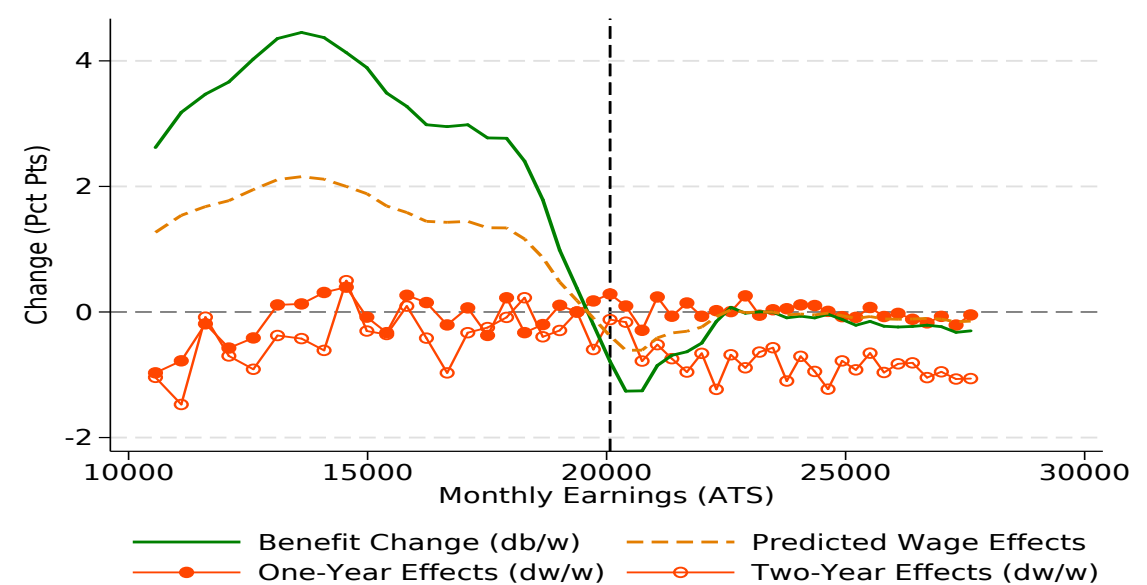

(c) 1985 Reform

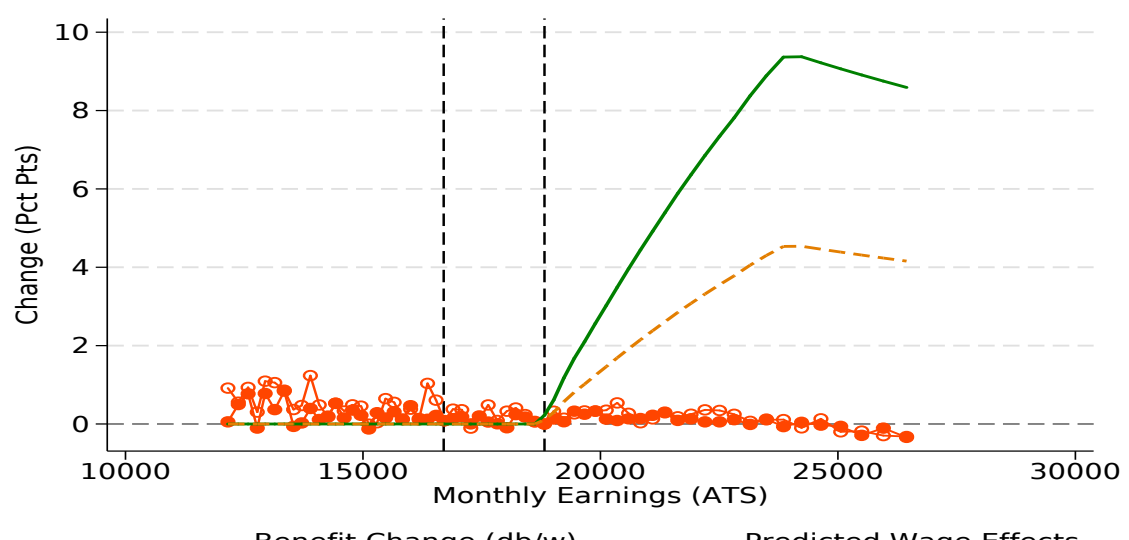

Benefit Change (db/w) - - - - Predicted Wage Effects (b) 1989 Reform

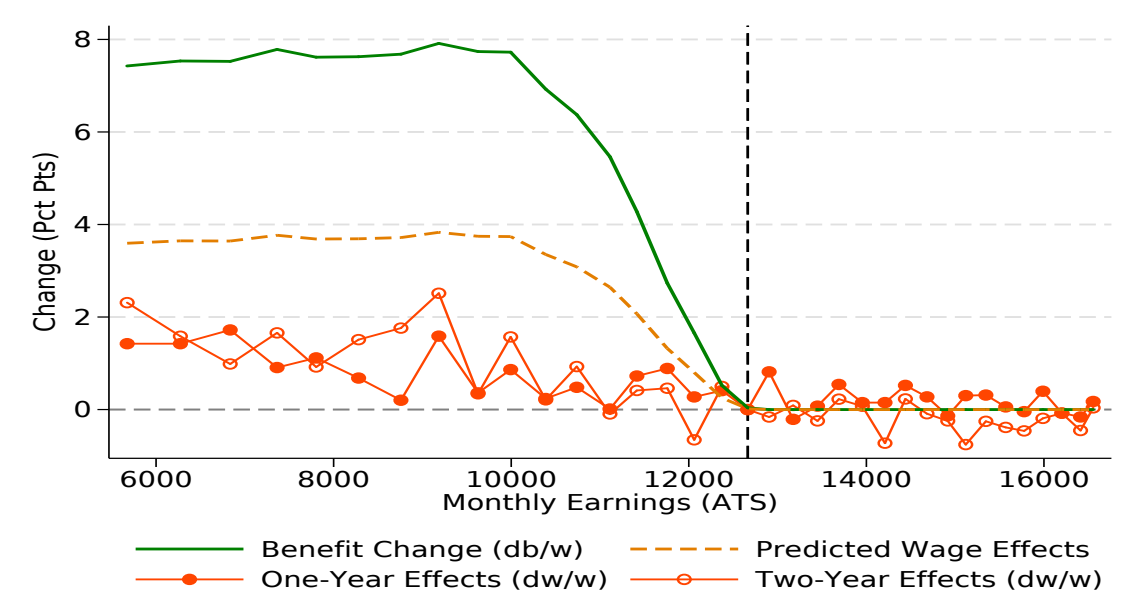

(d) 1976 Reform

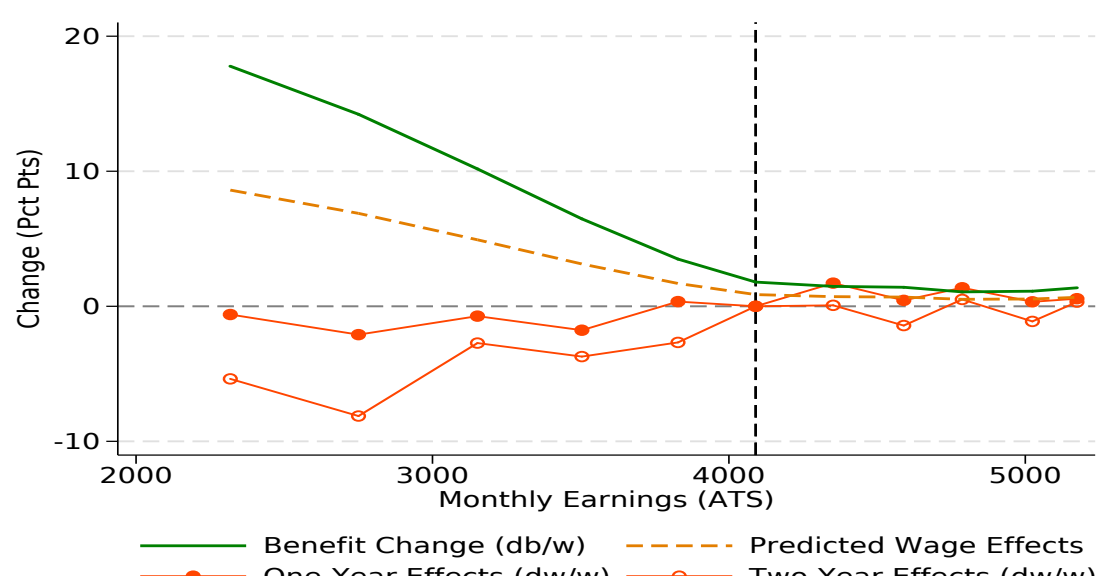

Note: The figure plots reform-induced replacement rate changes and wage effects for all four reform. Observations are binned by their base year (year before the reform was enacted) earnings percentile on the x-axis. The dashed orange line indicates the wage growth that the reform would induce in the calibrated bargaining model with a wage-benefit sensitivity of 0.48 . The red circles indicate the wage effects that the reform induced at the one- and two-year horizon. Section 4.2 provides more information. 
Figure 5: Scatter Plots of Wage Growth and Unemployment Benefit Changes

(a) One-Year Horizon

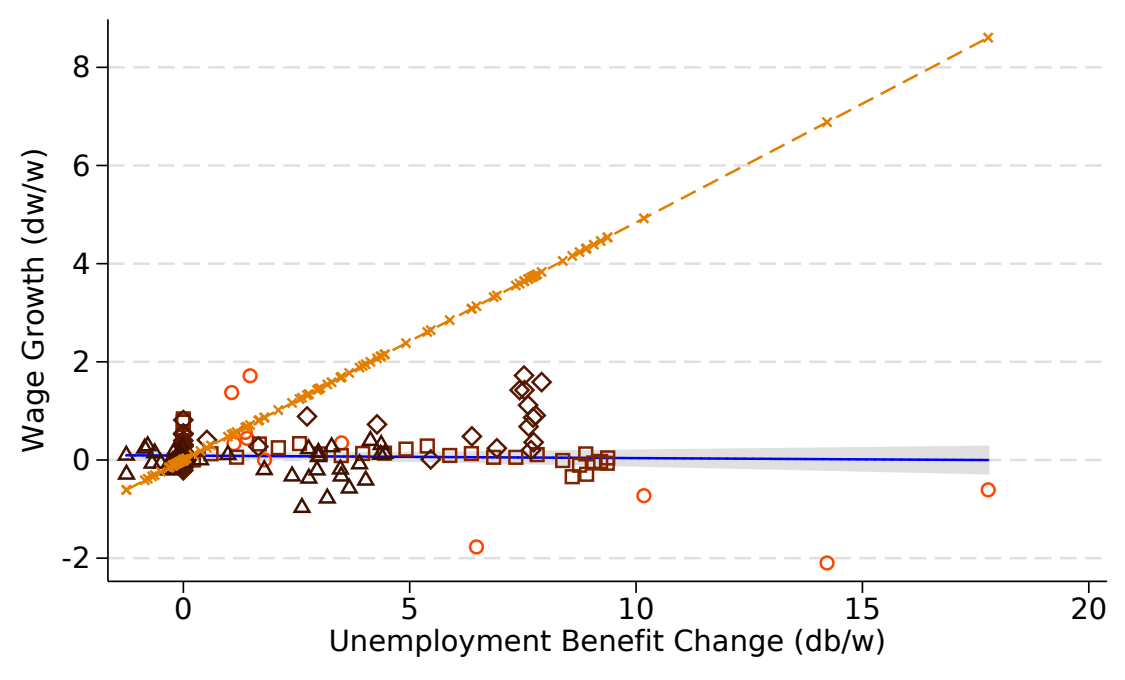

$\circ 1976$ 口 $1985 \diamond 1989 \Delta 2001 \times$ Predicted

Estimated Wage Sensitivity $\sigma:-.005$ (SE: .008)

Predicted Semi-Elasticity: .484

(b) Two-Year Horizon

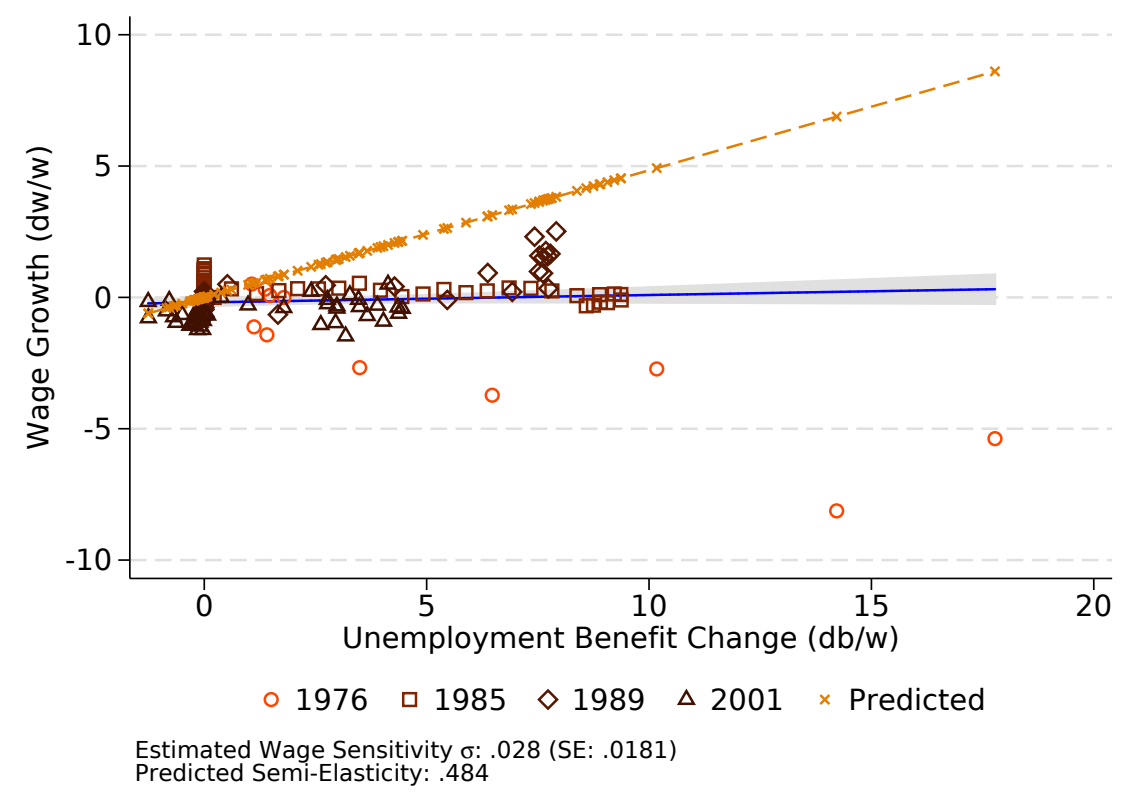

Note: The figures show scatter plots of wage growth (y-axis) and reform-induced replacement rate changes (x-axis), $d b / w$, pooling the four reforms outlined in Figures 4(a) through 4(d). Each dot corresponds to a percentile observation from one of the 4(a) through 4(d). The upper panel shows wage effects after one year and the lower panel effects after two years. The orange cross marks indicate the predicted wage growth that the reforms would have induced in the calibrated bargaining model with a wage-benefit sensitivity of 0.48 . The remaining symbols indicate actual data points for wage growth and benefit changes. The estimated wage sensitivities $\hat{\sigma}$ are calculated as the slope of wage growth with respect to changes in the benefit level. 


\section{Figure 6: Pooled Earnings and Benefit Change Bin Scatter Plots - Treatment Year}

(a) Year Fixed Effects

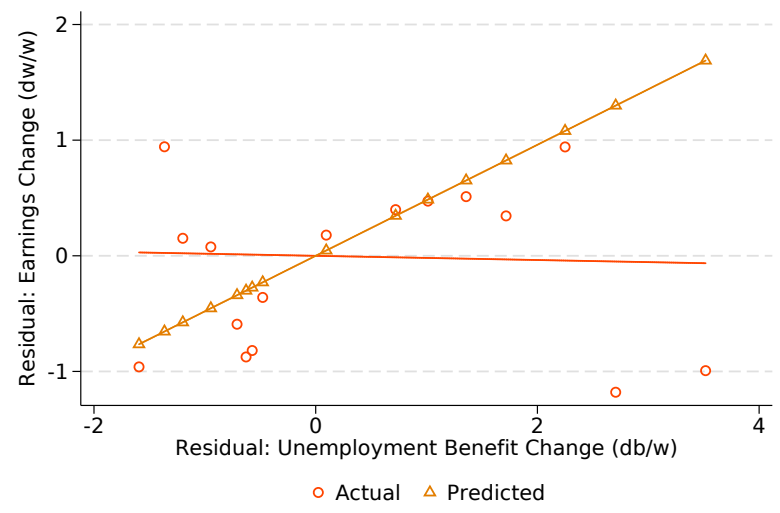

Slope: $-0.018(0.008)$ (b) Adding Earnings Percentile Fixed Effects

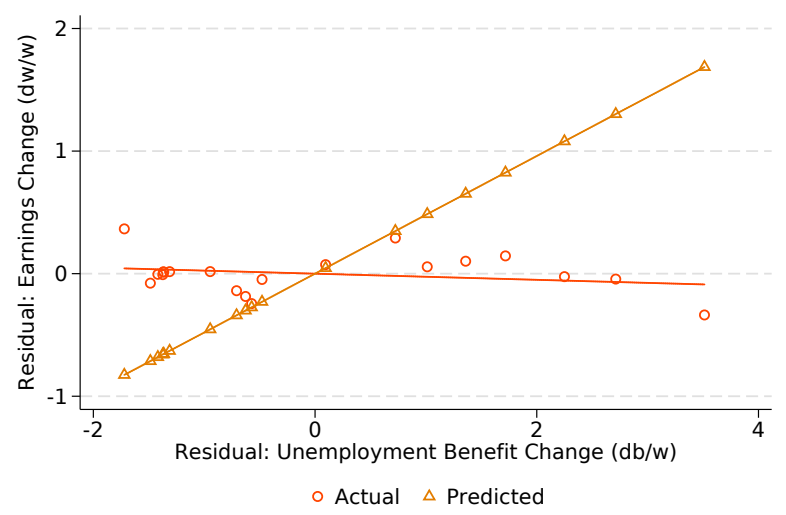

Slope: $-0.025(0.009)$

(c) Adding Year-Specific Log Earnings Controls

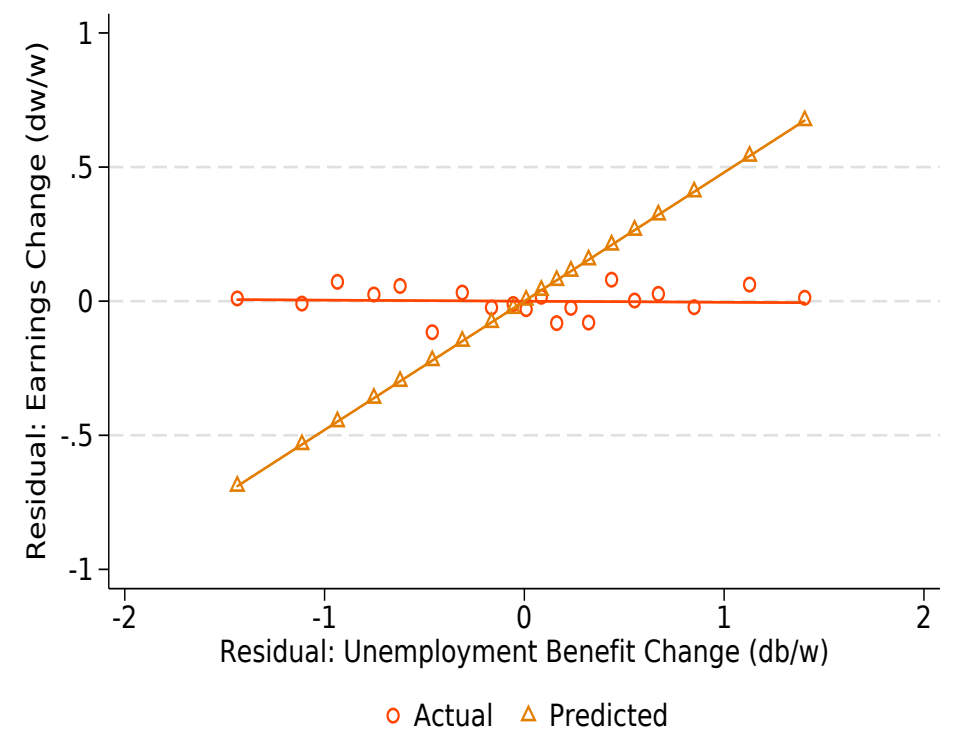

Slope: -0.004 (0.016), See Table 3, column (1), Row 3

Note: The three panels show the best-fit lines and binned scatter plots from estimating Equation 19 with a limited set of controls for the pooled sample of all four reforms. The best-fit line slope and standard errors are the coefficient and standard error on $\sigma_{0}$ in Equation 19. The binned scatter plot is estimated on earnings changes and reform induced benefit changes both residualized by the other included controls. Panel (a) only includes year fixed effects as controls. Panel (b) adds earnings percentile fixed effects. Panel (c) adds year-specific log earnings controls. The yellow predicted line plot the predicted earnings change for each benefit change based on the calibrated Nash bargining model. 
Figure 7: Heterogeneity of Wage-Benefit Sensitivity by Predicted Post-Separation Time on UI $\tau$ : Model Prediction vs. Empirical Estimates

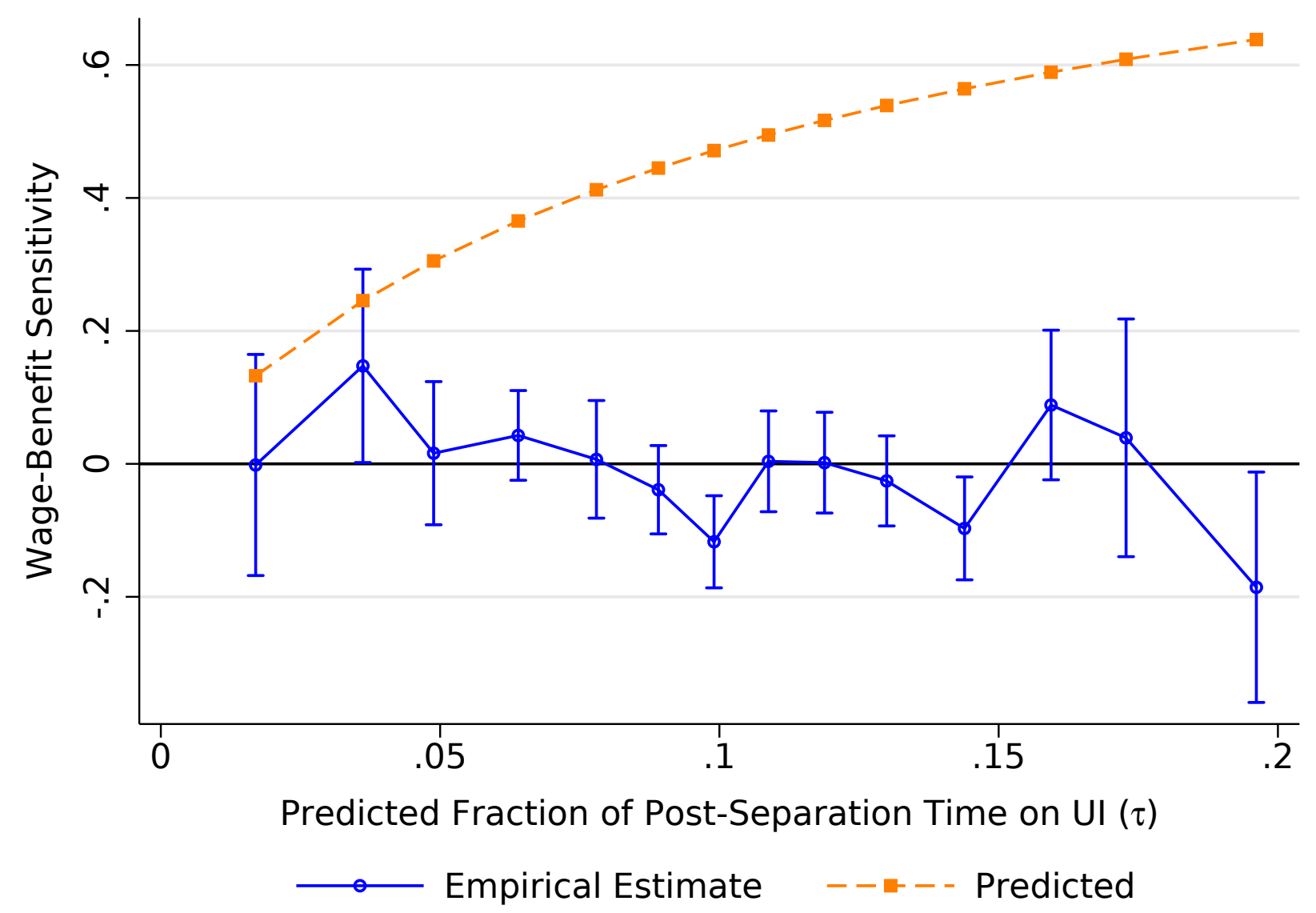

Note: The graph presents wage-benefit sensitivities for workers sorted by their predicted fraction of time on UI conditional on a separation, i.e. the $\hat{\tau}_{i}$ statistic described in Section 2.1.2, further detailed Appendix C, and summarized in Table 1. Specifically, the analysis sorts the regression sample (of each reform year) into 14 quantiles: the sorting starts with deciles, and then for additional dispersion, further splits up the top and bottom decline into two equally sized groups (ventiles), and then further splits up the resulting very top/bottom ventiles into two. The x-axis denotes the quantile-specific mean $\hat{\tau}_{i}$ values. The graph then reports two wage-benefit sensitivities. First, the yellow line (squares) plots the series of model-predicted wage-benefit sensitivity following Equation (6) and based on a Nash bargaining model with worker bargaining power $\phi=0.1$, inputting each group's mean $\hat{\tau}_{i}$. The blue line (hollow circles) presents the group-specific empirical heterogeneous treatment effects, estimated in a version of our main regression model (19) but interacting the treatment (reform-induced benefit changes) with a series of indicators for a worker's quantile membership regarding her $\tau$ value. 


\title{
Online Appendix of: \\ Wages and the Value of Nonemployment
}

\author{
Simon Jäger, Benjamin Schoefer, Samuel Young and Josef \\ Zweimüller
}

\section{A Additional Tables}

Table A.1: Take-Up of Unemployment Insurance among Nonemployment Spells

\begin{tabular}{llc}
\hline \hline & & \\
& & \\
& Prop. of NE Spells & No. Spells \\
\hline All Spells & 0.491 & 2984601 \\
2 Years or Shorter & 0.508 & 2640962 \\
2 Days or Longer & 0.532 & 2754233 \\
14 Days or Longer & 0.633 & 2240664 \\
28 Days or Longer & 0.662 & 2012286 \\
Between 28 Days and 2 Years & 0.724 & 1668647 \\
Men & 0.491 & 1523085 \\
Women & 0.491 & 1461516 \\
Blue Collar & 0.518 & 1538079 \\
White Collar & 0.551 & 1011599 \\
Excluding Ages 50-54 & 0.488 & 2814545 \\
Employed At Least 2 Years & 0.502 & 2011459 \\
Spells between 28 Days and 2 Years & & \\
Male & & \\
Male Under 50 & 0.756 & 825336 \\
Female & 0.755 & 772648 \\
Female Under 50 & 0.692 & 843311 \\
Blue Collar & 0.692 & 793565 \\
White Collar & 0.788 & 832004 \\
Excluding Ages 50-54 & 0.761 & 614514 \\
Employed At Least 2 Years & 0.723 & 1566213 \\
\hline \hline
\end{tabular}

Note: This table plots the share of workers who take up unemployment insurance after the end of an employment spell. The sample is restricted to prime-age workers (25-54) whose employment spell prior to nonemployment lasted at least one year and who were not recalled by their previous employer. We also drop workers who immediately transition from employment into other types of spells, e.g., maternity leave or disability. The sample period ranges from 1972 to 2000 . To illustrate, the table indicates that $63.8 \%$ of nonemployment spells of 14 days or longer led to take-up of unemployment insurance. 
Table A.2: Validation Exercise: Difference-in-Differences Regression Design

\begin{tabular}{|c|c|c|c|c|c|c|}
\hline & \multicolumn{3}{|c|}{ 1-Year Implied Benefit Change } & \multicolumn{3}{|c|}{ 2-Year Implied Benefit Change } \\
\hline & $(1)$ & $(2)$ & $(3)$ & $(1)$ & $(2)$ & $(3)$ \\
\hline Placebo: 3 Yr Lag & $\begin{array}{l}0.152 \\
(.029)\end{array}$ & $\begin{array}{l}0.148 \\
(.028)\end{array}$ & $\begin{array}{l}0.153 \\
(.028)\end{array}$ & $\begin{array}{l}-0.005 \\
(.025)\end{array}$ & $\begin{array}{l}-0.009 \\
(.024)\end{array}$ & $\begin{array}{r}-0.022 \\
(.026)\end{array}$ \\
\hline Placebo: 2 Yr Lag & $\begin{array}{l}0.097 \\
(.01)\end{array}$ & $\begin{array}{l}0.095 \\
(.01)\end{array}$ & $\begin{array}{l}0.105 \\
(.009)\end{array}$ & & & \\
\hline Treatment Year & $\begin{array}{l}0.808 \\
(.015)\end{array}$ & $\begin{array}{l}0.800 \\
(.015)\end{array}$ & $\begin{array}{l}0.807 \\
(.013)\end{array}$ & $\begin{array}{l}0.526 \\
(.024)\end{array}$ & $\begin{array}{l}0.515 \\
(.023)\end{array}$ & $\begin{array}{l}0.529 \\
(.021)\end{array}$ \\
\hline Pre-p F-test p-val & 0.000 & 0.000 & 0.000 & 0.825 & 0.702 & 0.399 \\
\hline$R^{2}$ & 0.798 & 0.807 & 0.853 & 0.629 & 0.654 & 0.773 \\
\hline$N(1000 \mathrm{~s})$ & 7202 & 7198 & 6354 & 5179 & 5176 & 4563 \\
\hline Mincerian Ctrls & & $\mathrm{X}$ & $\mathrm{X}$ & & $\mathrm{X}$ & $\mathrm{X}$ \\
\hline 4-Digit Ind.-Occ. FEs & & $\mathrm{X}$ & $\mathrm{X}$ & & $\mathrm{X}$ & $\mathrm{X}$ \\
\hline Firm-Year FEs & & & $\mathrm{X}$ & & & $\mathrm{X}$ \\
\hline
\end{tabular}

Note: To assess the extent to which reform-induced benefit changes, assigned based on lagged earnings, shift benefits implied by realized earnings, we estimate a variant of (19) with benefit changes implied by actual earnings realizations as the dependent variable:

$\frac{b_{t}\left(w_{i, t}\right)-b_{t-1}\left(w_{i, t}\right)}{w_{i, r, t-1}}=\sum_{e=-L}^{0} \delta_{e}^{V}\left(\mathbb{1}_{(t-r=e)} \times \frac{d b_{i, r, t}\left(\tilde{w}_{i, r, t}\right)}{w_{i, r, t-1}}\right)+\tau_{r, P_{t-1}}^{V}+\theta_{r, t-1}^{V}+\gamma_{r, t}^{V} \ln w_{i, r, t-1}+X_{i, r, t-1}^{\prime} \phi_{r, t}^{V}+\epsilon_{i, r, t}^{V}$.

The dependent variable is the normalized change in benefits calculated based on realized earnings while the regressors are the predicted shifts in benefits based on lagged earnings. For the 2001 reform, the relevant realized earnings concept in fact corresponds to lagged earnings. We normalize $\sigma_{-1}^{V}$ (and $\sigma_{-2}^{V}$ ) to zero in the specification with the one-year (two-year) implied benefit change as outcome variable. Standard errors based on two-way clustering at the individual and earnings percentile level are in parentheses. The null hypothesis of the F-test is that the coefficients of interest are all equal to 0 in the pre-period. The Mincerian controls include time-varying polynomials of experience, tenure, and age; time-varying gender indicators, and a control for being REBP eligible. The industry-occupation controls are time-varying fixed effects for each four-digit industry interacted with an indicator for a blue vs. white-collar occupation. 
Table A.3: Instrumental Variable Analysis

\begin{tabular}{|c|c|c|c|c|c|c|}
\hline & \multicolumn{6}{|c|}{ Earnings Effects } \\
\hline & $(1)$ & $(2)$ & $(3)$ & $(4)$ & $(5)$ & $(6)$ \\
\hline & \multicolumn{6}{|c|}{ Panel A: 1-Year Horizon } \\
\hline Treatment Effect & $\begin{array}{r}-0.0051 \\
(0.019)\end{array}$ & $\begin{array}{r}-0.0012 \\
(0.021)\end{array}$ & $\begin{array}{c}-0.024 \\
(0.018)\end{array}$ & $\begin{array}{c}-0.018 \\
(0.019)\end{array}$ & $\begin{array}{c}0.0027 \\
(0.016)\end{array}$ & $\begin{array}{c}-0.00048 \\
(0.017)\end{array}$ \\
\hline F statistic & 3250.5 & 3165.2 & 3208.5 & 3142.1 & 3705.2 & 3748.4 \\
\hline \multirow[t]{2}{*}{$N(1000 \mathrm{~s})$} & 7139 & 7139 & 7138 & 7138 & 6299 & 6298 \\
\hline & \multicolumn{6}{|c|}{ Panel B: 2-Year Horizon } \\
\hline Treatment Effect & $\begin{array}{c}-0.011 \\
(0.053)\end{array}$ & $\begin{array}{c}0.012 \\
(0.053)\end{array}$ & $\begin{array}{l}-0.048 \\
(0.057)\end{array}$ & $\begin{array}{c}-0.038 \\
(0.054)\end{array}$ & $\begin{array}{c}-0.036 \\
(0.046)\end{array}$ & $\begin{array}{c}-0.046 \\
(0.046)\end{array}$ \\
\hline F statistic & 437.5 & 429.7 & 452.0 & 442.3 & 507.5 & 505.0 \\
\hline$N(1000 \mathrm{~s})$ & 5021 & 5021 & 5020 & 5020 & 4417 & 4416 \\
\hline Mincerian Ctrls & & $\mathrm{X}$ & & $\mathrm{X}$ & & $\mathrm{X}$ \\
\hline 4-Digit Ind.-Occ. FEs & & & $\mathrm{X}$ & $\mathrm{X}$ & & $\mathrm{X}$ \\
\hline Firm-Year FEs & & & & & $\mathrm{X}$ & $\mathrm{X}$ \\
\hline
\end{tabular}

Note: We implement an instrumental variable strategy akin to the simulated instruments literature (see, e.g., Gruber and Saez, 2002; Kopczuk, 2005; Kleven and Schultz, 2014). In the instrumental variables interpretation, specification (A1) serves as first stage and (19) is the reduced form relationship, $\frac{b_{t}\left(w_{i, t}\right)-b_{t-1}\left(w_{i, t}\right)}{w_{i, r, t-1}}$ the endogenous variable, and $\frac{d b_{i, r, t}\left(w_{i, r, t-1}\right)}{w_{i, r, t-1}}$ the excluded instrument. We estimate the model with 2SLS and use two-way clustering by individual and by earnings percentile. The Mincerian controls include time-varying polynomials of experience, tenure, and age; time-varying gender indicators, and a control for being REBP eligible. The industry-occupation controls are time-varying fixed effects for each four-digit industry interacted with an indicator for a blue vs. white-collar occupation. All specifications also include reform-specific earnings percentile fixed effects, year fixed effects, and year-specific log earnings controls. 


\section{B Additional Figures}

Description of Appendix Figures A.1-A.4 Appendix Figures A.1-A.4 present additional non-parametric results for the 2001, 1989, 1985, and 1976 replacement rate reforms. The left column in each set of figures contains results for one-year earnings changes and the right column contains results for two-year earnings changes.

Panels (a) and (b) plot the average wage growth for the treatment year (navy scatter points) and the pre-period year (olive scatter points) over the earnings distribution. Their difference (orange scatter points) is the same earnings growth difference that is plotted in Figures 4(a)- 4(d). The navy and olive scatter point allow us to better assess the (lack of) pre-trends in earnings growth by comparing the earnings growth gradient in the treatment and control time periods. The difference (red scatter points) between average wage growth in the treatment and the pre-period year is normalized to be zero at the dashed vertical line.

Panels (c) and (d) plot the average of our predicted replacement rate change (the green line) and the average of the actual replacement rate change (the red line) over the earnings distribution. The predicted replacement rate change is calculated using the predicted earnings in the replacement rate reform year. See Section 4.1 for more details about this prediction process. The actual replacement rate change is the average of the replacement rate changes each individual actually experiences. In 1989, the two-year change (1988 to 1990) also captures a follow-up reform in 1990. Our interpretation of two-year wage effects in 1989 therefore largely captures delayed responses to the 1989 reform. Our two-year results are robust to excluding 1989. For 2001, since UI benefits are determined by lagged earnings, the predicted and actual replacement rate changes are identical for one-year outcomes.

Panels (e) and (f) further assess the parallel trends assumption underlying our identification strategy. Here, we estimate the effects of placebo reforms at the same earnings percentile ranges, but we lag both the reform period and the pre-period by by two years. This placebo exercise thus assesses whether the earnings percentiles affected by the reform experienced higher or lower wage growth compared to other earnings percentiles in periods before the reform was enacted. The results presented in these panels are the same as in Panels (a) and (b) except all years are lagged by one or two to estimate the effect the placebo effects. For 1976, we cannot run the two-year placebo check because it would require calculating earnings growth from 1971-'73 and our data start in 1972. In the main regression analysis, we still report two-year earnings effect estimates including the 1976 reform because this only requires data starting in 1972. 
Figure A.1: Additional Results: 2001 Reform

(a) Wage Growth: 2000-2001 vs. 1999-2000; 1 Yr

(b) Wage Growth: 2000-2 vs. 1998-2000; 2 Yr
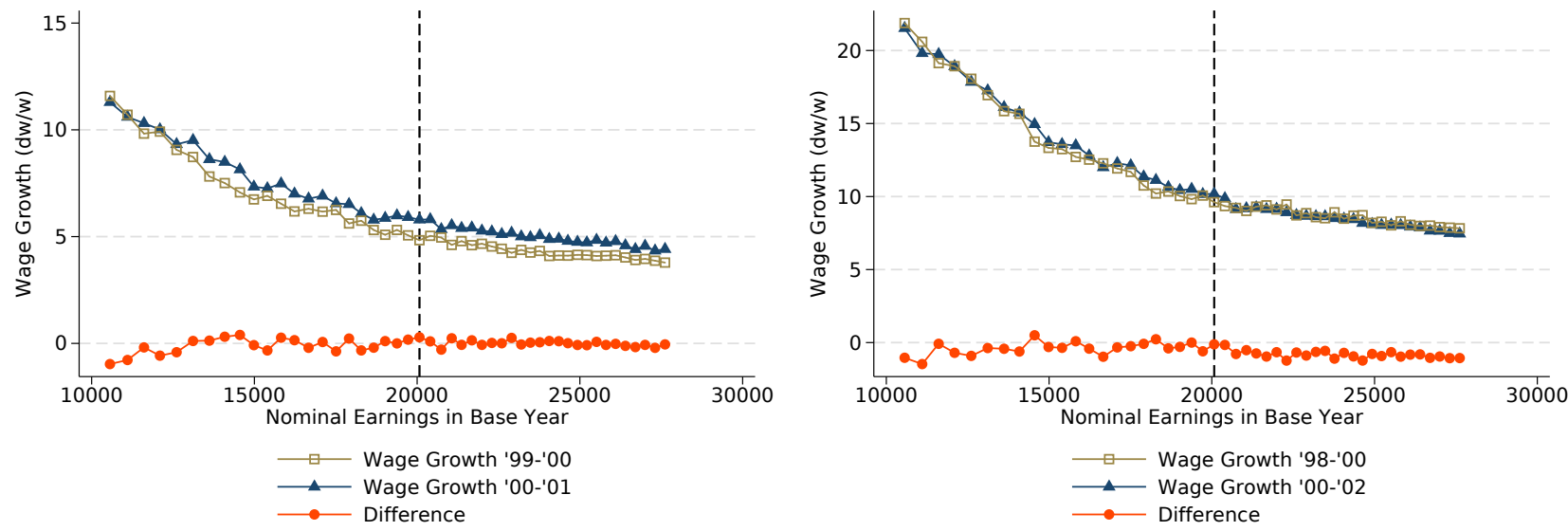

(c) Realized vs. Predicted Benefit Change; 1 Yr

(d) Realized vs. Predicted Benefit Change; 2 Yr
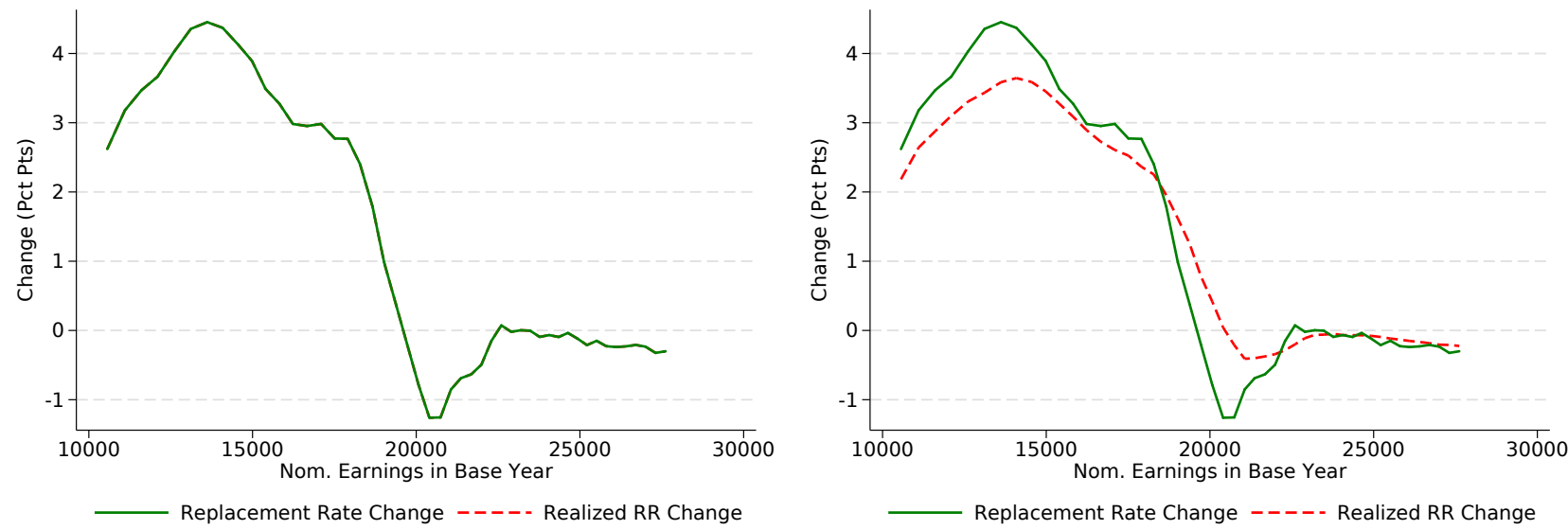

(e) Placebo 2000: 1998-9 vs. 1999-2000; 1Yr

(f) Placebo 1999: 1996-8 vs. 1998-2000; 2 Yr
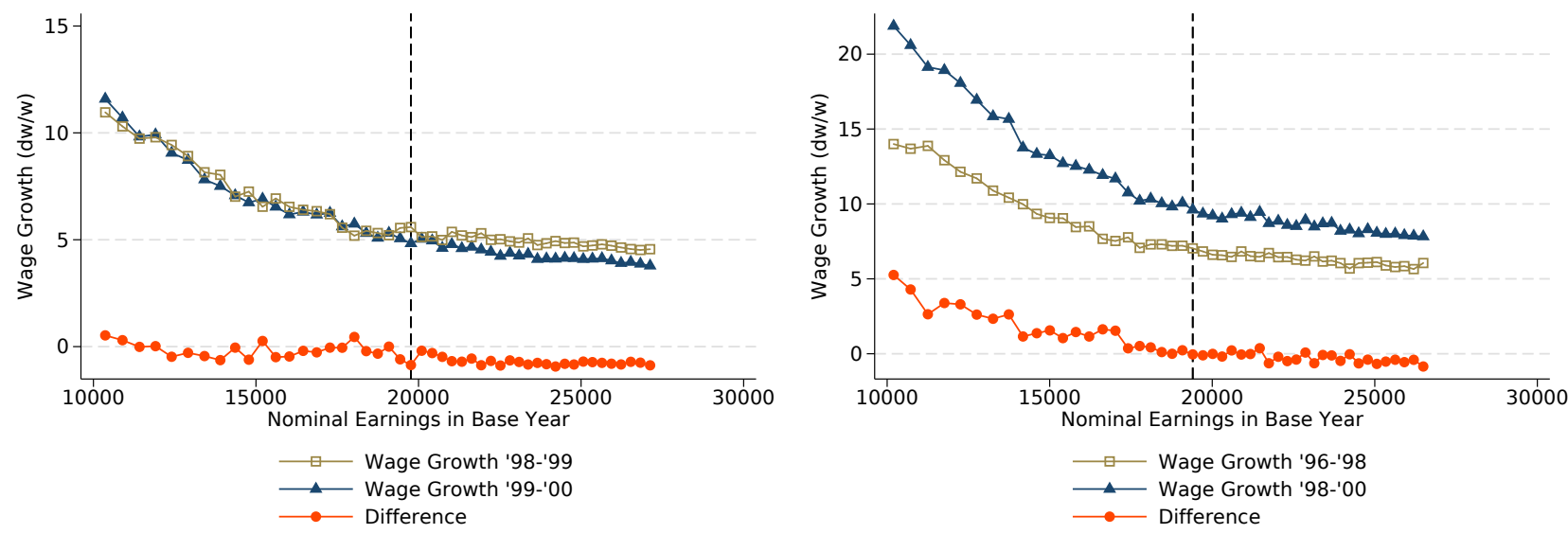

Note: The figure plots additional results related to the analysis in Figure 4(a). We provide a description at the beginning of this Appendix Section (B). 
Figure A.2: Additional Results: 1989 Reform

(a) Wage Growth: $1987-8$ vs. 1988-9; 1 Yr

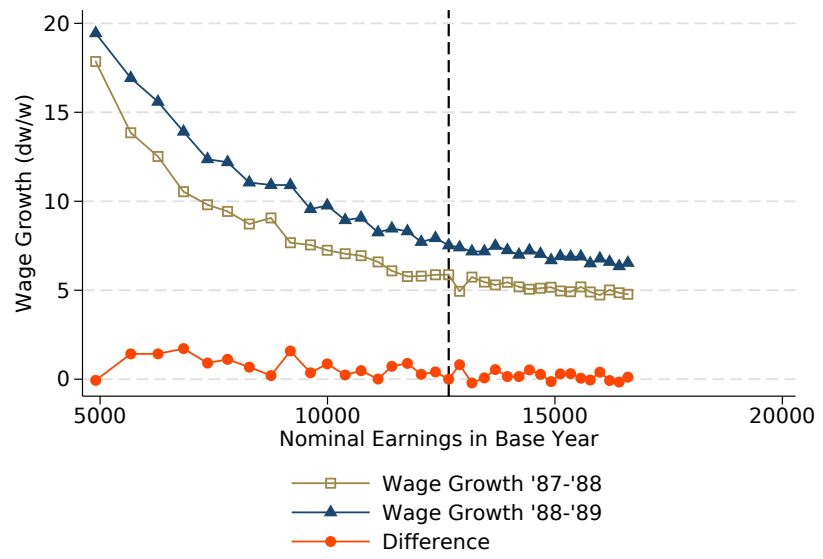

(c) Realized vs. Predicted Benefit Change; 1 Yr

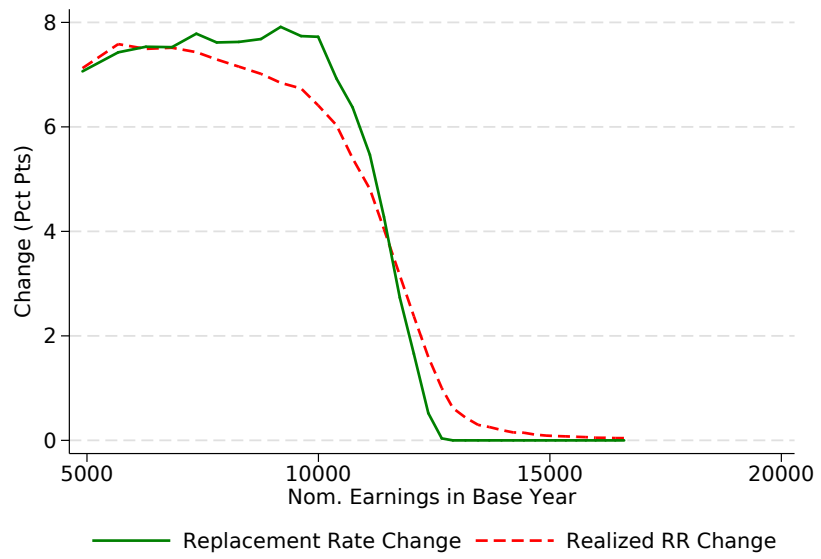

(e) Placebo 1988: 1986-7 vs. 1987-8; 1 Yr

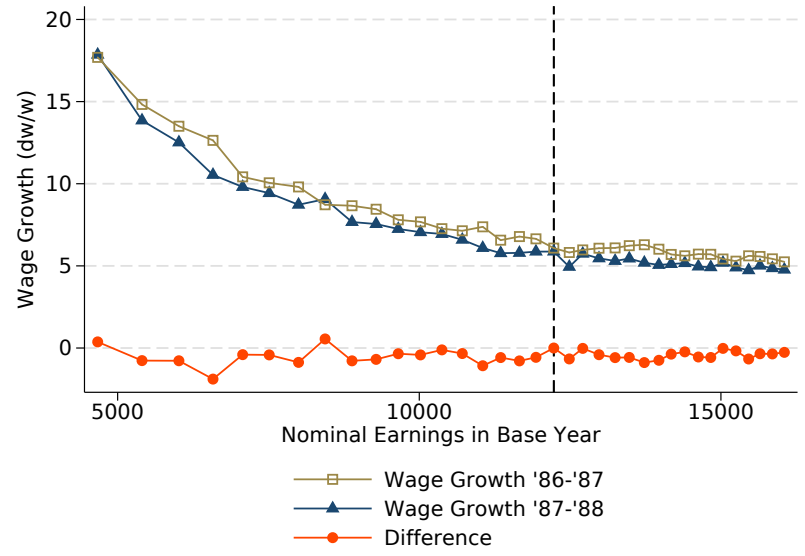

(b) Wage Growth: 1986-8 vs. 1988-90; 2 Yr

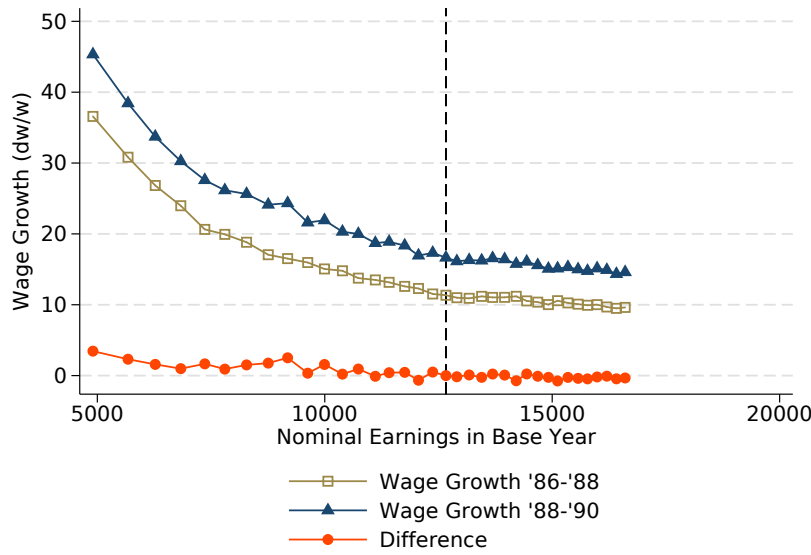

(d) Realized vs. Predicted Benefit Change; 2 Yr

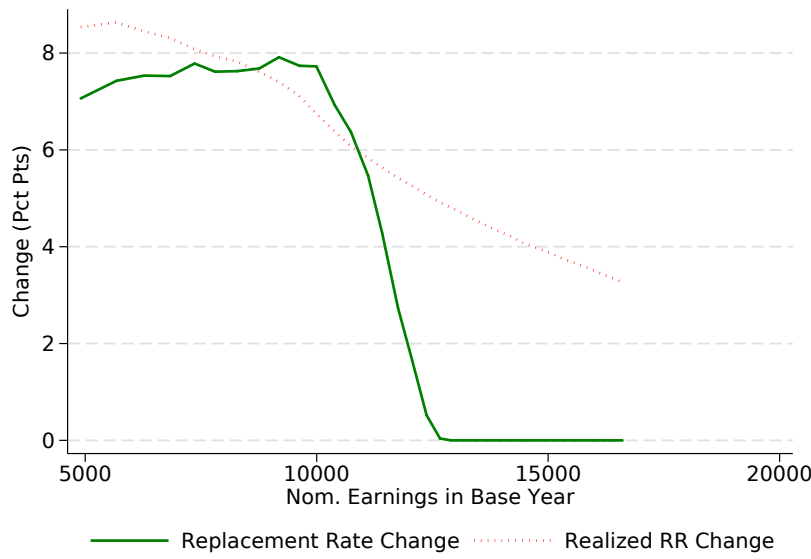

(f) Placebo 1987: 1984-6 vs. 1986-8; $2 \mathrm{Yr}$

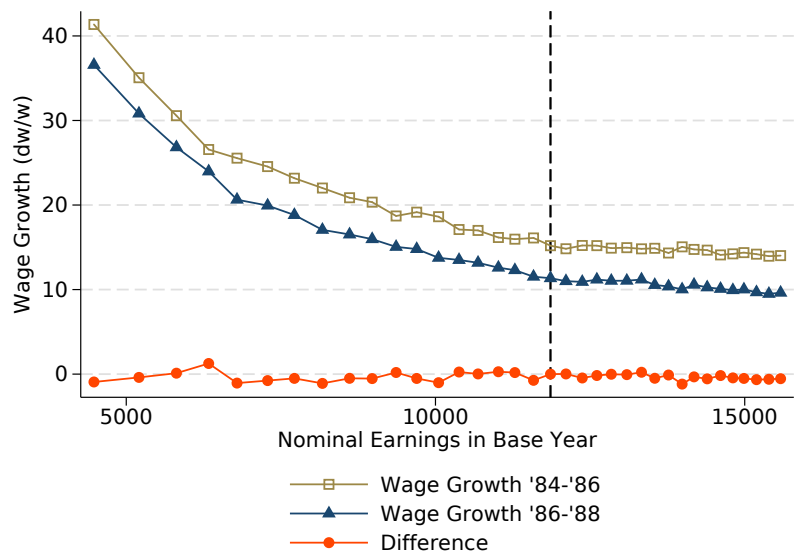

Note: The figure plots additional results related to the analysis in Figure 4(b). We provide a description at the beginning of this Appendix Section (B). 
Figure A.3: Additional Results: 1985 Reform

(a) Wage Growth: 1983-4 vs. 1984-5; 1 Yr

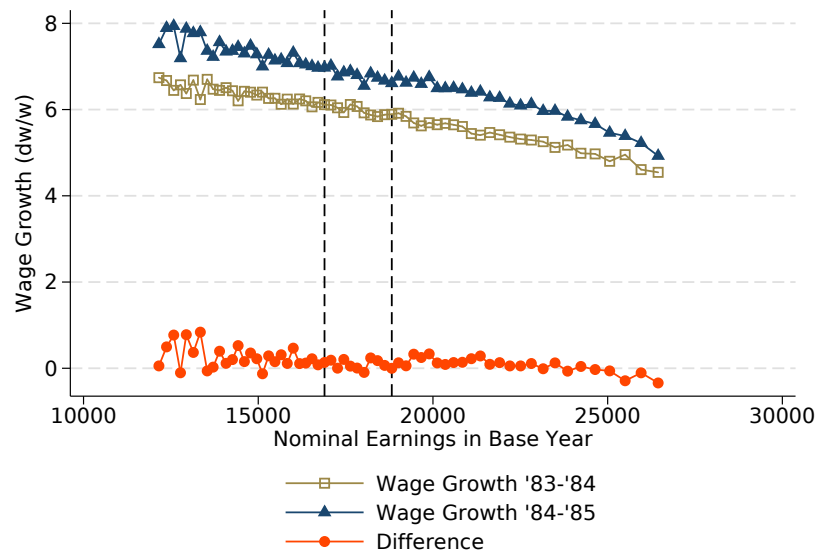

(c) Realized vs. Predicted Benefit Change; 1 Yr

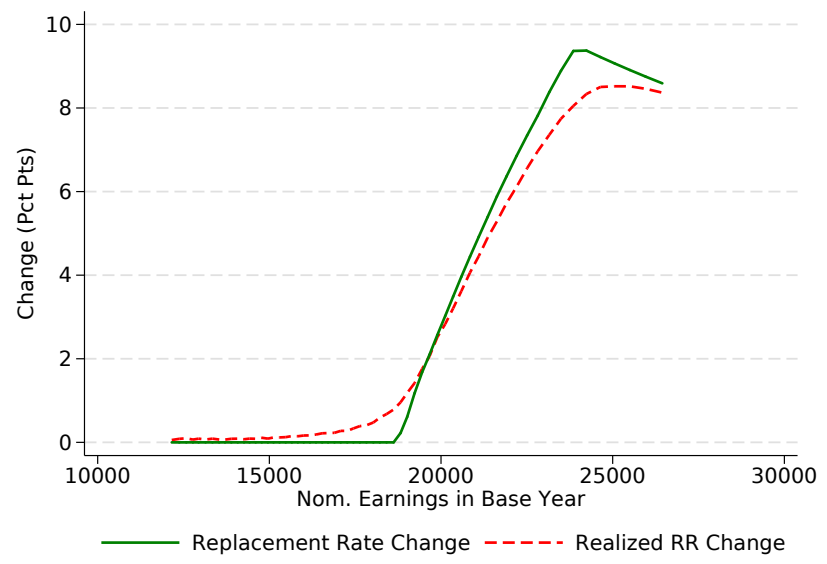

(e) Placebo 1984: 1982-3 vs. 1983-4; 1 Yr

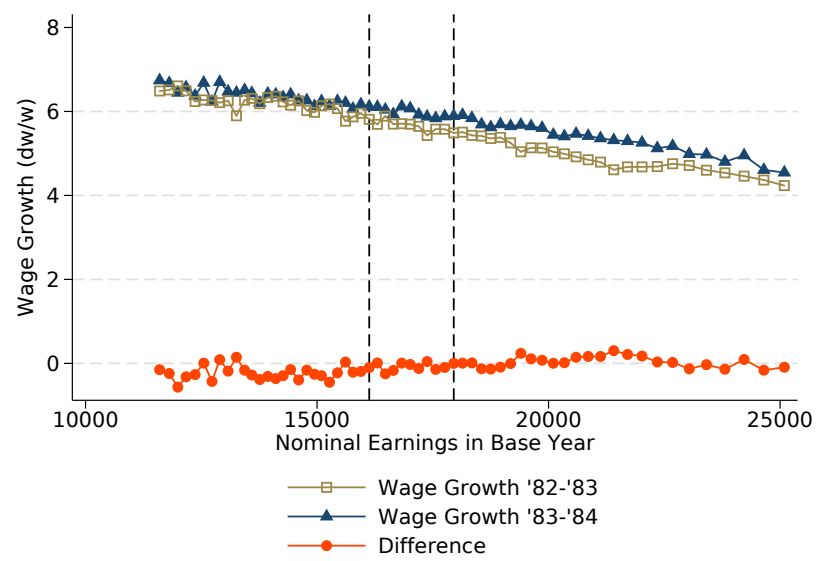

(b) Wage Growth: 1982-4 vs. 1984-6; 2 Yr

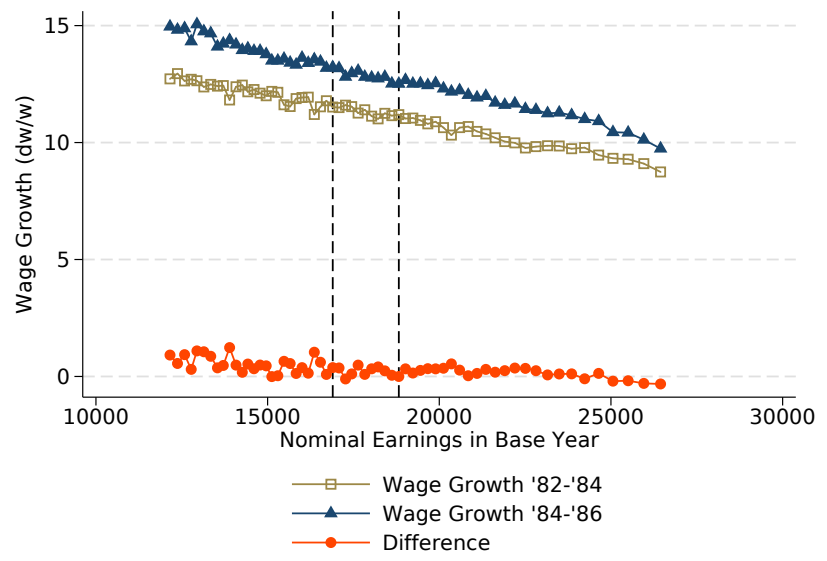

(d) Realized vs. Predicted Benefit Change; 2 Yr

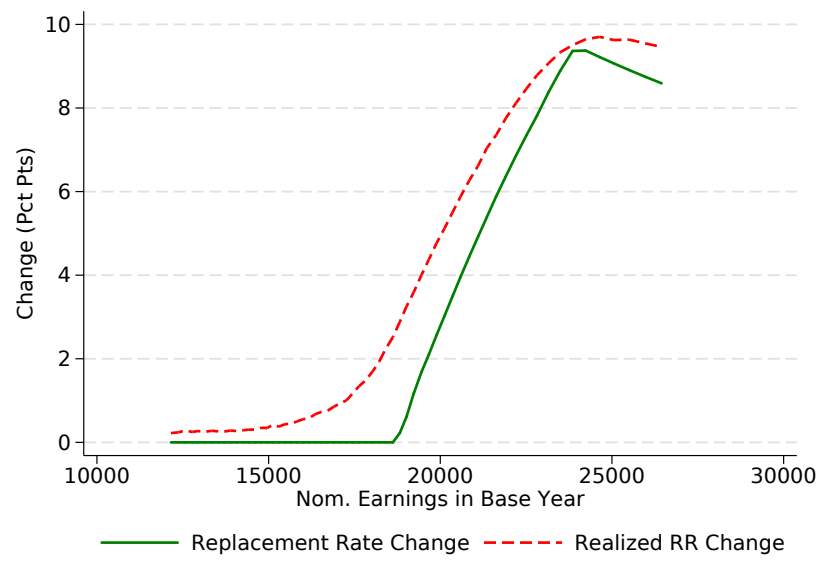

(f) Placebo 1983: 1980-2 vs. 1982-4; 2 Yr

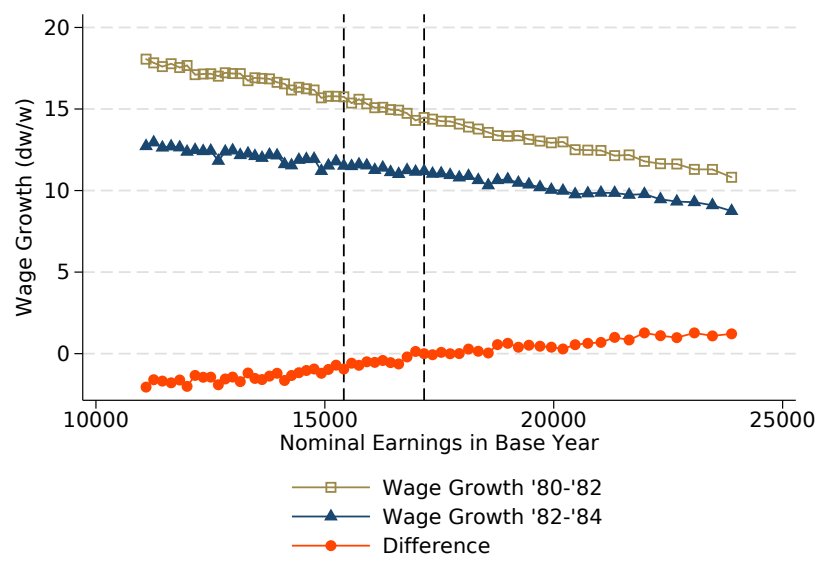

Note: The figure plots additional results related to the analysis in Figure 4(c). We provide a description at the beginning of this Appendix Section (B). 
Figure A.4: Additional Results: 1976 Reform

(a) Wage Growth: 1974-5 vs. 1975-6; 1 Yr

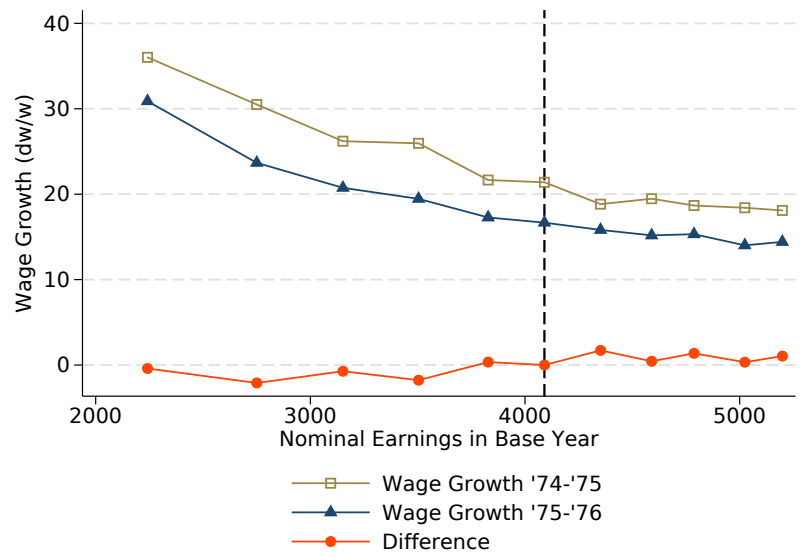

(c) Realized vs. Predicted Benefit Change; 1 Yr

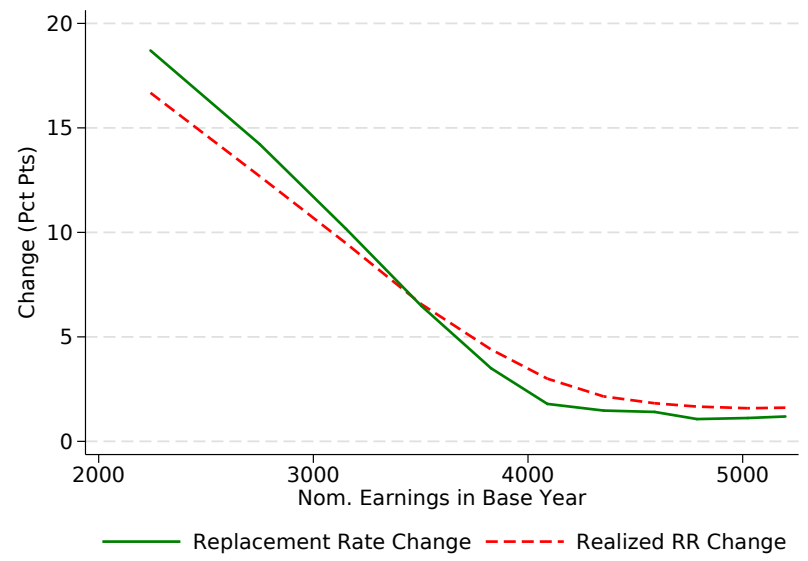

(b) Wage Growth: 1973-5 vs. 1975-7; 2 Yr

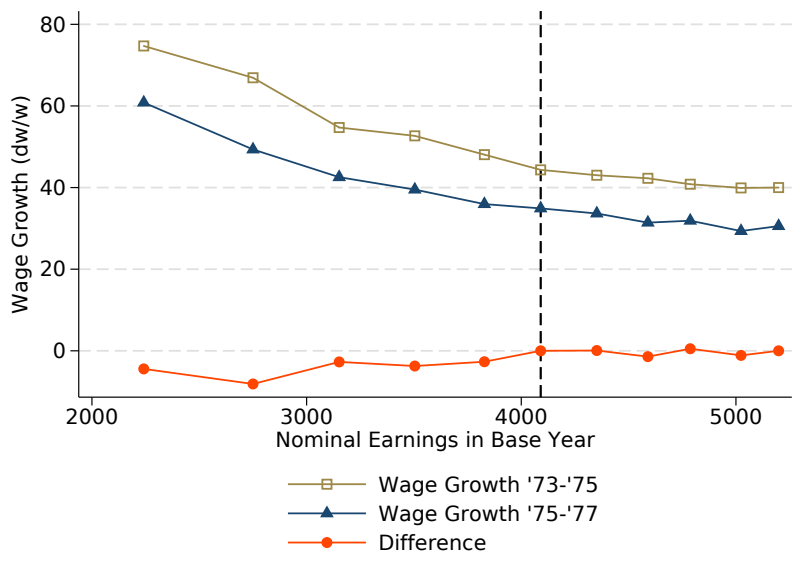

(d) Realized vs. Predicted Benefit Change; 2 Yr

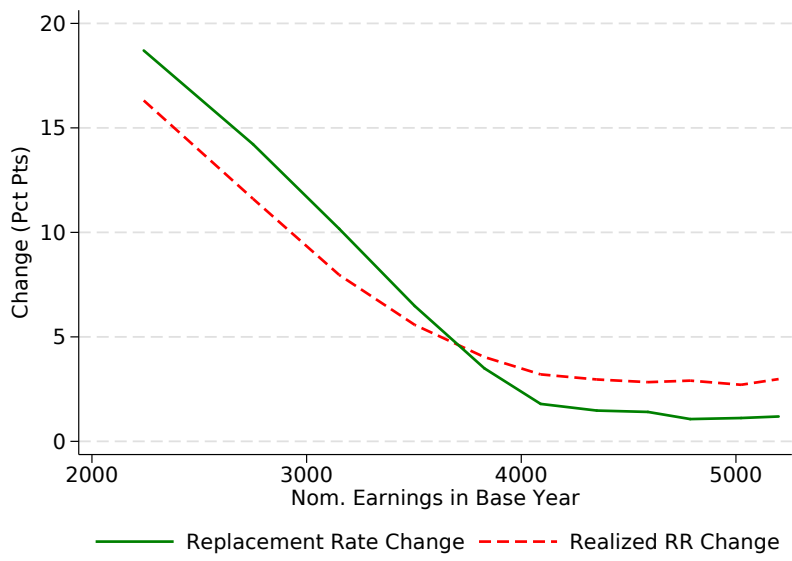

(e) Placebo 1975: 1973-4 vs. 1974-5; 1 Yr

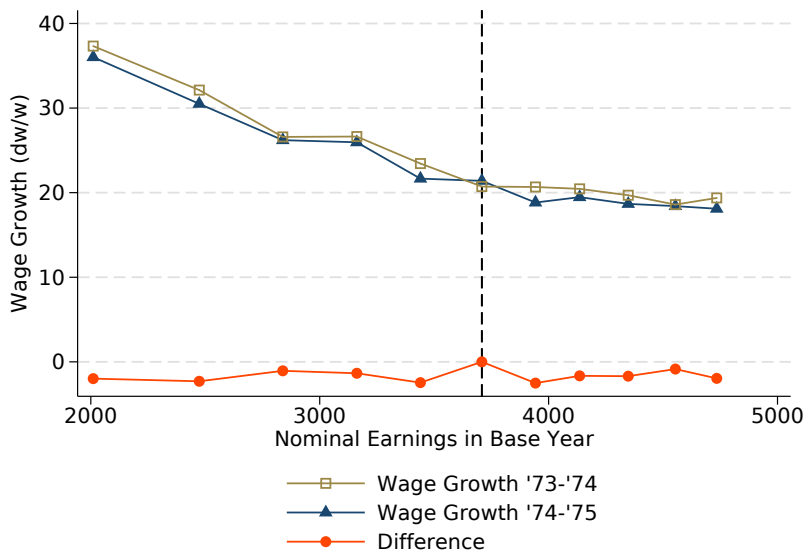

Note: The figure plots additional results related to the analysis in Figure 4(d). We provide a description at the beginning of this Appendix Section (B). 
Figure A.5: Pooled Earnings and Benefit Change Bin Scatter Plots - Placebo Years

\section{Year Fixed Effects}

(a) Year $e=-2$ Placebo Treatment Effects

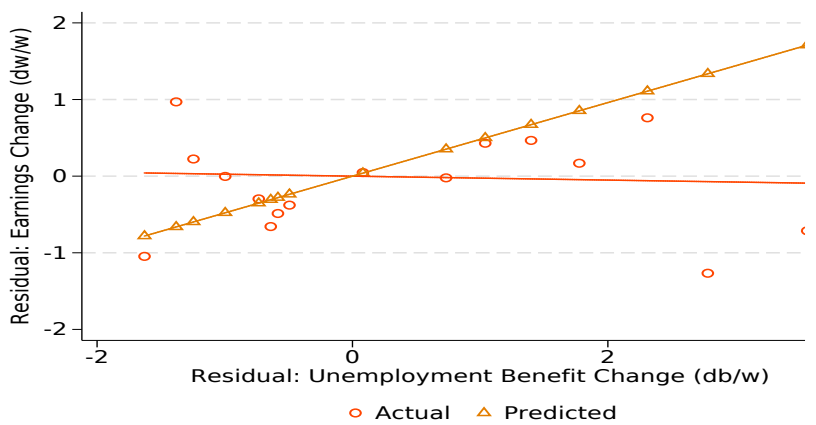

Slope: -0.026 (0.009) (b) Year $e=-3$ Placebo Treatment Effects

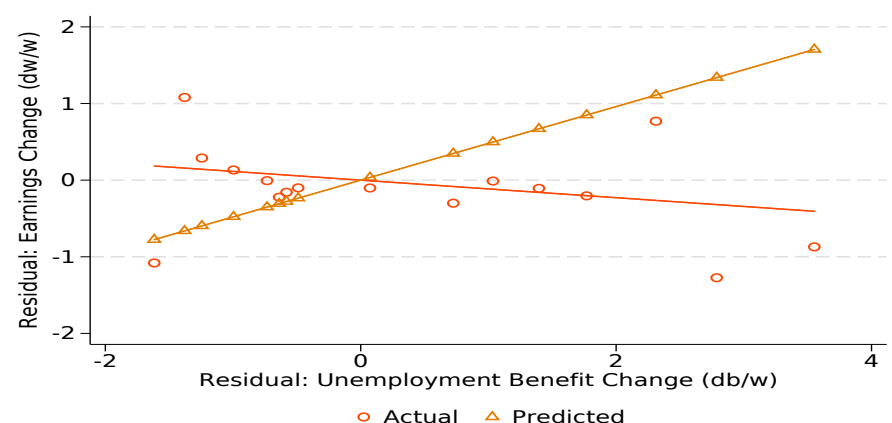

Slope: $-0.114(0.013)$

\section{Adding Earnings Percentile Fixed Effects}

(c) Year $e=-2$ Placebo Treatment Effects

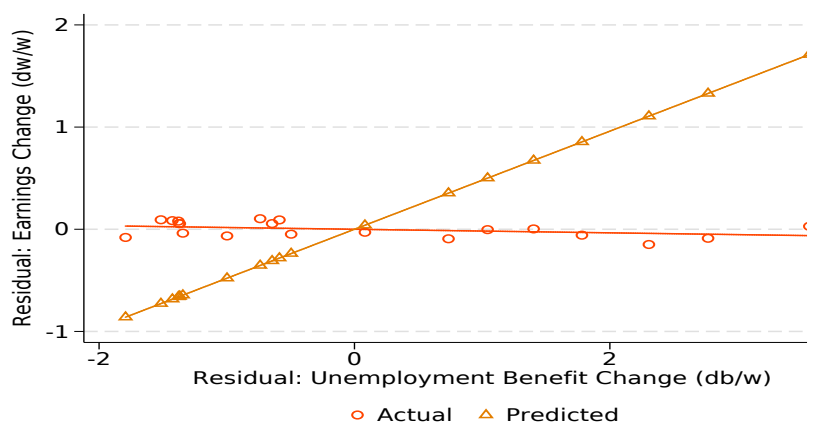

Slope: $-0.018(0.010)$ (d) Year $e=-3$ Placebo Treatment Effects

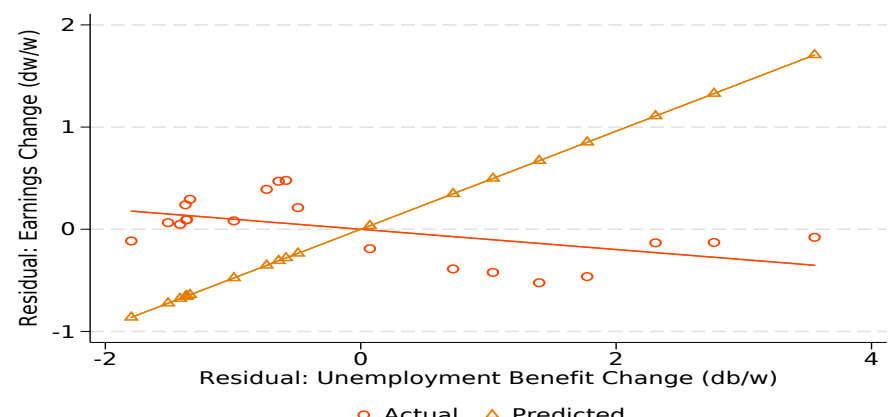

Slope: -0.099 (0.014)

\section{Adding Year-Specific Log Earnings Controls}

(e) Year $e=-2$ Placebo Treatment Effects

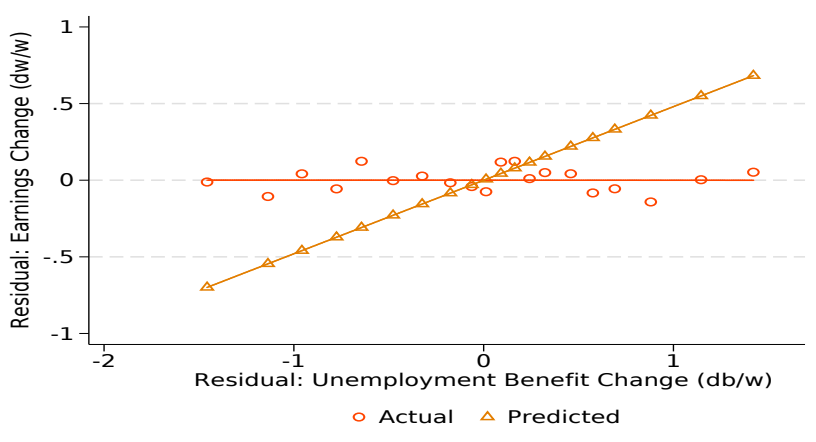

Slope: -0.001 (0.014), See Table 3, column (1), Row 2 (f) Year $e=-3$ Placebo Treatment Effects

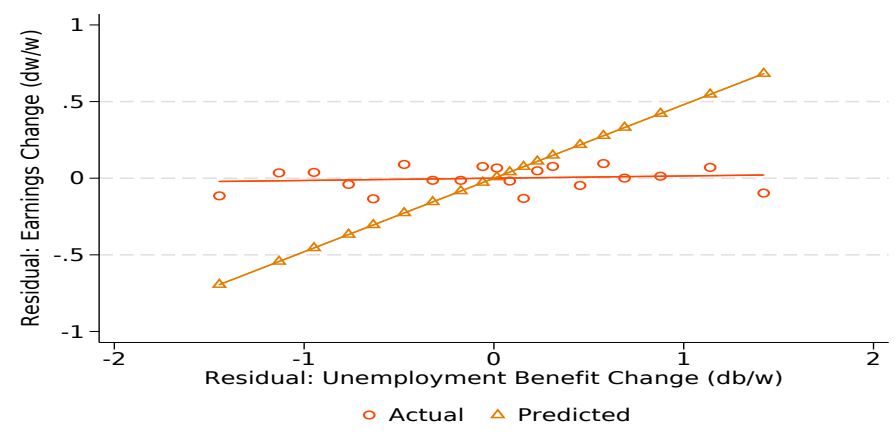

Slope: 0.016 (0.017), See Table 3, column (1), Row 1

Note: The six panels show the best-fit lines and binned scatter plots from estimating Equation 19 with a limited set of controls for the pooled sample of all four reforms. The best-fit line slope and standard errors are the coefficient and standard error on $\sigma_{-2}$ and $\sigma_{-3}$ in Equation 19. The binned scatter plot is estimated on earnings changes and reform induced benefit changes both residualized by the other included controls. 
Figure A.6: Robustness Check: Different Levels of Clustering

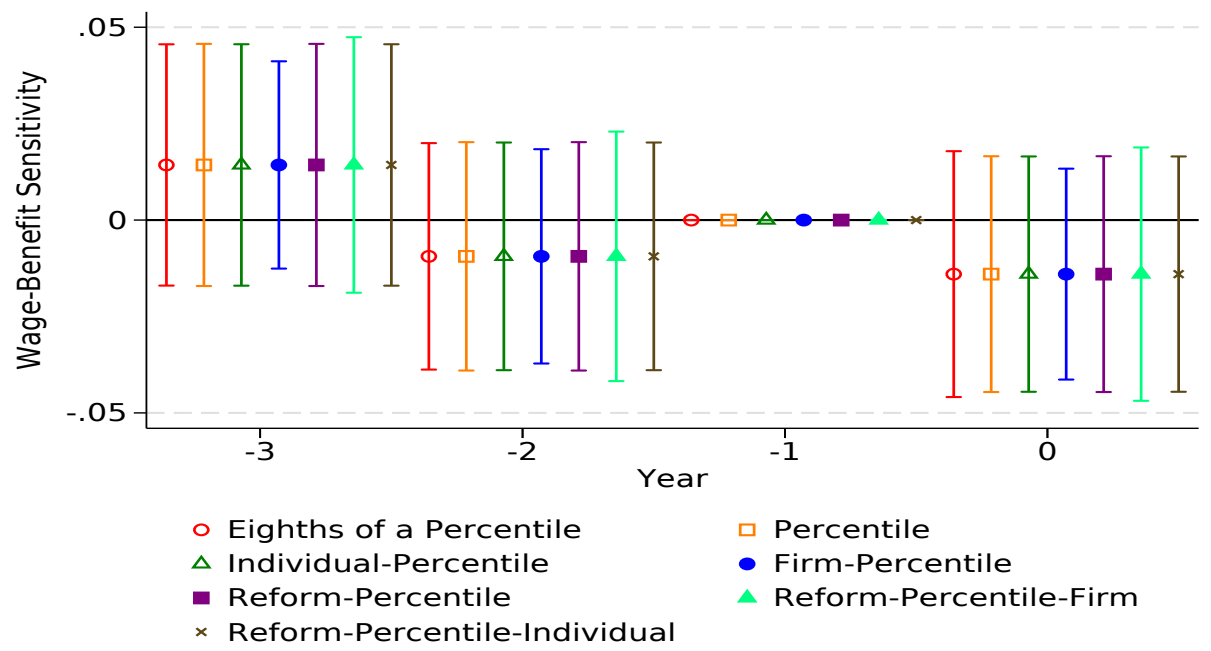

Note: The figure plots estimated $\delta_{0}$ coefficients and associated confidence intervals based on the differencein-differences specification in (19). It estimates specification (4) reported in Table 3 but changes the level of clustering used to calculate the standard errors. We calculate clustering based on: (1) the eighths of a percentile level, (2) percentile level, (3) two-way clustering at the individual and percentile level, (4) two-way clustering at the firm and percentile level, (5) clustering at reform-specific percentile, (6) two-way clustering at the reform-specific percentile and firm level, and (7) two-way clustering at the reform-specific percentile and individual level. Reform-specific percentiles are calculated as percentiles separately for each reform sample.

Figure A.7: Robustness Check: Outcome Variable Winsorization

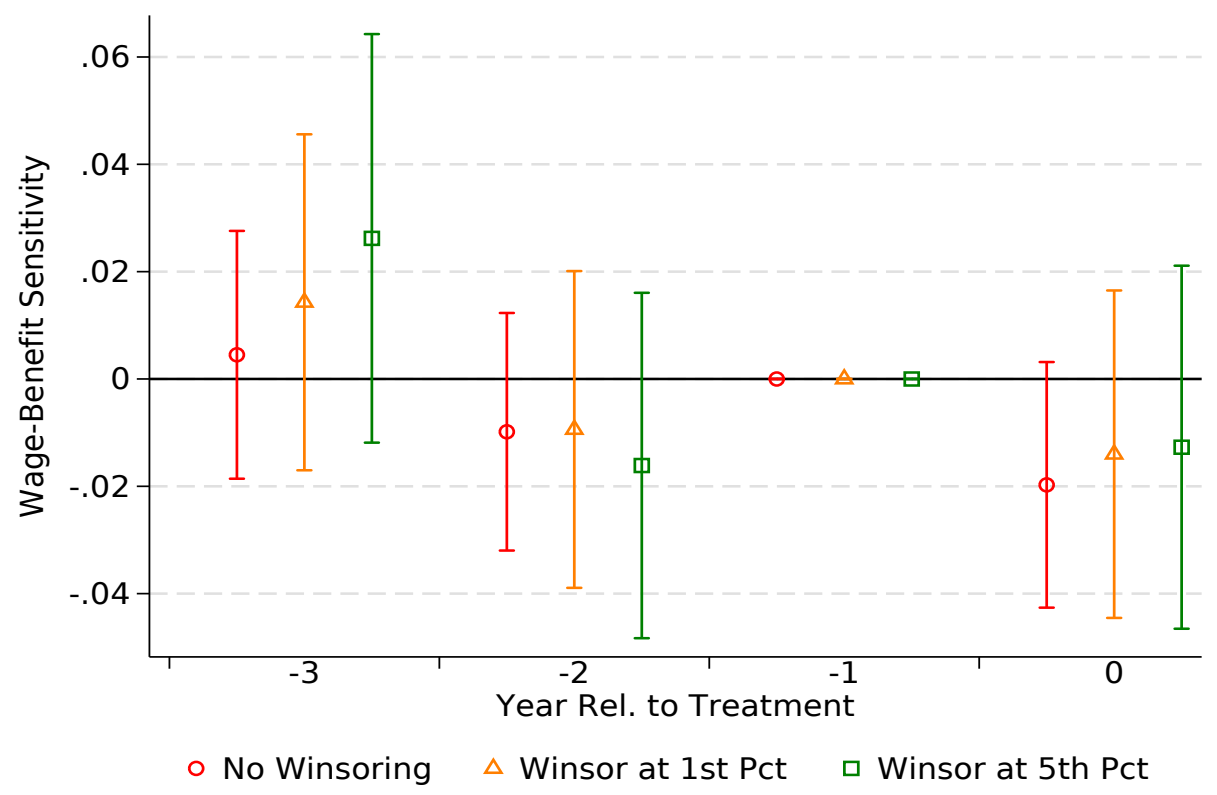

Note: The figure plots estimated $\delta_{0}$ coefficients and associated confidence intervals based on the difference-indifferences specification in (19). It estimates specification (4) reported in Table 3 but the level of winsorization we use for the outcome variables varies across specifications. 
Figure A.8: Robustness Check: Different Parametric Earnings Controls

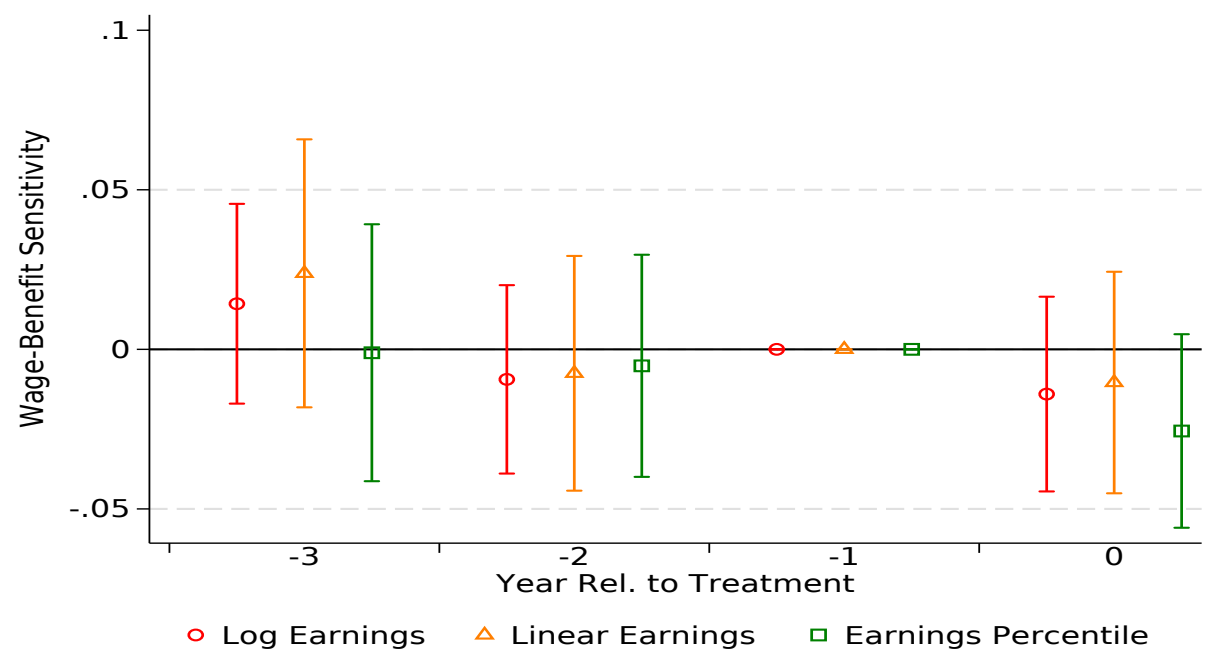

Note: The figure plots estimated $\delta_{0}$ coefficients and associated confidence intervals based on the difference-indifferences specification in (19). It estimates specification (4) reported in Table 3 but changes the year-specific parametric earnings controls used. The red estimates controls for log earnings, the yellow estimates controls for earnings linearly, and the green estimates control linearly for earnings percentiles.

Figure A.9: Robustness of Wage-Benefit Sensitivity Estimate to Dropping Observations near Treatment/Control Cutoff ("Donut Hole" Specification)

\section{Dropping Fixed Nominal Ranges}

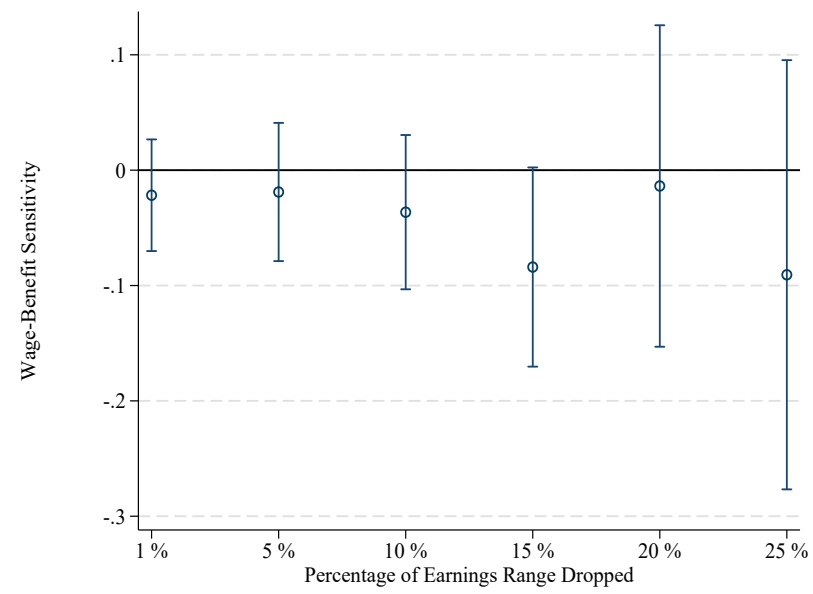

Dropping Fixed Percentile Ranges

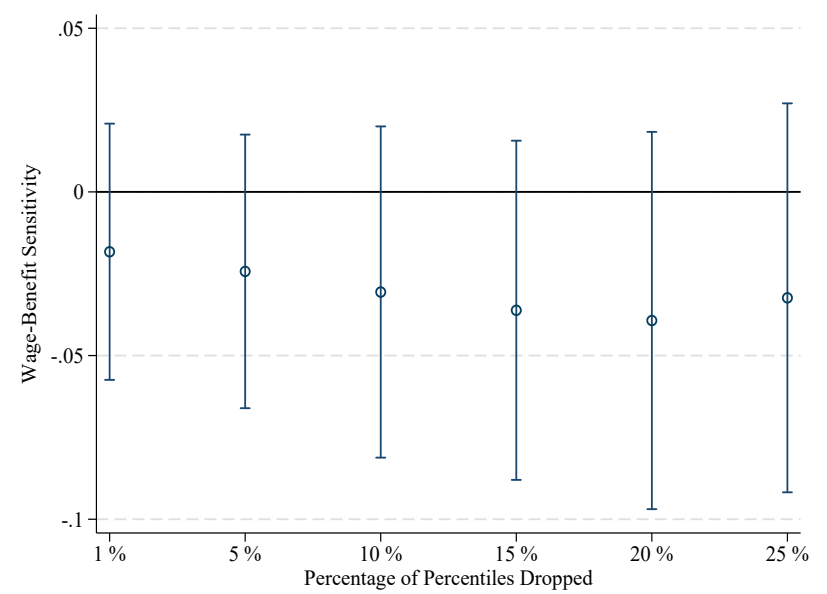

Note: These figures show $\sigma_{0}$ estimates from estimating Equation (19) but restricting the sample to not include treated and control individuals close to the treatment cutoff. The estimates are from specification (4) in Table 3. The left panel presents estimates where starting from the treatment/control cutoff earnings value, we drop a fixed percent of the nominal earnings ranges in the treatment and control groups. The right panel presents estimates where starting from the treatment/control cutoff earnings value, we drop a fixed percent of the earnings percentiles in the treatment and control groups. 
Figure A.10: Beliefs About UI Benefit Levels Among Employed Workers

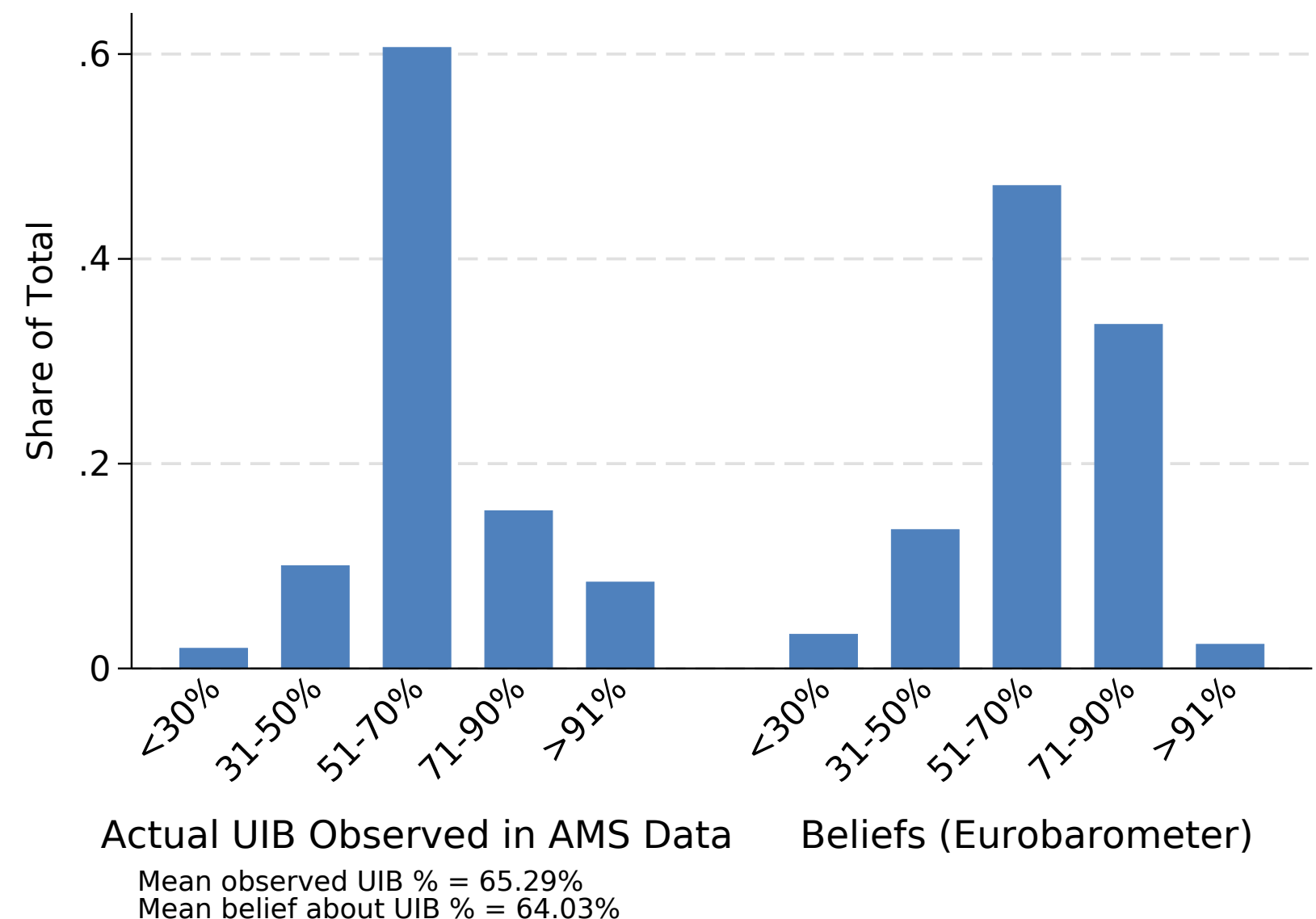

Note: The figure shows worker beliefs about unemployment benefits based on representative Eurobarometer 2006 data for Austria and compares it to data on actually paid out benefits among unemployed workers in 2006 based on AMS data. The Eurobarometer 2006 wave asked 568 employed respondents the following question: "Suppose you are laid off, what is your belief about the percentage of your current income that would be replaced through unemployment insurance and the Austrian social security system in the first six months?" The answer categories are 91 to $100 \%, 71$ to $90 \%, 51$ to $70 \%, 31$ to $50 \%$, less than $30 \%$, and a category for those who do not know. $90.1 \%$ of respondents provide a quantitative answer. The figure presents the distribution of actual benefits as a percent of net earnings and individuals' beliefs about their benefits. We bin the actual benefit ratios into the same interval bins that were presented in the Eurobarometer survey. To extract the mean response, we use an interval regression and find a mean of $64.03 \%$ (SE 0.72). We also report the actual replacement rate of unemployed workers in 2006 based on AMS data and find a mean of $65.29 \%$. 
Table A.4: 1 (Mth UI >0| Mth NE >0) ×100

\begin{tabular}{|c|c|c|c|c|c|c|}
\hline & $(1)$ & $(2)$ & $(3)$ & $(4)$ & $(5)$ & $(6)$ \\
\hline & \multicolumn{6}{|c|}{ Panel A: UI Takeup, 1 Year Ahead $(100 *$ Indicator $)$} \\
\hline Placebo: 3 Yr Lag & $\begin{array}{l}-0.090 \\
(0.110)\end{array}$ & $\begin{array}{l}-0.055 \\
(0.114)\end{array}$ & $\begin{array}{l}-0.119 \\
(0.109)\end{array}$ & $\begin{array}{l}-0.113 \\
(0.111)\end{array}$ & $\begin{array}{c}0.018 \\
(0.129)\end{array}$ & $\begin{array}{c}0.030 \\
(0.133)\end{array}$ \\
\hline Placebo: 2 Yr Lag & $\begin{array}{l}-0.200 \\
(0.114)\end{array}$ & $\begin{array}{l}-0.108 \\
(0.111)\end{array}$ & $\begin{array}{l}-0.143 \\
(0.101)\end{array}$ & $\begin{array}{l}-0.104 \\
(0.097)\end{array}$ & $\begin{array}{l}-0.129 \\
(0.114)\end{array}$ & $\begin{array}{l}-0.086 \\
(0.115)\end{array}$ \\
\hline Treatment Year & $\begin{array}{c}0.042 \\
(0.115)\end{array}$ & $\begin{array}{c}0.127 \\
(0.109)\end{array}$ & $\begin{array}{c}0.094 \\
(0.110)\end{array}$ & $\begin{array}{c}0.128 \\
(0.106)\end{array}$ & $\begin{array}{c}0.207 \\
(0.122)\end{array}$ & $\begin{array}{c}0.241 \\
(0.123)\end{array}$ \\
\hline Pre-p F-test p-val & 0.203 & 0.614 & 0.360 & 0.518 & 0.469 & 0.665 \\
\hline $\begin{array}{l}R^{2} \\
N(1000 \mathrm{~s})\end{array}$ & $\begin{array}{c}0.031 \\
910\end{array}$ & $\begin{array}{c}0.071 \\
910\end{array}$ & $\begin{array}{c}0.124 \\
908\end{array}$ & $\begin{array}{c}0.148 \\
908\end{array}$ & $\begin{array}{c}0.418 \\
609\end{array}$ & $\begin{array}{c}0.437 \\
608\end{array}$ \\
\hline & \multicolumn{6}{|c|}{ Panel B: UI Takeup, 2 Year Ahead (100* Indicator) } \\
\hline Placebo: 3 Yr Lag & $\begin{array}{l}-0.031 \\
(0.078)\end{array}$ & $\begin{array}{c}-0.026 \\
(0.084)\end{array}$ & $\begin{array}{l}-0.054 \\
(0.082)\end{array}$ & $\begin{array}{l}-0.060 \\
(0.085)\end{array}$ & $\begin{array}{c}0.066 \\
(0.097)\end{array}$ & $\begin{array}{c}0.044 \\
(0.096)\end{array}$ \\
\hline Treatment Year & $\begin{array}{c}0.145 \\
(0.081)\end{array}$ & $\begin{array}{c}0.124 \\
(0.083)\end{array}$ & $\begin{array}{c}0.163 \\
(0.081)\end{array}$ & $\begin{array}{c}0.138 \\
(0.081)\end{array}$ & $\begin{array}{c}0.221 \\
(0.085)\end{array}$ & $\begin{array}{c}0.198 \\
(0.086)\end{array}$ \\
\hline$\overline{\text { Pre-p F-test p-val }}$ & 0.696 & 0.753 & 0.511 & 0.485 & 0.501 & 0.646 \\
\hline$R^{2}$ & 0.032 & 0.074 & 0.124 & 0.147 & 0.386 & 0.404 \\
\hline$N(1000 \mathrm{~s})$ & 1127 & 1127 & 1126 & 1126 & 820 & 819 \\
\hline Mincerian Ctrls & & $\mathrm{X}$ & & $\mathrm{X}$ & & $\mathrm{X}$ \\
\hline 4-Digit Ind.-Occ. FEs & & & $\mathrm{X}$ & $\mathrm{X}$ & & $\mathrm{X}$ \\
\hline Firm-Year FEs & & & & & $\mathrm{X}$ & $\mathrm{X}$ \\
\hline
\end{tabular}

Note. We evaluate the effect of four reforms to the Austrian unemployment insurance benefit schedule on the take-up of UI. In particular, we begin with the months on UI in year $t+1$ or $t+2$ (as a share of total months), which appears in Appendix Figure A.14, and indicate if there are nonzero months on UI and nonzero months nonemployed. This indicator is missing if the individual has no months nonemployed in year $t+1$ or $t+2$, in order to isolate take up. The outcome complements the analysis fo the effect on months on UI observed in Appendix Figure A.14 (separation effects). This indicator is multiplied by 100 for legibility. Errors are two-way clustered at the individual- and percentile-level. 
Figure A.11: Distribution of Benefit Changes at the Firm and Industry-by-Occupation Level

(a) Firm Level

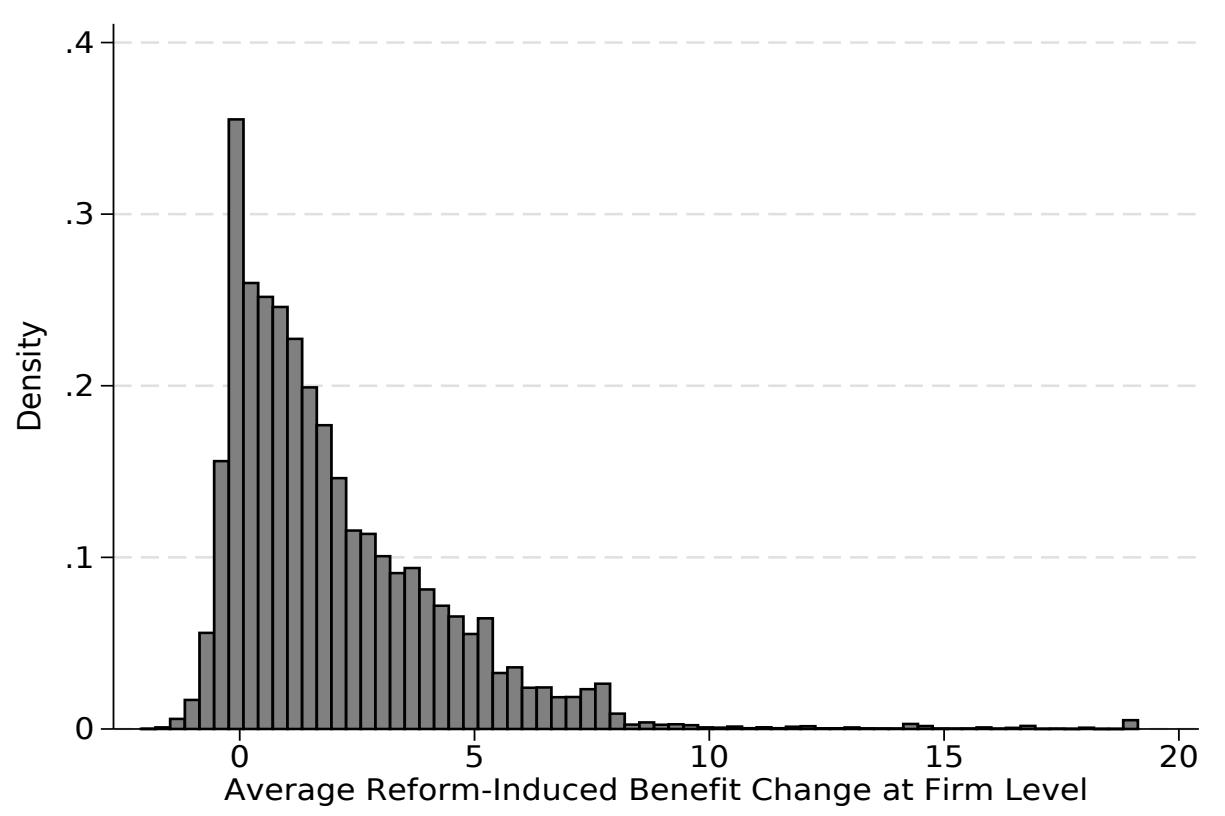

(b) Industry-by-Occupation Level

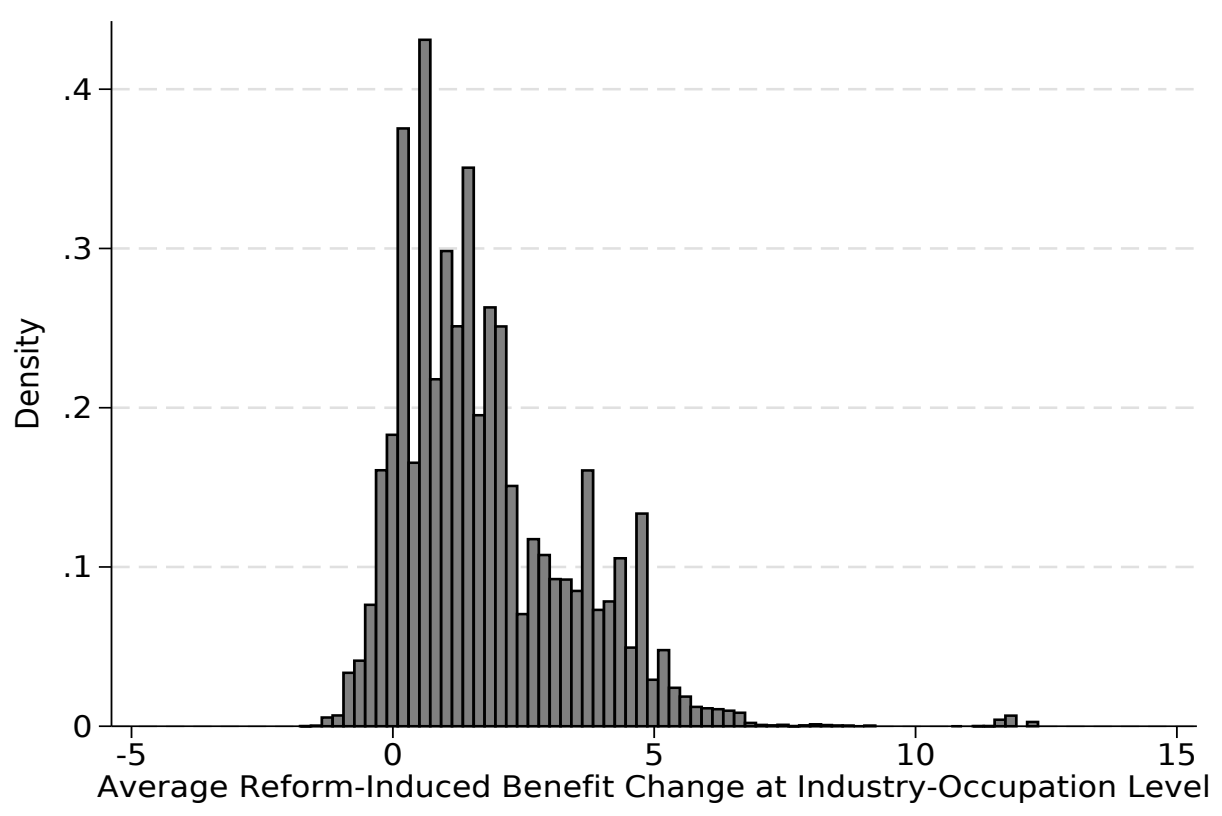

Note: The figure plots the distribution of the average reform-induced benefit change aggregated at the firm and industry-by-occupation level. 


\section{Measuring Fraction of Time on UI, and Calibrating the Wage-Benefit Sensitivity}

Here we describe the measurement of the share of time spent in the various labor market states and the implied wage-benefit sensitivity.

Separator Sample We measure subsequent time spent in different labor market states conditional on an employment to nonemployment separation. We start with our regression sample of workers, described in Section 4.1. Although the sample of workers is the same as for our main analysis, for the $\tau$ calculations we use data with labor market states recorded at the daily rather than monthly level. This allows for more precise measurement of the time spent in each labor market state.

We then define separators in each year $t$ as individuals who separate from employment into nonemployment for at least one day in the next year $t+1$. Importantly, we do not impose that the separator ever take up UI during nonemployment. In our baseline specification, we do not require the separators ever return to employment. In alternate, more realistic, specifications, we require that the separators have at least one subsequent employment spell in the next four years. This restriction drops emigrants or other permanent labor force exits.

Labor Market States For these separators, we count the fraction of time spent in the following three exhaustive labor market states:

$\tau^{E}$ : Employment - includes dependent employment (i.e. wage and salary work), minor employment, self-employment, civil servants/military/civil service, maternity/parental leave associated with a firm, and sick leave associated with a firm.

$\tau^{U}$ : UI-Affected Nonemployment For measuring $\tau^{U}$, "UI" encompasses both UA and UI.

$\tau^{U: U I}:$ Unemployment Insurance

$\tau^{U: U A}$ : Unemployment Assistance - Notstandshilfe, which is indexed nearly one-to-one to individual-level unemployment insurance and hence affected by the reform-induced UIB changes we study.

$\tau^{O}$ : Other Nonemployment - includes any other recorded ASSD spell statuses ${ }^{43}$ and other missing labor market states not recorded in the ASSD. ${ }^{44}$

For overlapping spells in the ASSD, we prioritize spells based on the following ordering $U I \succ$ $U A \succ$ Employment $\succ$ Non-UI Employment. For example, if on one day an individual has a UI and an employment spell, the day would be counted towards UI.

\footnotetext{
${ }^{43}$ Retirement and disability cover almost half of all reported non-UI nonemployment. Around a quarter is potentially spuriously reported social security payments without employer information. Another important category is registered job search (yet without UI receipt) - which in the literature is often counted as unemployment due to its search connotation, yet which we here carefully count as non-UI nonemployment.

${ }^{44}$ For example, if individuals emigrate from Austria their labor market states are not recorded in the ASSD.
} 
Time Horizons After Separation To calibrate $\tau$, we exploit the fact that the discount rate $\rho$ is negligible compared to the job finding and separation rates $(f$ and $\delta) . \tau^{E}, \tau^{U}$, and $\tau^{O}$ thus correspond to the share of time separators spend in each respective labor market state. Since our model has infinitely lived agents, we approximate these measures by counting for a "long time."

In our baseline specification, we stop counting labor market states (in both the numerator and denominator of the "share of time" calculation) at the earliest of 16 years post-separation or an individual's death. We stop at 16 years because it is the longest horizon we can study for all of our reforms (the latest of which is in 2001 and our data end in 2018). This variant is most conservative with respect to the wage-benefit sensitivity because it assumes that events such as retirement occur unexpectedly and hence essentially generate a state that is non-UI nonemployment but is still accounted for in the "denominator" of the fraction. We then add more realistic variants where we "stop the clock" earlier when an individual reaches

1. Absorbing Retirement: earliest of 16 years post-separation, death, or absorbing retirement. Absorbing retirement is entering retirement and never subsequently becoming employed or taking up UI.

2. Absorbing Retirement or Disability earliest of 16 years post-separation, death, absorbing retirement, or absorbing disability (defined analogously to absorbing retirement). ${ }^{45}$

Actual Share of Time Spent in Labor Market States Panel A of Appendix Table A.5 presents the average fraction of post-separation time in different labor market states for the restricted sample of separators. Columns (1) and (2) stop counting after either absorbing retirement or absorbing disability. Columns (3) and (4) stop counting after absorbing retirement. Columns (5) and (6) simply stop counting at 16 years or death. The even columns include no reemployment restrictions and the odd columns add the reemployed in four year restriction. Adding more conservative restrictions reduces the share of time spent in other nonemployment, $\tau^{O}$, but keeps the relevant share of time affected by UI, $\tau^{U}$, relatively constant.

Panel B of Appendix Table A.5 presents the average fraction of time spent in different labor market states for the entire regression sample, not conditioning on a separation. ${ }^{46}$ There are three reasons why the share of time spent on UI and UA are lower for this sample than the separator sample. First, the separation induces a nonemployment spell, whereas most of our full sample will not initially separate. Since Panel A conditions on a separation and we can only measure outcomes for a finite amount of time, the separator sample will by design have a higher share of time spent nonemployed. Second, the separation from employment may raise individuals' future separation rates (or lower job finding rates). Third, there may be compositional differences between individuals more or less likely to separate. We account for this below by adjusting the predicted $\tau$ estimates based on observables.

Predicting the Wage-Benefit Sensitivity We then assign each worker in our regression sample (whether she separates or not) a predicted $\hat{\tau}_{i}$. Since many of these workers will not separate, we construct these predicted values in order to account for compositional differences

\footnotetext{
${ }^{45}$ Over $90 \%$ of retirement and disability spells are "absorbing."

${ }^{46}$ Here there is no need to impose a 4-year reemployment restriction because all individuals in the sample are initially employed, so the only worker we would drop with the restriction is one that separates into permanent nonemployment on January 2nd for the next 4 years.
} 
between the regression sample and the separator sample in our $\tau$ calibrations. Our prediction model is an OLS regression of the separators' actual fraction of time spent in each state on the following predictors $\mathbf{x}_{i}$ :

- 4-digit-industry by occupation (blue/white collar) FE

- Fixed effects for tenure categories in 3-year steps up to 15 years (cutoffs 2, 5, 8, 11, 14)

- Fixed effects for experience categories in 5-year steps up to 25 years (cutoffs: 5, 10, 15, 20)

- Fixed effects for age categories in 5-year steps (cutoffs 29, 34, 39, 44, 49)

- Region of establishment FE (3-digit NUTS)

- Gender FE

- 6 categories of months since UI: 1 for the censored value, then year-specific quintiles

- Reform-Year FE

For our preferred specification, column (1) in Table 1 and in Appendix Table A.5, the $R^{2}$ for this prediction exercise is 0.09 . We then use the model coefficients on the $\mathbf{x s}$ to predict individual-level $\tau^{U}, \tau^{E}$, and $\tau^{O}$ for each individual in our regression sample.

Average Predicted Share of Time Spent in Labor Market States The first five rows in Table 1 present the average predicted $\hat{\tau}_{i}$ values across the entire regression sample. The six columns present the same specifications as in Appendix Table A.5. Compared to the average $\tau_{i}$ values just for the sample of actual separators in Appendix Table A.5, the average predicted $\hat{\tau}_{i}$ values across the entire sample in Table 1 are slightly larger for UI affected nonemployment and other nonemployment and correspondingly smaller for employment. These differences are consistent with the actual separators having characteristics associated with higher future separation rates. Yet, across the two groups, the $\tau$ averages are qualitatively quite similar.

Calibrating the Wage-Benefit Sensitivity Besides reporting the underlying $\tau$ values by state, we also report the implied wage-benefit sensitivities. We report the sensitivities from our baseline two-state model (described in Section 2.1) and the extended three-state model (described in Appendix Section D). In both versions, we assume $\phi=0.1$.

We construct the sensitivities in two different ways:

1. Individual-level $\hat{\tau}_{i}$ values, $\mathrm{E}\left[d w / d b\left(\hat{\tau}_{i}\right)\right]$ : Here we plug in the individual-level $\hat{\tau}_{i}$ values into the the two- and three-state wage-benefit sensitivity expressions and take averages over these individual-level wage benefit sensitivities. Since the wage-benefit sensitivity is a non-linear function of $\hat{\tau}_{i}$, this respects Jensen's Inequality. Additionally, for the three-state model where the wage-benefit sensitivity depends on $\hat{\tau}_{i}^{U}$ and $\hat{\tau}_{i}^{O}$, this method takes into account the individual-level correlation between the two different predicted values.

2. Average $\hat{\tau}_{i}$ values, $E\left[d w / d b\left(E\left[\hat{\tau}_{i}\right]\right)\right]$ : Here we take the average $\mathrm{E}\left[\hat{\tau}_{i}\right]$ values presented in Table 1 . and plug them directly into the two- and three-state wage benefit sensitivities. 
The two- and three-state calibrated wage-benefit sensitivities constructed in both ways described above are presented in the bottom four rows of Table 1. Across the different specifications, the two-state model predicts a pass-through of 0.45 to 0.49 . Additionally, in our preferred specification, column (1), the difference between the individual- and average-level $\hat{\tau}_{i}$ constructions is around 0.02 percentage points. The three-state model predicts a qualitatively lower pass-through of between 0.17 to 0.24 . 
Table A.5: Actual Fraction of Post-Separation Time on UI $(\tau)$

\begin{tabular}{|c|c|c|c|c|c|c|}
\hline \multirow{2}{*}{$\begin{array}{l}\text { Time Restriction: } \\
\text { Reemployment Restriction: }\end{array}$} & \multicolumn{2}{|c|}{ Ret'nt or Disability } & \multicolumn{2}{|c|}{ Retirement } & \multicolumn{2}{|c|}{ No Restriction } \\
\hline & 4-Year & None & 4-Year & None & 4-Year & None \\
\hline & $(1)$ & $(2)$ & $(3)$ & $(4)$ & $(5)$ & $(6)$ \\
\hline \multicolumn{7}{|c|}{ Panel A: Separators } \\
\hline UI-Affected Nonemployment - $\tau^{U}$ & 0.116 & 0.115 & 0.110 & 0.107 & 0.109 & 0.104 \\
\hline Unemployment Insurance - $\tau^{U: U I}$ & 0.087 & 0.087 & 0.082 & 0.080 & 0.081 & 0.077 \\
\hline Unemployment Assistance - $\tau^{U: U A}$ & 0.028 & 0.027 & 0.028 & 0.027 & 0.028 & 0.027 \\
\hline Employment - $\tau^{E}$ & 0.703 & 0.627 & 0.681 & 0.608 & 0.672 & 0.600 \\
\hline Other Nonemployment $-\tau^{O}$ & 0.181 & 0.258 & 0.209 & 0.286 & 0.220 & 0.296 \\
\hline \multicolumn{7}{|c|}{ Panel B: Full Sample (Not Conditioning on Separation) } \\
\hline UI-Affected Nonemployment - $\tau^{U}$ & $\mathbf{N} / \mathbf{A}$ & 0.041 & $\mathrm{~N} / \mathrm{A}$ & 0.040 & $\mathrm{~N} / \mathrm{A}$ & 0.039 \\
\hline Unemployment Insurance - $\tau^{U: U I}$ & $\mathbf{N} / \mathbf{A}$ & 0.032 & $\mathrm{~N} / \mathrm{A}$ & 0.031 & $\mathrm{~N} / \mathrm{A}$ & 0.030 \\
\hline Unemployment Assistance - $\tau^{U: U A}$ & $\mathbf{N} / \mathbf{A}$ & 0.009 & $\mathrm{~N} / \mathrm{A}$ & 0.009 & $\mathrm{~N} / \mathrm{A}$ & 0.009 \\
\hline Employment - $\tau^{E}$ & $\mathbf{N} / \mathbf{A}$ & 0.826 & $\mathrm{~N} / \mathrm{A}$ & 0.791 & $\mathrm{~N} / \mathrm{A}$ & 0.758 \\
\hline Other Nonemployment - $\tau^{O}$ & $\mathbf{N} / \mathbf{A}$ & 0.133 & $\mathrm{~N} / \mathrm{A}$ & 0.169 & $\mathrm{~N} / \mathrm{A}$ & 0.203 \\
\hline
\end{tabular}

Note: The five rows in Panel A and B present estimates of the fraction of time that individuals in our sample spend on unemployment insurance $\hat{\tau}^{U: U I}$, on unemployment assistance $\hat{\tau}^{U: U A}$, which we pool into a single $U I$ affected state $\hat{\tau}^{U}$ (the sum of $\hat{\tau}^{U: U I}$ and $\hat{\tau}^{U: U A}$, where unemployment assistance is included because it is indexed nearly one-for-one with UI, and we refer to "UI" in the text as encompassing both), employed $\hat{\tau}^{E}$, and in other nonemployment $\hat{\tau}^{O}$. The estimates here differ Table 1 because they are the actual fraction of time spent in each state rather than the predicted fraction of time for separators (Panel A), and for the full sample (unconditionally on a separation, Panel B). Panel A shows the fraction of time for actual separators and Panel B shows the fraction of time for the entire analysis sample. For the entire sample, we start counting future states in January of each year and do not need to add any reemployment restriction. The $\tau$ values for our preferred specification, column (1), are calculated as follows. We stop including labor market states in this share at the earliest of 16 years, reaching age 70, death, or absorbing retirement or disability (defined as entering retirement or disability and without any subsequent employment or UI/UA spells within the 16 year horizon). Columns (3) and (4) also stop counting at absorbing retirement but not disability, and columns (5) and (6) stop counting labor market states only at the earliest of 16 years or age 70 . The reemployment-restriction columns (1), (3) and (5) require that individuals in the separator sample return to re-employment (at any job) sometime in the next four years (for at least one day). 


\section{Accounting For Nonemployment Without UI Receipt: Three-State Model}

Our model in the main text in Section 2 considers a two-state model of employment and UIyielding nonemployment. We now consider a general case by which workers' nonemployment spell can consist of nonemployment with UI and without UI receipt. The setup can be interpreted to capture a series of specific institutional features such as limited take-up, finite potential benefit duration, or wait periods. We consider a series of such more specific cases in Appendix Section E.1.

The value of nonemployment continues to be denoted by value $N$. While nonemployed, the worker loops through states UI (value $U$ and instaneneous payoff $z^{U}(b)$ ), and other nonemployment (value $O$ with instantaneous payoff $z^{O}$ ). Transitions from state $s$ to $s^{\prime}$ are described by Markov process $x^{s \rightarrow s^{\prime}}$. We set $x^{O \rightarrow E}=x^{U \rightarrow E}=f$ and $x^{E \rightarrow N}=\delta$. When separating, due to a exogenous separation shock $\delta$ or due to the worker taking up the nonemployment outside option in bargaining, fraction $v$ workers start in UI, whereas fraction $1-v$ start in non-UI nonemployment. ${ }^{47}$

The associated value functions are defined as follows:

$$
\begin{aligned}
\rho E & =w+\delta(N-E) \\
N & =v U+(1-v) O \\
\rho U & =z^{U}(b)+f(E-U)+x^{U \rightarrow O}(O-U) \\
\rho O & =z^{O}+f(E-O)+x^{O \rightarrow U}(U-O)
\end{aligned}
$$

The flow value of nonemployment can then be reformulated as a weighted average of the instantaneous payoffs in each state, analogously to our baseline two-state expression (3) yet augmented with the third state of non-UI nonemployment:

$$
\rho N=\tau^{U} z^{U}(b)+\tau^{O} z^{O}+\tau^{E} w^{\prime}
$$

where $\tau^{E}=1-\tau^{U}-\tau^{O}$. Concretely in terms of transition rates and the discount factor, the $\tau^{s}$ weights are:

$$
\begin{aligned}
\tau^{E} & =\underbrace{\frac{f}{\delta+f+\rho}}_{=1-\tau^{N}} \\
\tau^{U} & =\underbrace{\frac{\delta+\rho}{\delta+f+\rho}}_{\tau^{N}} \cdot[\underbrace{\left[\frac{(1-\nu) x^{O \rightarrow U}}{x^{O \rightarrow U}+x^{U \rightarrow O}+f+\rho}+\frac{\nu\left(x^{O \rightarrow U}+f+\rho\right)}{x^{O \rightarrow U}+x^{U \rightarrow O}+f+\rho}\right]}_{\alpha} \\
\tau^{O} & =\underbrace{\frac{\delta+\rho}{\delta+f+\rho}}_{\tau^{N}} \cdot \underbrace{\left[\frac{(1-\nu)\left(x^{U \rightarrow O}+f+\rho\right)}{x^{O \rightarrow U}+x^{U \rightarrow O}+f+\rho}+\frac{x^{U \rightarrow O} \nu}{x^{O \rightarrow U}+x^{U \rightarrow O}+f+\rho}\right]}_{1-\alpha}
\end{aligned}
$$

which we can separate into a series intuitive weights.

(i) $\tau^{E}=\frac{f}{\delta+f+\rho}$ is the (discount-rate-adjusted) time spent in employment. (ii) $\tau^{N}=\frac{\delta+\rho}{\delta+f+\rho}=$ $1-\tau^{E}$ is the (discount-rate-adjusted) time spent in nonemployment. Within the nonemployment

${ }^{47}$ This consideration eliminates the need to consider separate wages for eligible and ineligible workers. 
state, (iia) workers spend fraction $\alpha$ of nonemployment time receiving UI, and (iib) share $1-\alpha$ of time nonemployment not receiving $z^{U}(b)$ but instead $z^{O}$. There are various ways by which workers end up in a given nonemployment state. They either enter the state initially (and then stay, or move out but then back in). Or, they enter the state from the other nonemployment state (and then leave, but may re-enter).

The Nash wage bargain follows the same structure as in the two-state model, yet augmented with the third state in the outside option:

$$
\begin{aligned}
w & =\phi p+(1-\phi) \rho N \\
& =\phi p+(1-\phi) \cdot\left(\tau^{U} z^{U}(b)+\tau^{O} z^{O}+\tau^{E} w^{\prime}\right)
\end{aligned}
$$

As in the full model in Section 2.2, we assume that $\frac{d z^{U}(b)}{d b}=1$ which implies that the wage-benefit sensitivity is:

$$
\frac{d w}{d b}=(1-\phi)\left(\tau^{U}+\tau^{O} \frac{d z^{O}}{d b}+\tau^{E} \frac{d w^{\prime}}{d b}\right)
$$

which, if again using $\frac{d w^{\prime}}{d b}=\frac{d w}{d b}$, solves into:

$$
\frac{d w}{d b}=\frac{(1-\phi)\left(\tau^{U}+\tau^{O} \frac{d z^{O}}{d b}\right)}{1-(1-\phi) \tau^{E}}
$$

Maximal attenuation vis-à-vis the two-state model arises if payoff $z^{O}$ is insensitive to $b$, i.e. $\frac{d z^{O}}{d b}=0$ (assuming away the curious case of $\left.\frac{d z^{O}}{d b}<0\right)$ :

$$
\frac{d w}{d b}=\frac{(1-\phi) \tau^{U}}{1-(1-\phi) \tau^{E}}=\frac{(1-\phi) \tau^{U}}{1-(1-\phi)\left(1-\left(\tau^{U}+\tau^{O}\right)\right)}
$$

Here, the higher $\tau^{O}$, the less weight nonemployment value $N$ puts on $b$-sensitive payoffs $z^{U}(b)$ or $w^{\prime}$, thereby attenuating either the mechanical effect or the feedback effect in the wage-benefit sensitivity, or both. In our baseline two-state model in Section 2.1, we permitted only two states - nonemployment with UI receipt and employment, and therefore $1-\tau^{U}=\tau^{E}$, effectively assuming that $\tau^{O}=0$. We calibrated $\tau^{U}$ to the empirical share of post-separation time spent on UI - a number that carries over to the extended three-state model (i.e. $\tau^{U}=\tau$ ). In the extended three-state model, the implied time in reemployment $\tau^{E}=1-\tau^{U}-\tau^{O}$ therefore is the $\tau^{s}$ that is attenuated by measuring and including $\tau^{O}$.

Comparison to Baseline Two-State Model Our baseline two-state model assumed that $v=1$ and $x^{U \rightarrow O}=0$. This implies that $\tau^{O}=0, \alpha=1, \tau^{N}=\tau^{U}$, and $\tau^{E}=1-\tau^{U}$.

Extensions Alternative setups are conceivable. A interesting setup we side-step above is one by which outside options are differentiated by eligibility status, which in turn may evolve while employed. Another setup would have workers be permanently, or expectedly, eligible or ineligible, with this status known to the bargaining parties. We cannot credibly differentiate these alternatives in the data. 
Calibrating the Wage-Benefit Expression in the Presence of Non-UI Nonemployment Table 1 presents estimates of the wage-benefit passthrough in expression A14 calibrated based on our estimates of $\tau^{U}$ and $\tau^{O}$. In our preferred specification, column (1), the estimated wage-benefit sensitivity from the three-state model is 0.24 , compared to $0.46-0.48$ in the two-state variant. See Appendix Section C for more details about the three-state model calibration. 


\section{E Additional Theoretical Material}

\section{E.1 Additional Model Variants}

Next, we show that the key prediction from the benchmark model carries over to a wide variety of richer models considered in the literature. In Section 2.3 we additionally discuss alternative models that insulate wages from the nonemployment value, and which may therefore rationalize the zero effect of $b$ on $w$ that we document in the empirical Section 4.

I. Equilibrium Adjustment: DMP Model Together, our difference-in-differences design and theoretical framework aim to isolate the micro effects of an idiosyncratic shift in the outside option on wages, holding constant (or netting out with a control group) market-level adjustment. Yet, we cannot definitely empirically rule out the concern that experimental groups populate segmented - rather than roughly the same - labor markets. Our treatment effect would then capture "macro" effects. Next, we derive this macro wage-benefit sensitivity explicitly with equilibrium adjustment in the context of a calibrated DMP model. We show that the magnitude and structure of the micro and macro sensitivities are strikingly similar quantitatively and structurally. We conclude that market-level spillovers cannot explain small zero wage-benefit sensitivities.

The canonical DMP Nash wage replaces the continuation term of the worker with an equilibrium value related to labor market tightness $\theta=v / u$, the ratio of vacancies $v$ to unemployment $u):^{48}$

$$
w^{\mathrm{DMP}}=\phi p+\overbrace{(1-\phi) b+\phi \theta k}^{=(1-\phi) \rho N}
$$

With a market-wide increase in benefits, the capital gain continuation term of $\rho N$ is pinned down by firm's free entry, such that the wage comovement is described by:

$$
d w^{\mathrm{DMP}}=(1-\phi) d b+\phi k d \theta
$$

Next we solve the free entry condition $\frac{k}{q(\theta)}=J=\frac{p-w^{\prime}}{\rho+\delta}$ for $k d \theta=-d w^{\prime} \cdot \frac{1}{\eta} \frac{f(\theta)}{\rho+\delta}$ to move into the wage equation (noting that $\theta$ is only affected by $b$ through $w$ and denoting by $\eta$ the elasticity of the matching function respect to unemployment):

$$
\begin{aligned}
d w^{\mathrm{DMP}} & =(1-\phi) d b+\phi\left[-d w^{\prime \mathrm{DMP}} \cdot \frac{1}{\eta} \frac{f(\theta)}{\rho+\delta}\right] \\
\Leftrightarrow \frac{d w^{\mathrm{DMP}}}{d b} & =\frac{1-\phi}{1+\phi \frac{1}{\eta} \frac{f(\theta)}{\rho+\delta}} \\
& \approx \frac{1-\phi}{1+\phi \cdot \frac{1}{\eta} \cdot\left(u^{-1}-1\right)}
\end{aligned}
$$

${ }^{48}$ In DMP models, the reemployment capital-gains term in the worker's outside option $\rho N=b+f\left[E\left(w^{\prime \mathrm{DMP}}\right)-N\right]$ is replaced with the firm's value of a filled job (recognizing the Nash sharing rule such that $(1-\phi) f\left[E\left(w^{\prime}\right)-N\right]=$ $\left.\phi f\left[J\left(w^{\prime}\right)-V\right]\right)$. Free entry has firms post vacancies until the value of vacancies is pushed to zero $V=0 \Leftrightarrow \frac{k}{q}=J$, implying that $\phi f\left[J\left(w^{\prime}\right)-V\right]=\phi k f / q=\phi k \theta$, due to the standard constant-returns matching function, by which $f(\theta) / q(\theta)=\theta$, such that $\phi k \theta$ now captures the worker's capital gain from reemployement $(1-\phi) f\left(E\left(w^{\prime}\right)-N\right)$. 
where step 2 uses $d w=d w^{\prime}$, and step 3 uses $\frac{f}{\rho+\delta} \approx \frac{f}{\delta} \approx \frac{1-u}{u}=u^{-1}-1$, where $u$ denotes the market-level unemployment rate (since $\rho$ is small compared to worker flow rates). Strikingly, this expression mirrors our structural micro sensitivity except for two differences. First, the $\phi$ factor in the denominator is divided by $\eta<1$, attenuating the sensitivity slightly. Second, the relevant unemployment rate $u$ refers to the market-level average rather than the worker's idiosyncratic time in nonemployment post-separation $\tau$. In both limits, we have $d w /\left.d b\right|_{\tau=1}=d w^{\mathrm{DMP}} /\left.d b\right|_{u=1}=1-\phi$. For $\phi=0.1$ (micro estimates from rent sharing), $u \approx 7 \%$ and $\eta=0.72$ (e.g., Shimer, 2005), we obtained a calibrated benchmark for the wage-benefit sensitivity of $\frac{1-0.1}{1+0.1 \frac{1}{0.72} \cdot \frac{0.93}{0.07}} \approx 0.32$. Note that the $u$ here need not coincide with the $\tau$ (or the $\tau^{U}$ we provide in the extended model with nonemployment without UI receipt), as the rate here is cross-sectional rather than tracking a worker after a separation (and, respectively, as some of that non-UI nonemployment state is spent out of the labor force while the model at hand only considers those workers actively searching). ${ }^{49}$ Moreover, higher unemployment $u$ increases the macro sensitivity almost exactly as a higher $\tau$ increases the micro sensitivity, which generalizes the implications of whether the sensitivity differs in the local unemployment rate, a prediction we test in Section 5.1. Therefore, our quantitative and structural benchmark for the wage-benefit sensitivity carries over to a macro context with equilibrium adjustment and perfectly segmented labor markets for the treatment group and the control group.

II. Stole and Zwiebel (1996) Bargaining with Multi-Worker Firms Extensions to multi-worker contexts highlight the complications that the splitting of the inside option entails with multi-worker firms and diminishing returns (see Jäger and Heining, 2019, for empirical evidence). We build on the derivation of the Nash wage with firm level production function $Y=n^{\alpha}$ in Acemoglu and Hawkins (2014) augmented with our worker-specific outside option $\Omega_{i}: 50$

$$
w^{\text {MultiWorker }}=\frac{\alpha \phi}{1-\phi+\alpha \phi} \cdot x_{f} \cdot n_{f}^{\alpha-1}+(1-\phi) \Omega_{i}
$$

That is, multi-worker firm bargaining preserves the sensitivity of wages to outside options $\Omega{ }^{51}$

III. Representative vs. Individual Households Implementations of matching-frictional labor markets are largely either in terms of individual households with linear utility or with large households that send off households into employment with full insurance in the spirit of indivisible labor (Rogerson, 1988; Hansen, 1985), for example Merz (1995), Andolfatto (1996), or Shimer (2010). In Appendix Section E.2.1 we extend this setting to an individual household with nonlinear utility. Our individual household bridges these setups with the assumption of perfect capital markets (and negligibly long unemployment spells).

\footnotetext{
${ }^{49}$ With $\eta=0.5$ instead of 0.72 , the sensitivity is 0.25 . With $\tau=0.05$ instead of 0.07 , we have 0.25 .

${ }^{50}$ Cahuc et al. (2008) also derive a dynamic search model with Stole and Zwiebel (1996) bargaining and heterogeneous worker groups $i$ that may differ in their outside options $b_{i}$ and derive the wage for group $i$ as $w_{i}(n)=(1-\alpha) \rho N_{i}+\int_{0}^{1} a^{\frac{1-\alpha}{\alpha}} F_{i}(n a) d a$.

${ }^{51}$ These models also imply that rent sharing estimates from firm-specific TFP shifts $x_{f}$ transferred to predict wage sensitivity to $b$ would require an additional scaling up if $\alpha<1$.
} 
IV. Endogenous Separations The Nash wage is the same in models with endogenous separations among existing jobs due to idiosyncratic productivity shocks, where $p$ is replaced with $p_{i t}$. Inframarginal surviving matches, i.e. those that we track in the data, exhibit the same pass-through of $\Omega_{i}$ into wages. ${ }^{52}$

V. On-the-Job Search On its own, on-the-job search with a job ladder (e.g., due to heterogeneous firms or match-specific quality) need not change the wage bargaining process as long as the worker is required to give notice to the firm before engaging in bargaining with the next employer. Nonemployment then remains the outside option in wage bargaining. This tractable route is taken by for example Mortensen and Nagypal (2007) and Fujita and Ramey (2012). We discuss alternative models with competing job offers as outside options in Section 2.3. In this class of models however, new hires from nonemployment still use nonemployment as their outside option in their initial bargain, where wages thus follow our baseline model.

VI. Finite Potential Benefit Duration While a common approach is to model benefits as having infinite potential duration, its duration is finite in Austria, as we describe in Section 3. Yet, in the Austrian setting, infinite benefit duration is a particularly good approximation for initially incumbent workers because only around $20 \%$ of unemployment spells end up in benefit exhaustion (Card et al., 2007). Moreover, after UI exhaustion, eligible Austrian workers collect a follow-up UI substitute $s(b)<b$ (Notstandshilfe, i.e. unemployment assistance (UA)). Importantly, $s(b)$ is explicitly indexed to a worker's pre-exhaustion UIB levels and - while in many cases lower - its level shifts almost one-to-one with changes in $b$. This feature leaves post-UI benefits sensitive to our reforms even for UI exhausters. ${ }^{53}$

Here, we extend the model to a two-tier system of finite-duration UIBs $b$, after which fraction $\alpha$ of still-jobless workers move into post-UI substitute $s(b)<b$. Denote by $\zeta$ the fraction of the unemployment spell a separator spends on UA (vs. UI). We treat $\zeta$ as the probability that a given separator moves into $s$ (UA) or $b$ (UB) post-separation. An initially employed worker's expected outside option is therefore $\Omega=\rho \mathbb{E}[N]=(1-\zeta) \cdot \rho N_{b}+\zeta \cdot \rho N_{s}=$ $\zeta\left(\tau_{s} \alpha s+\left(1-\tau_{s}\right) w_{s}\right)+(1-\zeta)\left(\tau_{b} b+\left(1-\tau_{b}\right) w_{b}\right)$. With permanent types and wages $w_{s}<w_{b}$, Nash still implies identical sensitivities $d w_{s} / d s=d w_{b} / d b$. Moreover, due to $f_{s}=f_{b}$, we have that once in a type, $\tau_{s}=\tau_{b}$.

In consequence, the wage sensitivity to benefits for the finite benefit duration is:

$$
\frac{d w^{\text {finite }}}{d b}=\frac{(1-\phi) \tau}{\frac{1}{1-\zeta\left(1-\alpha \frac{d s}{d b}\right)}-(1-\phi)(1-\tau)}
$$

Using the fact that only $20 \%$ of workers exhaust their benefits and the fraction of the unem-

\footnotetext{
${ }^{52}$ In these models, $b_{i}$ will also shift the reservation quality at which matches are formed and destroyed. Jäger et al. (2018) study a large extension of potential duration of UI for older workers and document substantial separation responses of that policy, which perhaps served as a bridge into early retirement in particular for workers in declining industries. In this paper, we do not detect significant separation effects to increases in benefit leves, perhaps because we study younger workers.

${ }^{53} \mathrm{UA}$ benefits are capped at $92 \%$ of the worker's UI benefits. Importantly, for uncapped workers, UA benefits shift 0.95 to one with the worker's UIB level. The precise formulate is $\mathrm{UAB}_{i}=\min \left\{0.92 b_{i}, \max \left\{0,0.95 b_{i}-\right.\right.$ Spousal Earnings ${ }_{i}+$ Dependent Allowances $\left.\left._{i}\right\}\right\}$. Due to the spousal earnings means test, not all workers are eligible for UA. For 1990, Lalive et al. (2006) report that median UA was about $70 \%$ of the median UIB. Based on data from 2004, Card et al. (2007) gauge the average UA at $38 \%$ of UIB for the typical job loser.
} 
ployment spell a separator spends on UA (vs. UI), we calibrate $\zeta=\frac{0.8 \cdot 0+0.2 \cdot 1 / f}{1 / f}=0.2$, where $1 / f$ denotes both expected duration remaining in nonemployment after benefit exhaustion as well as the average time at separation. A fraction $\alpha \approx 0.6$ of those workers move on to the post-UI substitute unemployment assistance. We calculate the fraction $\alpha$ as the share of workers who take up post-UI benefits within a 60 day window of exhausting their UI benefits; for this analysis, the sample is restricted to workers who do not take up employment in the same time window. Among those who receive them, the post-UI benefits are almost one-to-one indexed to the household's previous, actually received UI benefit level, and thus move in lock-step with benefit changes. ${ }^{54}$

As a result, the term $\left[1-\zeta\left(1-\alpha \frac{d s}{d b}\right)\right]=0.91$ provides negligible attenuation of the wagebenefit sensitivity: the wage benefit-sensitivity remains at 0.32 . This is an underestimate if the workers exhausting UI have a lower job finding rate and thus a larger $\tau$, which for that subset of workers would greatly amplify the sensitivity: setting $\tau=0.15$ rather than 0.104 will restore $d w / d b=0.4$ for those workers.

In other words, since an initially employed Austrian worker has a low probability of benefit exhaustion and, moreover, post-UI benefits are indexed to UI benefits our design is robust to finite benefit duration. Perhaps this fact also explains why we also do not find wage effects from potential benefit duration extensions in Section 5.1 and Appendix J. We have also not found evidence that workers with particularly high potential benefit durations exhibit different wage sensitivity to the unemployment benefit level.

VII. UI Wait Periods for Unilateral Quitters Austria has broad UI eligibility that encompasses even quitters. There is however a 28-day wait period, after which UI recipients enjoy full potential benefit duration (i.e. for 28 more calendar days than their peers receiving UI immediately). We evaluate this consideration in two steps. First, we define a probability $1-v$ that a bargaining progress breakdown leaves the worker eligible for UI whereas at probability $v$ leaves the worker ineligible (for any social insurance program). Ineligible workers wait 28 days until they receive UI, implying that $z^{\text {ineligigble }}=z^{\text {eligigible }}-b$ for initial period of nonemployment. In discrete time, $N^{i n}=z^{i n}+f^{m} \beta E^{i n}+\left(1-f^{m}\right) \beta N^{e l}$, such that:

$$
\begin{aligned}
\mathbb{E}[N] & =(1-v) N^{e l}+v N^{i n} \\
& =(1-v) N^{e l}+v\left[z^{i n}+\left(1-f^{m}\right) \beta N^{e l}+f^{m} \beta E^{i n}\right] \\
& =N^{e l}\left(1-v\left[1-\left(1-f^{m}\right) \beta\right]\right)+v\left[z^{i n}+f^{m} \beta E^{i n}\right]
\end{aligned}
$$

The effect of $b$ on the expected outside option is bounded from below by an attenuation factor times our previously derived sensitivity of $N$ to $b$, due to $d E^{i n} / d b \geq 0$ and $d z^{i n} / d b \geq 0$ :

$$
\frac{d \mathbb{E}[N]}{d b} \geq \frac{d N^{e l}}{d b} \underbrace{\left[1-v+v\left(1-f^{m}\right) \beta\right]}_{\approx 1-v f^{m}}
$$

\footnotetext{
${ }^{54}$ The law stipulates that post-UI benefits move with a slope of 0.92 along with previous UI benefits. There are additional additive components, e.g., benefits for dependents and reductions for other income, and the post-UI benefit level is capped at 0.95 times previous UI benefits. For the calibration, we pick the middle point between 0.95 and 0.92 and assume $d s / d b \approx 0.935$.
} 
where $\beta=0.9965 \approx 1$ at monthly frequencies. Therefore, the wage-benefit sensitivity is at least:

$$
\frac{d w^{\text {Limited Elig. }}}{d b} \geq(1-\phi) \cdot \frac{1-v f_{m}}{1+\phi\left(\tau^{-1}-1\right)}
$$

Calibrating the bracketed attenuation factor with $f=0.12$ (incorporating a monthly $\beta=0.9965$ will not change the result) implies that the attenuation is by 0.88 even if all separations were to go into nonemployment with initial ineligibility (i.e. $\nu=1$ ). That is, since so many nonemployment spells go beyond one month, this institutional feature has limited effects on the predicted wage-benefit sensitivity. ${ }^{55}$ This benchmark thereby also evaluates also delayed take-up for any reason even among the immediately eligible. In reality, most separations into nonemployment in Austria entail UI eligibility such that $\nu$ is closer to zero than to one, greatly limiting attenuation.

VIII. Wage Stickiness Rather than Period-by-Period Bargaining Real-world wage renegotiations may occur infrequently on the job, e.g. arrive at rate $\gamma$. Then, the measured wage response to a (permanent) shift in $d b$ is increasing in time-since-reform $d t$, and on average:

$$
\mathbb{E}\left[\frac{d w^{\text {sticky,dt }}}{d b}\right]=\left(1-e^{-\gamma d t}\right) \cdot \frac{1-\phi}{1+\phi\left(\tau^{-1}-1\right)}+e^{-\gamma d t} \cdot 0
$$

Empirically, we approach this aspect from three angles. First, we start with observing average wage earnings in the first full calendar year after the reform takes effect. ${ }^{56}$ We then additionally investigate earnings in the calendar year in the subsequent year, allowing two years for wage pass-through, whereas existing evidence on wage stickiness suggests half of wages to get reset within one year. ${ }^{57}$ Second, we consider wage effects in new jobs, for workers switching jobs with or without unemployment spells in between, where we follow the standard assumption that new jobs get to set wages initially in a flexible way. Third, we sort jobs (firms) by the usual degree of wage volatility, essentially by an empirical proxy for $\gamma$, and investigate heterogenous wage effects.

IX. Taxation Our bargaining setup so far sidesteps the tax system, but the results would carry over to a model in which both the firm and the worker face a (linear) income tax, and bargain over net surpluses by means of setting a gross wage. Taking into account taxation however would increase the effect of our UIB variation on wages. In Austria, benefits are not taxed, whereas wages and profits are. If the employer's and the worker's income taxes are approximately taxed by the same $\tau$, then changes in net benefits $b$ enter the worker's outside option relatively as $\frac{b}{1-\tau}$. For $\tau \approx 0.3$, accounting for the tax system would therefore amplify the predicted sensitivity of wages to $b$ by $\frac{1}{1-0.3} \approx 1.43$ for any given $\phi$. Analogously, a given wage response will, structurally interpreted in a model of Nash bargaining with nonemployment as the outside option, would for example imply 1.43 as large a worker bargaining power parameter. In an empirical robustness check in Appendix Table A.6 (graphical analysis in Appendix Figure A.18), we further report specifications in which we scale up benefits (and benefit changes) to

\footnotetext{
${ }^{55}$ This attenuation is further slightly reduced with finite PBD because the one-month delay does not reduce

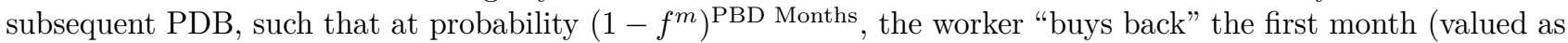
$b-\alpha s$, i.e. the premium over UI substitute $s$ adjusted for eligibility probability $\alpha$.

${ }^{56}$ An exception is the 1989 reform, which takes effect mid-year.

${ }^{57}$ See, e.g., Barattieri et al. (2014) for the United States, and Sigurdsson and Sigurdardottir (2016) for Iceland. Finally, the evidence on inside-option rent sharing documents same-year wage effects for incumbent workers.
} 
correspond to (hypothetical) gross benefit changes so that all calculations occur in terms of gross units. The results of the robustness check lead to the same conclusion as our main results and also reveal an insensitivity of wages to (gross) benefit changes.

X. Bounded Rationality: Myopia Our framework assumes that all workers and firms are rational in particular about their expectations about the nonemployment state. However, myopic agents may discount the future by more than the social planner would on their behalf. In our model, this consideration would most simply be nested with a larger $\rho$. Since the initial post-separation state is unemployment, $\frac{\partial \tau}{\partial \rho}>0$, implying that the agents put more weight on $b$, amplifying the effect on the wage-benefit sensitivity.

XI. Bounded rationality: bounded rationality and $k$-level thinking Other deviations from the fully rational benchmark may however attenuate the effect. The wage sensitivity consists of the direct effect as well as expectations about wage responses in subsequent jobs. The latter feedback effect is a strong ingredient into the theoretical sensitivity of wages to benefits and hard-wired into the model. A promising theory to attenuate the effect will therefore attenuate the feedback effect of re-employment wages into the wage bargain at hand. Perhaps $k=1$-level thinking may provide such a rationalization: agents act while ignoring equilibrium effects because they only consider one iteration of the equilibrium adjustment, but not the reemployment wage adjustment. The resulting wage-benefit sensitivity would then be limited to the direct effect:

$$
\frac{d w^{(k=1)}}{d b}=(1-\phi) \tau
$$

Calibrating the $(k=1)$ sensitivity to $\tau=0.1$ and $\phi=0.1$ would return a smaller sensitivity of 0.09 on average. Larger effects would emerge with $k>1$. However, the sensitivity is still increasing in $\tau$, linearly so now. In Section 4.4, we test whether workers with larger $\tau$ (predicted time on UI post-separation) have larger pass-through, and do not find evidence for a slope, in contrast to the prediction from even $(k=1)$-level thinking.

\section{E.2 Additional Wage Setting Models}

\section{E.2.1 Bilateral Nash Bargaining Between an Individual Household with a Poten- tially Multi-Worker Firm}

The model presented here forms the basis for the additional model variants presented in Section E.1. Here we generalize the structural wage equation by a variety of dimensions, starting with a bilateral bargaining between a worker and a multi-worker firm, long-term jobs and non-linear utility.

Hiring Costs and Ex-Post Job Surplus Employment relationships carry strictly positive joint job surplus because of hiring costs, $c^{\prime}(H)>0, c(0)=0$, which are sunk before bargaining. In consequence, both the worker and the firm would strictly prefer to form the match (for an efficiently set wage) than part ways.

Household Labor is indivisible and hours are normalized to one. In a given period $s$, the household is either employed or unemployed $\left(e_{s} \in\{0,1\}\right)$. There is no direct labor supply 
channel; workers accept job opportunities when they emerge. When employed, the worker earns wage $w_{s}$. The employed household incurs labor disutility $\gamma$. When unemployed, the worker collects unemployment insurance benefits $b$. With probability $f$, the worker finds a job and moves into employment (and wage bargaining) next period. With probability $1-\delta$, employed job seekers lose their jobs and become unemployed. Households can borrow and save at interest rate $r$, fulfilling a lifetime budget constraint. ${ }^{58}$ Households own firms and collect capital income in form of dividends $d_{t}$.

$$
\begin{aligned}
V^{H}\left(e_{t}\right) & =\max _{c_{t}} \mathbb{E}_{t} \sum_{s=t}^{\infty} \beta^{s-t} u\left(c_{s}\right)-\gamma \cdot \mathbb{I}\left(e_{s}=1\right) \\
\text { s.t. } \quad \mathbb{E}_{t} \sum_{s=t}^{\infty} \frac{c_{s}}{(1+r)^{s-t}} & \leq \mathbb{E}_{t} \sum_{s=t}^{\infty} \frac{\mathbb{I}\left(e_{s}=1\right) \cdot w_{s}+\mathbb{I}\left(e_{s}=0\right) \cdot b+d_{s}}{(1+r)^{s-t}}+a_{t} \\
\mathbb{E}_{t}\left[e_{s+1} \mid e_{s}=1\right] & =1-\delta \forall s \\
\mathbb{E}_{t}\left[e_{s+1} \mid e_{s}=0\right] & =f \forall s
\end{aligned}
$$

The household's problem can be cast in dynamic programming in familiar form associated with search and matching models:

$$
\begin{aligned}
U_{t} & =\max _{c_{t}} u\left(c_{t} \mid e_{t}=0\right)+(1-f) \beta \mathbb{E}_{t} U_{t+1}+f \beta \mathbb{E}_{t} \widetilde{W}_{t+1} \\
W_{t} & =\max _{c_{t}} u\left(c_{t} \mid e_{t}=1\right)-\gamma+(1-\delta) \beta \mathbb{E}_{t} W_{t+1}+\delta \beta \mathbb{E}_{t} U_{t+1}
\end{aligned}
$$

where $U_{t}$ denotes the value function of a worker that is currently unemployed $\left(e_{t}=0\right)$ and $W_{t}$ for the employed worker $\left(e_{t}=1\right)$. $\widetilde{W}_{t+1}$ denotes a potential subsequent job. The household's benefit from employment, at a given wage $w$, is pinned down by the difference in income, net of the disutility of labor, plus the shift in the continuation value (where we here simplify the setting to a lifecycle budget constraint that features a $\lambda$ unaffected by the stochasticity of separations and reemployment; a similar setting would emerge with complete markets or through a representative household):

$$
W_{t}(w)-U_{t}=\lambda(w-b)-\gamma+(1-\delta) \cdot \beta \mathbb{E}_{t}\left(W_{t+1}-U_{t+1}\right)-f \cdot \beta \mathbb{E}_{t}\left(\widetilde{W}_{t+1}-U_{t+1}\right)
$$

Firm The multi-worker firm, facing a competitive product and capital market, employs $N_{t}$ workers in long-term jobs and rents capital $K_{t}$ at rate $R_{t}$. Capital rentals are made given wages after bargaining. ${ }^{59}$ Production follows constant returns with all labor being of the same type and thus perfect substitutes, which together with rented capital implies linear production in labor, avoiding multi-worker bargaining complications. Each period, a fraction $1-\delta$ workers separate into unemployment exogenously, whereas the firm hires $H_{t}$ workers at cost $c\left(H_{t}\right)$. Employment follows a law of motion as a constraint in the firm's problem. The firm maximizes the present

\footnotetext{
${ }^{58}$ Due to the absence of moral hazard in job search and due to the law of large numbers on the part of the unmodelled lenders, the expected lifetime earnings do not complicate the borrowing potential of households. Since average unemployment spells are short in nature (on the order of $45 \%$ at the monthly rate in the US), we abstract from shifts in lifetime earnings in shifting lifetime wealth and therefore the multiplier on the budget constraint. Therefore, we assume that the budget constraint multiplier is approximately independent of the employment status, $\lambda(e=0) \approx \lambda(e=1)$.

${ }^{59}$ Rental of capital inputs and this timing conventions precludes the complication of potential investment holdup associated with bargaining.
} 
value of payouts to the households (stockholders):

$$
\begin{array}{r}
V_{t}^{F}\left(N_{t}\right)=\lambda \mathbb{E}_{t} \max _{H_{t}, K_{t}} \sum_{s=t}^{\infty} \beta^{s-t}\left[F\left(K_{t}, N_{t}\right)-w_{t} N_{t}-R_{t} K_{t}-c\left(H_{t}\right)\right] \\
\text { s.t. } \quad N_{t+1}=(1-\delta) N_{t}+H_{t}
\end{array}
$$

The firm's problem can be cast in dynamic programming in familiar form associated with search and matching models; where the firm's state variable is the employment level:

$$
\begin{aligned}
V_{t}^{F}\left(N_{t}\right) & =\max _{H_{t}, K_{t}}\left\{\lambda\left[F\left(K_{t}, N_{t}\right)-w_{t} N_{t}-R_{t} K_{t}-c\left(H_{t}\right)\right]+\beta V_{t+1}^{F}\left(N_{t+1}\right)\right\} \\
\text { s.t. } \quad N_{t+1} & =(1-\delta) N_{t}+H_{t}
\end{aligned}
$$

The firm's input demand (capital rentals and hiring) is described by the following first-order conditions and the envelope condition for $\mu_{t}$, the shadow value on the law of motion for employment, pinned down by the envelope condition:

$$
\begin{aligned}
F_{K}\left(N_{t}, K_{t}\right) & =R_{t} \\
c^{\prime}\left(H_{t}\right) & =\beta \mathbb{E}_{t} \frac{\partial V_{t+1}\left(N_{t+1}\right)}{\partial N_{t+1}} \\
\frac{\partial V_{t}^{F}\left(N_{t}\right)}{\partial N_{t}} & =\lambda\left[f_{\tilde{N}}\left(K_{t}, N_{t}\right)-w_{t}\right]+(1-\delta) \beta \mathbb{E}_{t} \frac{\partial V_{t+1}^{F}\left(N_{t+1}\right)}{\partial N_{t+1}} \\
\Rightarrow c^{\prime}\left(H_{t}\right) & =\beta \mathbb{E}_{t}\left[f_{\tilde{N}}\left(K_{t+1}, N_{t+1}\right)-w_{t+1}+(1-\delta) c^{\prime}\left(H_{t+1}\right)\right]
\end{aligned}
$$

These conditions describe input demand given the wages firms expect to pay at the bargaining stage. Firm's value of employing an incremental individual worker (hired last period and becoming productive, and thus bargaining, in period $t$ ) is:

$$
\Delta V_{t}^{F}\left(N_{t}, w\right)=\lambda\left[f_{\tilde{N}}\left(K_{t}, N_{t}\right)-w\right]+(1-\delta) \beta V_{t+1}^{F}{ }^{\prime}\left(N_{t+1}\right)
$$

Nash Wage Bargaining Nash bargaining solves the following joint maximization problem, by which the worker and the firm pick a Nash wage $w^{N}$ that maximizes the geometric sum of net-of-wage surplus of the match to the worker $W(w)-U$ and of the firm $\Delta V_{t}\left(N_{t-1}, w\right)$, weighted by exponents $\phi$ and $1-\phi$ :

$$
\begin{aligned}
w^{N} & =\underset{w}{\arg \max }(W(w)-U)^{\phi} \times\left(\Delta V^{F}\left(N_{t}, w\right)\right)^{1-\phi} \\
\Rightarrow W\left(w^{N}\right) & =U+\phi \underbrace{\left(\Delta V^{F}\left(N_{t}, w\right)+W\left(w^{N}\right)-U\right)}_{\text {Job surplus }}
\end{aligned}
$$

That is, the employed worker receives her outside option $U$ plus share $\phi$ of the job surplus: the sum of the parties' inside options net of their outside options. Worker bargaining power parameter $\phi$ guides the share of the surplus that the employed worker receives, on top of her outside option. Next, we solve for the Nash wage $w^{N}$ that implements this surplus split.

The model recognizes the long-term nature of jobs. ${ }^{60}$ Wages then not only reflect current conditions but also expectations about future inside and outside values, through the continuation

\footnotetext{
${ }^{60}$ We consider period-by-period bargaining in the main part of the this exposition.
} 
values. An important implication of Nash bargaining to apply also in subsequent period, renders the Nash wage identical to the myopic thought experiment except for a continuation term: ${ }^{61}$

$$
w^{N}=\phi f_{\tilde{N}}\left(K_{t}, N_{t}\right)+(1-\phi)(1-\beta) \frac{U}{\lambda}
$$

The condition mirrors the continuous-time conditions in the main text, where $1-\beta \approx \rho$ and $U / \lambda$ corresponds to $N$.

\section{E.3 Alternative Bargaining Model: A Simple Version of Credible Bargaining (Hall and Milgrom, 2008)}

We describe a simple version of the credible bargaining protocol proposed by Hall and Milgrom (2008) that relies on alternating offers. The model remains empirically untested but has been favored for its macroeconomic upside: it generates endogenous rigidity to shocks and therefore amplifies employment fluctuations (see, e.g., Christiano et al., 2016; Hall, 2017). Specifically, "the credible bargaining equilibrium is less sensitive to conditions in the outside market" (Hall, 2017, p. 310).

The firm and the worker make alternating wage offers. In between bargaining rounds, the firm incurs a delay cost $\gamma$. Importantly, in our discussion here we allow the worker's flow utility $z$ to differ from the flow unemployment benefits $b$, unlike in the existing treatments in macroeconomic applications of this bargaining protocol. After all, for an employed worker $z$ may capture leisure, disutility from bargaining, the old, still-prevailing wage, and so forth. Moreover $z$ may accordingly differ between an unemployed negotiator entering a new job, and an already-employed job seeker potentially seeking to renegotiate.

In between rebargaining rounds, the match may dissolve. The probability of this bargainingstage separation is $s$, which may be different from the probability of standard exogenous job destruction during production, $\delta$. N will therefore enter the problem either through $s$ or $\delta$, with importantly opposite effects on the worker's reservation wage, as we show below.

Inside Values Preserving unemployment value $N$ for the worker and a zero for the firm's vacancy value due to free entry, we define the inside value of the worker $W(w)$ and the firm $J(w)$ (where we have set vacancy value $V=0$ due to free entry):

$$
\begin{aligned}
E(w) & =\frac{w+\beta \delta N}{1-\beta(1-\delta)} \\
J(w) & =\frac{p-w}{1-\beta(1-\delta)}
\end{aligned}
$$

Strategies for Wage Offers The optimal strategies are described by reservation wages. The worker's reservation wage is $\underline{w}$, and the firm's reservation wage is $\bar{w}>\underline{w}$, which we have yet to

\footnotetext{
${ }^{61}$ The derivation recognizes that $\phi \beta \mathbb{E}_{t}\left(W_{t+1}-U_{t+1}\right)=(1-\phi) \beta \mathbb{E}_{t} V_{t+1}^{F}{ }^{\prime}\left(N_{t}\right)$ by Nash bargaining in $t+1$ in
} the job at hand. In consequence, the $(1-\delta)$-weighted continuation terms cancel out:

$(1-\phi)\left[\lambda\left(w^{N}-b\right)-\gamma+(1-\delta) \cdot \beta \mathbb{E}_{t}\left(W_{t+1}-U_{t+1}\right)+f \cdot \beta \mathbb{E}_{t}\left(\widetilde{W}_{t+1}-U_{t+1}\right)\right]=\phi\left[\lambda\left[f_{\tilde{N}}-w^{N}\right]+(1-\delta) \beta \mathbb{E}_{t} V_{t+1}^{F}\left(N_{t}\right)\right]$ 
derive. When it is the worker's (firm's) turn to make an offer, she (it) will offer $\bar{w}(\underline{w})$, leaving the firm (worker) indifferent between rejecting and rebargaining.

Worker's Strategy: Offer Firm's Reservation Wage The firm's indifference condition defines the worker's strategy, to offer the firm its reservation wage $\bar{w}$ :

$$
\begin{aligned}
\frac{p-\bar{w}}{1-\beta(1-\delta)} & =-\gamma+\beta(1-s) \frac{p-\underline{w}}{1-\beta(1-\delta)} \\
p-\bar{w} & =-(1-\beta(1-\delta)) \gamma+\beta(1-s))(p-\underline{w}) \\
\bar{w} & =(1-\beta(1-\delta)) \gamma+\beta(1-s)) \underline{w}-p(1-\beta(1-s))
\end{aligned}
$$

Firm's Strategy: Offer Worker's Reservation Wage Analogously, the firm offers the worker her reservation wage. The definition of the reservation wage is such that the worker is rendered indifferent between $\underline{w}$ and waiting a period to make her own offer to the firm - which in turn will optimally equal the firm's reservation wage $\bar{w}$ :

$$
\frac{\underline{w}+\beta \delta N}{1-\beta(1-\delta)}=z+(1-s) \beta \frac{\bar{w}+\beta \delta N}{1-\beta(1-\delta)}+s \beta N
$$

For $s=1$, i.e. rejection by the worker results in unemployment, the reservation wage is equal to $z$, the payoff while bargaining, plus an "amortized" (hence: flow) value of unemployment $U$ :

$$
\Leftrightarrow \underline{w}=(1-\beta(1-\delta)) z+\beta(1-\beta(1-\delta)) N
$$

The worker's reservation wage is maximally sensitive to $N$ if a rejected offer indeed results in unemployment, i.e. for $s=1$. In fact, if the time period is short, the reservation wage is the payoff of not accepting the offer (and thus forgoing $z$ this period), and the excess of that going forward compared to unemployment.

More generally, we can rearrange the terms to isolate the present value of wages promised by the firm to leave the worker indifferent:

$$
\begin{gathered}
\frac{\underline{w}}{1-\beta(1-\delta)}=\overbrace{z}^{\text {payoff while barg. }}+(1-s) \overbrace{\beta \frac{\bar{w}}{1-\beta(1-\delta)}}^{\text {Follow-up offer }}+\beta \overbrace{(s-\delta) \frac{1-\beta}{1-\beta(1-\delta)} N}^{\text {Rel. unemp. risk: bargaining vs. producing }} \\
\Leftrightarrow \underline{w}=(1-\beta(1-\delta)) z+(1-s) \beta \bar{w}+\beta(s-\delta)(1-\beta) N
\end{gathered}
$$

Given $N$, we can solve for worker and firm reservation wages. The worker's reservation wage (and the optimal wage the firm would offer the worker) is:

$$
\underline{w}=\frac{(1-\beta(1-\delta)) z+(1-s) \beta[(1-\beta(1-\delta)) \gamma+p(1-\beta(1-s))]}{1-\beta^{2}(1-s)^{2}}+\frac{\beta(s-\delta)}{1-\beta^{2}(1-s)^{2}} \times(1-\beta) N
$$

The wage insensitivity to the nonemployment value $(1-\beta) N(\rho N$ in our continuous time setting) 
is:

$$
\frac{d \underline{w}}{d(1-\beta) N}=\frac{\beta(s-\delta)}{1-\beta^{2}(1-s)^{2}}
$$

Therefore, for $s=\delta$, the wage is insensitive to the nonemployment value. And still, the model can still accommodate small rent sharing coefficients:

$$
\frac{d \underline{w}}{d p}=\frac{(1-s) \beta(1-\beta(1-s))}{1-\beta^{2}(1-s)^{2}}
$$

For $s=\delta \approx 0$, this becomes very close to zero:

$$
\left.\frac{d \underline{w}}{d p}\right|_{s=\delta \approx 0} \approx \beta \frac{1-\beta}{1+\beta^{2}}
$$

Therefore, the protocol can accommodate wages that are, in the same calibration, insensitive to outside options including the nonemployment value, and have small wage responses to inside option shifts such as rent sharing (e.g., for small $s$ ).

The Role of $s$ vs. $\delta$ in Mediating the Effect of $N$ on Worker Reservation Wages As in the standard Nash model, $N$ denotes both the outside option of the worker in case of bargaining breakdown during the bargaining process (weighted by $s$ ) as well as the value of an exogenous job destruction (arriving with probability $\delta$ ). The net effect of $U$ on the worker's reservation wage $\underline{w}$ depends on the relative size of $s$ and $\delta$ in the alternating offer bargaining protocol.

A useful benchmark is $s=\delta$. Here, the worker is exposed to $N$ with the same probability whether she decides to reject the firm's offer to get a chance to make her counteroffer (where with probability $s$ bargaining breaks down and she becomes unemployed), or whether she accepts the current offer - when therefore production begins a period earlier (which exposes her job destruction probability $\delta$, and thus she puts a $\delta$ weight on $N$ one period earlier). In this knife-edge case, the worker's reservation wage $\underline{w}$ turns completely insensitive to $N$-and thus $b$, and is only driven by the while-bargaining flow utility $z$ (which need not contain $b$ ) and the (present value of the) wage gain resulting from getting the chance to make the (in subgame perfect equilibrium expected to be accepted) counteroffer, $\bar{w}$.

Calibrating AOB to $\delta=s$ could in principle generate wage insensitivity to $N$ (and thus $b$, assuming that $z \neq b$ for an incumbent worker). However, for cases where $\delta$ is small relative to $s$, AOB may feature high sensitivity of $\underline{w}$ to shifts in $N$ and thus $b$. For bilateral negotiations, perhaps $s \approx 1$ with $\delta<5 \%$ may not be a poor approximation of the real world, for example.

Whether $s \approx \delta$ is empirically realistic as such is difficult to assess because independently calibrating $s$ directly to empirical evidence is not straightforward. ${ }^{62}$ For example, Hall (2017) calibrates $s=0.013$ and $\delta=0.0345$, which here would lead worker reservation wages to fall when $N$ were to increase ceteris paribus. Conversely, Hall and Milgrom (2008) sets $\delta=0.0014$ and $s=0.0055$ at the daily frequency, which in our version of the AOB model leads increases in $N$ to increase wages (reservation wages of the worker) ceteris paribus.

\footnotetext{
${ }^{62}$ For example, in a situation with multiple applicants, $s$ from the perspective of the worker should capture also the risk of losing out to the next applicant, with higher probability $s$ than the incumbent worker would worry about being displaced by a colleague or get high with a job destruction shock $\delta$. This would suggest that $s>>\delta$.
} 
The Role of $z$ vs. $b$ While we intentionally define $z$ (the flow utility of the worker while bargaining, perhaps not containing $b$ for, e.g., an incumbent worker) separately from $b$ (the nonemployment payoff, contained in $N$ ), the original authors and the follow-up literature (see, e.g., Hall and Milgrom, 2008; Christiano et al., 2016; Hall, 2017) set both to be the same, and thus explicitly include unemployment benefits in $z=b$. But these authors are interested in new hires and their wage responses; our setting also studied incumbent workers, whose $z$ is unlikely to contain $b$ but rather reflect a default, previous wage. Somewhat in tension to the model however, we do not find evidence for new hires' out of unemployment to exhibit large wage sensitivity. 


\section{F Interpreting Firm- and Industry-Level Rent Sharing Estimates in a Bargaining Setting}

A larger body of evidence examines the effect of idiosyncratic inside values of jobs on wages: rent sharing of firm- and industry-specific productivity and profit shifts, which is consistent with rent sharing. Card et al. (2018) review that literature. A leading interpretation is that shifts in surplus arise from TFP shifters. A structural interpretation of a shift in the inside value of the employment relationship in Nash bargaining is:

$$
\begin{aligned}
w^{N} & =\phi \times p+(1-\phi) \times \Omega \\
\Rightarrow d w^{N} & =\phi \times \underbrace{d p}_{\text {Rent sharing variation }}
\end{aligned}
$$

Below, we proceed under the assumption that $p$ shifts are well-measured. If so, the rent-sharing result can be readily interpreted in a bargaining framework.

Elasticity Specifications A common empirical estimate comes in an elasticity of wages with respect to value added per worker, measured at the firm or industry level: ${ }^{63}$

$$
\xi=\frac{d w / w}{d p / p}
$$

Structurally interpreted in the Nash bargaining setup, this elasticity turns out to capture a product of two distinct terms: the ratio of the marginal product over the wage, times bargaining power $\phi$ :

$$
\frac{d w^{N} / w^{N}}{d p / p}=\phi \times \frac{p}{w^{N}}
$$

Rent sharing elasticities $\xi$ therefore provide upper bounds for $\phi$ :

$$
\phi=\frac{w}{p} \cdot \xi \leq \xi
$$

Of course, if the ratio of $w$ to $p$, the marginal product of the worker, were known, $\phi$ can be immediately backed out. However, the very motivation of models of imperfectly competitive labor markets, which give rise to bargaining, rent sharing and wage posting, is that these two values can diverge dramatically and in heterogeneous ways.

This bound is tight if $\phi \approx 1$ or if $b \approx p$ since then, by Nash, $w \approx p$. However, this bound is less useful in case the elasticity is small. In that case, $\phi$ is implied to be small, and $w$ may deviate from $M P L$ greatly unless $b$ is close to $p$. In the data, $x$ is indeed estimated to be small, implying a small bargaining power parameter and also permitting a small wage-MPL ratio absent high $b$. In this case, information on the level of $b$ is required again to make progress. Formally, one can plug in the Nash expression for $w$ to obtain a correspondence between $\phi$ and

\footnotetext{
${ }^{63}$ Some studies consider profit elasticities rather than value added shifts; rescaling into value added elasticities that rely on strong assumptions about homogeneity and the comovement of variable and fixed factors with productivity shifts.
} 
$p, b$ and the measured wage-productivity elasticity $\xi$ as follows:

$$
\phi=\frac{b \xi}{p(1-\xi)+b \xi}=\frac{1}{\frac{p}{b} \cdot \frac{1-\xi}{\xi}+1}
$$

We caution that it may therefore be impossible to translate the elasticity estimates into bargaining power parameters without strong quantitative assumptions about the bargaining structure, chiefly because the observable variables, $w$ and perhaps $p$, do not uniquely map into $b$ and $\phi$.

An interesting example is Card et al. (2016), who among many verification tests also estimate the heterogeneity in $\xi$ for women and men. The elasticity for women is below the elasticity for men. However, even with measured productivity shifts being homogeneous, two distinct factors may cause the elasticity differences within a bargaining framework. First, either men and women wield differential bargaining power $\phi^{g}$ where $g \in\{w, m\}$. Second, $\phi^{w}=\phi^{m}$ yet $p^{f} / w^{f}<p^{m} / w^{m}$ or $p^{f} / b^{f}<p^{m} / b^{m}$. That is, the latter scenario could arise if the opportunity cost of working of women $b^{f}>b^{m}$, as would also be in line with their larger labor supply elasticities, higher unemployment, and lower participation overall.

The information needed to translate a given value added rent sharing elasticity into the point estimate for $\phi$ therefore requires strong assumptions or empirical knowledge about $b$. Measuring the level of the worker's flow valuation of nonemployment $b$ (and thus surplus $b=M P L-b$ ) is difficult even for an average household (see, e.g., Chodorow-Reich and Karabarbounis, 2016). $z$ includes unemployment benefits but also any utility differences between the employed and unemployed state, or other income. $\frac{z}{M P L-z}$ is similarly elusive and related to the fundamental surplus in Ljungqvist and Sargent (2017), which is $\frac{M P L}{M P L-z}$ ).

Identifying $\phi$ off level shifts in $p$ rather than percentage shifts eliminates the complications arising from elasticities. 


\section{G Additional Institutional Information and Validation Exercises}

\section{G.1 Average Daily Earnings Construction}

We construct our average daily earnings measure as follows:

1. For each individual-firm-year observation (even across multiple spells like recall), we calculate the total earnings the individual received from that firm during the year divided by the total number of days worked at that firm. These earnings include supplementary payments such as 13 th or 14 th month wage payments and extra vacation payments.

2. For each month where the individual is employed by at least one firm, we assign the individual the "daily earnings" from the firm at which the individual is employed for the longest during that year and employed at that month.

3. We calculate the average daily earnings as the average of these monthly earnings measures across all months the individual is employed by at least one firm.

\section{G.2 Earnings Base for Unemployment Benefit Determination Through- out our Sample Period}

From 1977 until 1987, the earnings base for calculating unemployment benefits are generally the earnings in the last full month of employment before the beginning of an unemployment spell (§ 21 (1) Arbeitslosenversicherungsgesetz 1977). Importantly, Austrian wage contracts are structured to pay out 14 instead of 12 monthly salaries, with the two additional ones typically paid out at the beginning of the summer and at the end of the year, respectively. These additional payments are proportionally factored into and added to the earnings in the last four weeks before the beginning of an unemployment spell to calculate unemployment benefits $(\S 21(2)$ Arbeitslosenversicherungsgesetz 1977). To illustrate, someone with constant monthly earnings of ATS 10,000 would be paid an annual salary of ATS 140,000. Unemployment benefits would be calculated based on monthly earnings of ATS 11,667 based on the monthly earnings of ATS 10,000 plus $1 / 12$ of the two additional bonus payments (ATS 10,000*2/ $12=$ ATS 1,667).

A reform in 1987 changed the calculation period from the last month before unemployment to the last six months before unemployment, while still factoring in the 13th and 14th monthly salary proportionally.

A 1996 reform then changed the calculation more substantially by using last year's earnings for unemployment spells beginning after June 30 of a given year and the earnings in the second to last year for spells beginning before June 30. The 1996 reform left the treatment of the 13th and 14th salaries unchanged.

An additional important feature of the Austrian unemployment insurance system is that times of nonemployment (Beschäftigungslosigkeit) are exempt from the calculation of average earnings (Art. 2 §21 Arbeitslosenversicherungsgesetz). As a consequence, average earnings for calculation of UI benefits of those who experienced a nonemployment spell in the relevant calculation time period are based on a division of total earnings by the actual days of employment in the relevant 
time window (multiplied by 30 to arrive at a monthly number) rather than the total calendar time of the time window. ${ }^{64}$

Sources The laws are contained in the respectively updated versions of $\S 21$ of the Unemployment Insurance Act (Arbeitslosenversicherungsgesetz, ASVG).

\section{G.3 Calculation of Predicted Benefits}

The crucial ingredient for our strategy to use shifts in the benefit schedule is the correct measurement of the income concept used by the UI system to assign employed workers the benefit they would receive conditional on a separation leading to nonemployment.

This step requires a review of the relevant earnings concept for UIB determination. Two of our four reforms we study occurred before 1987, when the earnings in the last month of full employment were the earnings concept. In 1989, the earnings concept referred the average earnings in the last six months. In our identification strategy for these reforms, we assign an employed worker her predicted contemporaneous earnings to assign her a benefit level.

To calculate predicted benefits, we rely on a purpose-built calculator of unemployment benefits in Austria. Through 2000, UI benefits were calculated using a table (Lohnklassentabelle) based on the earnings concepts outlined in Section G.2. The benefit table and the formula that replaced it in 2001 can be found in $\S 21$, Section 3, of the Unemployment Insurance Act and reports the earnings concepts at the daily (later monthly) level.

We collect all changes to the benefit table from 1972 through 2000 and the 2001 benefit formula by investigating all legal changes to the Unemployment Insurance Act as referenced in the Legal Information Database (Rechtsinformationssystem, RIS). The RIS is the Austrian government's online archive of the Austrian Federal Law Gazette (Bundesgesetzblatt), where all legislation passed by the Austrian Parliament and decrees by cabinet ministries are published. ${ }^{65}$ The UI benefit schedule for each year as a function of monthly gross earnings can be found in Appendix L.

Prior to 1994, the earnings base was a measure of earnings right before unemployment (see Section G.2 for details). For these years (i.e. the 1976, 1985, and 1989 reform samples), we undertake the following steps to calculate the predicted benefit change:

1. Begin with the daily gross earnings concept described in Section G.1.

2. Within each sample (across the whole ASSD, not just the percentile ranges used in our regressions), calculate the average annual growth rate from the year into the next year.

\footnotetext{
${ }^{64}$ This is in contrast to the US setting where spells of unemployment potentially lower earnings and thus subsequent unemployment benefits. In Massachusetts, for example, UI benefits are calculated based on the average weekly earnings in the two out of the last four quarters with the highest earnings. The earnings in those two quarters get divided by 26 to arrive at a weekly average regardless of actual time in employment. Holding wages while employed constant, nonemployment periods can thus lower average earnings and thus UI benefits-unlike in the Austrian setting. Source: https://www.mass.gov/info-details/ how-your-unemployment-benefits-are-determined.

${ }^{65}$ The RIS page with all references to the Unemployment Insurance Act in the Federal Law Gazette can be found here: https://www.ris.bka.gv .at/GeltendeFassung.wxe?Abfrage=Bundesnormen\&Gesetzesnummer= 10008407.
} 
3. Multiply the daily earnings in the year by the average earnings growth rate. Call this the inflated earnings.

4. Calculate the UI benefits corresponding to the inflated earnings value using the benefit calculator. This is $b$.

From 1994 onward, the earnings base was based on lagged earnings (see Section G.2 for details). From 1994 through 2000, we undertake the following steps to calculate the predicted benefit change:

1. Begin with the daily gross earnings concept described in Section G.1 but from the previous year.

2. Calculate the UI benefit corresponding to the lagged earnings value using the benefit calculator in each year. This is $b$.

For 2001, the earnings base is based on lagged net earnings:

1. Begin with the daily gross earnings concept described in Section G.1 but from the previous year.

2. Calculate the daily net earnings using the tax calculator described in Section K.

3. Calculate the UI benefit corresponding to the lagged net earnings value using the benefit calculator for 2001. This is $b$.

Before 1994, we also calculate realized benefits changes for our validation exercise:

1. Begin with the daily gross earnings concept described in Section G.1.

2. Calculate the UI benefits corresponding to the daiy gross earnings value using the benefit calculator. That is, we do not inflate by average annual earnings growth into the next year. This is $b$.

Note that "realized" and predicted benefits correspond exactly after 1994, i.e. for the 2001 reform.

\section{G.4 Validation of Benefit Calculation}

We assess the quality of our prediction of benefits based on the ASSD (see previous Section G.3) by comparing predicted unemployment insurance benefits for actual separators to actually received UIBs. To this end, we merge the unemployment benefit data (AMS) with the ASSD (social security based data), which contains our earnings measure. All measures are nominal and not inflation-adjusted.

Appendix Figure A.12 plots the relationship between actual and predicted UI benefit levels for all Austrian separators drawing UI benefits. The relationship traces out a slope that is on average $0.974 .{ }^{66}$ We therefore conclude that our approach accurately assigns employed workers by their ASSD-based earnings into the UI benefit levels.

${ }^{66}$ The $R^{2}$ is 0.69 . We would not expect $R^{2}=1$ even if we accurately predicted income for each individual since UIBs also include supplemental benefits based on the number of dependents (e.g., EUR 29.50 per month in 2018). These are not dependent on income and thus orthogonal to our variation. 
In addition, we also validate that our earnings prediction works well across the earnings distribution with coefficients on predicted and actual benefits close to 1 throughout (Appendix Figure A.13).

Figure A.12: Actual Benefit Receipts vs. Predicted Receipts from Measured Pre-Separation Average Earnings Among Sample of Separators

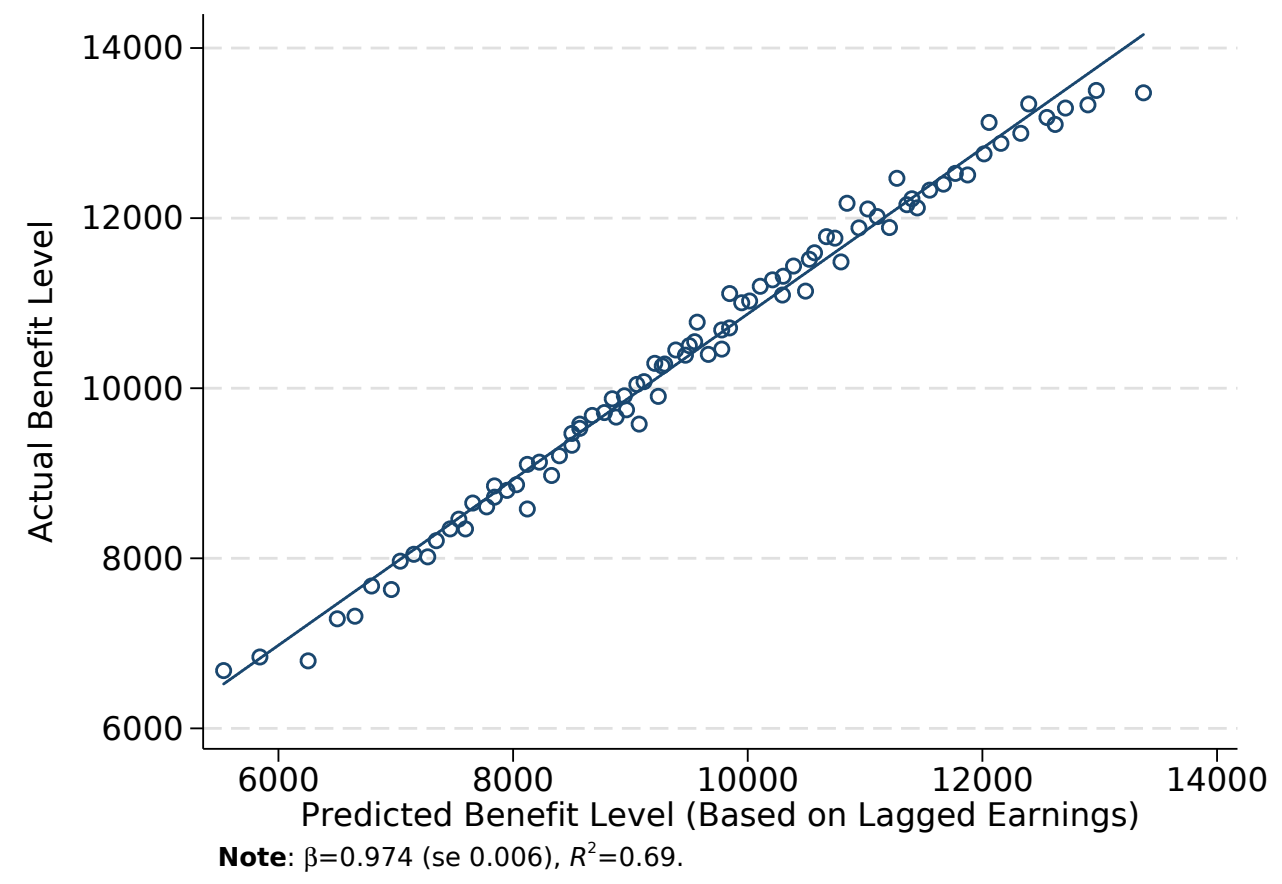

Note: The figure draws on earnings data from the ASSD and benefit data from the AMS. The x-axis shows predicted benefit levels based on earnings data from the ASSD. The y-axis shows actually paid-out benefits based on data from the AMS. The figure is a binned scatter plot based on individual-level observations. 
Figure A.13: Quality of Wage Prediction Procedure

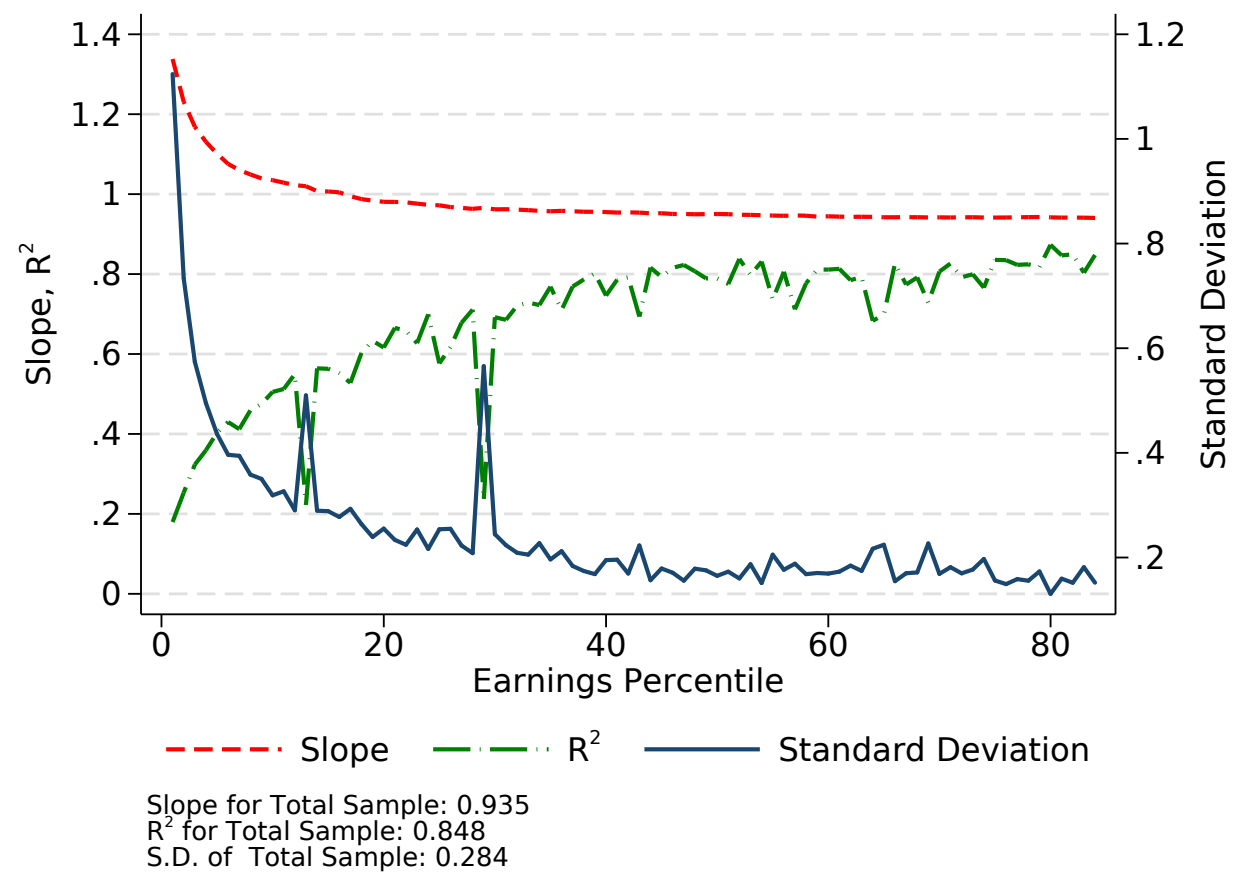

Note: The Figure reports several statistics by earnings percentile for the income prediction procedure. In particular, the figure reports the slope of actual to predicted wages, as well as the standard deviation of the residual and the $R^{2}$.

\section{G.5 Timeline for Reforms to Unemployment Benefits}

We report on the procedural timelines for each of the four reforms to the Austrian unemployment insurance system.

2001 Reform. The Budget Act of 2001 (Budgetbegleitgesetz 2001) was introduced in the Austrian Parliament on October 17, 2000, and passed on November 23 (Item 142 in the 2000 Federal Law Register). It went into effect on January 1, 2001 and included reforms to other laws apart from Unemployment Insurance Law of 1977. On November 17, the Budget Committee produced its report and requested adoption of the legislative proposal. It was discussed by parliament on November 23. Martin Bartenstein, the labor minister, argued during this session that the change to a $55 \%$ net income replacement rate was intended a means of improving transparency in the determination of unemployment benefits. The law was approved with 93 votes in favor and 70 votes against, and published in the official gazette on December 29. Changes to unemployment benefits went into effect January 1, 2001.

1989 Reform. The Amendment of the Unemployment Insurance Act 1977 and the General Social Insurance Act (AIVG-Novelle 1989) was introduced in Parliament on June 7, 1989, and passed 20 days later (Item 364 in the 1989 Federal Law Register). It went into effect on August 1. The AIVG-Novelle 1989 was approved unanimously with no modifications to the original draft, barring a proposed amendment from the Social Affairs Committee produced amending the salary contribution to the UI system. The unemployment benefit schedule in the final version was identical to the one in the original proposal.

1985 Reform. On October 16, 1984, the Austrian Ministry of Social Affairs published a 
decree (Verordnung) extending the unemployment benefit schedule which went into effect on January 1, 1985 (Item 416 in the 1984 Federal Law Register). The decree cited a requirement in the Unemployment Insurance Act ${ }^{67}$ that the Ministry extend the cap on the benefit schedule when the Parliament increases the maximum contribution from salaries to the UI system (Höchstbeitragsgrundlage). These increases are meant to adjust for nominal wage changes, and the requirement existed throughout the period of study in this paper. The 1985 adjustment was much larger than previous adjustments, however, because a year earlier, the Parliament had switched the maximum contribution to the UI system from that used for the national health insurance system to that used for the old-age pension system. ${ }^{68}$

1976 Reform. The Austrian government first introduced a bill increasing unemployment benefits (AlVG-Novelle 1976) at a session of Parliament on March 17, 1976, which was approved in a subsequent session on May 6 (Item 289 of the 1976 Federal Law Register). It went into effect on July 1, with the benefit increases exactly as proposed in the government's original bill. An amendment from a member of an opposition party increasing benefits for a slightly higher range of gross earnings was considered in a committee meeting but rejected during the May 6 parliamentary session.

${ }^{67}$ See $\S 21$, section 4, of the Unemployment Insurance Act (Arbeitslosenversicherungsgesetz, AlVG). Specifically, the law as of 1984 stipulates a deadline for these unemployment insurance cap extensions-i.e. within a year that the increased contribution cap takes effect - the size of the additional earnings brackets, and the benefit level at each bracket.

${ }^{68}$ See $\S 61$, section 1 , of the Unemployment Insurance Act for the definition of the maximum salary contribution to the UI system and $\S 45$, section 1, of the Social Security Act (Allgemeines Sozialversicherungsgesetz, ASVG) for the maximum contributions to the health insurance and old-age pension systems. The change in the maximum contribution originated as a bill proposed by a MP from the right-wing Freedom Party of Austria ( FPÖ) that was in a governing coalition with the Social Democrats $(S P O ̈)$. The bill was introduced in Parliament on October 21, 1983; passed in a subsequent session on November 29; and went into effect on January 1, 1984. Aside from tying the cap to a different maximum contribution, the law was also the first to stipulate a specific deadline of a year for the Ministry of Social Affairs to issue an appropriate cap extension. 


\section{H Alternative Outcomes}

In this section, we briefly discuss effects of the reforms on alternative outcomes: separations, unemployment duration, and sickness. Across specifications and outcomes, we find that the benefit increases were associated with quantitatively negligible effects on these outcomes that are statistically indistinguishable from zero in most specifications.

Separation and Unemployment Effects The improvement in the nonemployment outside option may lead marginal workers to select into nonemployment that would have otherwise experienced higher wage growth (e.g. because they are young or have low tenure, and therefore high wage growth). ${ }^{69}$ We therefore report treatment effects on separations and unemployment in Appendix Figure A.14 for one- and two-year horizons. The benefit change treatment is expressed in percentage points (i.e. 1 ppt $d b / w$ is 1 ), the outcome variables are range from 0 to 1 . We do not find a statistically or economically significant effect of the improved nonemployment option. 70 Appendix Figure A.14 also reports treatment effects for the probability of experiencing an employment to unemployment to employment (EUE) spell and the fraction of months spend on UI over the next one and two years. At the two-year level we see suggestive evidence that treatment increased the probability of an EUE spell and the fraction of months spend on UI, consistent with the prior literature on the effects of UI generosity on unemployment spell durations (see Lalive et al., 2006; Card et al., 2015, for evidence from Austria).

Efficiency Wage Effects: Sickness Incidence Efficiency wage mechanisms may mask bargaining-related wage effects by lowering productivity, if workers are more likely to reduce effort. Yet, we have not found retention effects in the previous robustness checks. We additionally study the treatment effect on registered sickness spells in our administrative data in Appendix Figure A.14. Sickness spells do not respond to the improved outside option. ${ }^{71}$

\footnotetext{
${ }^{69}$ See Jäger et al. (2018) for evidence for older workers separating into nonemployment in response to a large increase in the potential benefit duration, along with characterization of the incremental separators.

${ }^{70}$ Consider the one-year mover estimate of around 0.0001 . For a 10 percentage point increase in an individual's replacement rate, we can rule out an increase her mover probability by more than 0.1 percentage points. Compared to the baseline annual one-year mover rate of around $9 \%$, this would be an economically small increase in the mover rate. The upper end of the one-year mover confidence interval also implies that for a 10 percentage point increase in an individual's replacement rate, we can rule out an increase her mover rate by more than 0.5 percentage points.

${ }^{71}$ However, the productivity decrease would have had to be tremendous in order to account for the net wage effect of zero. If worker bargaining power were 0.1, then the 8ppt increase in the change in benefits (normalized by the wage) would have had to imply a $\frac{0.48 \times 8 \mathrm{ppt}}{0.1}=38.4 \mathrm{ppt}$ decline in the productivity/wage ratio to offset the bargaining channel and leave wages unchanged on net. Since we expect that $w / p \approx 1$ we would need a similar order of magnitude percent decline in productivity to offset the bargaining effect.
} 


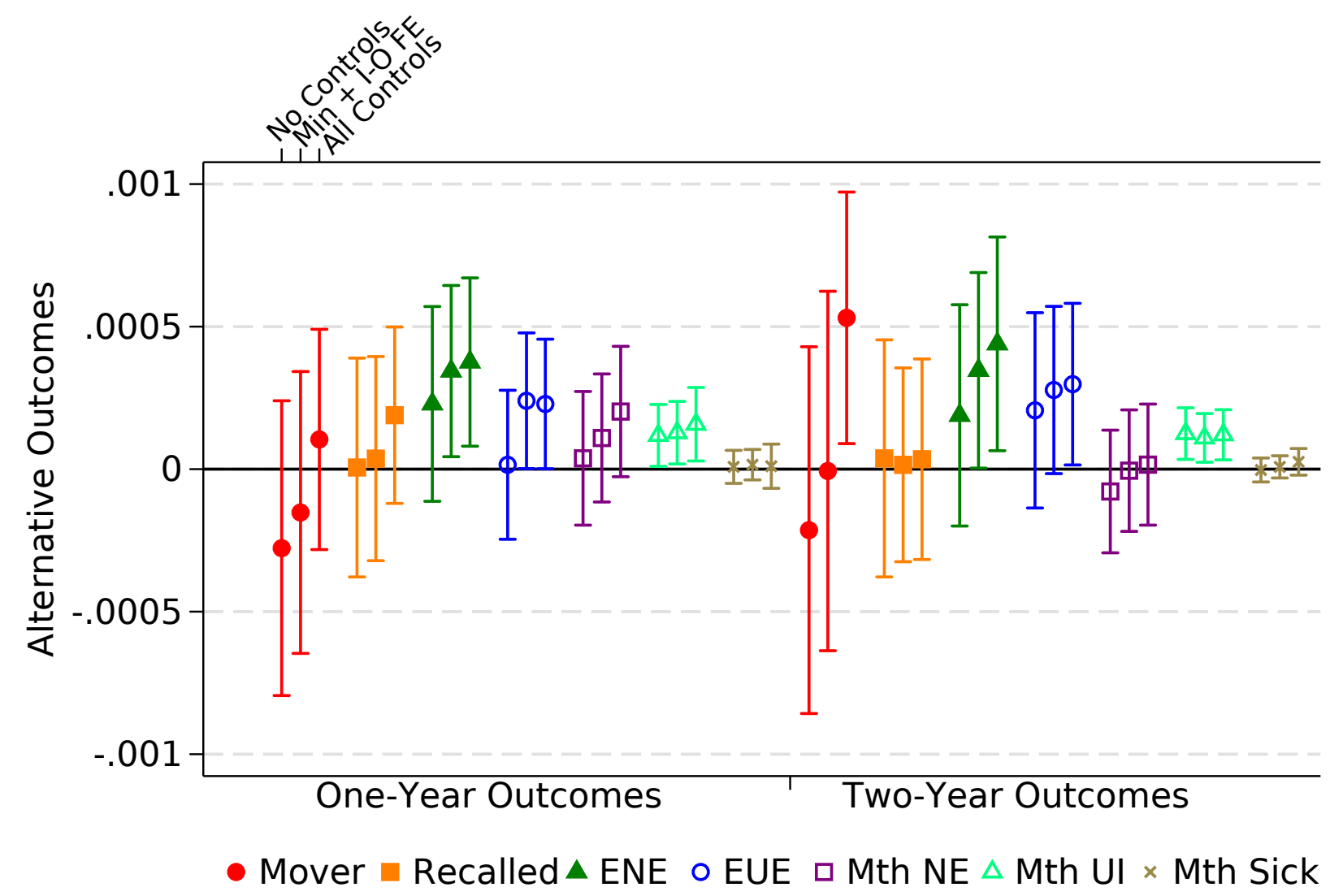

Note: The figure plots $\sigma_{0}$ coefficients from estimating equation 19 but replacing the $\frac{d w}{w}$ outcome with alternative outcomes. All of the alternative outcomes range from 0-1 (either transition probabilities or shares) and the dependent variable is the percentage point change in $\frac{d w}{w}$ (ranging from around 0 to 20). Mover, Recalled, ENE and $E U E$ refer to indicators for going through different employment transition types in the next one or two years. Specifically, mover refers to individuals who are observed at a new employer and do not return to their original employer within the next one or two years. Recalled refers to individuals who leave their current employer for another employer or nonemployment and then return to their original employer within the next year or two (depending on the specification). ENE refers to employer to different employer transitions with an intermediate nonemployment spell (excluding paternity leave). EUE refers to employer to different employer transitions with an intermediate unemployment spell (measured by any UI receipt). Mth NE, Mth UI, and Mth Sick are the share of months in the next one or two years spent in different labor market states (they range from 0-1). Mth NE refers to the share of months nonemployed. Mth UI refers to the share of months on UI receipt. Mth Sick refers to the share of months on sick leave. The industry-occupation controls are time-varying fixed effects for each four-digit industry interacted with an indicator for a blue vs. white-collar occupation. Firm FE indicates that time-varying firm-fixed effects were included. The base rates for the outcome variables averaged across all the pre-reform years are: Movers: 0.086, Recall: 0.035, ENE: 0.053, EUE: 0.032, Mth NE: 0.044, Mth UI: 0.017, and Mth Sick: 0.006 . 


\section{Construction of Regression Sample and Variables}

\section{I.1 Construction of Sample}

Begin with all individuals with non-missing earnings. To isolate the part of the income distribution we include for each reform sample, we use the idea of treatment and control groups. The distinctions play no further role in our main empirical analysis, however.

\section{I.1.1 Treatment}

The treatment region is defined as the percentile earnings range in the base year where the predicted benefit change is large and positive.

- Identify the average predicted UIB change for each percentile. See Section G.3.

- For the 1985 reform, the lower bound of treatment is the percentile at which the average predicted benefit change is more than $0.5 \%$ of earnings. The upper bound of treatment is 3 percentiles below the reform-specific adjusted ASSD cap.

- For the 1976 reform, the lower bound of treatment is one percentile above the first percentile (the ASSD minimum). We drop the first percentile because earnings growth is very volatile here. The upper bound is the highest percentile under the 12 th percentile $^{72}$ that experiences a predicted benefit change greater than $1 \%$ of earnings.

- For the 1989 reform, the lower bound of treatment is the lowest percentile at which the predicted benefit change is greater than $2 \%$ of earnings. This is because at the lowest end of the income distribution, there was not a very large change. We then drop an additional percentile because the earnings growth was very volatile. The upper bound is the highest percentile at which the predicted RR change was greater than $0.5 \%$ of earnings.

- For the 2001 reform, the lower bound of treatment is the percentile at which 10,000 ATS falls in 2000. The upper bound is the percentile at which 20,000 ATS falls in 2000.

\section{I.1.2 Control}

The control region is chosen as the percentile range in the base year closest to the treatment earnings range but received no change/a very small change in predicted benefits.

- Calculate the range of the treatment region, i.e. the number of percentiles included in the treatment region.

- For the 1985 reform, take the difference between the averaged predicted UIB change in the base year $r-1$ and three years before, $r-4$, for each percentile. Call this "excess db/w." This is an effort to make sure there is a region in the reform sample that has not been treated recently in the base year. It is 11 percentiles in 1984. Find the highest percentile for which this difference is 0 . This is the upper bound of the control region. Then subtract the treatment region range from the upper bound of control to get the lower bound of

\footnotetext{
${ }^{72}$ It must be the highest under the 12 th percentile because there is also a cap extension at the top of the income distribution, and choosing the 12 th percentile avoids the cap comfortably.
} 
control. In our main specification, we also include the "intermediate region" between the treatment and control region in our estimation sample for transparency; and we also check that our results are quantitatively robust to excluding this region.

- For the 1976 and 1989 reforms, the lower bound of the control region is an eighth of a percentile above the upper bound of the treatment region. Then add the treatment range to the lower bound of control to upper bound of control.

- For the 2001 reform, the lower bound of control is the upper bound of treatment. Then add the treatment range to the lower bound of control to get the upper bound of control.

\section{I.1.3 Percentile Ranges of Reform Samples}

While we describe sample restrictions and our empirical framework in percentiles, we operationalize the benefit aggregation (for placebo assignment) as well as the sample construction using eighths of percentiles, to create fine-grained benefit levels. This is especially useful in the small reform samples. We report the cutoffs at the level of eighths of percentile in parentheses:

\section{- 1976 Reform}

- Treatment: 1st (1.625) to 6th percentile (6.875)

- Control: 7th (7.00) to 12th percentile (12.25)

\section{- 1985 Reform}

- Treatment: 61st (61.125) to 87th percentile (86.75)

- Control: 24th (24.25) to 49th percentile (49.875)

- Skipped, due to repeated treatment: 50th (50.00) to 61st percentile (61.00)

\section{- 1989 Reform}

- Treatment: 2nd (2.5) to 19th percentile (19.75)

- Control: 20th (19.75) to 37th percentile (37.00)

\section{- 2001 Reform}

- Treatment: 8th (7.875) to 32nd percentile (32.25)

- Control: 33rd (32.375) to 57th percentile (56.625)

\section{I.2 Construction of Variables for Heterogeneity Analysis}

This section describes the construction of the variables we use for the analysis of treatment effect heterogeneity. Below, we describe how we divide the heterogeneity groups into quintiles (unless otherwise stated), which we calculate separately for each reform. Throughout, we draw on the sample of all workers, regardless of whether they are employed all year, unless stated otherwise. Prime-age below refers to the ages 25 to 54 . The variable status refers to workers' employment status in the ASSD status.

\section{Firm size.}


- Begin with the universe of prime-age workers.

- Count the total number of workers at the firm who are employed for the whole year.

- Separate into four groups (not quintiles): firms less than 10 people, between 11 and 100 people, between 101 and 1,000 people, and larger than 1,000 people.

2. The share of the worker's firm that was nonemployed in the last two years.

- Begin with the universe of prime-age workers.

- Count the number of workers at the firm whose current employment spell is less than 24 months and who was unemployed in the month before their current employment spell ( $\operatorname{status}=1$ ).

- Count the total number of workers at the firm.

- Divide the former by the latter.

- We separate the sample into quintiles by worker.

\section{Tenure}

- Begin with the sample of workers that is included in our analysis.

- Split the tenure variable by quintile.

\section{Four measures of the time since nonemployment.}

(a) Months since nonemployment (i.e. status $\neq 3$ ) Note that if employment spells are separated by only a single month of illness, then the month of illness and the two spells are counted as a single employment spell.

(b) Months since last UIB receipt (i.e. status $=1$ ). Note that the employment spell length keeps counting if the worker becomes sick, goes on disability, or takes a parental leave.

(c) Months since the last change in labor market status, skipping recalls from illness/leave. This is the same as (a), but if a worker becomes nonemployed (i.e. status $\neq 1,3$ ) and then returns to the same employer (i.e. the next status change is a change back into employment with the same firm), then the worker remains in the same employment spell throughout. Here, the spell count only resets when a worker receives UIB or when a worker becomes ill, goes on parental leave, etc. and does not return to the same firm when they are next employed.

(d) Months since the last UIB receipt, skipping recalls after unemployment. This is the same as 2), but if a worker becomes unemployed or nonemployed (i.e. status $\neq 3$ ) but then returns to the same employer (i.e. the next status change is a change back into employment with the same firm), then the worker remains in the same employment spell throughout. Here, the spell count only resets when a worker receives UIB and does not return to the same firm when they are next employed.

- We then implement the following procedures:

- Begin with sample of prime-age workers.

- Count the number of months for each of the four designations for each worker. 
- Split into quintiles.

- Time: year $t$

\section{Local unemployment rates.}

- Begin with the universe of workers aged between 25 and 54 in a given year.

- $A$ : Count the number of workers who are unemployed (status $=1$ ) by area of residence using the gkz variable. The relevant information is only available starting in 1987, so we use their 1987 location for pre-1987 years.

- $B$ : Count all the workers in the area of residence who are unemployed, sick, employed, self-employed, on parental leave, and in minor employment.

- Divide $A$ by $B$.

- Here, we separate the sample into quartiles, not quintiles, because the sample bunches (in areas with large populations).

\section{Industry growth rates.}

- Begin with the universe of prime-age workers in a given year. Measure the leave-out mean industry growth rate. That is, for worker $i$ in firm $j$ and industry $k$, the growth between $t$ and $t^{\prime}=t+1$ is

$$
\triangle S_{i j k}=\frac{\sum_{j^{\prime} \in J-j} \mathbb{1}\left(\text { Industry }_{j^{\prime}}=k\right) \cdot\left(\text { Employment }_{j^{\prime} t^{\prime}}-\text { Employment }_{j^{\prime} t}\right)}{\sum_{j^{\prime} \in J-j} \mathbb{1}\left(\text { Industry }_{j^{\prime}}=k\right) \cdot \text { Employment }_{j^{\prime} t}}
$$

- Count the number of workers in the firm (benr), not necessarily employed the whole year.

- Count the number of workers in the industry (nace08), not necessarily employed the whole year.

- Subtract, for each firm, its population from the number of workers in the industry.

- Find the same number for the next year $t+1$ (i.e. two years pre-reform), but only for workers employed at the same firm between year $t$ and year $t+1$.

- Calculate the percent difference between the leave-out employment in the industry between year $t+1$ and year $t$.

\section{AKM firm effects}

- For each year in the reform sample $t$ (i.e. the four years pre-reform), take the universe of prime-age workers from year $t-10$ to $t$. Before 1982, take 1972 as the earliest year. Do not use 1972 or 1973.

- Regress log-earnings on year fixed effects, a third-order polynomial in age, and an exhaustive set of worker and firm fixed effects (Abowd et al., 1999). We use the procedure in (Correia, 2017) for estimation.

- Save the firm fixed effects for year $t$ and assign to workers in the regression sample.

- Divide the sample into quintiles based on the firm effects. 
8. Age

- Sample identical to the one we use for analysis.

\section{Four measures of within-firm wage dispersion.}

(a) The standard deviation of year-on-year earnings growth within the firm.

- Focus on a sample of workers who stay with their firm from one year to the next.

- Drop workers at the ASSD cap and with missing earnings.

- Calculate the individual earnings growth relative to last year. Winsorize to the 5th and 95th percentiles.

- Calculate the standard deviation of the earnings growth by firm-year among workers who were in the same firm across the two years.

(b) The difference between the 75th and 25th percentile of within-firm earnings growth.

- Take the earnings growth variable and sample above.

- For each firm-year, calculate the percentile for each worker's earnings growth.

- Take the difference between the average earnings growth for an individual in the 74th-76th percentile to that for an individual in the 24th-26th percentile.

(c) The residualized standard deviation of log-earnings. We base this measure on the residuals from a regression of log-earnings on tenure-experience-occupationindustry-year fixed effects, with standard deviations calculated at the firm-year level. Tenure $n(i, t)$ is made up of 5 three-year categories and a category for those with more than 15 years of tenure. Experience $e(i, t)$ is made up of 5 five-year categories and a category for those with more than 25 years experience. Occupation refers to white- vs. blue-collar, for which there are often separate collective bargaining agreements. Calculate the log-earnings for each worker, and winsorize to the 5th and 95th percentile. Regress log-earnings on industry-occupation-tenure-experience-year fixed effects. Calculate residuals from this regression, and take the standard deviation of the residual by firm-year. Split the sample into quintiles.

(d) The mean squared residuals of log-earnings.

- Calculate the average by firm-year of the square of the residuals from the previous regression.

\section{Occupation.}

- Motivation. Survey data suggest that workers with more education/skills are likelier to bargain. Thus white-collar workers might bargain more and thus be more sensitive to the outside option.

- Place blue-collar workers in occupation group 1 (whitecoll $=0)$ and white-collar workers in occupation group 2 (whitecoll $=1)$.

\section{Three additional measures of industry-occupation unemployment risk.}

(a) Separation rate. This is the probability of being unemployed in the next period in a given industry-occupation, given that one is employed in the current period. 
- Sample the universe of prime-age workers.

- Create an indicator for whether the individual is unemployed (status $=1$ ) in the next year.

- Regress this indicator on industry-occupation fixed effects for that year, and save these fixed effects. I also run a specification with categories for tenure and experience and a linear control for age and keep the predicted values.

Regression: Let $Y_{i}$ be an indicator for being unemployed in the year $t+1$. Individual $i$ has occupation $o$ (blue or white collar) in industry $k$. Then, for all workers in year $t$,

$$
Y_{i}=\beta_{0}+\phi_{k(i), o(i)}+\epsilon_{i}
$$

(b) Expected months of unemployment. This is the average number of months of unemployment in the next period, conditional on being employed in the current period.

- Sample the universe of prime-age workers.

- Calculate how many months the worker is unemployed in the following year.

- Regress the number of months on industry-occupation fixed effects for that year, and save these fixed effects.

Regression: Let $t$ be the year three years before the reform. Individual $i$ has occupation $o$ (blue or white collar) in industry $k$. Then, for all workers in year $t$,

$$
Y_{i}=\beta_{0}+\phi_{k(i), o(i)}+\epsilon_{i}
$$

(c) Probability of being unemployed for more than 6 months. It is another measure of the "severity" of unemployment spells in the industry-occupation.

- Begin with the sample of prime-age workers.

- Create an indicator for whether the individual is unemployed for more than 6 months in the following year.

- Regress the indicator on industry-occupation fixed effects for that year, and save these fixed effects.

Regression: Let $Y_{i}$ be an indicator for being unemployed for more than six months in the year $t+1$. Individual $i$ has occupation $o$ (blue or white collar) in industry $k$. Then, for all workers in year $t$,

$$
Y_{i}=\beta_{0}+\phi_{k(i), o(i)}+\epsilon_{i}
$$




\section{J Alternative Variation in UI Generosity: Measuring Wage Effects from An Age-Specific Reform of Poten- tial Benefit Duration}

In this section, we analyze the effect of changes in potential benefit duration (PBD) of UIBs, rather than UIB levels, on incumbent wages. We do so by exploiting a reform in 1989 that changes PBD for workers aged 40 and above. Appendix Figure A.15 shows how the PBD schedule changed for individuals age 30-49. Before 1989, the PBD was only experience and not age-dependent. ${ }^{73}$ In 1989, these eligibility rules were changed so that individuals age 40-49 with at least five years of experience in the past 10 years were eligible for 39 weeks while individuals below age 40 were still only eligible for 30 weeks. For the analysis below, we focus on the PBD reform for individuals age 40-49 and compare their earnings growth to individuals age 30-39. ${ }^{74}$ We apply the same sample restrictions as in our main result for the full sample but drop all individuals present in particular Austrian regions where workers aged 50 and above were eligible for even larger PBD reform since $1988 .{ }^{75}$

The two panels in Appendix Figure A.16 plot the average earnings percent changes (one and two years) by age groups in the treated and control years. The left-panel plots the average wage growth from 1987-1988 (the control year) and from 1988-1989 (the treatment year) as well as their difference. If the PBD extension for older workers passed through to their wages, we would expect an increase in wage growth for older workers. The right panel plots the same for two-year wage growth. Neither figure shows an increase in wage growth for treated individuals.

In Appendix Figure A.17, we report results from estimating a specification similar to Equation (19) but replacing the replacement rate reform indicators with an indicator for being ages 39-42 and adding age-specific fixed effects. We also include the same controls included in specification (4) in Table 3. The figures show no significant treatment effects when the reform was enacted as well as a lack of pre-trends, validating our identifying assumptions. In conclusion, we do not find wage effects of PBD on incumbent wages either, thereby mirroring the insensitivity we document for UI level shifts.

\footnotetext{
${ }^{73}$ Individuals with less than 12 weeks of UI contributions in the last two years were eligible for 12 weeks, individuals with 52 weeks in the last two years were eligible for 20 weeks, and individuals with 156 weeks (3 years) and the last five years were eligible for 30 weeks.

${ }^{74}$ These rules applied to workers with at least 6 years of experience in the past 10 years, which is our sample restriction for this part of the analysis. See Nekoei and Weber (2017) for an evaluation of this reform on unemployed job seekers' spell duration and reemployment wages.

${ }^{75}$ We do not study the latter reform because of a regional reform that further increased PBD for workers older than 50 and led to separations (and thus attrition) among those older workers (Jäger et al., 2018), that would not allow for a measurement of wage effects.
} 
Figure A.15: PBD Schedule - Treated and Control Years

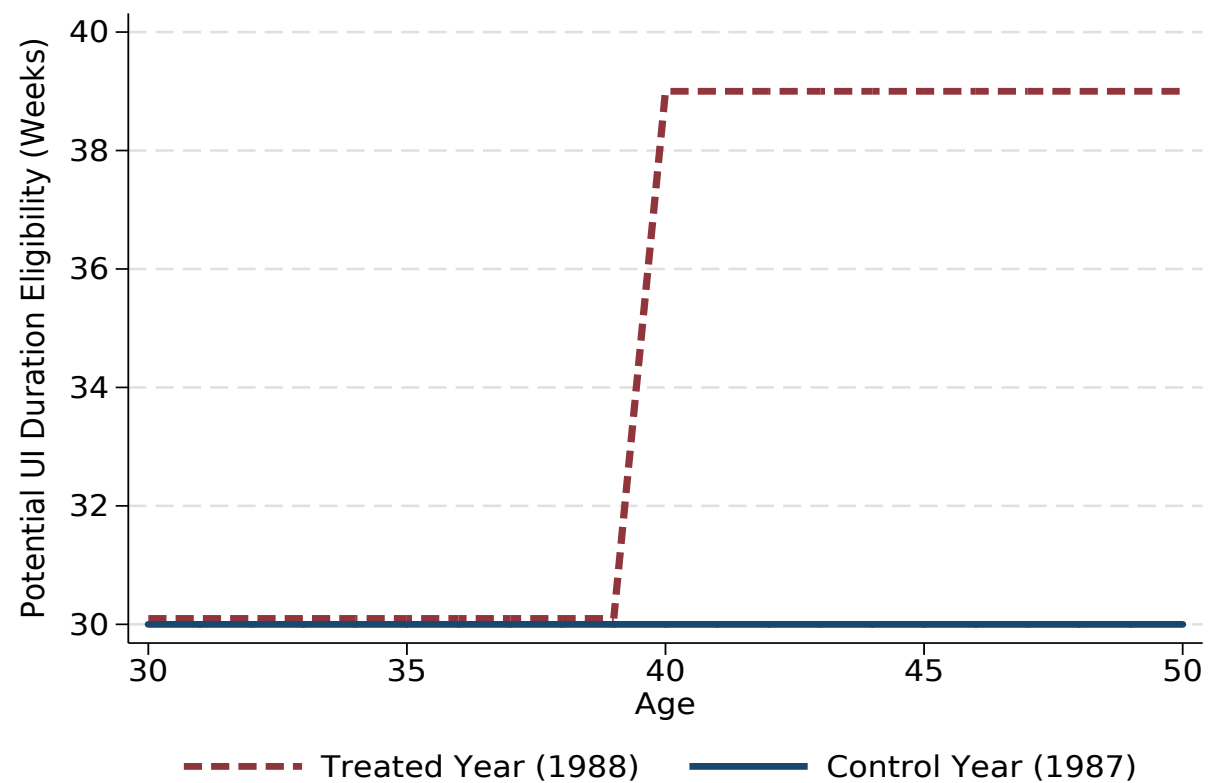

Note: The figure plots potential benefit duration (PBD) schedule by age for individuals in 1988 and 1989. Before 1988, all individuals with at least five years of work experience in the past ten years were eligible for 30 weeks of PBD. In 1989, individuals age 40-49 with the same experience were eligible for 39 weeks.

Figure A.16: Non-Parametric PBD Figures - One- and Two-Year Earnings Growth

One-Year Earnings Growth

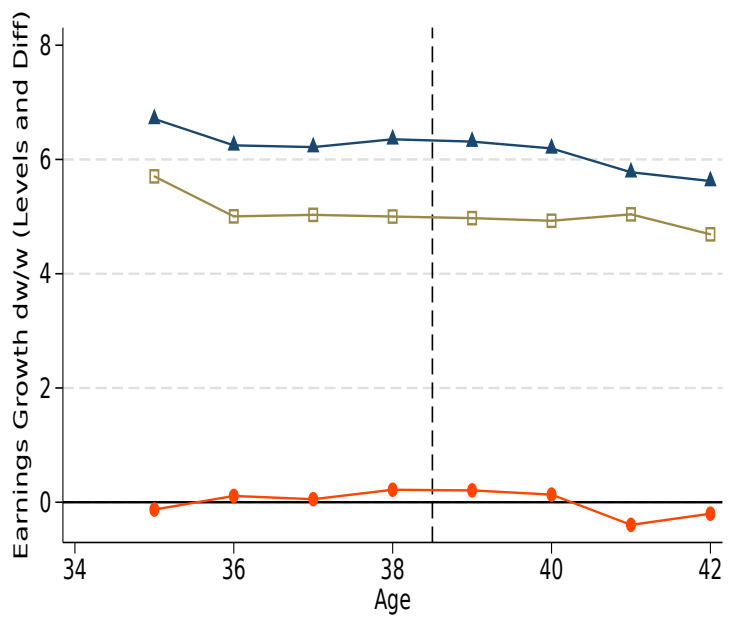

$\_$Wage Growth '87-'88
$\_$Wage Growth '88-'89
$\longrightarrow$ - Difference
Two-Year Earnings Growth

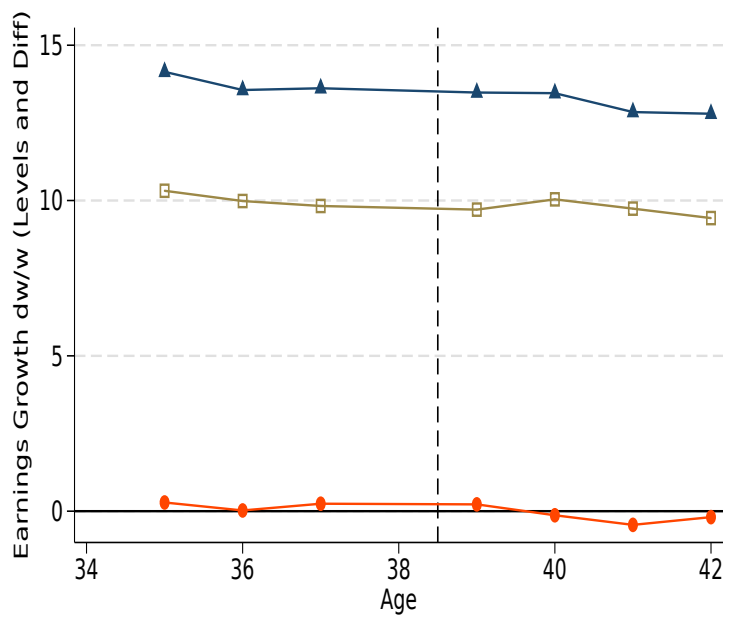

$\square$ Wage Growth '86-'88
$\longrightarrow$ Wage Growth '88-'90
$\longrightarrow \_$Difference

Note: These figures plot average earnings growth by age from 1987-1988 and 1989-1989 (the year the PBD extension went into effect). Consequently, they mirror the non-parametric analysis for the replacement rate reforms presented in the first two panels of Appendix Figures A.1-A.4. 
Figure A.17: Difference-in-Difference Coefficient Estimates

One-Year Earnings Growth

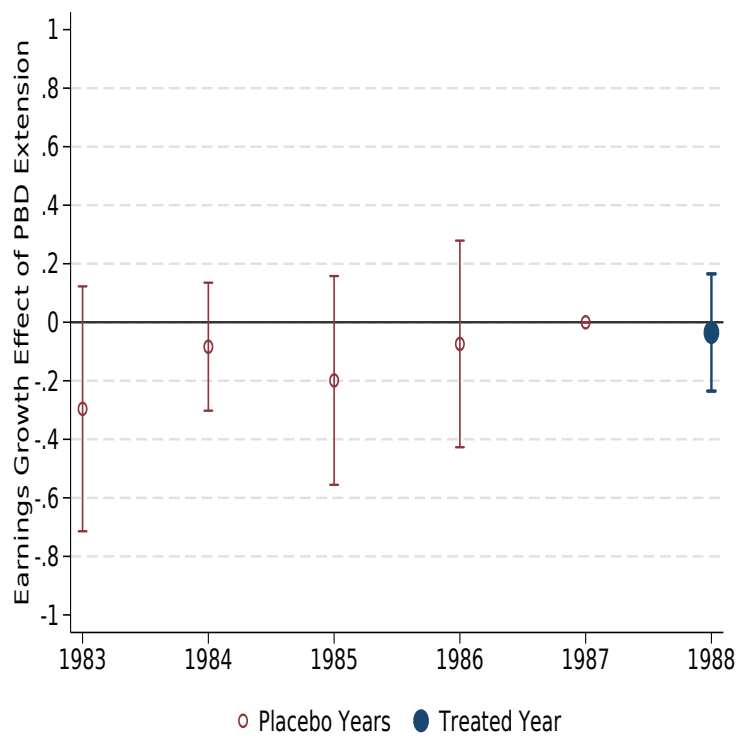

Two-Year Earnings Growth

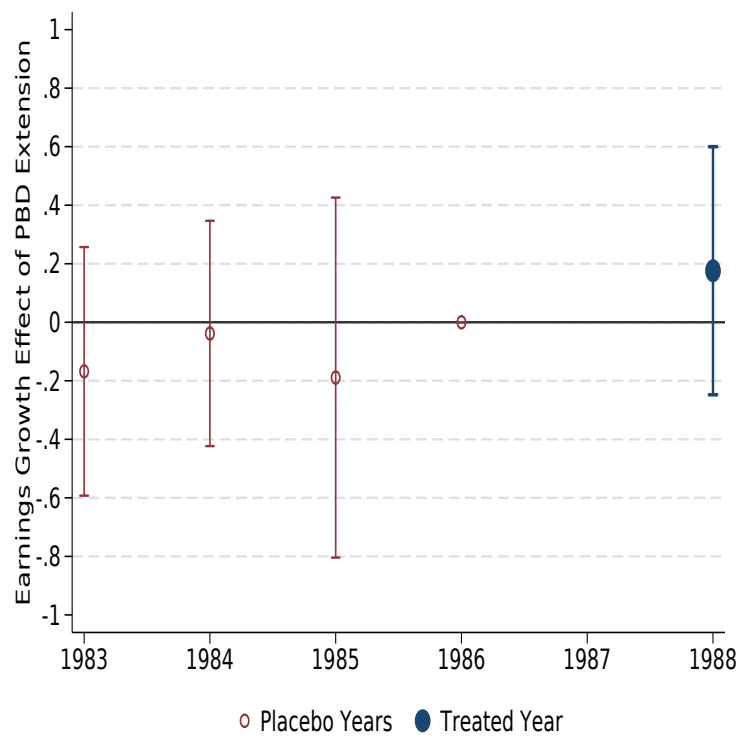

Note: These figures report results from estimating a specification similar to Equation (19) but replacing the reform-induced benefit changes with an indicator for being ages 39-42 in 1988 (treated by the PBD reform) and adding age-specific fixed effects. We include the same controls included in specification (4) in Table 3. 


\section{K Robustness: Constructing Gross Benefits}

To take into account that unemployment insurance benefits are not taxed in Austria, we verify that our results are robust to changes in gross benefits. Appendix Table A.6 reports those results. Appendix Figure A.18 presents the graphical analysis. Since the benefit changes are now larger, the implied gross-wage/gross-benefit sensitivities shrink compared to our main results using net benefits. Since our tax calculator may only imperfectly approximate individuals' actual tax situation in particular in the early years of our sample, our main results use the raw net (untaxed) benefit variation. We detail the tax calculator below.

Features of the Austrian Tax System We constructed a tax calculator that incorporates the key elements of the Austrian income tax system: ${ }^{76}$

1. Base salary (Bemessungsgrundlage). Austrian salaries are paid in 14 installments, usually of equal size. Twelve are paid monthly as a base salary, which is subject to a more elaborate tax schedule and eligible for more credits and deductions. We observe the annual pre-tax amount paid as base salary from each establishment to every worker in the ASSD.

2. Holiday bonuses (Sonderzahlungen). Austrian salaries are paid in 14 installments, usually of equal size. The 13th installment is usually paid during the summer (Urlaubszuschuss) and the 14th before Christmas (Weihnachtsremuneration). They are subject to a simpler tax schedule and social security contribution policies. We observe the annual pre-tax amount paid as holiday bonuses from each establishment to every worker in the ASSD.

3. Social security contribution. Each of three social welfare programs is partly financed by contributions as a proportion of workers' gross income: the unemployment insurance system (Arbeitslosenversicherung), health insurance system (Krankenversicherung), and old-age pension system (Pensionsversicherung). The proportions have changed over time. The salary contributions to unemployment insurance can be found in $\S 61$, section 1 , of the Unemployment Insurance Act (Arbeitslosenversicherungsgesetz, AlVG) through 1994 and in $\S 2$, section 1, of the Labor Market Policy Financing Act (ArbeitsmarktpolitikFinanzierungsgesetz, AMPFG) from 1995 onward. The salary contributions for health insurance and old-age pensions can be found in $\S 51$, section 1, of the Social Security Act (Allgemeines Sozialversicherungsgsetz, ASVG). There are also payroll contributions from employers to these programs that are not counted. Social security contributions are not taxed.

4. Base salary-only social security contributions. Workers make additional contributions as a proportion of their base salary to a national housing subsidy program (Wohnbauförderungsbeitrag) and the Austrian Chamber of Labour (Arbeitkammerumlage), an organization that represents workers and consumers in Austria and is independent of the trade unions and their federation (Österreichischer Gewerkschaftsbund, ÖGB). Unlike for trade unions, membership in the Chamber and the associated base salary contribution are compulsory for all Austrian workers. Together these contributions add 1 percentage

\footnotetext{
${ }^{76}$ For the years after 2000, we draw on a tax calculator that David Card and Andrea Weber generously shared with us.
} 
point to the proportion of the base salary taken for social security programs, and the contributions are not taxed.

5. Work-related expenses (Werbungskosten). There is a tax deduction for unavoidable expenses during work. We use the amounts available to workers who are not self-employed, which can be found in $\S 16$, section 3, of the Income Tax Act (Einkommensteuergesetz, EstG).

6. Special expenses (Sonderausgaben). There is a small tax deduction for various "special expenses" such as charitable donations and church donations. The amounts can be found in $\S 4$, section 3, of the Income Tax Act.

7. Income tax schedules. Tax schedules for the base salary can be found in $\S 33$, section 1, of the Income Tax Act and those for the holiday bonuses in $\S 67$, section 1, of the Act. We use the 1972 and 1988 Acts as well as intermediate reforms.

8. General tax credit (Allgemeiner Absetzbetrag). During our period of study, a tax credit was provided to all Austrian taxpayers. The amount - or the earnings schedule on which it is calculated in later years - can be found in $\S 33$, section 5 , of the Income Tax Act of 1972 and subsequent amendments and in $\S 33$, section 3, of the Income Tax Act of 1988 and subsequent amendments.

9. Commuting tax credit (Verkehrsabsetzbetrag). The Income Tax Act of 1988 introduced a tax credit for expenses related to commutes, and the amount can be found in $\S 33$, section 5 .

10. Wage earner's tax credit (Arbeitnehmerabsetzbetrag). Those who are not selfemployed can claim a small additional tax credit, the amount of which could be found in $\S$ 33, section 8, of the Income Tax Act of 1972 and subsequent reforms and in $\S 33$, section 5, of the Income Tax Act of 1988 and subsequent reforms.

Other Elements of the Austrian Tax System We have highlighted the key features of the Austrian tax system. However, there are many other tax credits and deductions, such as for households with children, pensioners, and those on disability and parental leave. Thus, our calculations are for an individual who is not self-employed and ignore exemptions for specific groups. In addition to focusing on observable characteristics of individuals in the ASSD, this also is in line with how the pre-separation income base is meant to be calculated for UI benefits after 2000, when benefits were determined using net incomes rather than gross incomes.

Calculating Net-of-Tax Rates We calculate the net income in the following steps, using values for each feature of the tax system.

- For the base salary:

1. Calculate taxable income

$=$ Gross base salary

- Social security contribution (as a proportion of gross earnings)

- Base salary-only social security contributions (as a proportion of gross earnings)

- Tax deduction for work-related expenses

- Tax deduction for special expenses 
2. Calculate the tax burden using the tax schedules and the taxable income.

3. Calculate the tax owed, which is then set to 0 if negative

$=$ Tax burden

- General tax credit

- Commuting tax credit

- Wage earner's tax credit

4. Calculate net base salary

$=$ Gross base salary

- Social security contribution (as a proportion of gross earnings)

- Base salary-only social security contributions (as a proportion of gross earnings)

- Tax owed

- For the holiday bonuses:

1. Calculate taxable income

$=$ Gross holiday bonuses

- Social security contribution (as a proportion of gross earnings)

2. Calculate the tax burden using the (simpler) tax schedules and the taxable income. There are no tax credits on the holiday bonuses, so this is also the tax owed. This is set to 0 if negative.

3. Calculate net holiday bonuses

$=$ Gross holiday bonuses

- Social security contributions (as a proportion of gross earnings)

- Tax owed

- Calculate total net earnings as the sum of the net base salary and the net holiday bonuses.

- Calculate the net-of-tax rate by dividing the total net earnings by total gross earnings.

The 1972 Tax Schedule The Income Tax Act of 1972 introduced income taxes on individuals, which went into effect for 1973 earnings. Prior to 1973, taxes were calculated on household incomes. To keep the 1972 net-of-tax rate calculation in line with those of later years, we extrapolate by assigning to each individual in 1972 the average 1973 net-of-tax rate of its earnings percentile. This choice has no bearing on our results because we assign $d b / w$ from the reform year to previous years to form placebos, i.e. the 1972 net-of-tax rate is not used in the 1976 reform sample.

Converting to Gross Units To make a direct gross-gross comparison, we convert each individual's UI benefit shift $d b_{i, r, t}\left(w_{i, r, t-1}\right)$ in specification (19) into gross terms by dividing by the individual's net-of-tax rate in the base year $t-1$. This inflates the change in the nonemployment value.

Placebo Years We treat benefit changes in placebo years just as we do with our standard benefit change (see Section 4.3.1), assigning individuals in pre-reform years the average $d b /(1-\tau) w$ of the eighth of a percentile in the reform year, where $\tau$ is the average tax rate. 
Figure A.18: Overview of Non-Parametric Results with Gross UI Benefit Changes

(a) 1976 Reform

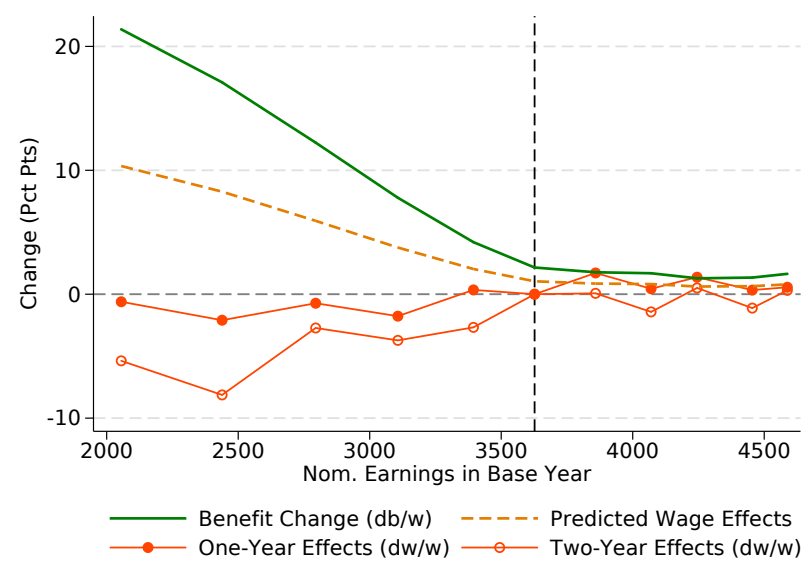

(c) 1989 Reform

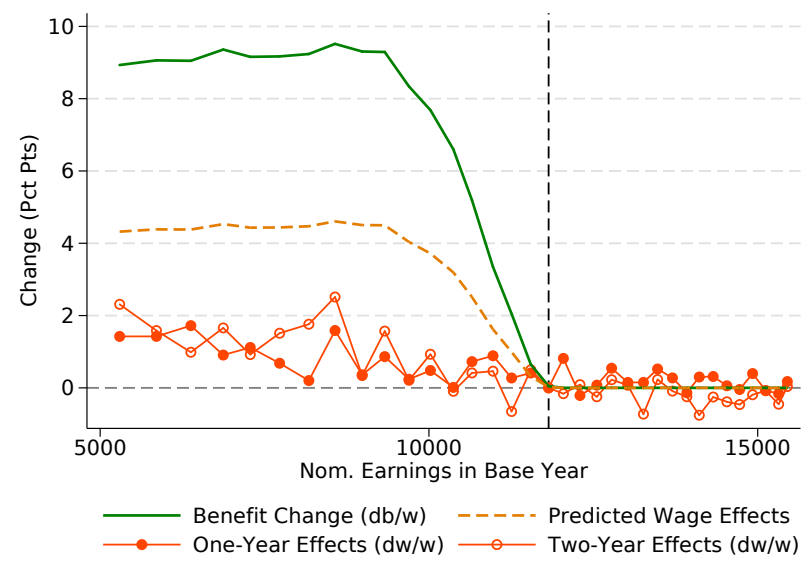

(b) 1985 Reform

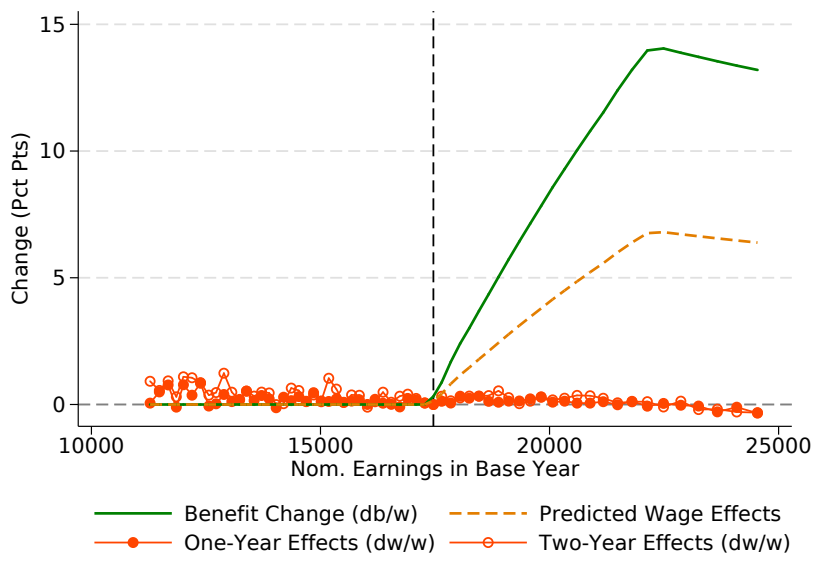

(d) 2001 Reform

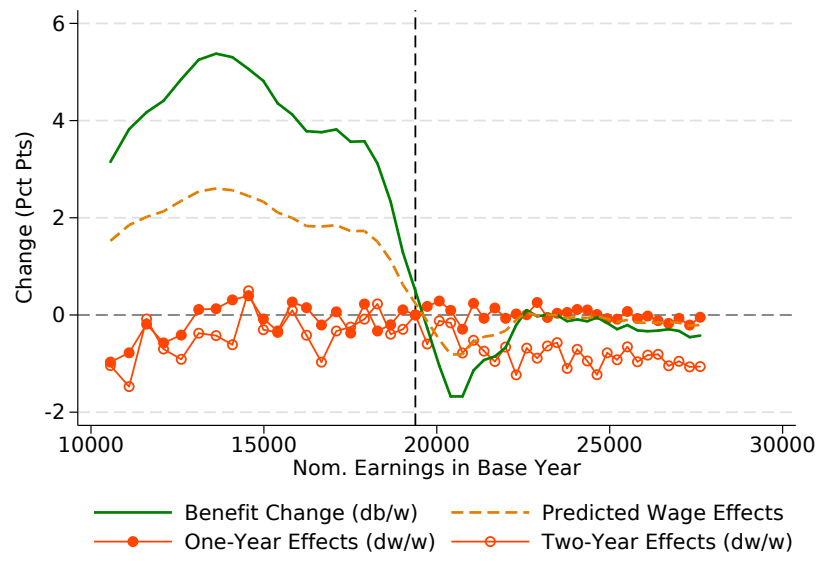

Note: The figure plots robustness checks for the results reported in Figures 4(a) through 4(d). The specifications reported here take into account that UI benefits are untaxed in Austria. To take non-taxation into account, we translate the UI benefit shift, $d b / w$ reported in the solid green line above, into a change in (hypothetical) gross benefits, $d b_{\text {Gross }} / w$, by scaling up the actual benefit shift by an individual's average net-of-tax rate so that both the benefit and the wage change are in gross units. See Appendix K for additional information on the tax calculation. 
Table A.6: Estimated Wage Effects with Shifts in Gross UI Benefits

Panel A: 1-Year Earnings Effects

\begin{tabular}{lcccccc}
\hline \hline & $(1)$ & $(2)$ & $(3)$ & $(4)$ & $(5)$ & $(6)$ \\
\hline & & & & & & \\
Placebo: 3 Yr Lag & 0.011 & -0.003 & 0.009 & 0.008 & 0.013 & 0.017 \\
& $(.011)$ & $(.01)$ & $(.011)$ & $(.01)$ & $(.009)$ & $(.009)$ \\
Placebo: 2 Yr Lag & -0.000 & -0.010 & -0.006 & -0.007 & 0.011 & 0.007 \\
& $(.009)$ & $(.009)$ & $(.01)$ & $(.01)$ & $(.009)$ & $(.009)$ \\
Treatment Year & $\mathbf{- 0 . 0 0 3}$ & $\mathbf{- 0 . 0 0 1}$ & $\mathbf{- 0 . 0 1 4}$ & $\mathbf{- 0 . 0 1 1}$ & $\mathbf{0 . 0 0 1}$ & $\mathbf{- 0 . 0 0 2}$ \\
& $\mathbf{( . 0 1 )}$ & $\mathbf{( . 0 1 1 )}$ & $\mathbf{( . 0 1 )}$ & $\mathbf{( . 0 1 )}$ & $\mathbf{( . 0 0 9 )}$ & $\mathbf{( . 0 0 9 )}$ \\
\hline Pre-p F-test p-val & 0.493 & 0.545 & 0.414 & 0.385 & 0.322 & 0.182 \\
$R^{2}$ & .048 & .067 & .076 & .094 & .257 & .281 \\
$N$ (1000s) & 7139 & 7139 & 7138 & 7138 & 6299 & 6298 \\
\hline Mincerian Ctrls & & $\mathrm{X}$ & & $\mathrm{X}$ & & $\mathrm{X}$ \\
4-Digit Ind.-Occ. FEs & & & $\mathrm{X}$ & $\mathrm{X}$ & & $\mathrm{X}$ \\
Firm-Year FEs & & & & & $\mathrm{X}$ & $\mathrm{X}$ \\
\hline \hline
\end{tabular}

Panel B: 2-Year Earnings Effects

\begin{tabular}{lcccccc}
\hline \hline & $(1)$ & $(2)$ & $(3)$ & $(4)$ & $(5)$ & $(6)$ \\
\hline & & & & & & \\
Placebo: 3 Yr Lag & -0.001 & -0.014 & 0.000 & 0.000 & -0.002 & 0.004 \\
Treatment Year & $(.014)$ & $(.013)$ & $(.016)$ & $(.015)$ & $(.014)$ & $(.014)$ \\
& $\mathbf{- 0 . 0 0 1}$ & $\mathbf{0 . 0 0 8}$ & $\mathbf{- 0 . 0 1 5}$ & $\mathbf{- 0 . 0 1 2}$ & $\mathbf{- 0 . 0 1 1}$ & $\mathbf{- 0 . 0 1 6}$ \\
& $\mathbf{( . 0 2 )}$ & $\mathbf{( . 0 2 )}$ & $\mathbf{( . 0 2 )}$ & $\mathbf{( . 0 2 )}$ & $\mathbf{( . 0 1 7 )}$ & $\mathbf{( . 0 1 7 )}$ \\
\hline Pre-p F-test p-val & 0.947 & 0.291 & 0.992 & 0.995 & 0.894 & 0.771 \\
$R^{2}$ & .103 & .125 & .14 & .16 & .305 & .332 \\
$N$ (1000s) & 5039 & 5039 & 5038 & 5038 & 4434 & 4433 \\
\hline Mincerian Ctrls & & $\mathrm{X}$ & & $\mathrm{X}$ & & $\mathrm{X}$ \\
4-Digit Ind.-Occ. FEs & & & $\mathrm{X}$ & $\mathrm{X}$ & $\mathrm{X}$ & $\mathrm{X}$ \\
Firm-Year FEs & & & & & & $\mathrm{X}$ \\
\hline \hline
\end{tabular}

Note: The table reports results of a robustness check for the specifications reported in Table 3 . The specifications reported here take into account that UI benefits are untaxed in Austria. To take non-taxation into account, we translate the UI benefit shift, $d b$ from specification (19), into a change in (hypothetical) gross benefits by scaling up the actual benefit shift by an individual's average net-of-tax rate so that both the benefit and the wage change are in gross units. For further information on the specification see notes for Table 3. To calculate individuals' net-of-tax rate, we rely on a purpose-built tax calculator for Austria. See Appendix Section K for details on the Austrian income tax system and constructing gross benefits. 


\section{UI Benefit Schedules in Austria: 1972-2003}

Figure B.1: UI Benefit Schedules 1972-1978

1972 and 1973

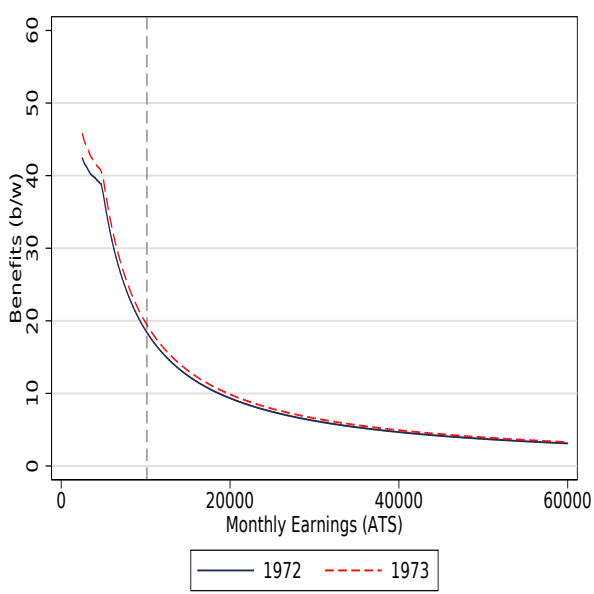

1975 and 1976

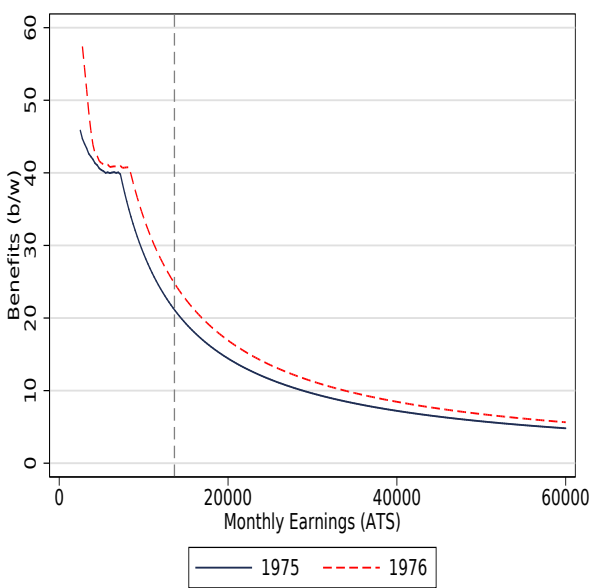

1973 and 1974

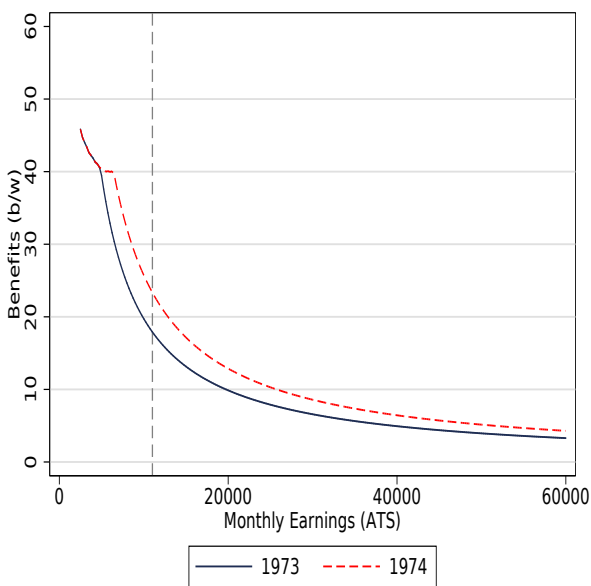

1976 and 1977

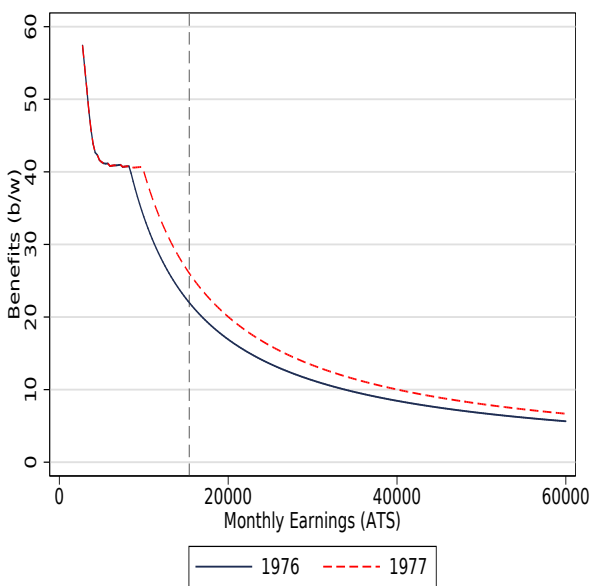

1974 and 1975

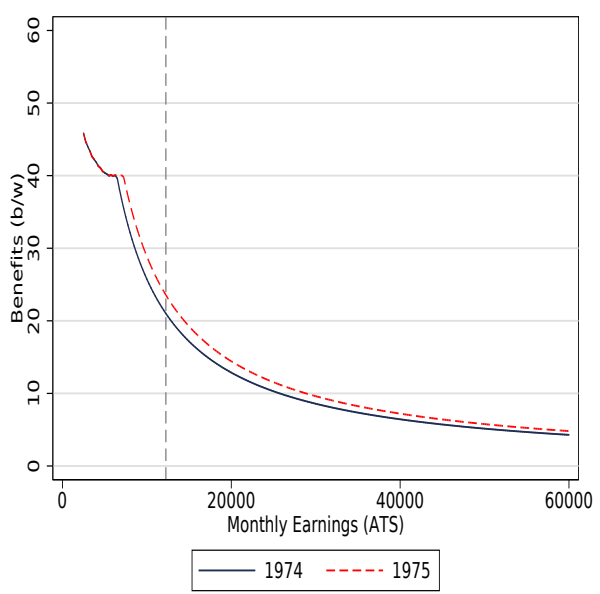

1977 and 1978

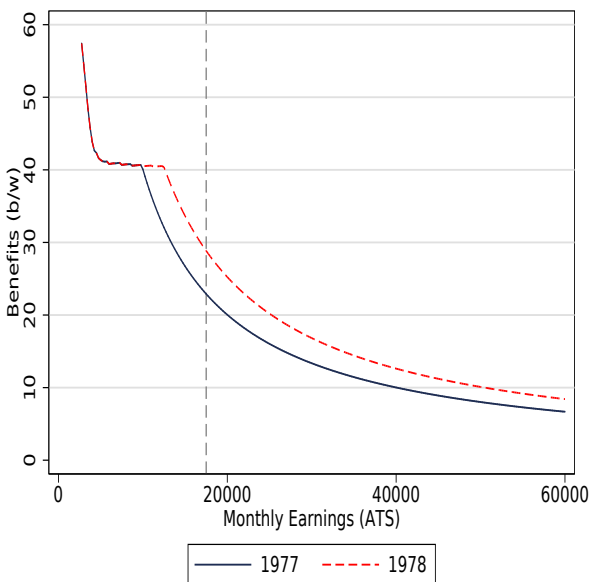

Note: The dashed vertical lines in gray correspond to the social security earnings maximum. 
Figure B.2: UI Benefit Schedules 1978-1987

1978 and 1979

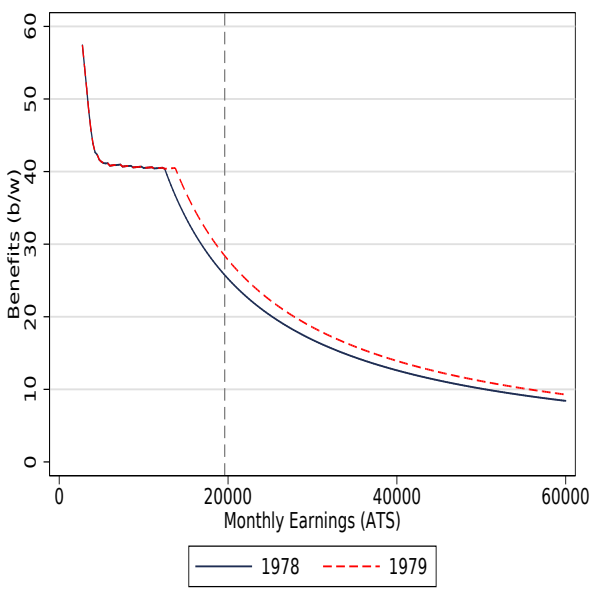

1981 and 1982

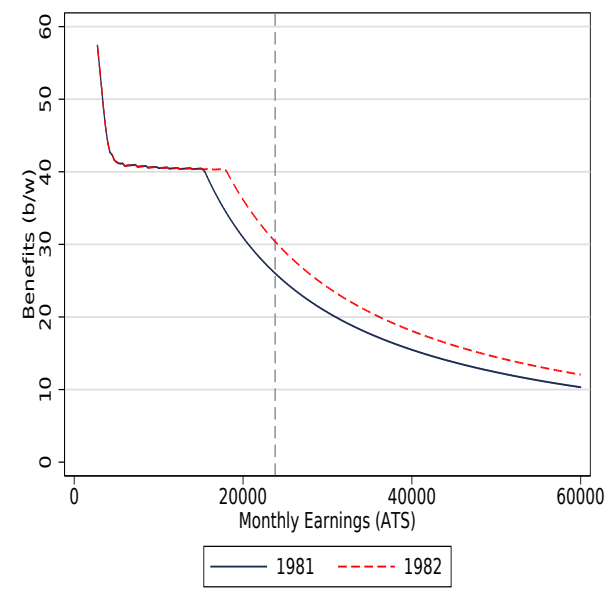

1984 and 1985

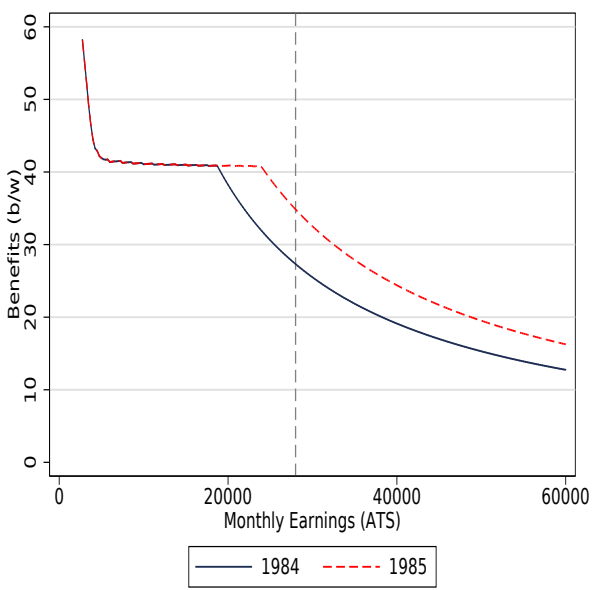

1979 and 1980

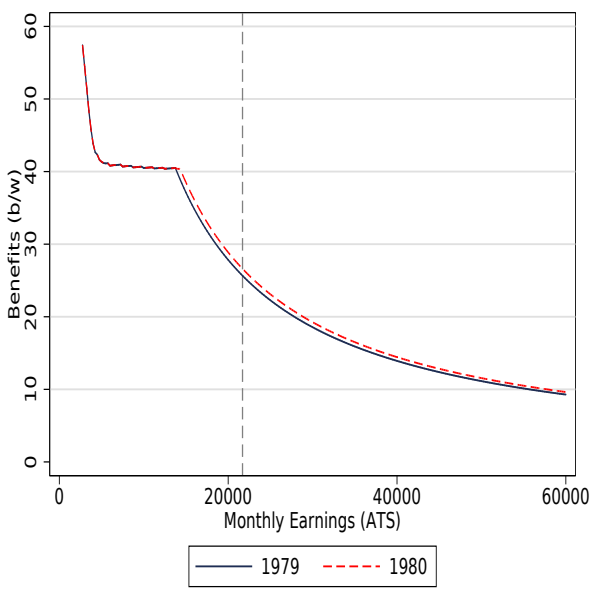

1982 and 1983

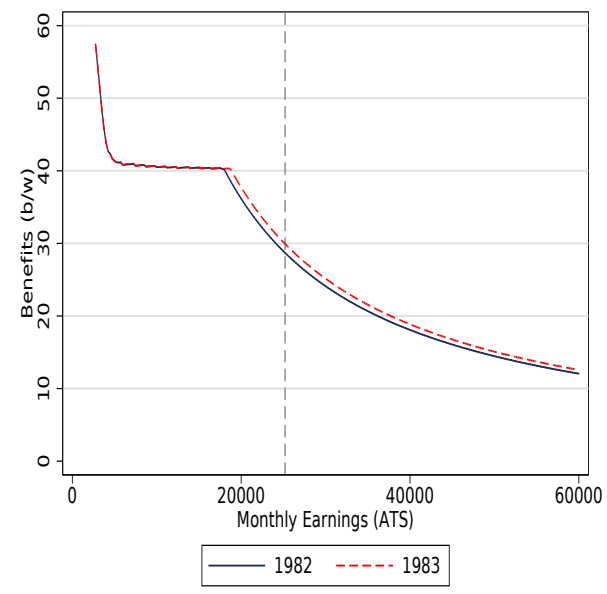

1985 and 1986

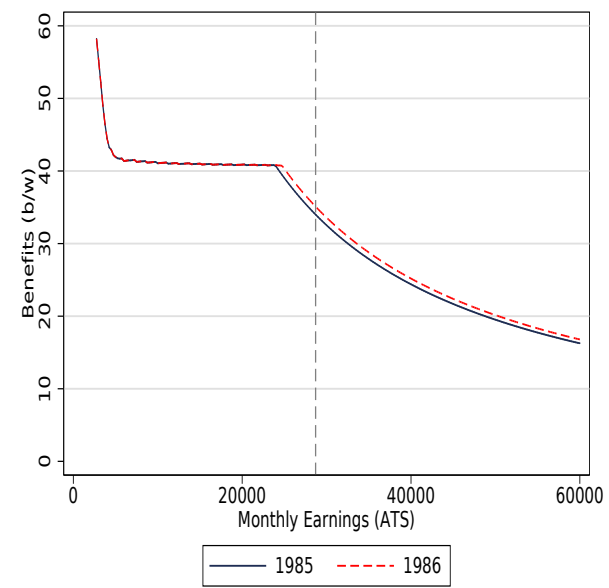

1980 and 1981

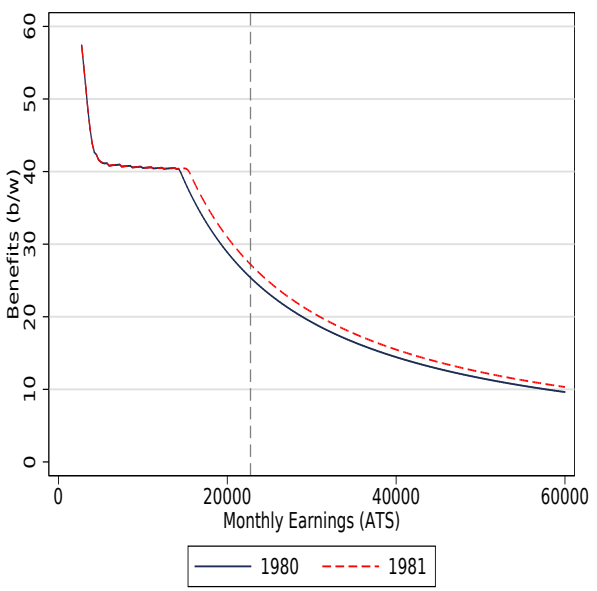

1983 and 1984

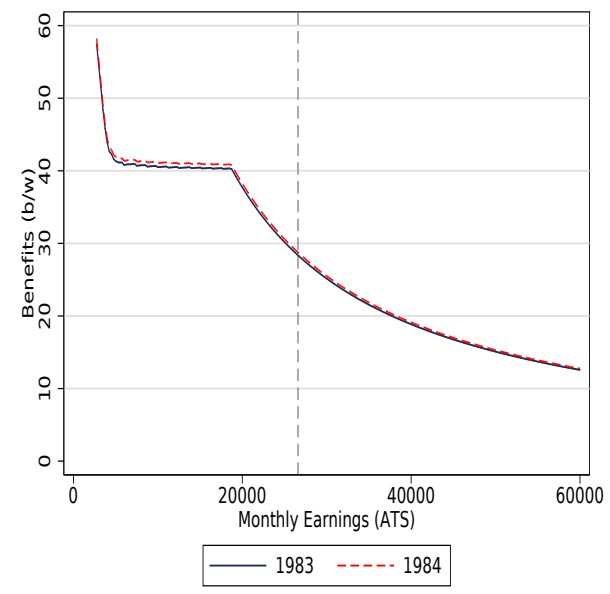

1986 and 1987

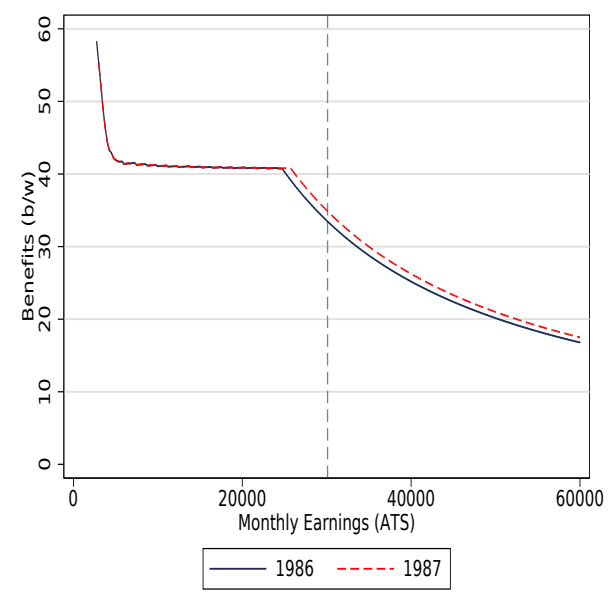

Note: The dashed vertical lines in gray correspond to the social security earnings maximum. 
Figure B.3: UI Benefit Schedules 1987-1996

1987 and 1988

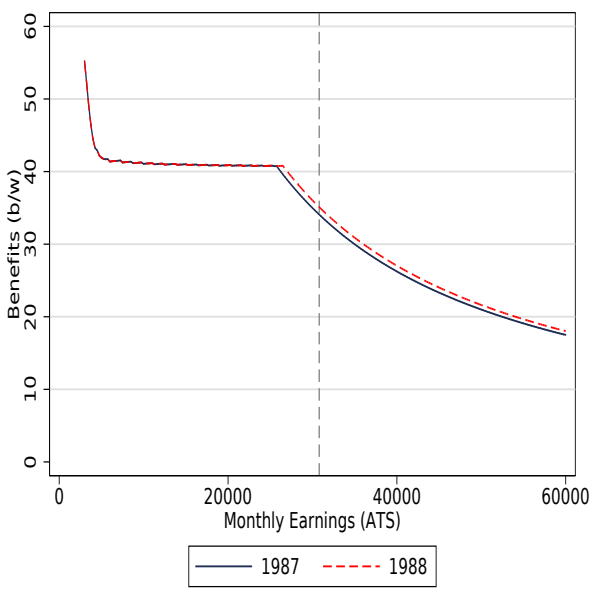

1990 and 1991

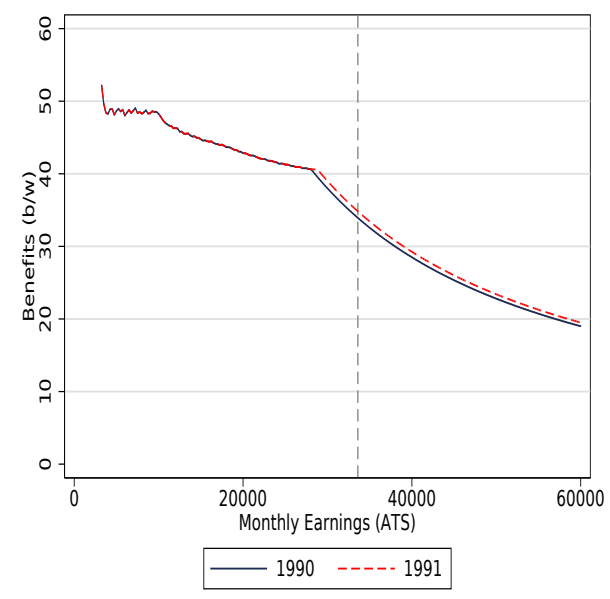

1993 and 1994

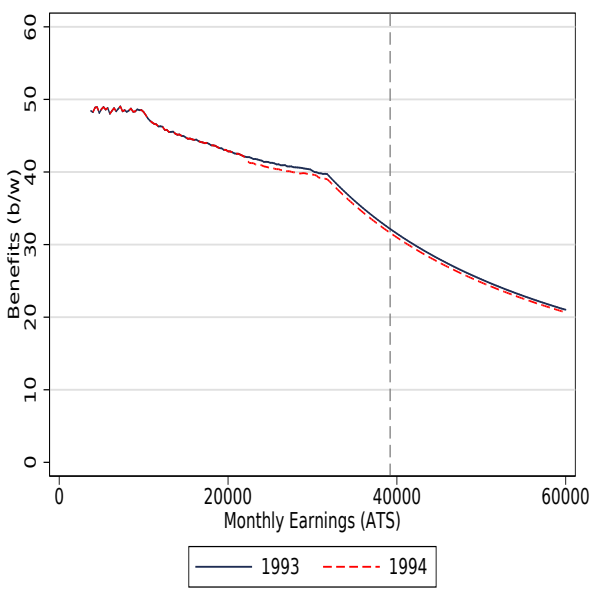

1988 and 1989

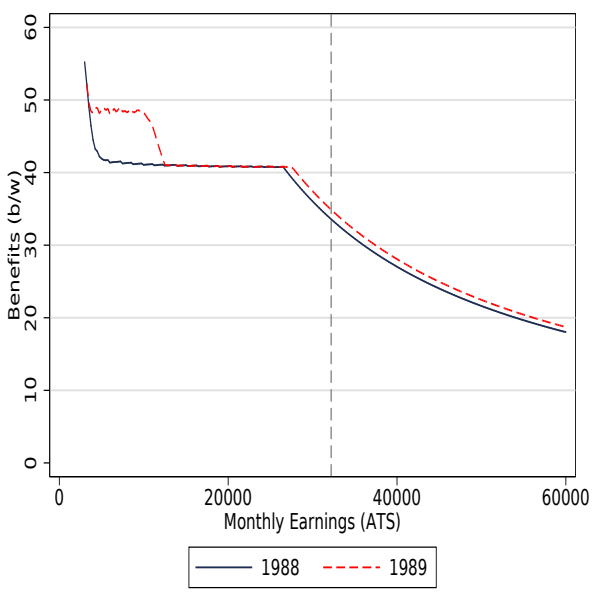

1991 and 1992

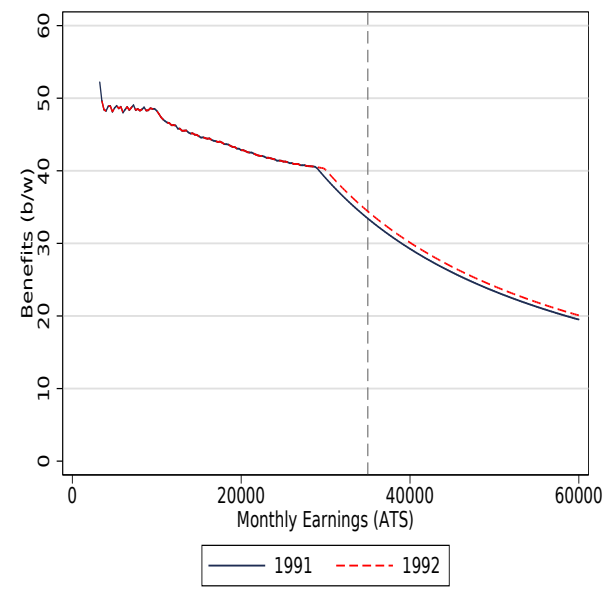

1994 and 1995

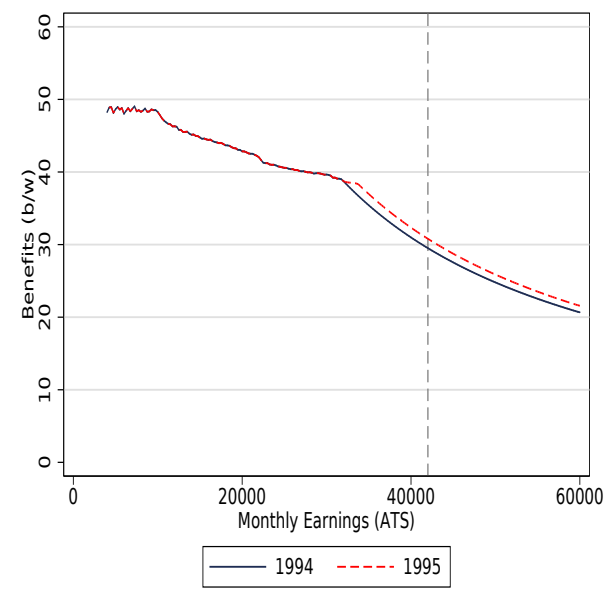

1989 and 1990

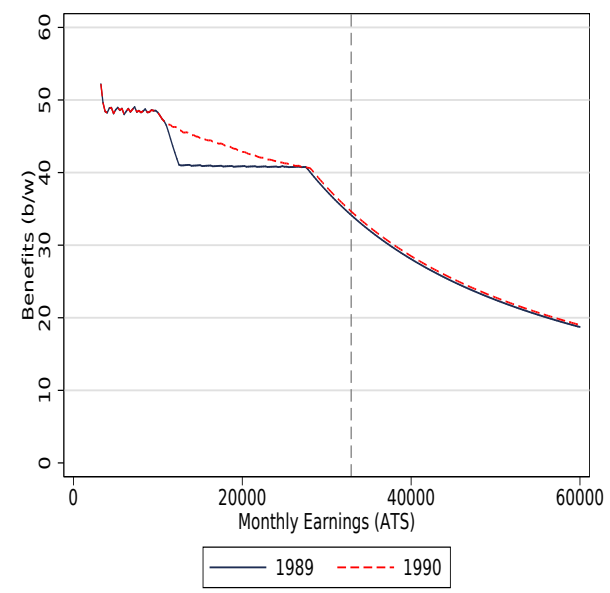

1992 and 1993

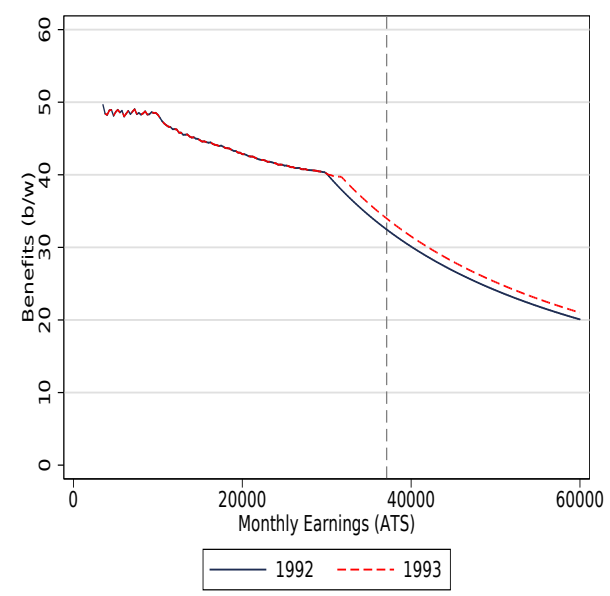

1995 and 1996

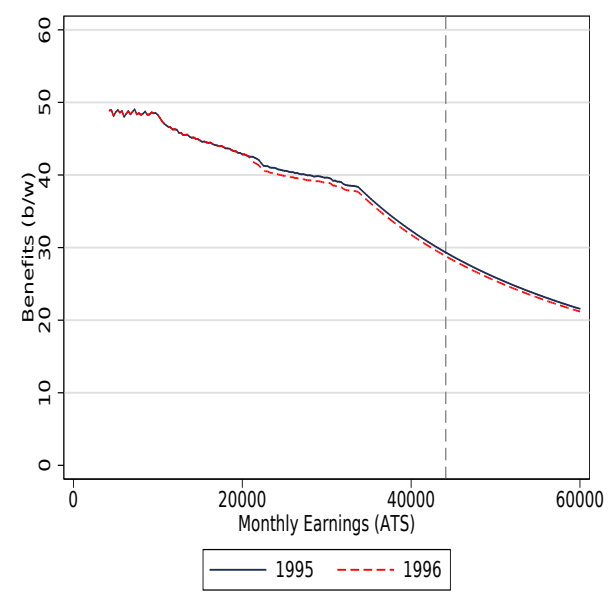

Note: The dashed vertical lines in gray correspond to the social security earnings maximum. 
Figure B.4: UI Benefit Schedules 1996-2003

1996 and 1997

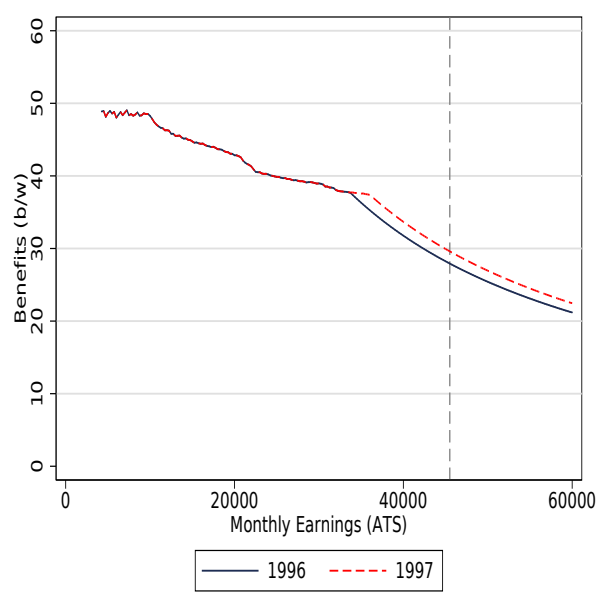

1999 and 2000

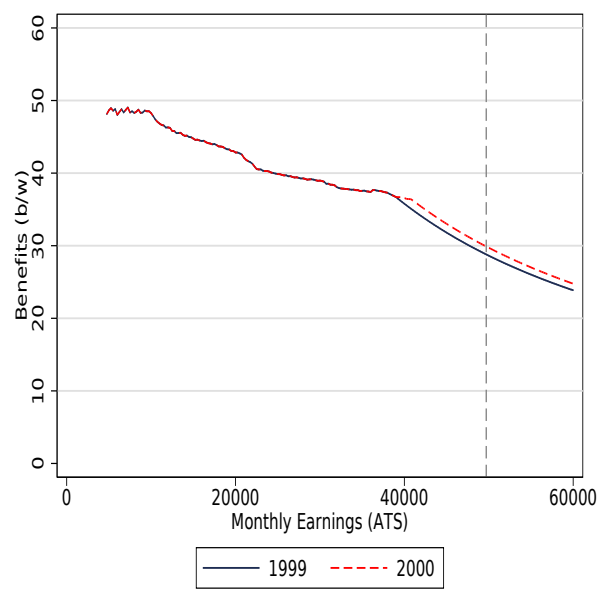

2002 and 2003

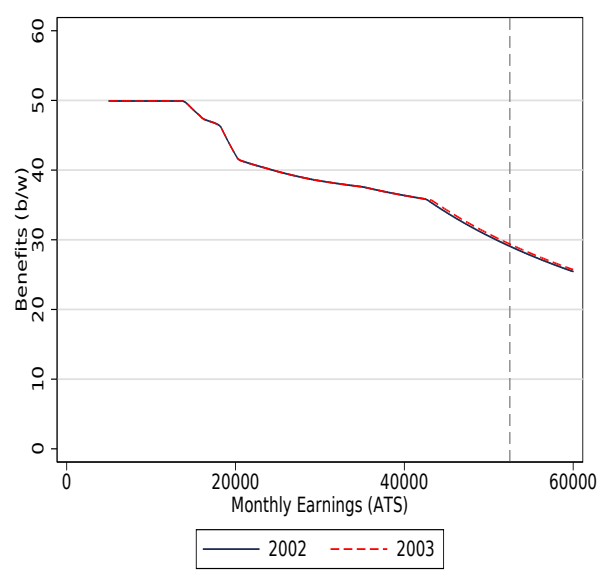

1997 and 1998

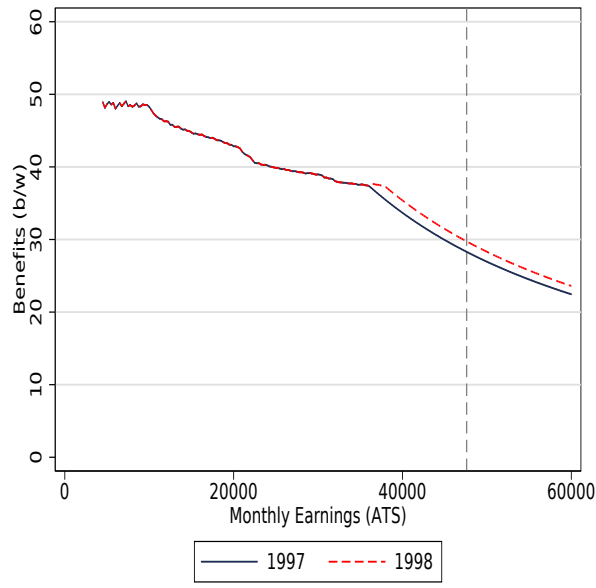

2000 and 2001

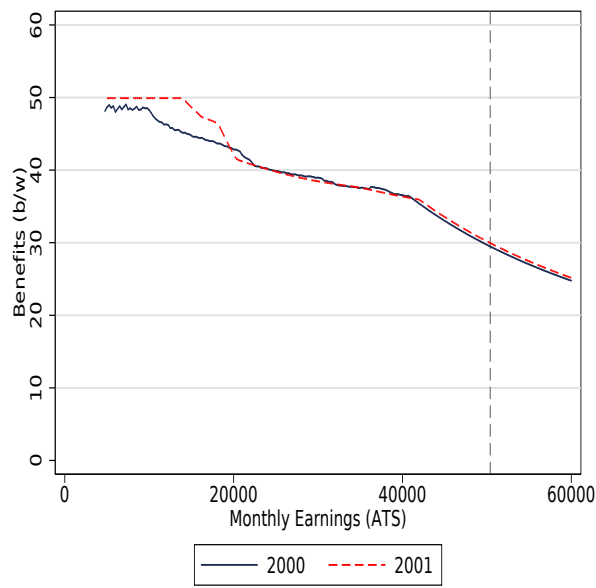

1998 and 1999

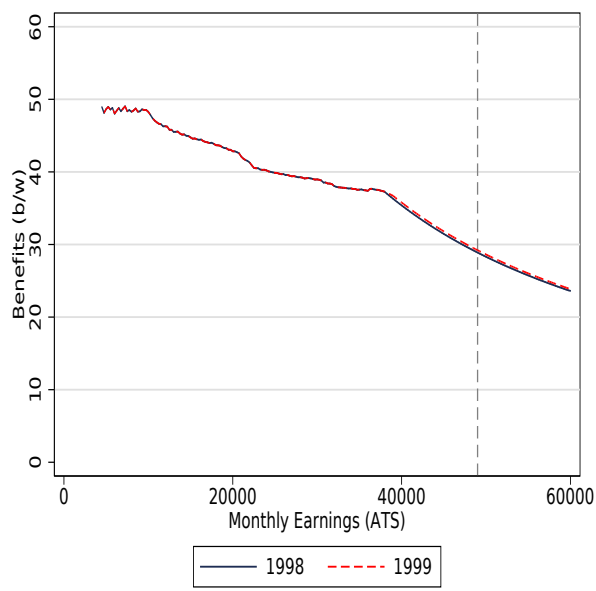

2001 and 2002

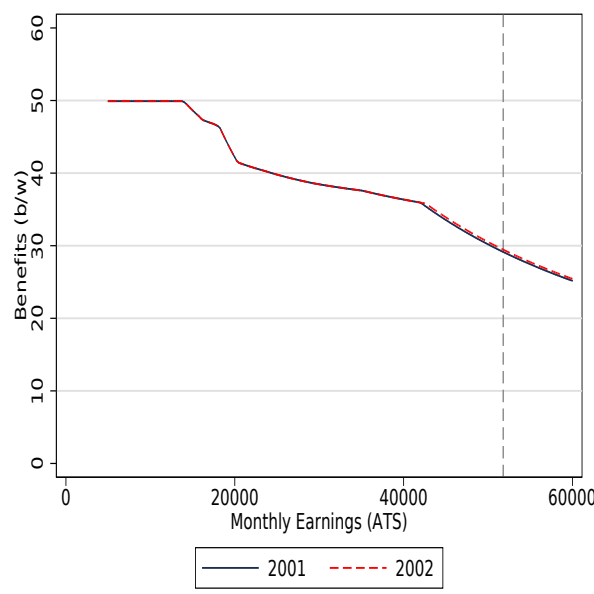

Note: The dashed vertical lines in gray correspond to the social security earnings maximum. 


\section{RECENT WORKING PAPERS FROM THE CENTER FOR RETIREMENT RESEARCH AT BOSTON COLLEGE}

The Equilibrium and Spillover Effects of Early Retirement

Simon Jäger, Benjamin Schoefer, and Josef Zweimüller, January 2020

Measuring Racial/Ethnic Retirement Wealth Inequality

Wenliang Hou and Geoffrey T. Sanzenbacher, January 2020

A Study of Longitudinal Trajectories of Health and Job Demand on Retirement Age Amal Harrati and David Rehkopf, January 2020

Participation and Pre-Retirement Withdrawals in Oregon's Auto-IRA Laura D. Quinby, Alicia H. Munnell, Wenliang Hou, Anek Belbase, and Geoffrey T. Sanzenbacher, November 2019

Why Are 401(k)/IRA Balances Substantially Below Potential? Andrew G. Biggs, Alicia H. Munnell, and Anqi Chen, November 2019

How Best to Annuitize Defined Contribution Assets?

Alicia H. Munnell, Gal Wettstein, and Wenliang Hou, October 2019

How Do Older Workers Use Nontraditional Jobs?

Alicia H. Munnell, Geoffrey T. Sanzenbacher, and Abigail N. Walters, October 2019

Will More Workers Have Nontraditional Jobs as Globalization and Automation Spread? Matthew S. Rutledge, Gal Wettstein, and Sara Ellen King, July 2019

Do States Adjust Medicaid Enrollment in Response to Capitation Rates? Evidence from the Medicare Part D Clawback

Laura D. Quinby and Gal Wettstein, June 2019

The Effect of Medicare Part D on Evergreening, Generic Entry, and Drug Prices Geoffrey T. Sanzenbacher and Gal Wettstein, May 2019

Is the Drop in Fertility Due to The Great Recession or a Permanent Change? Alicia H. Munnell, Anqi Chen, and Geoffrey T. Sanzenbacher, March 2019

Will Fewer Children Boost Demand for Formal Caregiving?

Gal Wettstein and Alice Zulkarnain, March 2019

The Relationship Between Occupational Requirements and SSDI Activity Matthew S. Rutledge, Alice Zulkarnain, and Sara Ellen King, February 2019 (https://crr.bc.edu) and can be requested by e-mail (crr@bc.edu) or phone (617-552-1762). 